\title{
A LIFE LIVED ON THE CORNER
}

\author{
By \\ Bronwyn Jewell McGovern
}

\begin{abstract}
A thesis
submitted to Victoria University of Wellington

in fulfilment of the requirements for the degree of

Doctor of Philosophy in Sociology
\end{abstract}

Victoria University of Wellington

2013 

This thesis is dedicated to two brothers

Warrick McGovern 24/10/67 - 11/05/94

Bernett Hana 08/02/57 - 15/01/12

Both of whom the street took too soon

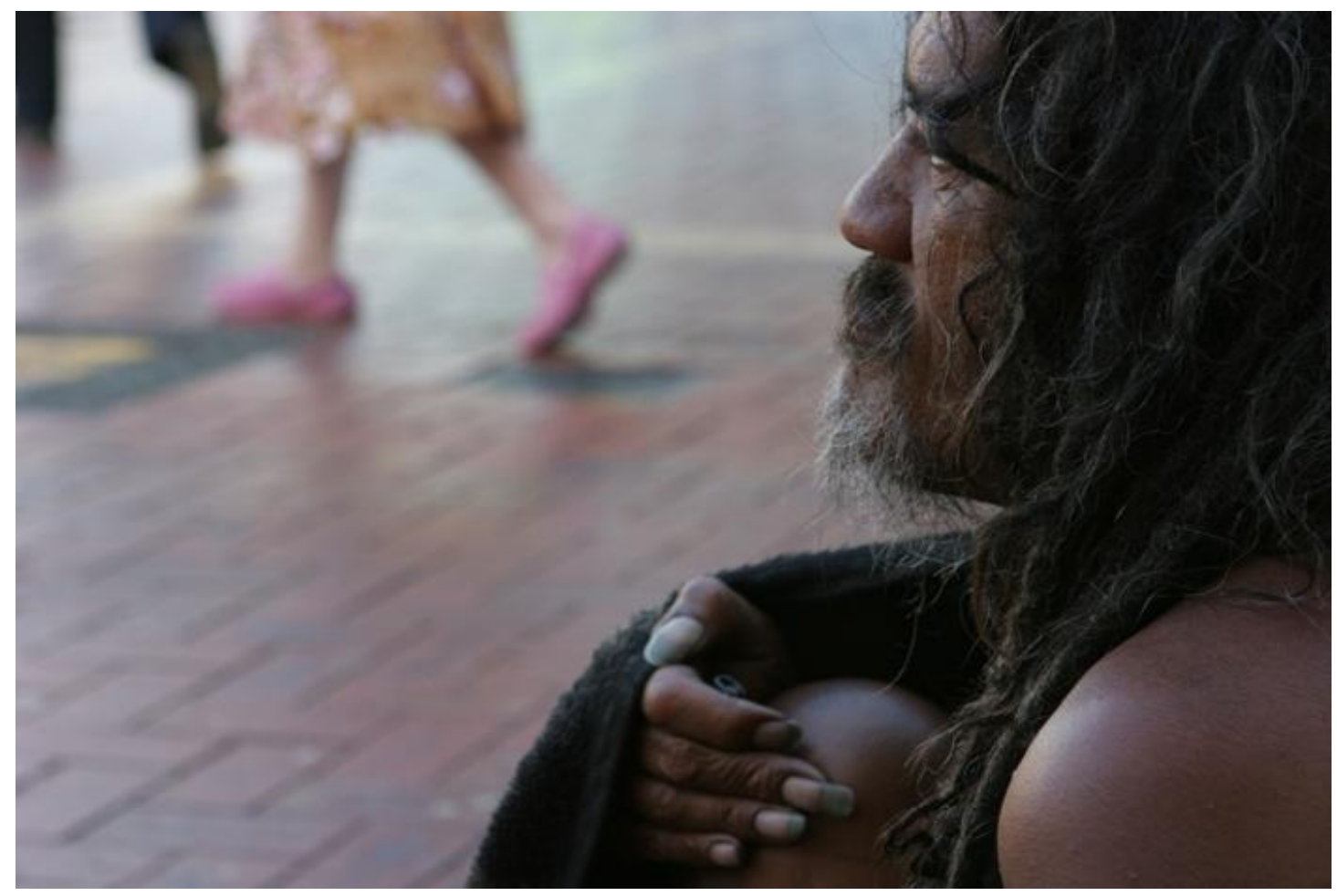

In memory of Brother, an independent spirit, impossible to classify 



\section{Abstract}

This thesis explores the everyday life of Brother, a well-known street dweller and local identity, who lives everyday life on a busy street corner in Wellington, Aotearoa New Zealand. Brother's way of doing 'being ordinary' attracts strong public curiosity, media interest, and monitoring by informal and formal social control mechanisms, including medical intervention. This research provides a comprehensive account of what can happen to those at the margins who dare, or are impelled, to do things differently. My research is inspired by the longstanding tradition of street corner sociology, and grounded within the sociology of everyday life orientation. My street ethnography involved participant observation over a three-and-a-half year period. In that time, I observed Brother and other street people, capturing the depth and nuanced complexities of a life lived in the open. Central to this thesis is an examination of the ways in which wider social structures and institutions bear upon the local micro-setting, in particular how classification processes act to 'make, remake, and unmake' people. Three core concepts of space, body, and social interaction are explored to examine, through the situatedness of everyday talk and social action, how social meanings are locally produced and understood. I argue that by developing spatial, bodily, and interactional methods, Brother has established organisational and social capacities, and lines of conduct, that are firmly founded in autonomous actions. Through his rejection of ascribed 'homeless' membership and his clear embracement of a street lifestyle, Brother's street life is shown to subvert and trouble normative understandings, while engendering and maintaining a lived sense of home in the city he calls his whare [house]. My research contributes an Aotearoa New Zealand perspective to the international sociological street corner landscape, and provides a Wellington perspective to the emerging domestic literature on street life. More broadly, my study aims to stimulate critical sociological reflection regarding different modes of being and belonging in the world and how we, as a society, respond to this. 


\section{Acknowledgements}

Brother, I am in your debt for granting me the privilege of 'letting me in' to learn how life is lived on the street corner. The big (sorta) book is finally finished.

Kevin, huge thanks for your insightful guidance, positive encouragement, and intellectual engagement. If nothing else, I'm confident I've mastered apostrophes'.

Michael, Jessie, Grace, Eilish, and Ruby - in the order you began to ground, define, and enrich my everyday life - you are my motivation. Thanks for being so patient.

Simon, thanks for your support, especially for picking me up from fieldwork at 3am when I had a flat car battery, no credit on my cell phone, and no money in my wallet. You are my knight in a shining Mazda.

To the postgrads who made everyday life on the $9^{\text {th }}$ floor a homely experience especially Rachael Fabish, Owen Hughes, Riki Mihaere, and Dionne Steven thanks, friendly faces and words made the difference.

Special thanks to: Kate Amore, who I know will long regret passing up the ultimate 'Big ups'; Sarah Wright, who has been on a long sociological and personal journey with me; Diana Watt, for her effervescent friendship, 'writer's massages' and 'real world' reminders; Belinda Brown, whose friendship includes the stunning photography that brings life and vitality to this work; Stephen Jinks for bringing his humour and tarot cards with him on his trips back home; and Sandra Grey and Adam Meers who remain loyal constants 'in my corner'.

Last, but not least, I am grateful for the support of a VUW Scholarship and the consistent work opportunities afforded to me from within VUW and from the Shore \& Whāriki Research Centre at Massey University in Auckland. 


\section{Contents}

Abstract

Acknowledgements $\quad$ vi

Contents vii

List of figures

Prologue

$\begin{array}{lll}\text { Chapter One } \quad \text { Introduction } & 1\end{array}$

$\begin{array}{lll}\text { Chapter Two } & \text { Researching on the margins of homelessness } & 11\end{array}$

Chapter Three $\quad$ Conceptualising an everyday street life $\quad 31$

$\begin{array}{lll}\text { Chapter Four } & \text { Doing street corner sociology } & 48\end{array}$

Chapter Five $\quad$ Interpreting Wellington's street scene 83

$\begin{array}{llr}\text { Chapter Six } & \text { Space matters } & 126\end{array}$

$\begin{array}{lll}\text { Chapter Seven } & \text { The socio-spatial body made meaningful } & 161\end{array}$

Chapter Eight Maintaining 'elbow room' in a publicly lived life 202

$\begin{array}{lll}\text { Chapter Nine } \quad \text { Home street home } & 237\end{array}$

$\begin{array}{ll}\text { Epilogue } & 255\end{array}$

$\begin{array}{ll}\text { References } & 260\end{array}$ 


\section{List of figures}

Prologue:1 Farewell messages of love, peace, and respect .................................................

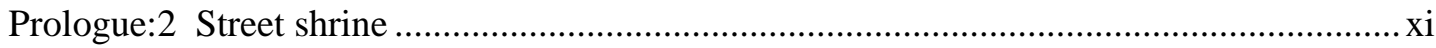

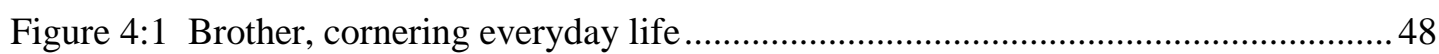

Figure 4:2 Observing from 'my throne' at the northern entrance to Cuba Mall ....................58

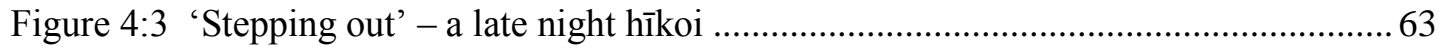

Figure 5:1 Wellington's Bucket Man and Blanket Man (Brother).......................................95

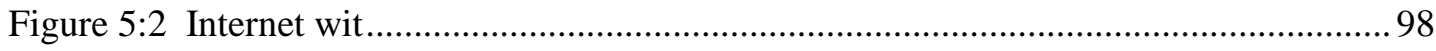

Figure 5:3 Comments posted on Blanket Man's Myspace page ……................................ 100

Figure 5:4 A British example of the championed 'tramp' status of an individual ............... 101

Figure 5:5 Brother Sharp and one of Westwood's 'Homeless Chic' models at Milan

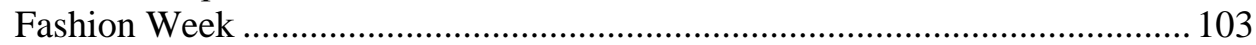

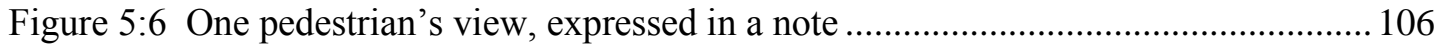

Figure 5:7 A letter added to signage outside Wellington's homeless men's shelter playfully elevates the status of the city's poorest, most marginalised

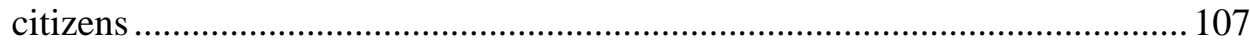

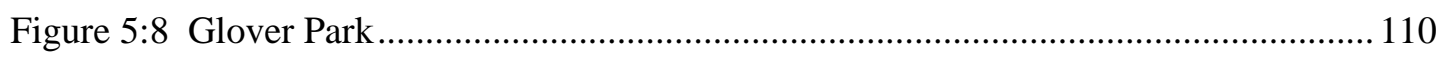

Figure 5:9 Hoardings erected around Glover Park, showing a yesteryear tramp and referencing homeless occupants .................................................................. 112

Figure 6:1 Brother domestically appropriating a city footpath as home space ................... 127

Figure 6:2 Signage outside Wellington's Public bar, located on one of Brother's

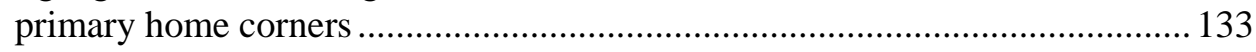

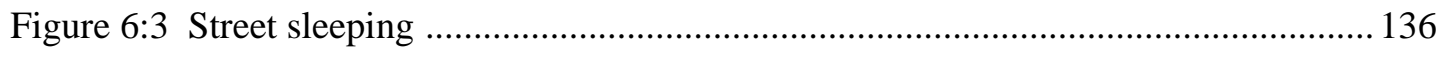

Figure 6:4 Courtenay Place and its immediate environs, marking Brother's city-as-

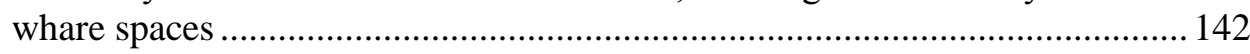

Figure 6:5 'Artist's' impression of a laser illuminating the 'Home of Ben' ........................ 143

Figure 6:6 Brother under police arrest on the Public Bar corner ........................................ 150

Figure 6:7 Brother exercising passive resistance ……................................................. 150

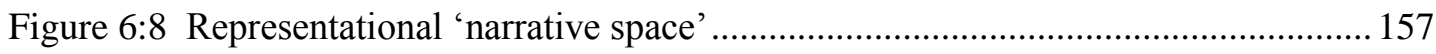

Figure 6:9 Logos of the organisations that the poster's creator considers played a role

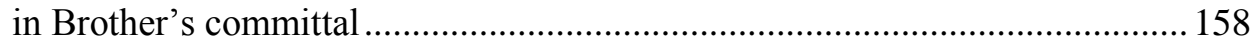

Figure 6:10 A message that was later added to the poster by another member of the

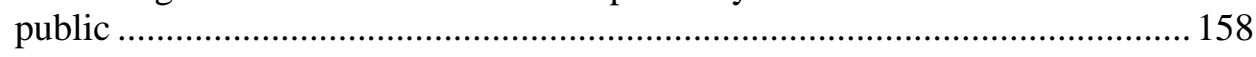

Figure 7:1 Occupying city space as intimate 'sunning space' .......................................... 161

Figure 7:2 Expressing the self through a material artefact associated with the body ..........173

Figure 7:3 Brother's 'contracted' body outside the ANZ Bank ......................................... 175

Figure 7:4 The horizontal, dirty, semi-naked presentation of the body in public ............... 177

Figure 8:1 A man plays his flute in Cuba Mall beside Brother........................................... 202 viii 
Figure 8:2 'Blanket Man’ impersonators paying Brother a street visit as they make their way to the sports stadium

Figure 8:3 Sevens revellers prodding, poking, and photographing Brother as he sleeps

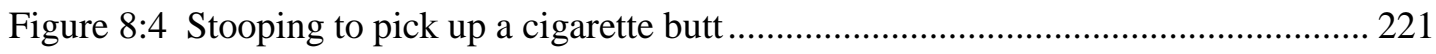

Figure 8:5 Brother's street enactment of the 'Māori side-step'

Figure 9:1 Brother dozing outside Fix - the new location he was forced to take up when prevented from occupying Primary location 1a during banking business hours

Epilogue:1 One of many public condolences expressed at the makeshift memorial 256

Epilogue:2 Brother in 2001, at Wellington's 'One Love' concert, which commemorates Bob Marley’s birthday . 


\section{Prologue}

On January 15th 2012, Brother ${ }^{1}$ died suddenly, unexpectedly, and alone in a Wellington Hospital bed during what was supposed to be a brief routine visit to monitor his bloods. Within two hours, Brother's death was being reported by the New Zealand news media. By nightfall, Brother's primary home on the footpath outside a bank in Courtenay Place was transforming into a vibrant street shrine. Candles lined the low ledge of the building above his 'spot', flickering in the breeze. On the ground, several people were camped out in sleeping bags, beginning a vigil that was to last a week - until Wellington City Council dismantled the shrine. Farewell messages of love, peace, and respect covered the facade of the building, for example: "Passing of a legend"; "You will be missed Ben Hana. Forever on this corner!"; "R.I.P blanket man - even if you did decline my noodles" (Prologue:1).

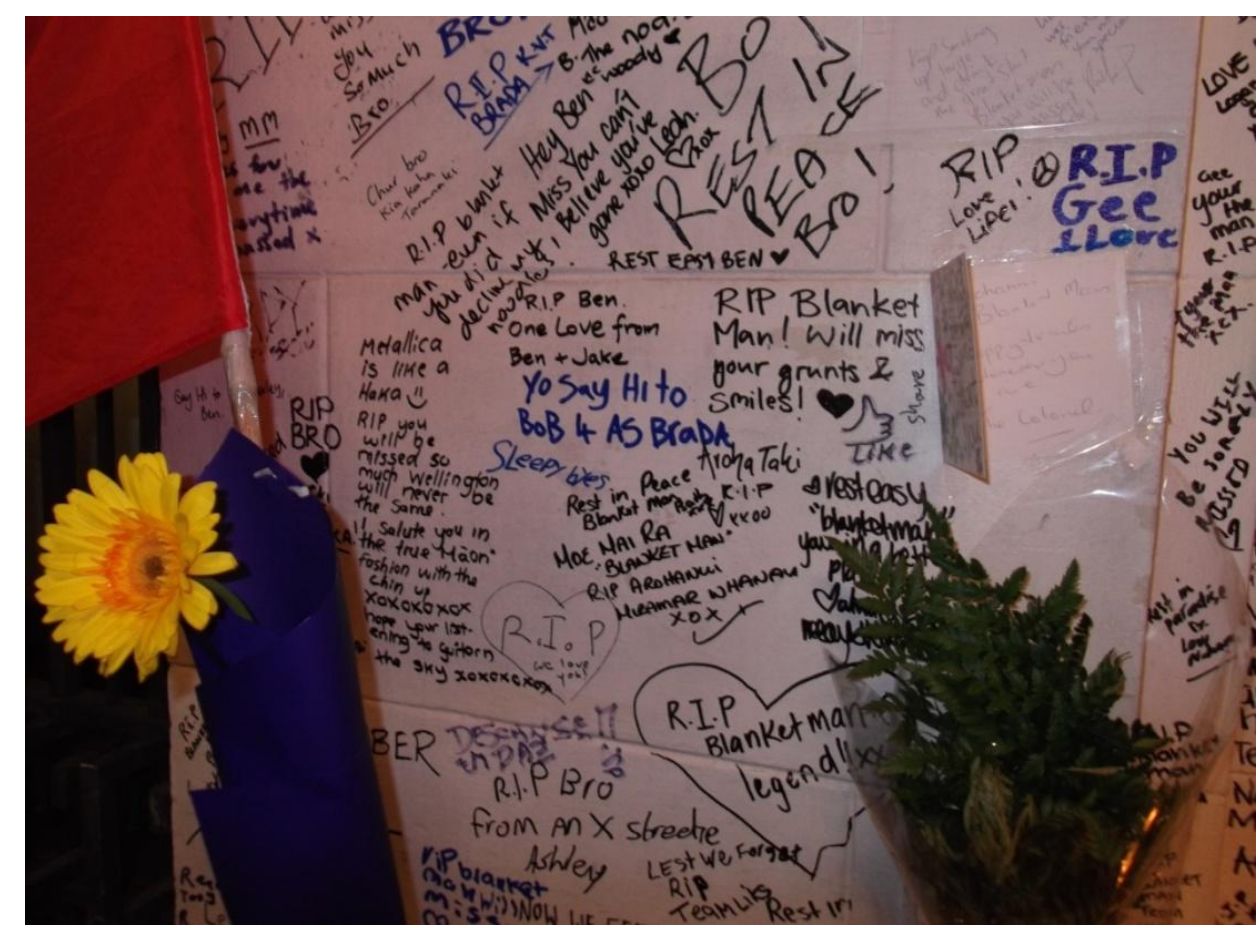

Prologue:1 Farewell messages of love, peace, and respect

Source: Author, 2012

\footnotetext{
${ }^{1}$ Brother is my research participant, the subject of this thesis.
} 
Flags and flowers brightened the space, and people left objects they felt represented Brother: cigarettes; takeaway food; bottles of alcohol; mock 'tinnies' (tin foiled measures of cannabis). Others left personal mementos of jewellery or ornamental offerings. The shrine continued to grow by the day, extending from the immediate space where Brother sat. People resorted to scaling the wall to find free writing space further up. It attracted constant streams of people who stood to simply read all the messages, write their own, or leave objects (Prologue:2).

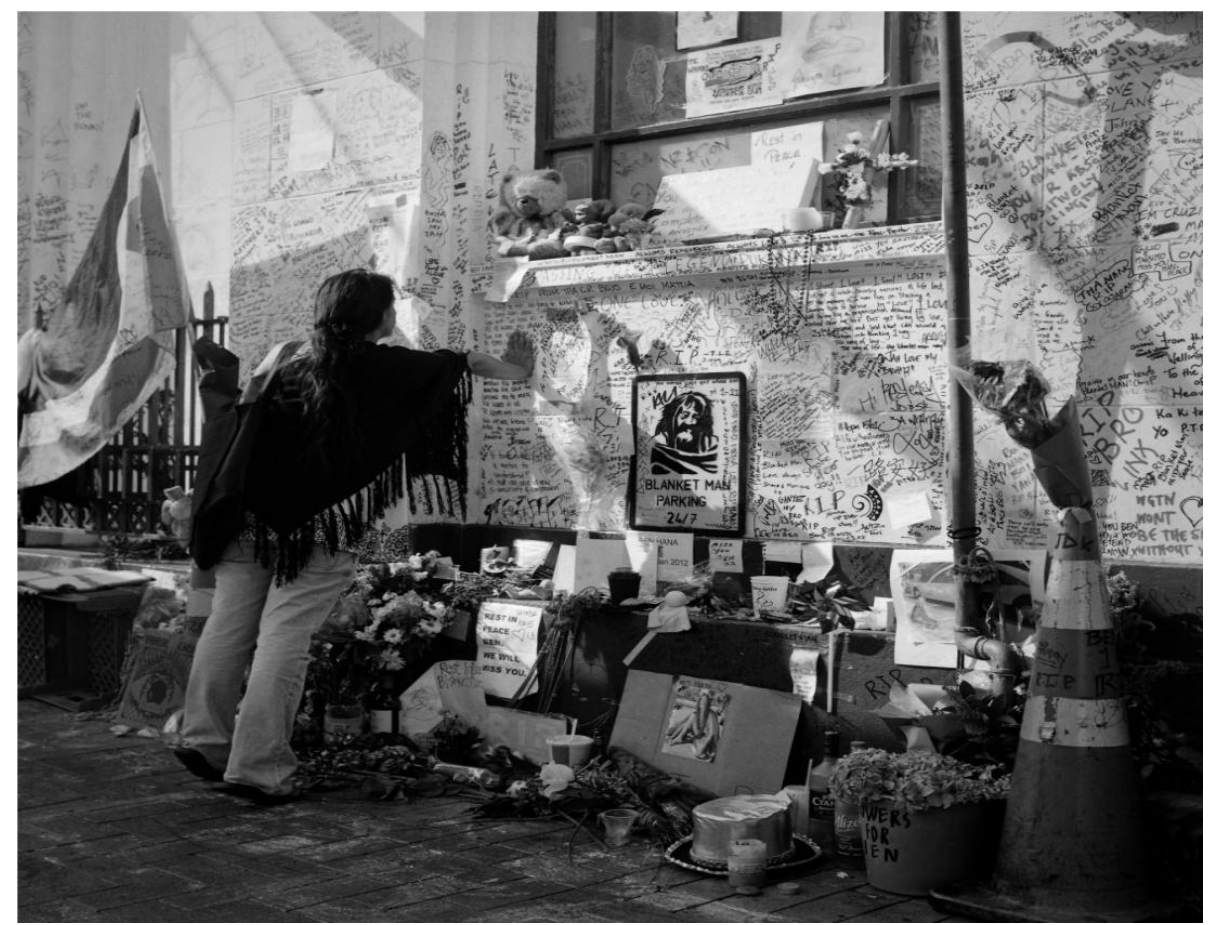

Prologue:2 Street shrine

Source: Darkhalide - Simon Burrow, 2012

Meanwhile, debate about Brother's life and death played out in the media, around office water-coolers, and on the streets for the next couple of weeks. Radio New Zealand's Mediawatch programme, for example, featured a lengthy report on Brother and the media surrounding him. His passing was likened to that of a celebrity. He was described as a 'national icon', whose death was being “eulogised, memorialised, and even iconised" (Hallett, 2012).

While this fanfare and rhetoric were being played out in the public domain, behind closed doors Brother's body lay first in the hospital morgue, then in a funeral 
home, and then in the home of one of his adult children. I was privileged to receive an invitation from Brother's whānau (family) to spend time alongside Brother as he lay in an eco-coffin among people who had known and cared about him. While I was there, his son opened Brother's bag of worldly possessions - released from the hospital morgue along with his body. Out came a small transistor radio, his stash of cannabis, cigarettes, and a small wooden cannabis pipe - a newly acquired possession that had been given to him on the street by a traveller. Last out of the bag were two forks belonging to me that signified the last two meals I had taken to Brother before he went into hospital. Those forks were later buried with Brother and his other possessions.

Brother is buried at the end of a row of plots next to a stand of native bush. His whānau were given a choice as to which end of a new row they wanted the gravediggers to start digging up for his plot. Choosing the green option, they joked that their father had spent enough time of late beside the road. ${ }^{2}$ I attended Brother's funeral, held in a city park, and the burial of his body at Mākara Cemetery afterwards. A large contingent of news media was conspicuous at each. I found the long procession of news camera-people filming the graveside proceedings to be intrusive and insensitive. Even in death, it seemed, Brother made a good story.

At the time Brother died, I had just embarked on writing the final version of this thesis. Initially, his death gave me pause to think about what approach I should take when continuing to write my research thesis. After careful consideration, I decided to keep on writing as I had been. This decision was made for two reasons. Firstly, with my grief still raw, the task of turning everything I had written to the past or 'deceased' tense was too arduous to contemplate. I reasoned that people often speak of the newly deceased as if they were still alive because they have yet to adjust to using the correct tense when they speak of them. Secondly, while Brother lived, I had strived to capture the living, breathing, interacting person in

\footnotetext{
${ }^{2}$ Told to me by Brother's whānau and included in this thesis with their permission. xii
} 
my writing. This aim took on renewed importance after his death as I endeavoured to convey Brother, as he had lived, in my work. I hope I have managed to achieve this goal in a way that Brother once instructed would not read "too staidly".

In the weeks following Brother's death, during a time when it was difficult to go on writing about his life, the title of this thesis came to me out of the blue while out walking. It felt perfect. Simple and unassuming, but also ambiguous in that it carries multiple meanings depending on how one interprets $A$ life lived on the corner. I'm sure Brother, who himself experienced being 'many things to many people', would have given this new title 'the ups' (a gesture prolifically used by Brother either as an interactional opener to greet others or to indicate his approval of something). 



\title{
Chapter One Introduction
}

\begin{abstract}
'Man's chief danger' today lies in the unruly forces of contemporary society itself, with its alienating methods of production, its enveloping techniques of political denomination, its international anarchy - in a word, its pervasive transformations of the very 'nature' of man and the conditions and aims of his life.

It is now the social scientist's foremost political and intellectual task - for here the two coincide - to make clear the elements of contemporary uneasiness and indifference. It is the central demand made upon him by other cultural workmen - by physical scientists and artists, by the intellectual community in general. It is because of this task and these demands, I believe, that the social sciences are becoming the common denominator of our cultural period, and the sociological imagination our most needed quality of mind.
\end{abstract}

(Mills, 1959, p. 20)

C. Wright Mills wrote The Sociological Imagination over fifty years ago. This influential work, premised on Mills' belief that social scientists must sociologically engage their imagination if they are to succeed in making a difference to the quality of the human life they study in their time, remains relevant today. A key conception underpinning this work is that neither the life of an individual nor the history of a society can be understood in isolation. It is imperative to understand both and to grasp how the two relate and are played out in everyday life.

An essential element of 'the sociological imagination' is the capacity to distinguish between 'troubles' and 'issues'. Troubles, as defined by Mills, occur within the character of the individual, the scope of their immediate social setting, and in relation to other individuals in their range. A trouble, therefore, “...is a private matter: values cherished by an individual are felt by him to be threatened" (1959, pp. 14-15). In contrast to troubles, issues transcend the contextual inner life of the individual, and while they are more difficult to define, Mills identified issues as public matters generated within and by the larger organisational and institutional 
structures or realities of a society. An issue "is a public matter: some value cherished by publics [that] is felt to be threatened" (1959, p. 15).

Despite its age, The Sociological Imagination has been inspirational and relevant for me as a contemporary scholar interrogating the connections between 'private troubles' and 'public issues'. Exploring the intersection of agency and structure, bridging the gap between micro and macro, is no easy enterprise. The Sociological Imagination provides intellectual insight on how the analyst might profitably grasp the interplay of an intimate setting with its larger structural framework.

This thesis is a socio-cultural study exploring the everyday life of a well-known street dweller living on and around a busy city intersection in Wellington, Aotearoa New Zealand. Although Brother's ${ }^{3}$ story is unique, it speaks to broader debates, and absences, within sociology. It is a story about an individual categorised as 'different' in ways that are open to contest and change, providing a comprehensive 'snapshot-in-time' account of what can happen to those at the margins who dare to do things differently. It is a story about who is thought to belong, and who is not. Brother does not live in a vacuum, thus it is also a story about the local street scene, about Wellington and its people.

At the centre of this thesis is an exploration of the social processes of classification, and how these act to 'make up' and 'unmake' people. Classifying or categorising others is a human tendency. It is how we make sense of who the other is and where they can be understood to fit in - or not, as is sometimes the case. Philosopher Ian Hacking (2007) wrote of the way classifying people creates 'human kinds'; Erving Goffman (1959) also sought to understand this process, focusing more on how people are 'unmade' through being ascribed to certain

3 In compliance with Bernett Hana's wishes, I used his preferred name of 'Brother' in my communication with him, and subsequently, I adopt this name when referring to him in my research. Brother is, however, addressed by the public-at-large using a variety of colloquialisms, including: Blanket Man; Blanket; Bro; Ben; Cave Man; Bernard; and Tarzan. The most prolifically used name heard throughout my fieldwork was 'Blanket Man' in recognition of Brother's ever-present blanket, providing him with clothing, cushioning, and warmth for his body. 
categories. C. Wright Mills spoke of "the human variety" (1959, pp. 147-148), suggesting that the social scientist seeks to understand the human variety in an orderly way. But, he also challenged, “...considering the range and depth of this variety...[i]s this really possible?" (1959, p. 148).

This thesis identifies and explains, through a detailed examination of Brother's 'private matters' (his day-in and day-out, ordinary, mundane, routine activities), the 'public issues' or socio-political responses unfolding and manifesting in reaction to his choice to live on the street and the domesticity this presents in the public realm. I demonstrate that through living on the street corner, Brother is ascribed membership to the category 'homeless', ${ }^{4}$ and because of his activities in public space, he becomes a person open to criminalisation and medicalisation processes. Together and separately, these processes act to make, remake, and ultimately unmake him as a person. I also reveal the ways in which Brother remains tenacious in his resolve to live by his values. With this steadfast commitment, he is able to remain autonomous against a backdrop of unsettling forces that ebb and flow, threatening his chosen lifestyle. Through his rejection of ascribed 'homeless' membership, his use of city space in specific ways, and his use of his body in innovative ways, Brother builds organisational and social capacities that enable him to sustain a lived sense of home in the city he calls his 'whare'.

C. Wright Mills (1959) urged scholars to utilise their own life experience in their intellectual work and to continuously examine and interpret this experience in dialogic relation to their intellectual work. I am a person who lives in a

\footnotetext{
${ }^{4}$ At the outset, it is important to signal that the word 'homeless' is used in this thesis in the way it is usually used by the public - to refer to 'street dwellers' or 'rough sleepers'. Scholarly and government definitions of homelessness increasingly reflect much broader populations than just people 'sleeping rough', as well as including explicit acknowledgement that people are not considered homeless if they are inadequately housed by choice (see, for example, Australian Bureau of Statistics, 2012; Statistics New Zealand, 2009). This thesis will reveal that Brother lives on a street corner by choice, and thus he would not be categorised as homeless by many contemporary definitions. However, the vast majority of the population would label Brother homeless, according to the popular understanding of the term and as the popular definition of 'homelessness' affects Brother's life far more than any scholarly one, this is the sense in which 'homelessness' should be understood when reading this thesis.
} 
conventional house. Built in the $19^{\text {th }}$ century, my house is steeped in the history of its inhabitants, including the experiences that my family have had between its walls. I am a nester. I do not move from house to house, seeking change and new beginnings within new houses, new neighbourhoods, or new cities. I am currently approaching my eighteenth year in my present home, situated only a few short streets from the first home inhabited after my birth; my later childhood having been spent in a neighbouring suburb. When visiting my local supermarket, many faces are not only familiar but can be dated back to various stages of my schooling. I have not always been such a settled 'home body'. During my teenage years, I ran with a free-spirited group - one girl failing to show one day was later found to have stowed away on a cargo ship to America, while an older man our group hung out with 'over the billy' ${ }^{5}$ was a bare-footed bohemian artist and socialist not given to obedience or conformity. It was in this spirit he had taken the name 'Fidel' for himself. Admittedly, youthful rebelliousness, along with a sense of invincibility, drove my desire to roam with the crowd while sleeping in unused buildings, squats, and abandoned vehicles. Upon leaving school and starting a job, 'real world' obligations and growing maturity slowly curbed my wandering ways. With this, I drifted away from that free-spirited crowd. My final year as a teenager brought about a new set of contingencies as I awaited the arrival of my firstborn child. By now, wings firmly clipped, my priorities shifted and settled. The 'nesting instinct' that kicked in then continues to ground my felt sense of place in everyday life today. This is my biography, my history - flimsily sketched out in its relational relevance to this research thesis.

Our histories, our backgrounds, and our present experiences combine to shape us into what and who we are today and who we will become and be tomorrow. During my fieldwork, various Wellington spaces were experienced as 'narrative spaces' - places rich with the history of past experiences or habitation, regardless of how mundane those experiences (Sennett, 1990). For example, a house on MacDonald Crescent, next to where an inner-city backpackers' hostel now

\footnotetext{
${ }^{5}$ The New Zealand expression 'Put the billy on' refers to boiling the kettle for a cup of tea.
} 
operates, marks a place I camped out in, eating dried soup straight from its packet. It is where 'Cat' crooned the lyrics to seventies ballads as he strummed his guitar, stopping only to make short work of a packet of raspberry buns. In another city street, another previously abandoned house is the site I remember hearing ABBA's debut blaring from a ghetto blaster. It was the squat from which people came and went, the ebb and flow of people the only constancy.

Moving around the streets of Wellington, fieldwork forays for the present study involved encounters with one or two vaguely familiar (now older) faces. Like the old school peers I will no doubt continue to greet (and sometimes avoid) when doing my groceries, these faces were recognisable as having belonged to that period. Last year, a person who had also moved about as part of the street scene, when learning of my research, had tracked me down via a mutual contact working at Victoria University of Wellington. We met, linking people, places, and paths that were mutually crossed or that could have been inadvertently crossed given the relatively small population of 'free-roaming teenagers' in the city at the time. Through this 'connecting the dots' of 'who's who and who's where now', I was not surprised to realise that although Brother and I did not cross paths back in the seventies, we might easily have done so. Brother was not a born and bred Wellingtonian, but he had lived in the city for a time during his own youth. Though he had moved in a different circle to my own, some of his friends had been friends with people in my crowd.

In light of these life experiences, I began this research from a distinctive position. I had the dual benefit of having once received a taste of 'the street' (albeit for a short period of time) on the one hand, with a long established history of 'homemaking' behind me on the other. I was therefore intrigued to learn what material and social processes would be involved for Brother in developing and sustaining an experiential firm sense of 'home' in the open. At a most basic level of inquiry, how might footpath spaces of the city street, literally the ground beneath other (housed) people's feet, transform into a lived sense of home for Brother? Further, through the privilege of returning to education as a mature tertiary student, my earlier Honours project exploring media representations of homelessness and 
homeless people in New Zealand (McGovern, 2005), prompted me to want to learn first-hand - beyond stereotypical media projections - more about the actual 'doing of homelessness' from those actually experiencing it. What level of social organisation is necessary to achieve a street lifestyle and what is required of the individual when living one's life in public space? How does one manage when one is more likely to be seen as the 'dangerous other', excluded, repressed, and displaced in all sectors of everyday life, often experiencing punitive police and city zoning practices pre-empted by negative stereotypes? How does one find some semblance of privacy in a publicly lived life? In what ways do objects and material conditions - social space and spatial divides - intersect with what people do to constitute or transform our sense of place that comes to inhabit us? (see Hacking, 2004; Latour, 2005) And how are social networks formed and maintained? Although this list of questions is by no means exhaustive, the foci of this thesis can be categorised into three areas of enquiry: space, body, and social interaction.

Three-and-a-half years of ethnographic fieldwork provided extensive data for interpreting and analysing the everyday nature of Brother's life - capturing the depth and nuanced complexities of his daily experience. I wanted to understand how space, body, and interaction intersect to bring forth a lived sense of 'city-aswhare' for this individual. I also sought to comprehend how larger structural forces impact on behaviour and interaction in the context of the setting being studied. In regard to structural forces, it is worth mentioning that initially my plan was to conduct a broader empirical study of 'street people' in central Wellington. However, not long after I gained ethical consent for the study, larger structural forces implementing new legislation setting in motion a process of emptying the inner city of the very people I had planned to observe thwarted my original plan. ${ }^{6}$

\footnotetext{
${ }^{6}$ I discuss this situation in Chapter Six, explaining what propelled the migration of homeless people into neighbouring areas.
} 
So, how can C. Wright Mills' (1959) articulation of 'private troubles and public matters' be understood and explained through a close examination of 'a life lived on the corner' in Wellington City, Aotearoa New Zealand?

I began this research with a broad question: How is life lived in public? Through this lens, and through what I was beginning to see in my fieldwork observations, I was able to gradually formulate other guiding research questions. These were as follows: How does Brother use space, make it his own, and interact with others who also share this space? How are his daily routines, activities, and 'presentation of the self' (Goffman, 1959) understood to 'make trouble' for others in city space? How is Brother 'made up', 're-made', and 'unmade' through categorisation processes, and how do these processes loop back to affect behaviour in the micro setting observed? How does Brother interact with classifications that categorise and re-categorise him bad, mad, and sad? Drawing upon these questions, in the next section I outline the thesis chapters, explaining how I structured my inquiry.

\section{Thesis Outline}

Chapter Two explores the various ways homelessness has been studied within a range of disciplines, including sociology, feminist studies, anthropology, geography, and psychology. Separating the international literature from the New Zealand literature, I argue that the majority of international work can be classified into four basic types. The first and second types are quantitative studies premised on understanding homelessness from a 'social problem' perspective. The aim of these works is to identify personal, societal, and economic factors correlated with homelessness. Studies of the first type tend to focus on the demographics, disabilities, and transitions into homelessness by individuals. Those of the second type assess the relationships between rates of poverty, unemployment, housing affordability, and rates of homelessness across cities. The third type examine how public understandings of homelessness are influenced by discursive practices in the public sphere, for example, how media representations construct homelessness. Studies of the fourth type are concerned with examining the lived experience of homelessness. Of these four types, I position my study alongside other works located within the third and fourth types. I then specifically discuss the New 
Zealand literature on homelessness. I critically assess how homelessness has been studied and evaluate what still needs to be done if we are to better understand this social phenomenon in contemporary New Zealand society.

Chapters Three and Four explain the methodological framework and the research methods used in this thesis. Chapter Three explains the key theoretical and conceptual underpinnings that have influenced and informed my thinking behind 'the doing' of this research. This chapter speaks to methodological and epistemological considerations and pathways chosen that facilitate an analytic ethnography grounded in the social action and interaction observed. Chapter Four explicitly maps out the qualitative methods used to conduct this sociological street corner study. I also discuss how methodological concepts can become 'muddied' and open to contest and change when they are put into practice 'on the street corner'. I tease out fieldwork issues such as 'getting started', 'getting in', and 'staying in'. I also suggest that though researcher reflexivity is usually discussed as a mental process, the researchers own body should not be overlooked within the ethnographic enterprise - it can be understood as a research tool for making pragmatic sense of the worlds we study.

Chapter Five has two aims. The first is to explore the interactive socio-spatial dynamics of the inner-city street scene in Wellington, including positioning Brother within this context and exposing what is both distinctive and ordinary about his particular way of doing street life. The second, interrelated aim is to explore the ways 'popular and expert knowledge' (Hacking, 2007) identified in this thesis as being generated by the newspaper media, social media, the public, and the 'institutions of control' - the police, homelessness advocates, politicians, and legal and medical professionals - can lead to classification processes that frame homeless people as a 'human kind' (Hacking, 2004). A small case study of an inner-city park illuminates the way these discursive practices lead to negative stereotypes of homeless people and how these are given life in mundane everyday situations. 
Chapter Six is the first of three chapters analysing field notes, focused on Brother's everyday street corner life. In this chapter, the aim is to investigate Brother's daily spatial mapping to understand how space is used and how it matters in everyday street life. How others - average Wellingtonians and those in authority - respond to his appropriation of public space as home space is examined. Building on arguments introduced in Chapter Five, I examine how Brother is able to 'make himself up' while simultaneously resisting others' attempts to categorise and re-categorise him. Significantly, this chapter includes an analysis of what happens, in Brother's case, when agency and structure collide. A trajectory of legal interventionist practices is explored as a first step towards understanding how Brother is classified as a 'bad' homeless man and a 'criminal'.

Chapter Seven expands on arguments about agency and structure by exploring the body and its material objects as an integral part of spatial analysis. Positioning the public body of Brother and his two bodily objects as central to my analysis, I examine the various ways in which the homeless body intrudes into everyday awareness and the ways in which it is rendered meaningful (Kawash, 1998; Wardhaugh, 1999). A primary aim in this chapter is to understand how the "physical (homeless body), by occupying public space, becomes itself the threat" (Kawash, 1998, p. 325), in the contest over public space. I demonstrate that as new knowledge about 'the criminal' (Brother) is brought to light from the community of experts (Hacking, 1986), Brother becomes re-categorised as 'mentally ill'. In chronicling a medicalisation of deviance process, my fieldwork is taken off the streets and into Wellington Hospital's acute mental health unit in this chapter.

Chapter Eight is about Brother's interactive relationships with others in public space. It is a chapter about people, home-making, and belonging. Positioning the thinking, acting, talking, laughing individual at the centre of analysis, I focus on Brother's expressions of agency and autonomy to examine the nature and form of Brother's social interactions with the public at large. Discussion is framed around a repertoire of humourous talk and actions to understand how humour functions as both an interactional opener and as a distancing mechanism for Brother when socially organising who, when, and how others may interact with him. I seek to 
learn how Brother's 'tricks' in his interactional 'toolkit' enable him to preserve a back stage self during front stage projections in a publicly lived life.

The final chapter will draw together the findings and arguments developed throughout the thesis. These conclusions are set in the context of three fields of research: street corner sociology, homelessness studies, and everyday life studies. 


\section{Chapter Two \\ Researching on the margins of homelessness}

\section{Introduction}

Homelessness is commonly understood as lacking a home. Yet, many people view their houses as much more than simply places of shelter, with emotional and social aspects also attached to the notion of home. Historian Witold Rybczynski reflects on this second meaning of home, tracing the Western concept of home back to seventeenth-century Holland:

Home brought together the meanings of house and household, of dwelling and of refuge, of ownership and of affection. Home meant the house, but also everything that was in it and around it, as well as the people, and the sense of satisfaction and contentment that all these conveyed. You could walk out of the house, but you always returned home (Rybczynski, 2001 cited in Schrader, 2005, p. 10).

Ruskin, writing in 1868 , makes a similar distinction:

The 'true nature' of home is the place of peace, the shelter, not only from all injury, but from all terror, doubt and division...so far as the anxieties of the outer life penetrate into it...it ceases to be a home, it is then only a part of the outer world which you have roofed over and lighted a fire in (Ruskin, 1868 cited in Bennett \& Watson, 2002, p. 2).

These definitions of what makes a home are applicable to contemporary understandings of home. Now, as then, for most people the notion of home is linked to identity and a sense of belonging; it is an identifiable and fixed place of residence, comprising a physical and social fabric. In providing a retreat from the outside world, the concept of home is understood as synonymous with physical and emotional shelter.

For Wardhaugh (1999, p. 93) the semantic contrary of homelessness serves "to delineate home, in a dynamic and dialectic fashion." Understandings of what a home provides define everyday understandings and perceptions about what 
homelessness does not provide, especially for those living without any shelter at all. Olufemi (2002) examined the definition, meaning, and interpretation of home and homelessness via theoretical constructs and the perspectives of homeless people. He observed that the most minimal definition of homelessness is constructed in terms of a lack of shelter, not a lack of abode. For example, the United Nations Centre for Human Settlements (UNCHS) defines adequate shelter as more than a roof over one's head:

It means adequate privacy; adequate space; adequate security; security of tenure; physical accessibility; structural stability and durability, adequate basic infrastructure such as water supply, sanitation and waste management facilities; adequate lighting; heating and ventilation; suitable environmental quality and health-related factors; adequate and accessible location with regard to work and basic facilities: all of which should be available at an affordable cost (UNCHS, 1997 cited in Olufemi, 2002, pp. 455-456).

Olufemi (2002) found that interpretations of inadequate/adequate shelter among homeless people sleeping in shelters and on the streets corroborated conventional meanings of inadequate/adequate housing. Olufemi also stresses a pivotal concern for homeless people is one of emotional detachment and disconnectedness (see also May, 2000).

Brother, whose street life is lived day-in and night-out on the city street, lacks many of the requirements of adequate shelter. However, one of the challenges in this thesis is to demonstrate that despite Brother not having adequate shelter, he is nevertheless able to achieve some of the basic needs identified by UNCHS. Moreover, as this thesis will illustrate, through experiencing a great deal of public interest and interaction, Brother achieves a sense of connectedness with others and a sense of belonging on the street. Wardhaugh (1999) observes that "[h]ome and 'homelessness' serve to define each other at a phenomenological level' (p. 91): while it might be incomprehensible to the casual onlooker that Brother finds home living in the harsh conditions of public terrain without adequate shelter, bereft of material possessions (other than what can be kept in a small carry bag), his own definition of home is simple, "Home is where ever you feel most comfortable" (Fieldwork: 28/03/10). 
Homelessness is a complex issue that has attracted a long history of scholarly attention in a range of disciplines, including sociology, human geography, feminist studies, anthropology, and psychology. This chapter provides a review of the homelessness literature to show where my work both diverges from and fits within the broader scope of this literature. I also indicate where my work is able to build on previous studies to contribute new insight into street life as a preferred lifestyle. I have chosen to separate my discussion of the literature into two sections: international and New Zealand. Because the volume of New Zealand literature is comparatively very small, the content is made more salient when discussed separately from the larger body of literature.

\section{International literature on homelessness}

The large proportion of the literature can be classified into four basic types. The first two types involve large quantitative studies, which aim to identify personal, societal, and economic factors that lead to homelessness. The first type incorporates cross-sectional, survey-based studies, focusing on the demographics, disabilities, and transitions into homelessness by individuals (for example, Anderson \& Christian, 2003; Wong \& Piliavin, 1997). Generally, these studies examine drug or alcohol dependency and mental illness as predecessors to homelessness (for example, Baumohl \& Huebner, 1991; Calsyn \& Morse, 1990; Fischer \& Breakey, 1991; Stein \& Gelberg, 1997). The second type consists of macro-level multivariate studies assessing relationships between rates of poverty, unemployment, and housing affordability, as well as variation in rates of homelessness across cities (for example, Burt, 1992; Colton, 2003; Kemp, Lynch, $\&$ MacKay, 2001). The aim of this type of work is to understand and identify causal factors leading to homelessness from a societal perspective. I am not so concerned with the literatures within these first two types, which generally begin from a premise viewing homelessness and homeless people as a 'social problem' and are more interested with questions of composition, magnitude, and reasons for homelessness. However, given that this literature tends to conclude that the reason why someone is homeless stems from some pathology, this literature shapes and influences official actions taken in relation to homeless people. 
Research that assumes marginality of homeless people and other groups can reproduce social deficit, and so reinforce social marginalisation of the groups being studied (Hurley, 2007). This can be seen in the work by Lee, Farrell, \& Link (2004), which examined the results from a United States national survey conducted in 1990 to understand how contact between housed persons and homeless persons affects the former's view of the latter. The authors' examined both parties in the panhandling encounter, homeless people and the public, in an attempt to shed light on the idea of panhandling being perceived as a problem. Their discovery that the public commonly viewed panhandling as an urban activity pursued by isolated men with substance abuse and mental health difficulties, led the authors' to concede that homeless individuals were usually understood by the public to have resorted to panhandling because of their many problems entrenching them in homelessness. Furthermore, the public considered that they lacked the skills and resources necessary that would enable them to escape the situation. Lee et al also contended that the surveys were unable to tell them anything definite about panhandling non-homeless persons, a caveat they stress is necessary to avoid perpetuating the stereotype that only homeless persons panhandle. However, when questions asked of the data were guided by insights deriving from ethnographic literature on panhandling (for example, Duneier, 1999; Lankenau, 1999; Snow \& Anderson, 1993), the researchers found public attitudes challenged the notion that panhandling constitutes a threatening feature of urban life.

A third type of research examines how public understandings or 'imaginings' of homelessness and homeless people are influenced by discursive constructions in the public sphere. Media accounts provide a central source of information for many people. They are sometimes also the primary source of information about homelessness for housed people who may have limited exposure to homelessness in their own lives. However, the influence of the media has also been argued to inform impressions even among those people who are familiar with homelessness in their own communities (Silverstone, 2007). Importantly, then, people's personal attitudes and understandings of homelessness are often shaped by what they read, 
hear and see as presented by the media (Schneider, Chamberlain, \& Hodgetts, 2010; Toro \& McDonell, 1992).

Given that media texts do not stand alone but rather are situated within a broader contextual frame of reference, a close reading of newspaper texts provides an avenue for investigating how social relations and identities, often portrayed through hegemonic representations, can position and invite readers to accept particular ideologies (Marston, 2004). Deciphering common themes appearing in media reporting on particular social issues within the societal context in which they are written is one way of understanding how meanings are constructed and how new meanings are developed (Marston, 2004). In New Zealand where direct exposure to homelessness and homeless people 'on the street' is far less common than that experienced overseas (O'Brien \& de Haan, 2000; Wellington City Council, 2004), media organisations arguably play a greater role in influencing public attitudes and perceptions of homeless people. Homelessness studies that have explored this aspect have provided a useful comparative platform for me when wanting to understand how the Wellington newspaper media might also contribute to social processes that contribute towards a 'making or unmaking' of some Wellington street people.

Research has found newspaper reportage on homelessness commonly projects a view of 'them' and 'us' - the housed and the unhoused (Pascale, 2005; Platt, 1999).This type of representation has been argued to "bind the public within a moral order by providing a sense of coherence to our understandings of homelessness" (Bunis, et al., 1996 cited in Hodgetts, Cullen, \& Radley, 2005, p. 30). Studies that have explored newspaper constructions of homelessness generally attest to an overwhelming representation of homeless people as dirty, deviant and dangerous (Amster, 2003). Homelessness scholars have further found that negative constructions of homelessness, in creating a poor public attitude or low tolerance of homeless people, leads to social distance between housed and unhoused persons in everyday life situations (Bullock, Fraser Wyche, \& Williams, 2001; Lee, Link, \& Toro, 1991; McNulty, 1992; Min, 1999). 
Studies have also examined portrayals of homelessness within documentary, television, and fictional film. Work by Hodgetts, Cullen \& Radley (2005) for example, explored the degree of partiality within characterised television storytelling about homeless people in the United Kingdom. Overall, they argued a patterning portraying homeless people as requiring control and regulation exacerbated public calls for more social control of this group. Phillips' (2000) analysis of British television documentaries produced a similar argument. Fictional accounts of homelessness are also understood to perpetuate homelessness mythology. Russell (1991) found that American literature and music, from Jack Kerouac's On the Road to John Denver's On the Road Again, engendered a romanticised view of the homeless man and tramp for the good part of a century. By comparison, homeless women were either ignored or simply mentioned in passing (Russell, 1991). Elsewhere, Cresswell (1993) proposes the invisibleness of homeless women was possibly due to their being perceived as a community of double outsiders that belonged on the 'margins of a margin'. However, the growing number of homeless women that were visible on Britain's streets by the mid 1960s ensured that the homeless women could no longer be ignored (Watson \& Austerberry, 1986).

Through their growing visibility as a social group and as public awareness of the urban homeless woman also developed, the depiction of the solitary 'shopping-bag lady' (Hand, 1983) began to emerge within news reports and fictionalised accounts about homelessness during the early 1980s (Russell, 1991). However, as scholars writing on contemporary homelessness have observed, the presence of women within media constructions of homelessness still tends to be easily overshadowed by the more "troublesome population of rough sleepers, beggars and addicts who threaten the civility of a revitalized public space and whose lead players are, almost without exception, cast as men” (May, Cloke, \& Johnsen, 2007, p. 123). Wardhaugh (1999) considers a primary reason that women's homelessness continues to remain largely invisible is due to the peculiar stigma attached to the 'unaccommodated woman' who presents as a contradiction in terms of pervading constructions of femaleness linking women to hearth and home (see also Radley, Hodgetts, \& Cullen, 2005; Watson, 2000 for similar arguments). 
The studies discussed have revealed that the media predominately constructs homelessness as a social group that requires official intervention and control. In line with this view, the homeless person is usually understood as a threatening 'other'. Consequently this dominant view affects how homelessness is responded to impacting upon the everyday lives of homeless people. Amster (2003) notes that although homeless people lack almost all markers of societal power and pose no viable threat to the dominant culture; their presence inspires overt hostility from mainstream society. Exploring contemporary manifestations of spatial exclusion and marginalisation within anti-homeless legislation and regimes of spatial control in Tempe, Arizona, Amster argued that the predominant 'disease' metaphor used within mainstream newspaper constructions, connecting the homeless identity with filth and decay, encouraged a negative public attitude about street people. Ultimately, however, Amster contended that the pervasive 'disease' metaphor, in political terms, empowered city officials to act on behalf of "the community" by implementing legislation that served to spatially exclude homeless people from public space.

In addition to interpretations of homelessness, the embodiment of homelessness has been a major focus within the literature. A substantial body of work in sociology and the social sciences more generally has employed a variety of ethnographic methods to understand the lived experience of homelessness. It is primarily this third body of literature focusing on the texture and dynamics of street life and the adaptive survival strategies of homeless people that I draw from when interpreting and analysing my own empirical material in this thesis.

While sociologist Nels Anderson's work The Hobo (1923) provides an early example of a study of the homeless man in his own habitat (see also Spradley, 1970) and George Orwell's (1933) autobiographical Down and out in Paris and London portrays an early sociological account of the tramping experience, a plethora of sociological ethnographic studies since then provide a rich corpus of contemporary work examining various aspects of the homelessness experience. Homelessness scholars have explored the experience of homelessness in particular geographical locations providing rural perspectives of homelessness (for example, 
Aron \& Fitchen, 1996; Cloke et al., 2000) to urban accounts in different cities (for example, Daly, 1996; Karn, 1990; Koegel, Burnam, \& Baumohl, 1996). Within these studies, researchers have explored the differences between homeless people's experiences and use of outreach (Rowe, 1999) and other services offered to homeless people such as soup kitchens (Glasser, 1988), with the experiences of non-users (Sosin, 1992).

While a vast percentage of literature derives from studies conducted in the United Kingdom, the United States of America, or Canada, the experience of homelessness is increasingly gaining the attention of qualitative scholars elsewhere. For example, Ezawa (2002) and Guzewicz (1998) have studied homelessness in Japan, Patel and Masselos (2003) have explored the homelessness experience in Mumbai, and Olufemi (1998) has explored the experience of street homelessness in Johannesburg. To illustrate the nature of this research, Stephenson (2006) placed homeless narratives within a framework of theoretical perspectives on social and spatial exclusion to examine the interaction between space and social identity within the regimes of homelessness settlement and homelessness control in Russian society. Her research aimed to advance the understanding of homelessness in Russia as an extreme case of social-territorial displacement, and to set out its causes and its individual consequences within the larger social and political context in which it has developed. Also studied from within a Russian context and perspective, Fujimura (2003) investigated the cultural and environmental hazards faced by street children living in Russia.

In order to filter an extensive and diverse body of literature on homelessness, I narrowed my focus to concentrate on the experience of urban homelessness and studies that have explored the experience of a literal form of street homelessness involving rough sleepers. Research of this nature has examined homelessness across a broad spectrum ranging from identified skid row quarters of various cities (for example, Hirschoff \& Hart, 2002; Hoch \& Slayton, 1989) and homeless people living in cities' underground subway systems (for example, Love, 1957; Morton, 1995), to others living in homeless encampments under bridges and motorways (for example, Underwood, 1993). Within this corpus, research has 
explored the daily mapping and mobility paths of homeless people to understand the different ways space, when perceived as a margin or boundary, functions in the homelessness experience (for example, Rowe \& Wolch, 1990). In addition, other studies have examined the use of specific public spaces, for example, homeless people's use of public libraries has been well documented within the literature (for example, Black \& Crann, 2002; Grace, 2000; Hersberger, 2005; Shuman, 1996).

Many of these spatially orientated studies have explored the issue of how homeless people manage their own bodies and organise their social networks in the routines of everyday interaction. Focusing on the embodiment and spatiality of interaction has revealed the various ways homeless people are able to resist stigma, exercise resistance, and manage social identity, while also retaining a sense of one's own self-identity (for example, Bridgman, 1999; Dordick, 1997; Wagner \& Cohen, 1991)

Snow and Anderson's (1993) study Down on their Luck focused on identity work among homeless people living in Austin, Texas, providing portrayals of men and women described as highly adaptive, resourceful and pragmatic. In exploring the ways homeless people constructed and asserted personal identities through engaging various forms of 'identity work', and how these identities could change over time, the authors found that by distancing themselves from imposed categories, homeless individuals were able to reduce the risk of stigmatisation, marginalisation, and degradation. In a chapter titled Salvaging the Self (pp.198230) the authors examine existential and identity-orientated meaning in regard to how homeless people establish who they are through their interactions with others. In part, the authors sought to discover whether the personal identities that homeless people construct and negotiate when interacting with others reflect highly stereotypic and stigmatised identities attributed to them or whether they reflect an attempt to carve out and sustain a less demeaning self-conception. Distinguishing between types of identity (associational, role, and institutional) and types of embracement (role and ideological), these authors proposed that meanings of self and social identity were accessible through the talk of homeless people. Yet, the 'identity' talk analysed involved mainly listening to conversations 
between homeless people and conversations with agency personnel, and only occasionally involved talk between homeless people and housed people. Given that the authors identified homeless people as adaptive, resourceful, social agents, it is surprising they did not look more closely at the way homeless people can construct their relations with housed people through the use of specific locations in urban space and the extensive nature of these interactions with non-homeless people (see also Snow \& Anderson, 1987).

Studies by Wagner (1993) and Wright (1997) also examined 'identity work' as an important repertoire of social action of homeless groups, arguing that identity work can be understood as a form of tactical resistance. For example, Wright's (1997) study found that homeless people in San Jose and Chicago countered negative labels and low status by distancing themselves from shelter staff.

Other studies have examined and reported on more specific features inherent to the homeless experience. Examining the banal activities of homeless people offers a fruitful way for accessing the ways homelessness stereotypes are given life in the everyday experiences and interactions of marginalised people living in public space. A paper by Lankenau (1999) focused on panhandlers (street beggars) in Washington D.C., who, in publicly displaying their homelessness status, found that experiences of rejection and humiliation become a regular feature of everyday life. However, Lankenau argued that in spite of this panhandlers can, by attending to the presentation of self in important ways and through conforming to certain interactional norms, enhance their status and develop relationships with passersby (see also Lee \& Farrell, 2003). Rowe and Wolch's (1990) Los Angeles-based ethnography, which explored the way social networks operate within a specific time-space framework, included an examination of homeless women's experiences of panhandling. Their study found that social networks formed with members of the homed community through panhandling could be a source of logistical, material and emotional support, boosting positive esteem for homeless women. They also discovered that women panhandlers were perceived as less threatening by housed people than their male counterparts, facilitating friendly social interaction. Yet, women were also said to be particularly vulnerable to 
experiencing abusive behaviour from passersby. To deal with the latter, women learned to draw boundaries in social interactions, and worked to distinguish themselves apart from women who were prostitutes in order to preserve identity and self-esteem. This study, though it addressed women's coping mechanisms, nonetheless provides insight into some of the ways homeless people use space in order to symbolically demarcate personal boundaries and safe space in public.

A provocative ethnography focused on the changes that occur in homeless and former homeless persons living in the Netherlands regarding their perception of time and space. van Doorn (2010), discovered that the longer people had been living on the streets, the more their bonds to social institutions tended to loosen, and their perception of time shifted away from a linear perception into a cyclical perception of time. Investigating further how homeless people's perceptions of space enabled them to manage privacy in public space, van Doorn found this allowed homeless people to filter impressions relating to a sense of ownership and autonomy. van Doorn's paper is useful for my research with its central focus on time and space examining how abstract concepts matter and take on lived relevance to the concrete everyday doing of homelessness.

Other ethnographies have specifically examined the different experiences between male and female homelessness. Word on the Street: Homeless Men in Las Vegas (Borchard, 2005) explored notions of personal responsibility when interpreting individual men's accounts of their homelessness. Another study of homelessness and masculinities (Nonn, 1995) has explored the coping mechanisms that men develop in order to dispel misunderstandings that contribute to the social stigma and isolation of homeless men. Identifying masculinity as a social process, Nonn outlines the ways homeless men use 'versatile masculinity' to transcend hegemonic masculinity. By accepting racial, ethnic, cultural, and sexual differences between other homeless men, Nonn argued this connected them as a distinct social group, and enabled them to cope while avoiding what might otherwise have been an exclusionary existence. 
Julia Wardhaugh (1999), in her work on the gendering of the 'homeless body', argued that for homeless people, "the homeless body assumes increased, even paramount importance. Lacking access to that second skin, the home, the homeless body becomes the first and often only line of defense against a dangerous world" (p. 102). Wardhaugh identified that women tended to live shadowy existences on the peripheral of the male dominated street scene and rarely engaged in activities such as begging that would mark them as visibly homeless. Because of their peripheral existence, she argued that women have more ambivalent relationships to the street. In contrast to the shadowy body presented by Wardhaugh, Casey, Goudie and Reeve's (2008) exploration of homeless women's use of space and buildings in England challenges the dominant argument presented in the literature which purports homeless women shy away from using highly visible public spaces. Drawing on survey data collected in social service agencies across England, these authors found women used resistance to challenge the rules associated with occupying public spaces that either directly or tacitly excluded them in order to avoid being labelled as homeless. Likewise, Sophie Watson's (2000) ethnographic work identified how some homeless women deliberately challenged traditional gender roles by rejecting a clean, well-groomed appearance. Instead, these women would dress eccentrically, or pierce and tattoo their bodies in ways that deliberately heightened their visibility as if to say 'we are not like you' (p. 168). Similarly, May, Cloke, and Johnsen's (2007, p. 132) study reveals how one woman secured herself an esteemed position in the street hierarchy through rejecting her own femininity and promoting values normally associated with the 'hard masculine body' when gaining herself a reputation for violence Accordingly, transgressing traditional feminine binaries is said to enable women to experience high visibility in places where homeless people gathered (Watson, 2000; May et al, 2007).

Though these studies provided a conceptual and empirical platform when thinking about and doing my own ethnographic research, central to my thesis is an observational study by sociologist Mitchell Duneier (1999), which examined what it means to be homeless in Greenwich Village, New York. To grasp the character of homeless street life and the dynamic relationship among homeless subsistence 
practices (magazine street vending), Duneier's work focused on the organisational, political, and spatial constraints the men confronted in daily life, closely attended to how homeless vendors negotiated and responded to their interactions in situ with passersby and police. In analysing everyday street talk, Duneier was able to pinpoint for example, what can 'go wrong' when certain street people 'harass' passersby. In order to extend understanding of how forces of a more political, socio-spatial, and economic nature, affected the social world he was observing, Duneier 'followed his nose', checking up on less visible structures and processes that engendered, sustained and complicated the lives of the men. Focusing on what he described as more middle-range work using a strategy he terms "an extended place method" (1999, p. 344), Duneier spoke to park managers, railway station officials, restaurant owners, and city officials to examine how proximate linkages and invisible traces of organisational structure affected sidewalk life.

In an earlier study, Duneier (1992) provides an important critique on distorted media and social science images of black men and the black class structure as it is experienced by a community of men. For example, his examination of the banal everyday interactions observed between marginalised men and housed workingclass men, offers understanding of the way substitute kinship ties form through the mundane daily activities of people regularly sharing a setting.

\section{Research on homelessness and homeless people in New Zealand}

New Zealand research on homelessness has been modest in quantity with early studies employing an individualist approach in their investigations of homelessness. It is apparent from this early research that defining homelessness in New Zealand is an unresolved problem. For example, an early research paper involving the residents of the Christchurch City Mission Night Shelter described the physical condition of homelessness and also the psychological traits of deprivation associated with being homeless (Ayres, 1974). This is indicative of the way homeless people were considered homogeneously at that time. Ayres' (1974, p. 15) paper reveals a little about the attitudes towards homeless people when distinguishing that single homeless men present "as a minority group in [the] New Zealand society where the majority group makes the rules for societal living”. 
The study further noted that while the Crimes Act served to define the ways homeless people were dealt with by law, the Crimes Act also recognised that homeless people were still human beings and because of this they were to be treated like human beings "irrespective of their failures and deficiencies".

Another New Zealand study, Homelessness in the Auckland Region (Percy, 1982) though primarily concerned with an emergency housing shortage, found there was a very limited awareness of homelessness and partly due to this, there was no legal definition in New Zealand. Other research produced during the 1980s (for example, Lea \& Cole, 1983; McClintock, 1982) also demonstrated the view that homeless people were understood heterogeneously. However, they were a group nevertheless linked by their inadequate income and their inability to access and sustain adequate housing (Thorns, 1989). This approach to understanding homelessness is also evident in Kearns, Smith, and Abbott's (1991) study examining the relationships between housing and health which includes a discussion of incipient homelessness among people described as inadequately housed.

In 2004, Wellington's Downtown Community Ministry (DCM) conducted 30 biographical interviews with people who were either currently homeless, or had been homeless in the city, to understand the events that led some people to becoming homeless. This work described three major pathways encompassing the complexity and interrelating factors leading some people into homelessness. These pathways are: 1) Driven - adverse childhood experiences are a prevalent biographical feature; 2). Dropped - addictions and unemployment are often precipitators; and 3). Drawn - association with homeless subculture engenders a sense of freedom and connection not otherwise experienced. Other research conducted from within a public health framework examined pathways into homelessness with the aim of preventing and alleviating homelessness based on public health principles (Al-Nasrallah et al., 2005).

The available literature as I have discussed it so far accords with the literature outlined within the first two types identified within the international literature. To 
recap, the focus of that literature was directed on answering questions of composition, magnitude, and on providing explanations and solutions for homelessness.

Meanwhile, two other studies by Laurenson and Collins $(2006,2007)$ have debated homelessness policy. In the earlier paper the authors considered the political and normative dimensions of local government responses to homelessness. In outlining the context for local government action, and approaches adopted in three city case studies, the authors argued for a rejection of anti-homeless regulations that they claim criminalised visible manifestations of poverty. The second paper investigated the ways New Zealand local authorities could be seen to respond to homelessness. The authors' found that while some punitive bylaws targeting homeless people exist, they are not widespread. However, they also identify that local authority attitudes are subject to political whim, and that on occasion, these attitudes can be understood to articulate an exclusive vision of public space that is linked to concern for public safety and city image. Though the authors conclude that the actions of New Zealand cities depart significantly from the dominant approach internationally, they also conceded that this could in part be explained by the relative invisibility of homelessness in New Zealand.

Drawing on their research with clients of Auckland City Mission (O'Brien \& de Haan, 2000), O'Brien and de Haan (2002) attempted to deconstruct stereotypes about homeless people. The authors revealed that despite the often negative experiences and the current situations of their homeless participants, their aspirations and motivations were generally consistent with those of the wider community. O'Brien and de Haan considered this finding significant as it challenged pre-existing assumptions that homeless people lacked motivation, ambition, and did not share in the same ideas and values of the community-atlarge. O'Brien and de Haan also discovered that many participants were quick to disabuse them of the notion that living on the street represented some form of 'idyllic alternative', with one participant quoted as saying: 
Some people reckon that homelessness is the route to enlightenment...to be really honest I feel it is the worst thing that can happen to anybody. It's so degrading, smelly; I mean you know it's just disgusting (p. 33).

Their study concluded that the majority of participants expressed a need for not only a place of safety but also a sense of security and identity, a place that would in fact, give the sense of being 'home' that I discussed at the outset of this chapter.

During the 1980s, an aberration to normative approaches and concerns directing research is evident in a sociological observational study that was conducted among skid row alcoholics in Christchurch (Wilkinson, 1983). The goal of this research was to convey the importance of spatial and ecological factors in relation to the everyday life and routines of homeless people. Wilkinson's study also examined the psychological and social ties skid rowers had to agencies of social control. A substantive portion of Wilkinson's study dealt with the 'spatial', 'temporal', and 'social' as underlying structures of subjective orientation to the life world. Through exploring the way in which skid rowers were observed using different sites around the city and their relationships with the agencies of social control, Wilkinson noted how the skid rower attempted to place himself in a 'routine' framework in order to present a 'conventional' identity. For Wilkinson's 'skid row' homeless men, it was the warm crowded atmosphere of the pub that provided them with a sense of being 'at home'.

Other postgraduate research has more recently examined aspects of homelessness in New Zealand. Marsh (2006) has examined from an anthropological perspective, the representations and experiences of female homelessness in Christchurch. Marsh's research primarily centred on the narratives of homeless women and found that homeless women are predominately understood and positioned as social failures. Consequently, Marsh argued the homeless women she studied were ill equipped or unable to reproduce social norms, to govern themselves, or create meaningful or enduring social networks. Cooper's (2001) doctorate research explored from a social geography perspective the way space and homelessness intersect in Central Auckland. Of particular comparative value for me doing street observations in Wellington were Cooper's ethnographic descriptions depicting the 
nature of street life in central Auckland and the responses to this by the public and authorities. Cooper identified that Aotea Square was a popular 'hanging out' space for both homeless people and members of the housed public. Therefore, it represented a notable site of contention where tensions and conflict were argued to occur. Of particular note to my research interests were Cooper's interpretations of the ways homeless people in Aotea Square negotiated processes of marginalisation and exclusion in contentious space. Further, Cooper's examination drew on how homeless people managed the appearance of their selves in the settings investigated in order to attract the least public attention. Cooper found that the path of least resistance was often the route taken as homeless people's appropriation of prime public space was often deliberately fulfilled outside the temporal peaks of public usage and therefore away from the public gaze, in their attempts to reduce conflict. Her study further identified the role space can be understood to play in the constitution of 'normality' and acceptance for homeless people when taking the path of least resistance. Such spaces were argued to symbolise places where accepted forms of difference are more readily tolerated and permissible. For example, a café located on Auckland's Karangahape Road, an area characterised by an eclectic Bohemian and alternative social scene, was identified as a representative space, which functioned to provide a sense of temporary belonging for homeless people within their daily use of space.

In addition, a group of homelessness scholars examining homelessness in the Auckland and Waikato regions from a psychology and health perspective have made a significant contribution to the New Zealand research. To unpack the contribution this research has made and continues to make to knowledge and understanding of homelessness in the New Zealand context, and to show where it has been useful for conceptualising my own data, their ethnographic project can be summarised as one that recognises the importance of doing research that does not displace homeless people from their own stories. Therefore, the approach favoured by these authors, is one that recognises talking to homeless people (rather than talking about them) includes the perspective of participants within research investigating relationships between homeless and housed people. In examining how the living situations and possibilities for homeless people are grounded in 
"material, symbolic, spatial and relational contexts", Hodgetts et al. (2008, p. 937)

define their project as one engaging:

...observational, visual and verbal qualitative methods to provide a close focus on the lifeworlds associated with homelessness. It involves fieldwork, including site visits, engagement with participants in their various locations and with their objects, and observations of domiciled people's reactions to homeless people in public spaces.

A notable feature of this body of research is how social relations are examinable in both representational spaces such as newspaper reports and in the physical locations of prime social space where homeless people and housed people share common ground. The studies produced from this ethnographic project provided me both points of reference and divergence when interpreting my own data about street life in Wellington and in particular, Brother's highly visible life as it was observed and interpreted within the Wellington context. My research articulates a local narrative firmly grounded in a sociological everyday life approach, which contributes to the larger narrative of homelessness and the homeless experience provided by these studies conducted in the Waikato and Auckland regions of New Zealand.

Also contributing to the current New Zealand literature are two articles from my earlier study (Lloyd \& McGovern, 2007, 2008) which draw from ethnographic material and engage sociological and media studies debates to examine the social processes that contribute to 'the legendary life' of a locally known homeless man living in Wellington (Brother). Contrasting with the dominant emphasis that argues the importance of the 'media's' role in celebrity creation, findings in these studies emphasised the continued importance of the spatial routines and face-toface interaction of everyday life contributed significantly to the construction of this locally identifiable individual.

\section{Conclusion}

This chapter has provided a literature review that has identified and presented four key bodies of research within the international literature. In doing so, I have signalled the two types that have the most relevance for my research: media 
constructions of homelessness and the lived experience of 'doing' homelessness. I have also indicated where my ethnographic material can be understood in relation to these studies presented. In particular, I have discussed studies that have explored socio-cultural constructions or representational spaces of homelessness, and the socio-spatial dynamic of the daily homelessness experience. However, while many studies have explored the ways in which homeless people utilise space and the individual body to demarcate personal territories in public space, the expressive agency of individuals in the settings where they are enacted has received scant attention. Duneier's $(1992,1999)$ studies do, however, provide comprehensible and detailed examinations of the nature and form of social interaction in the lives of homeless people from a grounded sociological perspective.

A review of the New Zealand literature has revealed that although this is a small body of research, interest in homelessness research has taken on impetus producing a comparatively large number of studies within the past decade. Clearly, homelessness is a concern firmly back on the academic agenda. My discussion of the New Zealand literature also exposed that other than Wilkinson's study, there is a lack in research in this area by sociologists. However, Wilkinson's (1983) study of homeless men in Christchurch closely reflects my research aims as it was focused on the 'life world' of a group of homeless men who lived on a river bank in New Zealand during the late 1970s. His account of the men's daily lives provided an earlier 'snap-shot-in-time' account of the daily dilemma's that were faced by homeless men at the time. Hodgett et al's, collective enterprise influenced by the social and health psychology position underpinning their approach has contributed contemporary portrayals and a valid point of reference for understanding the ways other New Zealand homeless people have been found to exercise resilience and manage social inclusion within the experience of being homeless. Cooper's (2001) study in providing an interesting analysis of the intersection of space and homelessness in Central Auckland also provided a point of engagement for me when exploring how space matters in Brother's life. Her research framed and firmly grounded within a clearly definable geographical perspective, located how public space functions in the lives of homeless people. 
Though Cooper's work included examining the agency of homeless people, this was approached more from a position that examined how homeless people exercised agency through opting to take the path of least resistance. My research more explicitly examines transgression as a form of agency and builds on understanding what can happen when the path of most resistance is the path traversed. This thesis further contributes a close examination of how popular and expert knowledge social construction processes lead to the 'making' and 'unmaking' of homeless people and how this affects the day-to-day 'doing' of street life. My review of the literature also established that the role of humour within social encounters between homeless people and housed people has not been considered. This study will demonstrate how humour strategically used in social interaction can function to demarcate both a physical and personal boundary for somebody opting to dwell $24 / 7$ in prime public space.

The international and local literature has been valuable in providing a rich source of material from which I was able to gain a broader comparative understanding of the issues faced by homeless people living in other places. However, as was also revealed, there has not, until now, been any study of what I prefer to call 'street life', conducted in Wellington. My study will therefore not so much 'fill a gap' in the literature as it will plant seeds in what has remained until now, unexplored sociological terrain in Aotearoa New Zealand's capital city. 


\section{Chapter Three Conceptualising an everyday street life}

\section{Introduction}

"How's the book going?" Brother asks. "Slowly" I say. He chuckles, "Aye the follies of a wordsmith. Just don't make it too staid. Remember to tell it like it is, fantastical." A man in business attire and wearing sports shoes pauses in his stride and deposits a pile of small change on the ground, "You two have a good day, ya hear." Moments pass quietly before Brother continues, "People think they understand but they still don't know. They have this idea as they scurry between their castles [homes] and their towers [office blocks]. Ah well, I'll just carry on doing it the slow way. Trouble is I try and do it politely but they persist and I resist. Lock him up says the judge down at the court house." A dog takes advantage of his long lead to hover his nose over the pavement area in front of us. His owner jerks on the lead to steer him away, while avoiding looking at us. "I used to have a dog when I lived in the park," Brother tells me as he rummages in his bag to remove a semi-squashed pack of cigarettes, "Dog was his name." As he deftly removes the cigarette lighter from my hand, two women walk past and I catch the words, "... and she's no better," as the other casts me a disgusted look. A trolley bus loses it poles and I watch them bounce from wire to bus to wire again. Stepping down from the bus to reattach them and on noticing Brother, the driver calls, "Too cold mate, too cold". Brother, still contemplating, ignores him, "You're a bit of a windfall after all," he tells me, "even if it will be your interpretation" (Fieldwork: 18/09/09).

These field notes, set against a backdrop of pedestrian commuters, are representative of the typical weekday morning street scene I observed throughout my fieldwork. It depicts a mundane context wherein ordinary housed people are going about their routine practices, such as going to work and walking the dog. Equally, it portrays a street scene wherein Brother is going about his usual morning routine after waking on the street, where it was his standard practice to remain for the first few hours of each day. It is further illustrative of the casual talk Brother and I would have as I sat observing in the research setting. The nature and form of that talk is revealed in Brother's musings relating to past events and ongoing trials and tribulations faced by him in daily street life. Remarkable insights, also evident in Brother's talk, lend themselves to particular epistemological commitments, while also speaking to methodological concerns 
regarding the research process itself. Brother not only alludes to the way he would like his life represented in my writing, he also forecasts an end-product that will ultimately be premised on my knowledge and interpretation of that life.

Importantly, Brother's talk illuminates the vulnerability that can confront research participants within ethnographic enterprises, where it is all too easy for the researcher to privilege their own authoritative voice. As the next chapter will elucidate, a pivotal endeavour within my research approach has been to explore the terrain of self-reflexivity and non-exploitation throughout the doing of this research. As Brother's talk also recognises, tied in closely with considerations of research methods is the issue that researchers' constructions of the worlds they study are inevitably subjective to a certain extent.

Within ethnographic accounts, as with all research, questions of claims to knowledge vary depending on the different theoretical and philosophical underpinnings informing the study and the research methods chosen for “investigating, describing, dissecting, analysing, and communicating about everyday life" (Jacobsen, 2009, p. 17). The epistemological approach taken in this thesis is critical realism. The distinctive broad view of this approach is the denial that "any 'objective' or certain knowledge of the world" can be achieved, rather, "all theories about the world are seen as grounded in a particular perspective and world view, and all knowledge is partial, incomplete, and fallible" (Maxwell, 2012, p. 5). In accepting that there are different valid perspectives on reality, critical realism holds that the world, as we perceive it and therefore live it, is structured by our concepts. As Maxwell explains, “...concepts and perceptions, as held by the people we study as well as by ourselves, are part of the world that we want to understand, and...our understanding of these perspectives can be more or less correct" (Maxwell, 2012, p. 9, original emphasis). Working from an epistemological anchor eschewing notions of an absolute reality, in this research I reject that of Brother as a victim, which is the way homeless people have commonly been portrayed in the literature (as discussed in Chapter Two). A realist epistemology provides for challenging such stereotypes by recognising the capacity homeless people have to exercise agency and human initiative in their 
lives. As Dordick (1997) argues, homeless people are not the passive recipients of fate who have no control over how they choose to live their lives.

Methodologically, this thesis is firmly grounded in my observation of, and extensive personal engagement with, Brother's street life for over three-and-a-half years. This chapter works as one of a pair to explain the research methodology and methods used in this research. The undertaking in this chapter is to elucidate the type of sociology I ascribe to and 'do', and to outline the thinking of other sociologists that has influenced and inspired the conceptual approach informing my study. In the next chapter, my methodological focus shifts to a reflexive account, explaining the elected research methods and the challenges I confronted when 'doing' urban street sociology.

\section{Ordinary life is pretty complex stuff}

Sociologists have long recognised that public and private settings provide rich sites for accessing the content and structure of everyday life, an "enormously complex, multi-faceted and encompassing phenomenon" (Scott, 2009, p. 26). More recently, there has been an expansion in popular accounts of ordinary people going about their everyday 'doings'. The films Jiro Dreams of Sushi (Gelb, 2011) and Kenny (Jacobson, 2006) exemplify this trend of bringing out the 'everyman' and his routine activities, which are shown to define and ground everyday experience in the doing of everyday work. American Splendor (Berman \& Pulcini, 2003) is another film about everyday life. Based on an autobiographical comic book series for 'grown-ups', it chronicles the complexities of the monotonous, dull, and frustrating everyday realties of Harvey Pekar and his interactions with those around him as he battled a year with cancer. Aspects of the film capture the nuanced, taken-for-granted experiences making up everyday life that can range from queuing at the supermarket checkout to being at work. Yet, these routine activities subtly illuminate how mundane elements of everyday life are accomplished. The act of queuing, for example, though an ordinary activity is shown to be reliant on people socially cooperating so as to function in an orderly manner. As Pekar (played by Paul Giamatti) observes, "Ordinary life is pretty complex stuff'. The strength of films depicting 'everyday life' is their ability to 
invite the lay sociologist to notice 'the stuff' that is ordinarily taken for granted within the stream of everyday life consciousness.

In addition, contemporary literary works based on biographical and semibiographical accounts of the everyday lives of homeless people have produced award-winning books such as Stuart: a life backwards (Masters, 2005) and Blindsight (Gee, 2005). In recent years, reality television has included homelessness within its scope, ostensibly conveying on-the-ground experiences of the everyday challenges faced by homeless people and what it might mean to be homeless (see Hodgetts et al., 2005 for an examination of televised representations of homelessness in the United Kingdom).

Within academia, resurgence in everyday life sociologies over the past two decades has brought a new wave of studies, extending understanding of the breadth and depth of 'the everyday'. These studies range from exploring the social organisation of strip clubs (Bradley-Engen \& Ulmer, 2009), to the pressures of modern urban life erupting during road rage incidences (Lupton, 2002), to the sociological significance of sleep, or more specifically, the lack of sleep in waking life (Williams \& Bendelow, 1998). Everyday life sociologies also recognise the significance of space and place in daily life, from the local pub to the family sitting room (Bennett \& Watson, 2002).

In order to interpret and explain the embodied socio-spatial realities observed in the everyday life of Brother, as lived in the social world of the street, I locate my research within the sociologies of everyday life research orientation. A key analytical concern of this orientation is to explore how everyday routines and activities are socially organised in natural settings (Highmore, 2002; Scott, 2009). The charge is to treat mundane everyday orderliness as a concrete phenomenon for investigation (Lloyd, 2006), and to question and expose the trivial and banal (Jacobsen, 2009).

Everyday life is commonly recognised as being the everyday rhythms and repetition, that happen day after day, and are by and large routine, mundane, and 
taken for granted. In the words of Henri Lefebrve (1971, p. vii), and as the fieldwork excerpt at the beginning of this chapter conveys, for most, the characteristics of everyday life involve "dull routine, the on-going go-to-work, pay-the-bills, homeward trudge of daily existence". In noting the banal form of everyday life, Felski (2000, p. 81) wrote, "The temporality of the everyday...is that of repetition, the spatial ordering of the everyday is anchored in a sense of home, and the characteristic mode of experiencing the everyday is that of habit". Yet, as Highmore (2002, pp. 1-2) highlights, to stress only the banality of everyday matters would miss the mark, because "everyday life is not simply the name given to a reality readily available for scrutiny; it is also the name for aspects of life that lie hidden", and therefore it is the task of everyday life sociologists "to make the invisible visible".

Most everyday life sociologies strive for a middle ground, connecting the micro and macro, "to try to grasp the connections between individual lives" in the micro settings studied and the macro forces" structuring "them at every turn" (Duneier, 1999, p. 344). Jacobsen (2009) considers the imperative of the committed everyday life scholar is to somehow link agency and structure at the basis of everyday life in order to make "the unintelligible intelligible" (p. 19). In this way, everyday life - and with it everyday life sociologies - is securely located at the intersection of individual and society (Jacobsen, 2009; Scott, 2009). Within this methodological framework, everyday life sociologies seek to make individual and biographical 'private troubles' meaningful and intelligible through linking them to and seeing them through wider 'public issues' (Mills, 1959).

The dialectical nature of everyday life is further stressed as the primal site for meaningful social resistance, with everyday life described by Lefebrve as "the inevitable starting point for the realisation of the possible" (1971, cited in Goonewardena, 2008, p. 130). Michel de Certeau pointed to the significance of how ordinary people's ways of doing everyday life can include using tactical resistance to overcome the strong, "whether the strength be that of powerful people, or the violence of things or of an imposed order" (1984, p. xix). To borrow from Scott's (2009) deconstruction of de Certeau's thinking in the abstract, 
"resistance need not entail grand gestures of political uprising, but rather that individuals could subvert authority by breaking minor rules in their everyday lives" (p. 4). de Certeau's (1984) term 'making do' describes the breaking of minor rules in everyday life through every day practices that involve following norms while still being creative, adaptive, and defiant (Scott, 2009). In this study, Brother's adaptation of footpath space as home space and his use of a blanket to demarcate his territory are demonstrative of de Certeau's arguments - these practices play a significant role in the agentic way Brother lives his ordinary life while maintaining resistance to social norms.

Accounts of everyday life emphasising its monotonous nature would likely resonate with housed peoples' day-in, day-out experiences. This thesis will demonstrate the mundane, banal aspects of Brother's 'doings', which provide a street-level semblance of daily orderliness. Through these ordinary, routinely produced activities, I argue he achieves an experiential sense of connectedness and belonging with both place and people. However, given that his everyday practices are further demonstrated to involve substantial measures of de Certeau's 'making do', others more readily construe them as 'making trouble'. For Brother, everyday life is the site of implicit and explicit conflict, making it a site for exclusion and segregation that disrupts everyday practices. Despite negative reactions to his presence, Brother's practice of 'making do' leads to much friendly public recognition and material support given to him by others.

\section{Street sociology: the beginnings}

The relevance of the works of the Chicago sociologists is that they contain a lot of information about this and that. And this-and-that is what the world is made up of (Sacks, 1989, p. 254).

My focus on the ordinary life of Brother as lived in public city space was stimulated by the Chicago School tradition that established the importance of qualitative inquiry for the study of group or community life in the 1920s and 1930s (see Roberts, 2006; Silverman, 1993). This tradition developed participant observation and the case study method. It consisted of two strands. The first, represented by the work of Robert Park and Ernest Burgess, was most noted for its 
concern with city life, urban spatial patterns, and the experience of urban life, with emphasis placed on social interaction, social processes, and meanings given in social situations (Francis \& Hester, 2004). This strand of Chicago sociology produced many small-scale empirical studies, with Nels Anderson's work The Hobo (1923) exemplifying an early study of a homeless man in his own habitat.

The second strand, which emerged in the 1950s and 1960s, is associated with the work of Everett Hughes. This new wave of interactionist sociology involved the study of a much wider range of social action in society (Roberts, 2006). This tradition, with its attention to observing naturally-occurring social life, has a long history of focusing on how acts and individuals come to be defined as deviant through the meanings assigned to certain kinds of interactions. These studies were significant in producing insight into ways of life with which most people were unfamiliar. The work of the Chicago School showed that the practices involved in different ways of life had unrecognised rationality when viewed in their social context (Roberts, 2006; Scott, 2009).

My work builds on a Chicago School tradition known as 'street corner' sociology, which grew out of the second strand described above. Traditionally, researchers in this field studied everyday street corner life with a focus on ordinariness, designed to counter the then dramatic media and political accounts depicting lives of crime and unemployment on street corner America (Roberts, 2006; Scott, 2009). Corner studies were significant in providing insight into the way day-by-day routines, social hierarchies, and roles are socially organised and expressed in social interaction. The findings of such studies served a valuable role enabling the reader to see and understand the 'workings of the street corner' (Roberts, 2006). Key works among corner ethnographies include Tally's Corner (Liebow, 1967), Street Corner Society (Whyte, 1943), and A Place on the Corner (Anderson, 1978). These studies used participant observational methods to 'hang out' and interpret the ordinary lives of people congregating on the street corner and in other public places. My study, exploring in detail the everyday street life of one Wellington street dweller, fits with the ethos of corner sociologies. Although Brother lives alone, he lives in public on busy city thoroughfares. In this way, and as Howard 
Becker (1998, p. 99) observed, sociologists do not study the life and experience of just one person. Even when the focus is on one person, "they usually include all the people that central character comes in contact with regularly".

Howard Becker's work is illustrative of the way sociological studies dealing with urban sub-cultures challenge conventional stereotypes and break down rigid social labels (Francis \& Hester, 2004; Roberts, 2006; Silverman, 1993). Venturing into the worlds of dance musicians, art students, and drug users, Becker's work uncovered how social groups symbolically interpret their own 'insider' status according to understood norms and values shaping the interactions of the subjective world of group participants. Instrumental in Becker's work is a key methodological 'trick' - replacing the 'why' question, which directed many of the earlier Chicago inquiries, with a 'how' question, seeking to learn how people 'do' things within mundane situations (Becker in Molotch, 2012). By conceptually shifting focus in this way, it is possible to carefully observe the step-by-step processes that lead one to become a stable marijuana smoker, for example (Becker, 1953). From this position, the researcher is able to learn more about the complex interactions and people's own understandings surrounding their activities. As Becker argues (in Molotch, 2012), asking why people use drugs (rather than how they use them) invariably leads to explanations that distinguish between types of people, and findings that emphasise individualistic physiological or psychological factors as predisposing certain people to drug using behaviour.

Within the realm of contemporary daily life, 'why' questions are the prevailing form of inquiry. Many 'why' questions were put to me throughout this research, as people (both members of the public and people in my own personal circle, including university colleagues) sought to make sense of Brother's choice to live his everyday (and 'everynight') life on the street corner. Newspapers also periodically asked 'why' questions about Brother's high profile public lifestyle. The man behind the blanket (Hunt, 2010) is an example of one such journalistic endeavour to contextualise and explain why Brother not only lives on the street but why he was committed to a psychiatric facility. Drawing on his personal and family background (gleaned by speaking to three relatives who had not had any 
contact with Brother for periods of ten, twenty, and thirty years, respectively), his criminal history (based on media reports and recollections of a police officer who had known him in his home town some ten years earlier), and hearsay, this article featured sensationalist and moralistic overtones. Within this one article, 'Blanket Man' is described as "homeless", "vagrant”, “quirky character”, "filthy”, "smelly”, "bedraggled", “drug-addled”, “charming”, “abusive”, "dangerous”, "family black sheep", "Māori-related political activist", "eccentric", "unwell”, "insane - living in "la-la land", "a novelty", "a father", "a criminal", and "a nuisance". This projection of Brother portrays him as a social problem and as a type of person for whom the consequences of intervention and containment are unavoidable, for his 'own good' and for the wider interests of the city.

Becker argues that people think it is necessary to say why something has happened because "they don't want to have random stuff going on in the world" (Becker in Molotch, 2012, p. 428). Following Becker, I have strived to interpret and explain social processes by adopting a 'how' strategy, working inductively and deductively with ethnographic data to understand the detail of Brother's activities within the context of his social life and interactions. For me this started out as the question: How is life lived in public? Through this lens of inquiry, certain activities were revealed to be salient, leading to an identification of other 'how' questions, such as: How does Brother use humour to invite others to interact with him? Conversely, how does Brother use humour to shut down others' interactional attempts? How does Brother challenge or resist the stigmatisation or marginalisation practices of others? How is Brother's blanket imbued with symbolic value, maintaining boundaries of space and the self? As Becker (in Molotch, 2012) reasons, inquiring into 'how' avoids “...the methodological difficulty of finding a route to go at it, and the difficulty of dealing with indeterminacy" (p. 430). In this present study, I discovered that through methodically attending to processes of 'how', it is possible to arrive at an understanding of 'why'.

Erving Goffman, influenced by Blumer and other symbolic interactionists, also practiced the 'how' principle in his efforts to understand the creation and exchange 
of symbolic orders via social interaction. His approach has been described by Hacking (2004) as 'bottom up research' given the methodical way he began with interpreting individual face-to-face interaction when developing explanations of how such exchanges constituted lives. Goffman's focus on the intimacies of daily social interaction, most notably his concern with how individuals in particular settings enter into or avoid social interaction when in the presence of others, provided me with a foundational toolbox that I returned to time and again when working with data from my own street level micro-observations. Abundantly rich in conceptual insight and development of metaphor, several aspects of Goffman's work, including his theories of 'the territories of the self' (1971), 'role distancing behaviour' (1961b), and 'back and front stage dynamic' (1959), are critically engaged in my own analyses of Brother's methods. These are conceived of as strategic techniques for socially organising an everyday life within the face-to-face domain of social action, identified by Goffman as the 'interaction order' (1983).

\section{Extending ethnography}

This thesis uses ethnography to examine the social interactions and everyday routine activities observable in Brother's everyday street life. Simply defined, 'ethno' means 'folk' or 'people', while 'graph' derives from 'writing' (Monaghan, 2007). Ethnography generally refers to highly descriptive writing about particular groups of people, aiming to communicate a social story that draws the reader into the lives of respondents (Crotty, 1998; Francis \& Hester, 2004; Silverman, 1993).

In order to best understand the 'how' of Brother's everyday routine activities conducted in the social context of the city street, this research uses ethnography influenced by ethnomethodological principles. Silverman's (2007, p. 4) expression "ethnomethodologically inspired ethnography", which describes such an approach, captures my intentions in this research. Ethnomethodology is a tradition that builds on the relevance of the work of the Chicago School and is an approach that fits with the ethos of everyday life sociologies. As Harvey Sacks (1989) observed, the connections between good interactionist ethnography and ethnomethodology are not so much theoretical as they are methodological. Ethnomethodology, a variant of ethnography, means 'ethno-methods belong to the 'people' or the 'folk' (Crotty, 40 
1998; Hester, 2009). On this note, Hester makes a useful distinction, explaining that the 'ethno' methods referred to in 'ethnomethodology' are those used to do concrete, specific, ordinary, activities:

Whatever the 'ethno' methods are that people use, for whatever activities, they are interesting in their own right, they require understanding 'from within' the cultural practices that exhibit their use and are not to be evaluated in terms of their shortcomings compared with other methods that might be deployed...[regardless of whether activities] are simple or complex they have to be accomplished and such accomplishment involves the use of methods of one sort or another (2009, p. 235).

An ethnomethodological approach to ethnography makes visible the mundane, banal aspects and taken-for-granted structures of everyday life, making them available for sociological reflection (Hester, 2009). In contrast to symbolic interactionist work, which attempts to get at the meanings behind social actions, an ethnomethodological inquiry favours understanding everyday practices over meaning (Francis \& Hester, 2004, Silverman, 1993). Examining activities as participants conduct them, a key concern is to understand the ways in which people make sense of their everyday world through socially situated activities. Within this, shared culture is understood to be accomplished through making observations of sameness and difference - as people recognise their sameness with others by seeing that others think or act in the same ways as themselves (Francis \& Hester, 2004).

A study by Jimerson, Oware, and Matthew (2006) examining interactions between black basketball players is a good example of what an ethnomethodologic approach to research can produce. This work explores codes of conduct, defined by the authors as sets of social norms that prescribe, proscribe, and describe how specific sets of people ought to behave. Whereas a straight ethnographic approach would portray how people saw things in the settings observed, using ethnomethodology, these authors focused on what was observable in the concrete activities conducted, enabling examination and explanation of both the cause and consequence of conduct. 
Harold Garfinkel's (1967, p. 37) methodological approach to finding the remarkable in the mundane was to "start with familiar scenes and ask what can be done to make trouble". This can be achieved, according to Garfinkel, by 'bracketing' known and prior assumptions about what is normal, natural, or inevitable, as much as possible. From this position, phenomena can be viewed as locally produced through the activities of particular people in particular settings with as few presuppositions in place as possible. By going beyond what appears to be immediately observable, and treating taken-for-granted actions, settings, and events as potentially remarkable, underlying rules, routines, and regularities in the behaviour observed can reveal something about how the setting is socially organised. Further, challenging obvious assumptions about the world provides a view of what happens when norms and rules are broken. As noted earlier, Brother's spatial presence - using city space as domestic space coupled with his daily routine activities in these spaces - makes a notion of trouble visible to others. $^{7}$

During my observational fieldwork, sitting at ground level alongside Brother on the street corner, it did not require any great leap of the sociological imagination to understand how this bodily presentation of the self in public 'made trouble'. 'Ordinary' members of the public do not generally sit themselves down at the edge of a gutter for the day, seemingly doing nothing. My obvious social and spatial association with Brother frequently led to my own experiences of stigma, as people mistook me for a homeless woman (among many other cases of misinterpreted identity). However, through my experience of stigma-byassociation, I was able to use myself as a research tool to observe (and feel) how others responded to this overtly embodied act of 'spatial-Garfinkeling' (Cresswell, 1996). From this vantage point, I gained perspective on what can happen when the familiar is made strange. Until commencing fieldwork, my normative experience when using the city had been as a vertical, purposeful person-in-transit, moving

${ }^{7}$ Garfinkel's writings have been described as an extraordinary achievement because they "embody a grasp of the foundations of social action, intersubjective understanding and social organisation in a single core phenomenon: the methodically accountable character of ordinary social activity" (Heritage, 1987, p. 266). 
from A to B to achieve C. In transgressing that usual practice, I was able to look out, as it were (via my participation in what Garfinkel (1967) would define as a 'breaching experiment'), to observe (and experience) how others reacted to my visible presence. This brought me valuable experiential insight into some of the ways stereotypes are given life in the everyday through face-to-face interactions. I return to explore this aspect more closely when discussing the 'doing' of street corner sociology in the next chapter.

The Chicago sociologists were fundamentally concerned with 'making up people' - from Orrin E. Klapp's 'social types' (1954) ${ }^{8}$ to Erving Goffman's (1961a) 'mental inmate'. Hacking (2004) has noted the way in which Goffman's work leaned more towards understanding the processes leading to an 'unmaking of the person', he also concedes that a making inevitably exists in the unmaking. Hacking is also concerned with 'making up people', but by his own admission, his work on this is "too philosophical and abstract" given that he reflects too little on the ordinary dynamics of human interaction (2002, p. 222). However, with Goffman's approach being one strongly committed to understanding how people are constituted in face-to-face interactions in 'concrete' locations, and with Hacking's (2006) position articulated through his theoretical framework of understanding more abstract processes through which 'making up people' can also occur, I draw from each theorist when formulating arguments in this research. Because I argue Brother is both made and unmade at the interpersonal level by members of the public on the street, by the media, and by those Hacking (2002) describes as the "community of experts", identified in this research as justice personnel, police, and health professionals, Goffman's 'un-looping of the person'

\footnotetext{
${ }^{8}$ Writing in the 1950 s, Klapp produced a number of papers on 'social types'. He defined 'types' as part of our basic apparatus for making sense of the world, saying that from an early age we use partial information to assign things and people we encounter to known categories, and on the basis of such 'typification' we are able to 'proceed as usual' with respect to culturally available ideas that express specific departures from the conventional. How to do 'an ordinary member of society' is illustrated by the circulation of these types. In Heroes, Villains and Fools as Agents of Social Control, for example, Klapp identifies three 'types' and subtypes within each. Subtypes of 'the villain', for instance, include: the persecutor; traitor; flouter; fiend; and rogue. For Klapp, "In heroisation, vilification and fool-making, we may also see rituals of solidarity and nonaffirmation. People draw together to applaud a hero, fight a villain or laugh at a fool" (1954, p. $62)$.
} 
and Hacking's 'looping effect of how people are made up' each provide a fruitful source for analytical engagement when working with my own ethnographic material.

Of further theoretical utility and of much inspirational value are two community studies by sociologist Mitchell Duneier. These works build on and reaffirm the value of the Chicago School realist tradition, while also raising new awareness about the nature of contemporary street life. Slim's Table (1992) is a book resulting from Duneier's doctoral study. Focusing on two men and the table they routinely occupy at a café, it challenges stereotypical and racist media portrayals and homogenised urban ethnography accounts of the working class black man. The second book, Sidewalk (1999), resulted from Duneier's extensive participant engagement over six years among poor black male book vendors inhabiting New York's Greenwich Village. Through closely observing the men's routine activities and forms of social ordering and organisation, and by integrating new approaches and insights from conversational analysis and feminist theory, Duneier was able to make sociological sense of how the social order underpinning street relationships involves its own ingenious moral order.

Duneier's work is committed to the descriptive process, and an appendix in Sidewalk details his method of inductively and deductively developing hypotheses about the social life and interaction he was observing. The following passage describes his methodological approach that he calls "diagnostic ethnography" (1999, p. 342). Through this approach he was able to test theoretical questions that came to the fore during his empirical research. Duneier's outline of his approach provided a useful guiding template for me as a new ethnographer embarking on street research for the first time:

I begin observation by gaining an appreciation of the "symptoms" that characterize my "patient". Once I have gained knowledge of these symptoms, I return to the field, aided by new diagnostic tools - such as photographs - and try to "understand" these symptoms (which is some amalgam of "explain" and "interpret" and "render meaningful"). I also read in more general literature, seeking ideas that will illuminate my case...the scholarly literature of, say, "work and personality", Conversation Analysis...urban poverty formation, the sociology of 
emotion...to make sense of what was taking place on the sidewalk...I...don't set out with theories that I know I want to reconstruct. So I observe patterns of interactions that I wish to explain, and move from diagnostics to theory reconstruction, almost in spite of myself (1999, pp. 342-343).

On further methodological reflection, Duneier's 'tricks of the trade' (Becker, 1998) developed in-situ during his extensive participant fieldwork on the streets of New York, and many of the concepts he developed through this, not only provided me with empirical foreknowledge, they were later found to be theoretically 'transferable' in relation to what I was discovering in my own observations. That is, as Snow, Morrill, and Anderson (2003, p. 187) have observed, theoretical transferability "does not develop new theory per se, but it extends pre-existing theoretical or conceptual formulations to other bounded contexts or places, or to other socio-cultural domains". In this way, a particular concept imported to another context away from where it was first developed can be examined for its relevance or applicability within another setting. Snow et al. (2003) argue that while theoretical transferability is likely the greater the similarity between two settings, theoretical development is greatest under conditions of either pronounced contextual similarity or dissimilarity. In this thesis, concepts formulated by Duneier (1999), observing in Greenwich Village, New York, are reactivated by my observational data and by my own processes of sociological reasoning when confronting the theoretical implications of the street scene I observed here in Wellington, Aotearoa New Zealand. My analysis of ethnographic material in the forthcoming chapters actively engages Duneier and Molotch's theorising, in particular, conceptions of 'interactional vandalism' (Duneier \& Molotch, 1999) and the 'Fuck it! mentality' (Duneier, 1999). In doing so, Snow et al.'s (2003) claim is shown to have validity in my research as I am able to explain some interesting new relevancies.

\section{Conclusion}

This chapter has explained the methodological approach adopted in this thesis to study an everyday street life. A small fieldwork excerpt sets the scene, with Brother occupying street space as home space in the social setting of the city 
street. Though Brother afforded me privileged insight by letting me into his life to observe what the ordinary observer or passerby would not be privy to, his talk exposes an awareness of the way in which this study would ultimately produce an interpretative analysis based on my understanding of his life. Throughout the doing of fieldwork and beyond, I never lost sight of the privilege granted to me by Brother; the fact that I am considered "a windfall after all" suggests a level of acceptance and trust that was able to develop alongside this awareness. Just how this trust was able to develop and grow is discussed in the following chapter.

Extending my ethnographic approach to incorporate Garfinkel's (1967) and Sacks' (1989) insights into social interaction as an accomplishment has enabled me to view Brother's methods in this thesis as an interactional resource with considerable strategic and contextual relevance. The various methodological decisions informing and directing my research have been carefully chosen to enable me to tell 'it like it is' and 'keep it real' from Brother's perspective, while also providing me scope to produce a rich sociological analysis of the social action and processes through which an (extra)ordinary street life is accomplished. For Brother, lived experience of ordinary life is fantastical. Without doubt, his is an ordinary life lived year-by-year, day-by-day, and indeed hour-by-hour, under extraordinary circumstances.

I have discussed how a key methodological charge of asking 'how' rather than 'why' in order to transcend common perceptions and taken-for-granted assumptions about how everyday life on the street is lived. I have argued that by directing my focus away from Brother's 'otherness' - the dominant way he is read by others - and instead closely attending to how his activities are achieved within a particular socio-spatial context, the ordinariness of his actions are observable. Even among people who are othered, there is "stability and regularity in human action" because "people do not act randomly" (Becker, 2009, n.p.). By conceptualising an everyday street life as a "theoretical problem" (Jacobsen, 2009, pp. 17-18, original emphasis), my research approach will allow understanding of 'order in the disorder' and 'power in the resistance' of Brother's choices. In this thesis, the everyday actions of this particular street dweller are shown to be 46 
intelligible in their intent and context, revealing Brother as an 'ordinary man', identified by de Certeau as “... a common hero, an (sic) ubiquitous character, walking in countless thousands on the streets" (1984, p. v). 


\section{Chapter Four Doing street corner sociology}

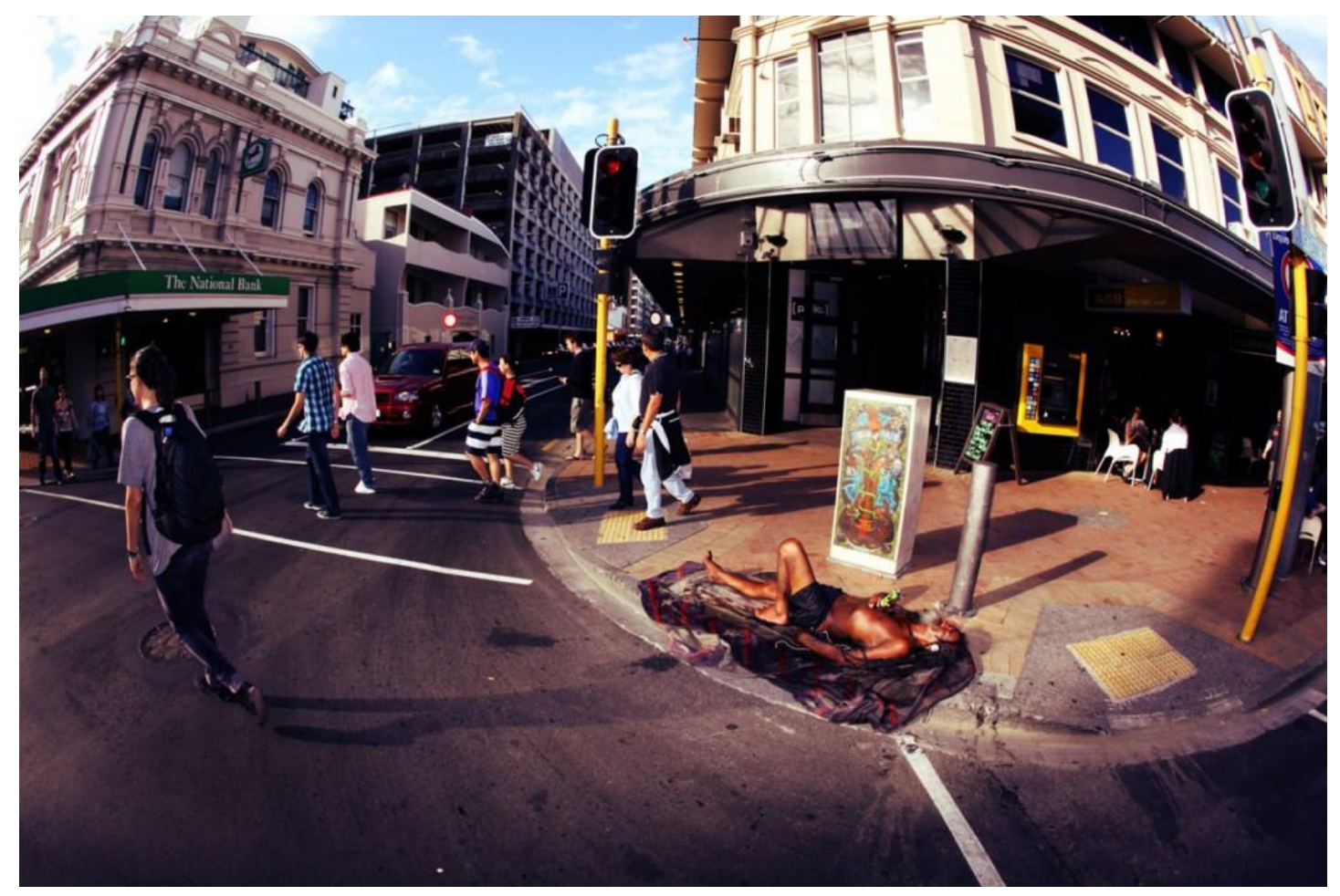

Figure 4:1 Brother, cornering everyday life

Source: Dean Tirkot

\section{Introduction}

The conceptual approach outlined in Chapter Three is compatible with relatively open forms of ethnographic research. The purpose of this chapter is to explain the methods used in this thesis to do street corner sociology. I detail how I collected and analysed the data. I discuss how methodological concepts become 'muddied' and open to contest and change when qualitative research methods are put into practice 'on the street corner'. Despite having read widely on social science research methods and 'how to do' ethnographic research (for example, DeWalt \& DeWalt, 2011; Silverman, 1993) prior to commencing my fieldwork, I discovered that no book can really prepare you for what you might find out, encounter, or need to negotiate when doing street corner sociology. I quickly learned I needed to be intuitive, adaptive, and flexible. This was especially so given I was working 
closely in a one-to-one research relationship over a long period. In this chapter, I demonstrate how the subjective relationship that developed between us had a significant bearing on shaping and reshaping my method. By extension, I detail how I was ineluctably drawn into the world of the street with my researcher role progressively repositioned throughout phases of the research.

\section{Getting started: Street ethnography}

I did not just observe Brother, I observed both him and his interactions with a range of people, as the street setting is characterised by a diverse blend of nine-tofive workers, business people, shoppers, and an active street life throughout the day and evening. My fieldwork also focused on other Wellington homeless people and people 'of the street' (collectively referred to hereafter as street people), but was not confined to these people. It is more accurate to say that the project operated within an inner-city milieu where homeless and street people are prominent. My fieldwork therefore included interaction with street people, members of the general public (from young children to the elderly), commuters, shoppers, retailers, tourists, buskers, drug dealers, a professional photographer, street cleaners, street wardens, and police officers. Because my "day-to-day digging into social life" (Becker, 1998, p. 4) was interested in ordinary people's assumptions and observations of street life, my fieldwork involved investigating what ordinary people had to say in everyday talk when interacting with Brother on the street. This included informal conversations overheard during lengthy and repeated periods of time spent in the field.

Observational fieldwork was conducted over a three-and-a-half year period from January 2007 to July 2010. Approximately four hundred hours were spent doing participant observation alongside Brother on the street corner. The times chosen for fieldwork were purposefully selected to ensure observations covered all hours of the day by the time they were completed. The earliest starting time for doing observations was 4.30am, which happened to be the time that Brother woke up on that particular day; the latest time for finishing an observation was also 4.30am. Sometimes I split observations over a 24-hour period by doing several morning hours and then returning later in the day or evening to do another period of 
observation. Overall, the fluctuating hours of fieldwork over the three-and-a-half years covered and captured the 24/7 nature of Brother's street life. As well as observing the mundane, ordinary everydayness of Brother's street life and street interactions with others, the fieldwork was also planned to coincide with public holidays and during big events, such as international sporting matches, in order to observe variations in interactions between Brother and the wide range of other people who use the city streets. Overall, the shortest observation was twenty minutes long and the longest lasted ten consecutive hours. Most observations lasted three to four hours, with my time evenly spread between day and night.

In terms of physical location, my observational work was conducted wherever Brother happened to be on any given day. In Chapter Six, I include a spatial map (Figure 6:4) that identifies locations regularly inhabited by Brother over the course of my fieldwork. Due to Brother's particular way of living his street life, much of the fieldwork took place with me sitting beside him on footpaths outside shops, banks, in pedestrian malls, city parks, and on either of two corners bordering a busy traffic intersection.

During the course of my fieldwork, I also made several trips to the Wellington District Court, following Brother's frequent arrests on the street. Some of his court appearances led to incarceration, which ranged from a few short days to several months. Consequently, there were periods when I was unable to do any observational work. When employing the 'hīkoi method' (observing in motion) in my fieldwork with Brother, we made several excursions in and around the city (this method is explained later in the chapter). These included visits to the Community Law Centre, Downtown Community Ministry, ${ }^{9}$ Work and Income New Zealand, ${ }^{10}$ the Courts (High, District, and the Court of Appeal), banks, a local printing business, as well as brief visits into retail outlets to purchase food or

9 Downtown Community Ministry (DCM) is an inner-city, non-government social service agency, used by many homeless and otherwise disadvantaged people.

${ }^{10}$ Work and Income New Zealand (WINZ) is the New Zealand government's social security agency. 
alcohol. I also visited Brother in Ward 27 (Wellington Hospital's mental health unit, now called Te Whare o Matairangi), accompanied him on foot back to the ward one evening, and on another occasion, drove him back to the ward after he had been on day leave. The longest hīkoi (walk) spanned eight hours, covered several city kilometres, and incorporated visits to several government agencies.

My method for observing street people other than Brother was to blend into the scene, as inconspicuously as possible. I would position myself in full view and within hearing distance of groups of street people in central city spaces - small parks and outdoor pedestrian malls, for example - and manage my demeanour as one of 'civil inattention' (a form of unfocused interaction involving distancing oneself unobtrusively in public) (Goffman, 1972). Appearing as an ordinary member of the public, open book in lap, sometimes smoking, occasionally writing, I would actually be carefully observing, listening, and recording via field note jottings what was going on in the setting: what was being said and done as people interacted with each other and their immediate physical environment.

\section{Getting it all down: Field notes and diaries}

Field observations were documented using a two-step process recommended by Lofland and Lofland (1984). This involved jotting brief notes about what I was observing and hearing in the setting and then elaborating upon these as soon as I had left the street. When observing using the 'hìkoi method', the procedure was essentially the same, jotting down key phrases 'on the trot', so long as they did not interfere with the pace or nature of the outing, and again, writing a full set of descriptive field notes in a sequential narrative form as soon as possible after the period of observation.

One way of managing the data in the initial phases of the research was by keeping systematic and detailed field notes that were divided into two different sets of notebooks: observations of Brother; and observations of other street people. These data were further divided into two categories: descriptions of the physical settings; and detailed descriptive notes on what was said and done between interactants within the settings. Written field notes filled four 'Brother notebooks' and one 
'other street people notebook' - this latter notebook recorded the doings of street people, which helped me to obtain a sense of the street life scene as a whole in the central city. I also kept a personal diary, recording my own experiences and reflections throughout the research process.

\section{A picture speaks a thousand words}

As well as field notes, photographs are included in this thesis. The use of photographs is argued to allow "for a closer link between the abstractive process of conceptualization and experientially derived observations", contributing significantly to analysis in ethnographic work (Suchar, 1997, p. 52). For Duneier (1999), incorporating photography into his study Sidewalk involved an intensive collaboration with a professional photographer. The resulting photographs, Duneier wrote, "enabled him to see things he had not otherwise noticed" (p. 12). The majority of photographs in this thesis were taken by professional photographer Belinda Brown, who spent several months in 2007 documenting Brother's daily activities on the street for her portrait exhibition Brother, held at a Wellington theatre. Unlike Duneier, I did not collaborate with Brown, but my research has benefited from her photographic work. Brown's images offered a reflexive tool when later making sense of some of the things I had seen and heard, and were therefore useful in triggering different insights depending on the different questions and classifications I asked of them. Added to this, the photographer's presence in Brother's life provided another interaction for me to examine. This presented opportunities to observe the interactive relationship that developed between subject and photographer - Brother and Brown. Being there also allowed me to understand the context of the resulting photographs - I knew what else was going on and who else was present in the setting at the times the photographs were taken.

Beyond providing reflexive utility for researchers, the use of photographs is also said to contribute to the reader's experience of ethnographic work (Pink, 2007; Suchar, 1997). Images help to not only evoke the texture of a place but also provide a connection between what researchers or readers can take in through their eyes with the cognitive, analytic framework that is applied through the text (Rose, 52 
2007). The photographs included in this thesis visually bring to life and communicate Brother in action appropriating footpath or corner space when living his ordinary everyday life in the city. Therefore they are representative of not only what I was able to see during my fieldwork, they reflect what other Wellingtonians can observe for themselves as they use the shared city spaces depicted in their own everyday lives. Without a doubt, Brother cuts a visceral corporeal presence on the urban landscape. Visually, his unique imagery translates into still photography exceedingly well. Therefore, including images in this thesis is intended to enhance the reader's experience in line with Becker's (2002, p. 11) assertion:

What can you do with pictures that you couldn't do just as well with words (or numbers)? The answer is that I can lead you to believe that the abstract tale I have told you has a real flesh and blood life, and therefore is to be believed in a way that is hard to do when all you have is the argument and some scraps and can only wonder if there really is anyone like that out there.

In similar vein, Duneier (in Duneier \& Back, 2006, p. 554) argues that showing people in photographs, instead of keeping them anonymous lends:

...a certain kind of immediacy to the people as people and makes it possible to really conceive of them as full human beings in ways that, because this is a work of non-fiction, is much harder when you can't show those things.

For Duneier, 'showing people as people' is not an agenda taken seriously enough by contemporary ethnographers. He proposes that another way sociological ethnography can work harder at showing people as people is through ethnographic writing. I will return to this claim when I explain my elected approach to data representation later in this chapter.

\section{Brother's writing}

Continuing in the ethnographic tradition, Brother's own writing is used throughout the analysis sections. Forty-three pieces of writing, written over a sixyear period from December 2005 to November 2011, were collected and 
analysed. These writings express Brother's philosophical vision and political views. ${ }^{11}$ Brother encouraged me to use his writings. During my second year of fieldwork, Brother began keeping copies of any new writing to give to me the next time he saw me. Handing it over, he would sometimes say, "Here, for the book". On several occasions we went on short hîkoi to a printing store to collect a copy of his latest writing for me. From an ethnographic standpoint, Brother's writing provided another interpretive layer for analysing, contextualising, and understanding his interactive street life, embedded in time and space. Reading what he had to say provided a useful tool for making further sense of the snippets of information shared with me in conversation. In this vein, his writing helped to fill in the gaps and offered more scope for understanding, over and above observing and listening.

The qualitative research methods used in this thesis to explore and illuminate the everyday life of Brother involved working closely alongside Brother on the street corner. It was therefore very important within this ethnographic endeavour to develop a positive research relationship. Yet as Hughes (1990, p. 143) notes, "Research methods are where philosophical conceptions get their hands dirty". I discovered, as is often the case with qualitative inquiry, research does not always go according to plan, but can shift in response to the lived situations encountered in the field setting. The next section is concerned with examining how the boundaries of qualitative research can be contested and negotiated when in the throes of doing research. I describe how 'getting in' and 'staying in' were made easier by being flexible and by allowing my research to be partly 'participant led' Within this process, I illustrate how Brother instigated 'the method within the method', producing an interactively rich source of observational data that I otherwise would not have been able to attain.

11 Brother's method involved writing his philosophical thoughts and visions on to paper, then taking it to a local printing business Phantom Billstickers where he held an account. His brief was for each piece of writing to be typed and transformed into two hundred A3-sized street posters to be pasted on to outdoor street sites, distributed into retail outlets, or both. The Central Business District was nominated as his target area. As per Phantom's usual practice, each piece was exhibited for a week. 


\section{Getting in}

Somewhere underneath the prose of social science lies some human contact (Agar, 1999, p. 53)

In ethnography, a rising awareness of the researcher's own positional role is sometimes characterised as the 'reflexive turn' (Mauthner \& Doucet, 2003); this has facilitated a fundamental shift in the way ethnographers locate themselves within the context of their research and writing (Coffey, 1999). Mauthner and Doucet (2003, p. 416) observe the way in which, "[t]he reflexive turn in the social sciences has contributed towards demystification and greater understanding of theoretically and empirically based knowledge construction". Significantly, as Kusenbach (2003) points out, the role of the ethnographer can and should be continually observed and analysed in a self-reflexive way by the investigator throughout all phases of the study.

The excerpt below is taken from the very first entry written in my personal research journal, a diary in which I chronicled my own researcher experiences during the years spent in the field. It refers to my first meeting with Brother, when I went down to the street with my information sheet and consent form to see whether he would agree to be part of my study. Brother was sitting right on the edge of the kerb in front of a large rubbish bin. To avoid standing over him, I sat down on the kerb beside him. The following reflects on how that initial meeting unfolded:

...... [as he's] telling me he's a dumb cunt and the last of the ugliest dumb cunts left in Aotearoa that cannot read, I start reading the information sheet to him. Despite my earlier angst as I'd struggled to find the right pitch - not too ivory tower and not too street - I realise that in this context, with my feet placed literally in the gutter, it's sounding wrong. Feeling Brother's intense stare as he susses me out, I am highly conscious of the way I am speaking and of the words I am reading. I make a snap decision to reject the academic spiel. Now looking at him (and not the paper) and using everyday talk, I tell him what I want to study and what his role would be if he agrees to take part. This improvising makes a difference; I sense a shift as my words now reach him. I tell him I cannot do it without his consent. He looks at me and quietly weighs up all he has heard. Sitting as I am, on the corner, I am excruciatingly aware of the people in cars who stare our way as they wait for the traffic lights to turn green. I offer 
Brother a cigarette and, taking it, he asks if it would be just me -no media and no police. I assure him - only me. He tells me he has plans, action lined up, and may not be around forever. Taking the pen out of my fingers, he now agrees, "Just you, and tell my story, not that bullshit courthouse story". I place the consent form in the only available immediate space - on the road itself. As he scribbles his consent, he reiterates, "Can't read, can't write" (Personal journal: 21/11/06). ${ }^{12}$

\section{Hanging out on the street corner: A negotiated relationship}

A strong relationship was to develop between Brother and me on the street corner, but as with all relationships, keeping things working involved negotiating and renegotiating boundaries as to how things would be done. Over time, Brother and I built a tacit understanding. I came to understand that things worked best if I mostly let Brother call the shots. After all, I was not simply sitting in public space, but rather, from his lived perspective, I was a visitor in his home. Some days, he was very receptive to having me there; he was warm, witty, and chatty. On other days, we could sit side-by-side watching the street for long stretches in mostly companionable silence; Brother usually with headphones on listening to music, me with notebook and pen jotting down notes about what was going on. Sometimes, sitting watching the street like this, Brother would silently help himself to my cigarette by deftly removing it from my fingers. I read this mundane act as a sign that reinforced his familiarity both with me and with the research. Although he never once reacted negatively to my arrival, never said that I was not welcome, some days he was clearly in a disgruntled mood and then the best strategy was to sit quietly and let him initiate any conversation. There was one exceptional occurrence: Brother, again irritated by yet another meddling passerby, told me, "... and you can fuck off too". When Brother was less receptive, it was also prudent to keep questions out of any conversation that did occur. When silenced in this way, my research reflected the most inductive approach in qualitative methods, as Brother effectively foreclosed what is fundamentally the most salient aspect of social science research - the right to inquire. However, in respecting

\footnotetext{
${ }^{12}$ Brother's own writing was to later prove that he could, in fact, read and write. His 'being dumb' façade during that initial meeting was in keeping with the impression he chose to give to others. He dropped this façade with me as rapport and trust developed in the research relationship.
} 
limitations occasionally imposed by Brother, I was able to "let slip the cloak of authority" (Etherington, 2007, p. 600), which contributed to balancing power between Brother and me. Inevitably, the quality of the relationships developed in research is ultimately reflected in the quality of the research product produced (Gunzenhauser, 2006). Therefore, paying attention to Brother's needs, sometimes only readable through his silence, was pivotal in establishing a relationship based on respect.

Knowing when to ask questions and knowing when to keep quiet was just one of the ways Brother taught me the 'method within the method' - how doing ethnographic research would play out in his case. His control over the method is exemplified in the way he gradually invited me closer into his personal space. When I first began my fieldwork, I would arrive and greet Brother before finding a position nearby from where I could observe him on the street without being intrusive. After a couple of weeks, Brother changed this arrangement saying, "Here, sit yourself down on your throne", gesturing to the short ledge on the building against which he rested. After a couple more weeks of sitting in this slightly elevated position beside him on the ledge or stone wall (depending on which space we were occupying), Brother invited me even more intimately into his space by asking me to join him at ground level. The first time this happened, I was walking towards him - on noticing my approach, he had called out, "Here, woman, come and get your arse over here", while patting the pavement to his left. From here on, my observational work was conducted with me sitting on the ground next to Brother wherever he happened to be: gutters; footpaths; intersections; and so on. The image below is illustrative of the second phase of researcher positioning, when I sat on ledges or walls to observe the street scene. 


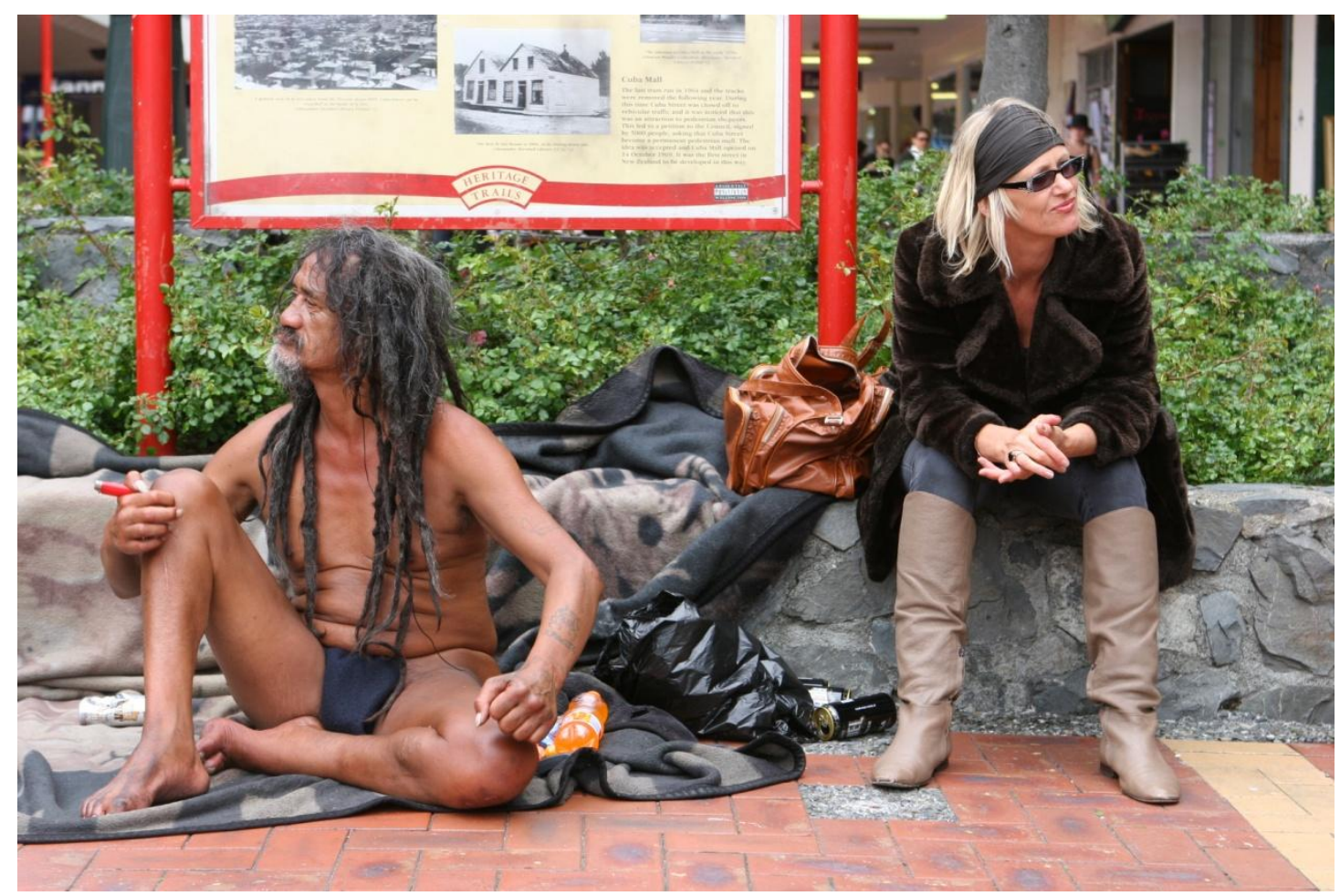

Figure 4:2 Observing from 'my throne' at the northern entrance to Cuba Mall

Source: Belinda Brown Photography, 2008

There were several advantages to this evolution in researcher positioning on the street. Firstly, once I was invited down to ground level, I had the same perspective of the street as Brother, so was seeing things from the same level and angle as him. I was able to observe the public more directly, as they in turn observed Brother. Secondly, sitting beside Brother in close proximity offered a much more conducive position for hearing what people said to one another, what they said to Brother, and any mutual communication exchanged between the public and Brother. Thirdly, being ensconced properly within the research setting encouraged others to speak to me. This provided another analytical category not previously anticipated. Under the former arrangements - sitting nearby, then sitting on ledges and stone walls - people had not connected me with Brother. Fourthly, sitting beside Brother gave me an immeasurable appreciation of 'being there' - being there to pick up on Brother's responses to things as well as being there to receive whatever he chose to share with me. This position allowed me to literally 
experience 'hanging out', while getting a real sense of how street life is lived 'Brother-style'. ${ }^{13}$

Each of these four advantages links to the physical body: the first two reference enhanced visual and auditory benefits; the third refers to how others were able to link me with Brother through visually noting my physical placement; the fourth refers to my sense of 'embodiment'. ${ }^{14}$ Through gradually becoming repositioned into the micro-space proper of Brother's home territory on the street, an experience of 'full immersion' in the research setting was realised. From this position, the research was conducted in close body-to-body proximity for hours at a time, which proved advantageous in other important ways. Learning through my body and then describing issues that arose in my relationship (Crang, 2003) with Brother and other people encountered in the research setting, produced reflections on "body space relations such as smells, tastes, gestures, reactions, clothing, glances and touches" that can "often slip away unnoticed and/or undocumented" (Longhurst, Ho, \& Johnston, 2008, p. 208). Moreover, as Longhurst et al. have further observed, because "things such as feelings of unease, disgust and abjection belong in the category of the everyday, prosaic and banal, since these are common experiences for most of us" they are often considered as "intellectually unimportant" and get sidelined from research (2008, p. 213).

In similar vein, Erving Goffman, in a talk on fieldwork, pointed to the embodied experience inherent with observational research methods:

13 Other urban ethnographers have written on the 'getting in' process. Duneier (1999, p. 11) describes how his entrée to the social world was gained by becoming a browser and a customer at a homeless book vendor's table. Through his association with one vendor, he met other vendors and eventually he became a trusted fixture within the network, and even worked as a general assistant watching vendors' tables, running errands, assisting in scavenging missions through trash and recycling bins, and "going for coffee". His participation in such activities gave him a grounded appreciation of various aspects of the men's everyday routine activities.

${ }^{14}$ I borrow from Radley (1996, p. 569) to explain how I employ the broad term of 'embodiment' to describe my sense of place and being in the world, that is, my embodied capacity to "take up and to transform features of the mundane world in order to portray a 'way of being', an outlook, a style of life that shows itself in what it is". 
...participant observation...[is a way of] getting data...by subjecting yourself, your own body and your own personality, and your own social situation, to the set of contingencies that play upon a set of individuals, so that you can physically and ecologically penetrate their circle of response to their social situation, or their work situation, or their ethnic situation, or whatever. So that you are close to them while they are responding to what life does to them. I feel that the way this is done is to not, of course, just listen to what they talk about, but to pick up on their minor grunts and groans as they respond to their situation...the standard technique is to try to subject yourself, hopefully, to their life circumstances...you try to accept all of the desirable and undesirable things that are a feature of their life. That "tunes your body up" and with your "tuned up" body...you are in a position to note their gestural, visual, bodily response to what's going on around them and you're empathetic enough - because you've been taking the same crap they've been taking - to sense what it is they're responding to. To me, that's the core of observation. (Goffman, 1989, pp. 125-126)

My own research experiences strongly connect me with Goffman's depiction of doing fieldwork. Brother grunted and groaned. He scratched and spat. He belched. In warm weather he would sit naked apart from a flimsy makeshift loincloth that did not always cover his genitals. He usually smelt. To deal with the latter, I learnt to keep what became my 'fieldwork coat' in the back of the car so that this one item of clothing then predominately absorbed his pungent odour. Having a fieldwork coat eliminated the need for washing every item of clothing after each period of fieldwork. It also meant I could remove the coat afterwards and go into other settings without carrying the scent of an unwashed body around with me. Sometimes, however, when Brother's smell was exceptionally pungent and the wind blew a certain way, his smell permeated not only my clothing but seeped into my very skin. While for many researchers, writing up or reading field notes represents the scene to them once they have left it (Carlin, 2003); for me, catching strong whiffs of Brother's distinctive odour served to keep the setting alive long after I had left his physical presence and the street behind me. However, habitually wearing that one coat did not go unnoticed by Brother, who commented to me during the second winter of fieldwork, "Ah, you're still wearing that coat". I bantered back, "And you're still wearing that blanket", which had made him laugh. 


\section{Problematic encounters with difficult others}

As I became accustomed to sitting in Brother's company, and got to know and understand him better, any initial feelings of uncertainty surrounding not knowing what to expect gave way to a sense of ease. However, sometimes tension unpredictably ignited in the setting through other people stopping and being a nuisance, which often led to having to also negotiate with them. Below, I set out one such case, and show how such episodes helped to develop rapport. The difficulties of street ethnography are also highlighted, illuminating the darker side of the street and how this could be managed from an ethnographer's standpoint.

This somewhat extreme case involved a male in his thirties who had stopped and attempted to swap a sachet of instant soup with Brother in return for a cigarette. Brother ignored the man by swaying to the beat of music he was listening to through headphones, while also utilising the 'middle-distance stare' (an interaction avoidance technique that is analysed in Chapter Eight). The man responded by quickly becoming angry and turning his attention to me. The following from my observational field notes describes what had happened next:

.....he rants and raves about the devil, hate, and heads on sticks. I hear the word paedophile in there somewhere. He moves in closer towards me, and with his face now only inches from my own, I notice spittle forming into tiny bubbles at the corners of his mouth. I now feel saliva spray my face as he yells about how lucky 'Cave Man' (his name for Brother) and I are because he has love and not hate in his heart today... Yet, he is all over the place, screaming one minute, scowling and pacing quite manically the next....."Wanna see my knife?" he asks while opening his leather jacket and patting an inner pocket. To deal with the volatile situation unfolding I refuse to allow him to intimidate me or draw me in. I speak calmly and only when necessary, such as when I am asked the direct question about the knife. Saying little and making limited eye contact helps to avoid two things. One, I do not want to risk inciting him further by saying the wrong thing - less is best, neutrality the best diffuser. Two, by not overly attending to him, I evade being seen as challenging. I manage to extract myself from the situation by pretending to leave. I collect up the empty polystyrene drink cups and my bag off the ground, walk to the bin, dump the rubbish, and walk off towards the corner. Reaching the traffic lights, I turn to see him disappearing into the far distance in the other direction. Returning to Brother, he looks up at me and removes one earphone saying, "Ah, so you got him today". Grinning, he rolls his eyes. Removing his bag 
from under his blanket and rummaging inside it, he hands over a heap of coins saying, "Three sugars in mine" (Fieldwork: 23/06/08).

Later, after arriving home, I made sense of the incident in my personal journal, reflecting:

Telling me I had got the man today suggests Brother was well versed on this particular person, so I think he set me a challenge to see how I'd handle the situation. Would I be street savvy enough to sort myself out when confronted by the presence of a difficult other? Would I be able to calm the man down? Get rid of him? Would I make matters worse? Would I leave? Basically, you want to hang out around here with me, here's a test, let's see what you're made of (Personal journal: 23/06/08).

\section{The Hīkoi Method}

Another way boundaries were negotiated - shifting and broadening 'the doing of research' in the process - was when Brother began to invite me to hīkoi with him as he attended to various daily needs like shopping. Hīkoi, a Māori word, translates to "step out, plod, pace" (Ryan, 2008) and is often used by Māori to describe a significant spiritual journey. The word hîkoi was first used by Brother one morning: we were sitting on the street when he started to pack up his bag and get to his feet, telling me, "Come on, we'll hīkoi down there together". From that first invitation, the hîkoi method was given life, altering the form and nature of how I did my ethnographic fieldwork.

In its simplest form, to hīkoi with Brother was to move from one regular spot to another, usually to follow the sun. Sometimes changing spaces included walking a circuit of the immediate city block. Brother never gave any explanation for these hîkoi, but I interpreted them as providing physical reprieve for the body, allowing a much-needed stretching of legs between long, inert periods of sitting. I often got the impression that the hîkoi had another benefit - they brought Brother a lot of attention, especially at night when revellers were congregated at tables and chairs outside the many bars and restaurants we passed on the circuit. Walking with him, copious murmurings could be heard rippling among the people we passed, such as, "Look, there's Blanket Man", as well as sentiments called out to him: "I love you 
Blanket Man", "You're my hero", and "Hey bro, strut your stuff" (Fieldwork: 15/11/07). Walking alongside him, a sense of Brother as a local celebrity was palpable as cameras flashed in the night, capturing his approach or passing.

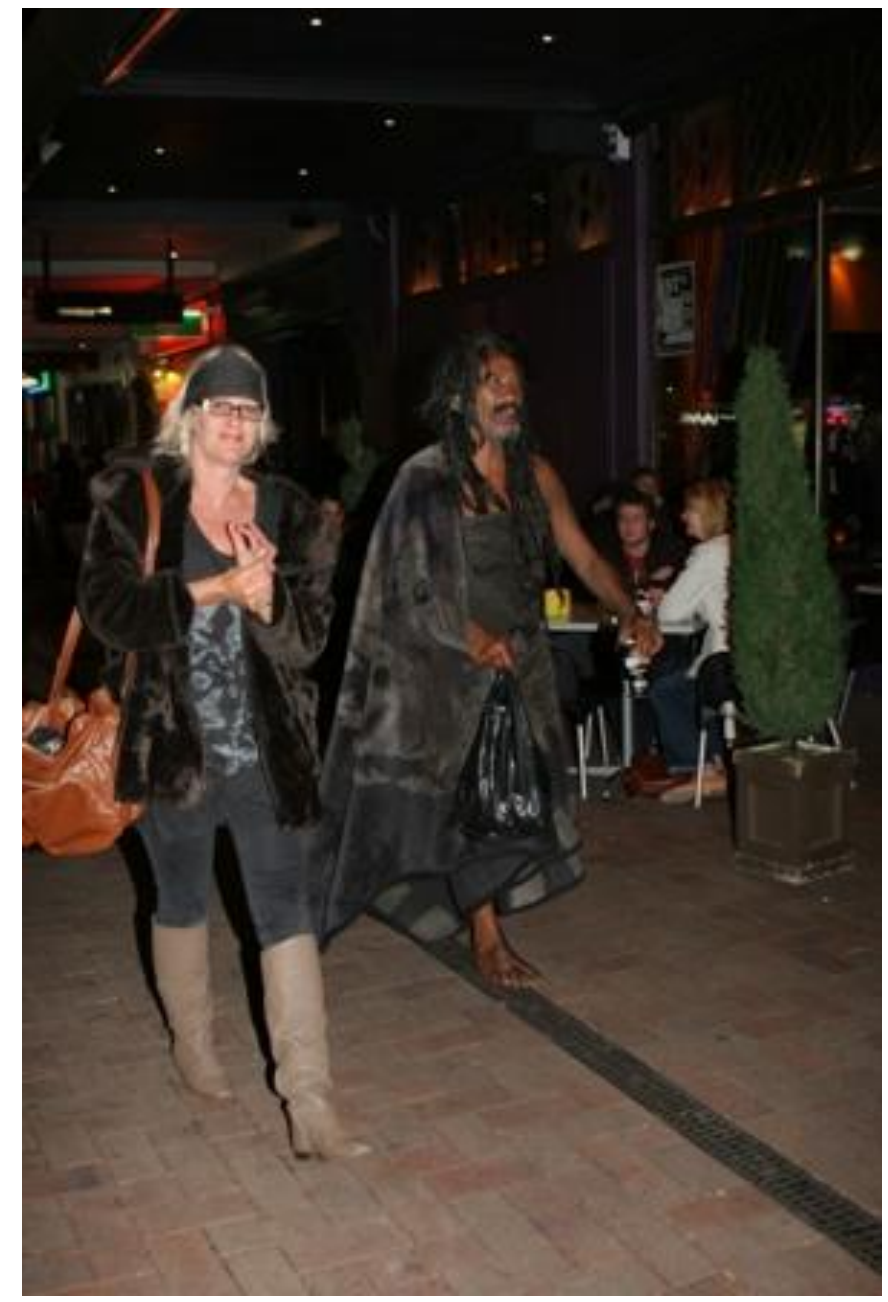

Figure 4:3 'Stepping out' - a late night hīkoi

Source: Belinda Brown Photography, 2008

We covered many kilometres using the hîkoi method, walking in and around the city on various undertakings, which also took us off the streets and into shops, government departments, advocacy agencies, courts, and a hospital. The hìkoi method marked an important tool that extended the research setting into other settings used by Brother in daily life.

Other ethnographers have written about the value of observational work conducted on the move. Katz (2010) advocates for ethnographers in urban sociology, 
particularly those seeking to understand public space behaviour, to move beyond the atemporal fly-on-the-wall perspective of the situationally specific participant observer. In doing so, he argues, the current situation can be understood within the longer-term framework of the participant's biography, as they move from one setting of situated interaction to another.

Kusenbach (2003) describes this type of method as 'the go-along':

...the innovative method of the go-along, through combining some of the strengths of ethnographic observation and interviewing, is a tool particularly suited to explore two key aspects of everyday lived experience: the constitutive role and the transcendent meaning of the physical environment, or place (p. 458).

To understand the connections between macro and micro, Duneier (1999, p. 344) developed what he calls an "extended place method" which involved moving his fieldwork "on, out, and across other spaces". This allowed him to comprehend behaviour and interaction in context, and to examine the ongoing linkage of the construction of meaning and the outcomes of events. Expanding the boundaries of the traditional neighbourhood study allowed the economic, political, and moral forces configuring the city at the time to be taken into account.

A prime advantage of this method is that it captures the spatial footing of experiences in everyday life, as it involves fieldworkers accompanying individual informants on their "'natural' outings, and - through asking questions, listening and observing - to actively explore their subjects' stream of experiences and practices as they move through, and interact with, their physical and social environment" (Kusenbach, 2003, p. 463). Effectively, the go-along is a more modest, systematic, and outcome-orientated version of 'hanging out' with key informants, an ethnographic practice that is highly recommended in virtually all fieldwork manuals and textbooks. In Kusenbach's view, what makes the go-along technique unique is that ethnographers can observe their informants' spatial practices in situ while accessing their experiences and interpretations at the same time. 
By accompanying Brother and observing his interactions with others as well as his use of space in various sites, I was able to capture in my field notes what Katz describes as "a series of sequential, situated involvements...[which are able to] compete in data quality and analytic precision with the increasingly powerful stationary audiovisual recorder" (2010, p. 26). Significantly, through this process, and following other urban ethnographers, I was able to follow up on repercussions experienced by Brother through his choice to live on the corner. The hỉkoi method expanded the boundaries of my study, enabling me to not only observe Brother's arrests on the street, but to go to court to observe directly what happened next. This provided understanding about how various bail conditions ranging from where he could sit in public space to what he wore in public affected how Brother lived his everyday life. Informal and formal mechanisms designed to monitor and control Brother's public life are examined in the first two empirical chapters.

Being invited into the micro research setting - Brother's home - and accompanying Brother on various missions 'on the trot' gave me a privileged perspective and engendered a sense of full engagement in his street life. Hour upon hour in each other's company brought understanding and appreciation of the other. With this, rapport grew. ${ }^{15}$ My age and gender also seemed to be advantageous in according me privileged access. Being female and close in age to Brother made my hanging around look more 'natural' to others. Importantly for Brother, this meant my academic role remained hidden and his 'street cred' remained intact. From the public's perspective, my association with Brother was often understood as friend, journalist, advocate, or religious savior. For example, once I was told, “Stop speaking God to him" (Fieldwork: 02/03/10). Sometimes I was mistaken for his girlfriend, as evidenced by expressions or greetings of 'Mrs. Blanket Man' or 'Blanket Woman'. ${ }^{16}$ Brother often alluded to our common ground in regard to the

\footnotetext{
15 Though a level of trust was shown by Brother's readiness to provide me access to his life, Duneier (1999) cautions participant observers to be humble about rapport, because one never really knows how the participants feel.

16 Occasionally, I was mistaken for his girlfriend even when not in Brother's company. For instance, having just dined at one of Wellington's top restaurants (a rare treat), as we were leaving I overheard another female diner ask her companion in a shocked stage whisper, "What's Mrs. Blanket Man doing here?"
} 
musicians he enjoyed, sharing whether it was Hendrix, Cocker, Joplin, or Marley he was listening to at any given time, and always adding, "Our generation". He also made reference to shared commonalities in terms of our respective children, smoking addictions, and what he referred to as, "Old fart bones" (the stress on the body that comes with sitting for long periods on the ground). My presence, however, was not always so easily accepted by other street people who were generally not permitted to hang out with Brother and would sometimes challenge him, wanting to know why he let me sit there but not them (Fieldwork: 27/02/10).

With trust established, from time to time Brother made me his 'wise person'. Goffman (1963a, p. 28) describes wise persons as:

Persons who are normal, but whose special situation has made them intimately privy to the secret life of the stigmatised individual and sympathetic with it, and who find themselves accorded a measure of acceptance.

The wise individual may also be of valuable social use providing people stigmatised as deviant with social validation. So, while on the one hand, Brother was happy for me to be understood as a 'street sister' on some level, he also welcomed my note-taking activity beside him as it made him look important to others. Was I perhaps a reporter interested in his life or a lawyer working for him? Field notes attest to my status as 'wise person', with Brother telling me on occasion how he had told people in my absence, "I'll run that past Bron" or "I'll see what Bron has to say about that" in regards to various matters (Fieldwork: 22/09/08). In this capacity, Brother sometimes asked me to assist him. Could I get him a photo from the photographer? Could I get Trevor Mallard (Member of Parliament) down to the street, to his turf, to see him? Could I come back with my laptop later? Could I buy the booze if they won't serve him? Could I follow up with the medical staff about his CAT scan results?

An unexpected reciprocity also developed. I was a regular bringer of food and supplier of tobacco and Brother sometimes had various foodstuffs waiting for me, - chocolate biscuits, grapes, and so on - telling me, "For your tamariki [children]". Other times he insisted on paying for the teas and coffees I routinely fetched for 66 
the pair of us. From Brother's position, the street symbolises hearth and home and I was a visitor within that home, so his sharing of food made him not only a hospitable host but reciprocity also operated as a temporary leveller, blurring status differences. As Sahlins (1972) noted, food offered cross culturally in a generalised way has social and exchange value in fostering good relations. He wrote, "Food is life-giving, urgent, ordinarily symbolic of hearth and home, if not of mother" (p. 215). Rather than taking shop-bought food, from the beginning I chose to take food hot from my oven straight to the street. The home-cooked meal most regularly taken to him was 'boil up' ${ }^{17}$. Taking food that I had cooked at home proved to be a good intuitive choice, as Brother later often lamented on takeaway food, the predominant type of food given to him by the public. Even though he chose to live on the street, I understood his indifference to takeaway food and likened it to the hankering one develops for home-cooked food when one is away from the home for any extended period.

The reciprocal nature of giving and receiving extended to Brother one day handing me a blanket, which I interpreted as a sign I had been fully 'let in' as a participant observer researcher. Field notes (24/09/08) describe this exchange:

Brother offers me a present. It is a polar fleece blanket not dissimilar to his one, only it is plain blue and not as bulky. I accept the blanket as I understand it is his way of establishing a measure of reciprocity in our exchanges. I am not sure whether he intends for me to wrap it around myself and I hope that this is not the case. It is one thing to assimilate and sit next to him on the ground... and that took some getting used to. It would, however, be another stretch again to imagine myself wrapped in a blanket adopting his look and signalling visually and corporeally what could be (mis)read by others as my full membership (as a homeless woman) in his street life. Brother seems to read my thoughts. He tells me, "For your bum, sit on it" and I realise that he intends for me to use it as a

\footnotetext{
17 'Boil-up' is the name given to a Māori dish made by boiling up pork bones, potatoes, pumpkin, kumara, puha (watercress), and dough boys (dumplings). This meal became Brother's favourite choice among the home cooked food I took to him during participant observation. I continued this nutritious and nurturing tradition after my fieldwork was complete and was still delivering boil ups to him only days before his sudden death.
} 
folded square to cushion my backside as I sit for hours at a time on the hard concrete surface of the street. I am relieved. This, I can do.

Though I would always help Brother with small requests where I was able, disagreement would arise from time to time over my refusal to purchase him alcohol. By the end of my fieldwork, there was only one liquor store that still agreed to sell alcohol to Brother (although licensed 24-hour convenience stores were happy to sell him alcohol, these stocked wine and beer, but not his preferred pre-mixed bourbon and cola drinks). However, this one remaining liquor store also monitored his purchases, usually not allowing any purchases exceeding one sixpack, and refused any attempts he made to buy liquor on subsequent visits within the same day. Given this social control by retailers, Brother would sometimes ask me to buy liquor for him. I would explain how my doing so could result in us both being in trouble - he for breaching the liquor ban and me for purchasing the alcohol knowing he was going to flout the ban. Although most of the time he understood this, occasionally my refusal caused friction. For example, he once told me, "You just want me to have what you want me to have. It's pissing me off, but if you buy it (alcohol), I will be more receptive towards you again" (Fieldwork: 01/06/09).

I reflected on this situation in my research journal:

Actually, he had a point; my refusal could be read as joining ranks with others who similarly decide what's 'best' for him when making what are essentially moral judgments. Reminded me of the small research grants committee saying I could not give him koha (donation) of cigarettes because the university had a 'smokefree' policy! Never mind that he would be smoking them on the street corner and not anywhere near the university. Tricky situation. Yes, I was happy to give him date scones, and yes, I didn't want to jeopardise my study, had already had run-ins with police officers accusing me of street drinking with him. But, still, my refusal and his reaction on this occasion created a catch-22, emphasising ethnographic authority...And seriously pissing him off could equally threaten our relationship and therefore the future of my study (Personal journal: 01/06/09).

Situations involving giving and receiving, and, conversely, not giving, were tricky - difficult to read, they became part of the territory of negotiation in this 
participant observational research. Other, more experienced ethnographers have also commented on prickly situations arising in the course of their own research endeavours that involved stepping outside of their comfort zones. Wacquant (2009), for instance, reflects on his ethnographic immersion where he learnt the craft of boxing in a gym of Chicago's black ghetto. In a detailed fieldwork excerpt describing being given a 'fade' haircut (the black hairstyle currently in vogue in the ghetto at the time) by a research participant, Wacquant reveals how the social value of receiving the cut helped to solidify his place within the inner circle of the club's regulars. Notably, he argues the ways in which his 'fade' highlighted the social and cultural organisation of the gym as it represented his placement within a fictive kin relationship and visually signalled to others his full corporeal membership in the group:

...I quickly found myself enmeshed in the material, symbolic and affective exchanges that weave the fabric of the gym day to day and gradually learned, now with pleasure and now with apprehensiveness, and not a few bouts of feelings of awkwardness and incongruity, to conform to its mores, to respond to the expectations and requests of its members, and to adapt, physically as well as morally, to its peculiar demands (Wacquant, 2009, p. 511).

Researcher reflexivity is usually discussed as a mental process (see, for example, Mauthner \& Doucet, 2003; Neyland, 2008). Cloke et al. (2000, p. 151) write:

The practice of research can never be a neutral exercise. For good or ill, the very act of entering the worlds of other people means that the research and the researcher become part co-constituents of those worlds - academic lives are also real and should not be reified or rendered abstract...academic researchers who are willing to enter into 'selfconscious' and dialogic work will inevitably expose some of their selves within the research process.

Yet, as writers such as Merleau-Ponty (1962) have pointed out, the meanings we apply to things are continually in the process of shifting and evolving within a spatial-temporal context, as perception does not just occur in one's head. Rather, the meanings we give to things derive from bodily experience brought about through our embodied engagement in the world. The next section argues researcher reflexivity can be equally understood as a physical process when using 
relatively open forms of ethnographic research. Goffman's (1989) notion of the 'tuned up body' (presented earlier in this chapter) is used to demonstrate how the researcher's body, reframed as research tool, becomes part of the process of making sense of fieldwork situations and their meanings.

For Wacquant, while wearing his 'fade' provided plenty of scope for reflexive practice - broadening his understanding of social and cultural organisation within the gym - the physical process of receiving it proved a test in bodily endurance:

Honestly, I don't know if I'm going to be able to withstand the ache!...I close my eyes and wince. It's sheer torture, I can't believe it. I do not dare to even look at the state of his clippers. The blades must be completely blunt and twisted, it's unfathomable (2009, p. 513, original emphasis).

Corporeal experience stimulated further reflections for Wacquant who came to tacitly understand the haircut could not be refused, inscribed as it was within a broader cycle of exchanges based on reciprocity. The haircut was not simply a gift. It provided a platform from which the haircutter could show off his personal skill of a bodily craft, bringing him "corporeal capital...in the battle of social existence" (2009, p. 512).

In my research, sitting inertly on concrete for hours on end gave me enormous appreciation for what Brother's body endures quite effortlessly. It also gave rise, particularly in the early phase, to experiences of degrees of awkwardness and embarrassment in my conspicuous placement on the street corner beside a notorious street dweller. My experience was no longer that of an upright citizen traversing footpath space as I attended to mundane aspects of everyday life. Sitting at ground level brought significant departure from my normative experience, and, combined with being lower than other (upright) bodies, challenged my existing imagery of the local space. I felt I was participating in a 'breaching experiment' (Garfinkel, 1967) wherein routine aspects of everyday life become problematised (Garfinkel's notion of 'breaching experiments' is engaged to theorise empirical data in Chapters Five and Six). Physically, I learned through the materiality of my own embodiment that carbon monoxide levels in cities are highest nearest the ground, and that concrete is an uncompromising surface that retains the cold and 70 
reflects the heat. Sitting in public with Brother also brought insight into how it feels to be publicly 'othered' in city space. I discuss this part of the experience in the next section.

\section{Stigma by association}

Anderson and Calhoun (1992) suggest that perhaps the most widespread assumption regarding observing deviant populations is that they are suspicious groups with whom it is particularly difficult to establish rapport, arguing that this assumption is only partially justified. Deviant groups, they continue, present special opportunities for developing rapport "through the researcher's willingness to accept stigma by association, or what Goffman...referred to as a "courtesy stigma"' (1992, p. 492). This was certainly my experience, particularly early on when I was acutely aware of the public gaze - the prolonged or pointed glare exhibiting distaste, curiosity, or sympathy. There were dismissive glances, open gawps, and the times throughout fieldwork where I was mistaken for a homeless woman. As I became more comfortable, a process of desensitisation occurred where I became less concerned with my own visibility and the reactions of passersby to my presence, and instead more adept at attending to the task of doing fieldwork.

Experiencing stigma by association in my case extended to my children (to a lesser degree) through my combined mother and researcher role. Given Brother's highly visible 'cornering' of everyday life on a main road, one of my teenaged daughters received a text message early on in my fieldwork from a school peer, reading, "jus saw ur mutha sittin in da gutta wid da blanket man. Lol'. Despite the 'lol' ('laugh out loud' in ordinary language), this was no laughing matter for my daughter, who pleaded that I not sit with Brother in public. In time, however, a similar desensitisation process seemed to occur in my children. Several months on from the text message, while I was walking on a crowded downtown pavement, accompanying Brother using the hîkoi method, I heard a friendly "Hi Mum" as the same daughter, friend in tow, approached from the opposite direction. Sometimes Brother voiced insight about the way his stigmatised identity could tar me by association. For instance, one night when sitting on the footpath amid a lively 
street scene, he commented that if my daughters were out and about they could be embarrassed by seeing me with him (Fieldwork: 27/02/10).

In Chapter Five, I draw from empirical data to reveal the various ways homeless people in Wellington's central city are either singled out or grouped - they often become individually or collectively named and recognised. I will argue that this social phenomenon signals a shifting of attitudes that serves to not only reinforce stereotypical attitudes regarding homelessness and homeless people but also paradoxically challenges prevailing thinking in new and specific ways. I further reveal how sorting and naming processes influence definitions of homelessness, laws about homelessness, and practices designed to curb homelessness. However, the point I make here in relation to the practices I outline resides in philosopher Ian Hacking's (2004, p. 280) conceptualisation of 'human kinds' and how 'making up people' can be understood as "realism in action....and...making and moulding people as the events [are] enacted." To be sure, my perceived 'hanging out' with Brother brought many instances of mistaken identification as a homeless person.

\section{Mistaken (homeless) identity: A case of membership categorisation in action}

Throughout fieldwork, I experienced random offerings of food and drink from passersby, which suggested others assumed - because I was with Brother - I was also homeless. The very first time this happened I was sitting beside Brother on the footpath when a chunk of bread landed at my feet. Looking up, I saw a pedestrian reaching into a brown paper bag and heard him say, "Here, you have some too" as a second hunk landed on Brother's blanket. Brother's reaction to me being fed along with him was to sniff the bread and make a satisfied "Ah" sound, before muttering about it being fresh and still warm. He had then grinned at me and popped his chunk into his bag for later eating. Writing about this first experience

of mistaken identity, I noted how it had reduced me in the first instance to identify foremost with the pigeons pecking at the ground nearby in their search for food (Fieldwork: 11/02/08).

Sometimes my standard refusals to more direct offers caused offence: 
He stands over me, gesturing the takeaway drink cup towards me. Looking up at him, I shake my head. He gestures it closer towards my face saying, "Too sweet for me". Again I shake my head. Not taking no for an answer, he cajoles, "It's clean. I've only taken one sip". I ignore him. "Don't be so damn fussy and so bloody ungracious", he says as he stoops to place the cup on the ground in front of my feet before huffily walking off (Fieldwork: 22/09/08).

Such episodes proved analytically fruitful. They afforded valuable insight into how others understood my presence in Brother's company, leading to acts that 'othered' me as a homeless woman, and allowing me to fully experience the way stereotypes are given life during everyday interactions. Recalling Goffman's 'tuned up body', with my own body experiencing the same 'crap' as Brother put up with (though he experienced it on a daily basis), I was able to get inside the experience of being homeless, if only momentarily. Experiencing people's assumptions that I was homeless and learning how to handle acts of unwanted charity that came with those assumptions, I became efficient at also deciphering the subtleties involved in Brother's honed and tactical management of unwanted interactions (his strategic interactional techniques are examined in Chapter Eight).

The local constabulary sometimes wrongly construed my co-presence as troublesome, assuming I was 'of the street' and therefore potentially a partner-incrime, participating in street drinking or drug use alongside Brother. On two occasions I sensed imminent arrest had I not complied 'to the letter' with what the officers were asking. One of these hostile police encounters, in which I narrowly avoided arrest, is included in Chapter Eight. Members of the public drew similar connotations from my presence beside Brother. For example, one young male, giving the thumbs up as he passed, said, "You sharing a cone with Blankie. Magic." (Fieldwork: 11/08/08). I was also repeatedly asked, in various ways, where to 'score' (buy drugs), offered cannabis to purchase, and invited to participate in smoking marijuana.

So far in this chapter, I have explained the research process, detailing some of the issues faced when collecting empirical data out in the field, amongst the action on the street corner. The remainder of this chapter will discuss how the data were 
approached, made sense of, and will detail my analysis approach. I begin by explaining my elected methods for representation of observational material in this thesis.

\section{Data analysis and representation}

Continuing in the ethnographic tradition, I have elected to present data in this thesis in vignettes capturing everyday street life. For brevity purposes, in some cases several sentences are removed from the original accounts. I indicate where this has occurred with the inclusion of five full stops in the text. It should be noted, however, that I subsequently draw from the descriptive vignettes in their original entirety when summarising or analysing the material. Observational data are also woven into my citations of the scholarly literature when describing and interpreting people and their actions as observed in my study. Personal reflections taken from my research journal are also included, which are designed to compliment and extend the material. Presentation of material in this chapter has already illustrated this way of using my fieldwork data. In taking this approach, my goal is to enhance reader understanding while making the data transparent enough to demonstrate my sociological analysis. Including reflections from my personal journal also aims to further demonstrate how 'practicing ethics' is a process in the doing of research. As Etherington (2007) observes, through the display of self in our writing, "the interactions between ourselves and our participants from our first point of contact until we end those relationships...can be understood, not only in terms of what we discovered, but how we discovered it" (2007, p. 601, original emphasis).

Ethnography bases many of its claims to robustness and relevance on being close to the action and providing significant detail on that action (Neyland, 2008). Though as Erikson (2008, p. 404) considers, the challenge for sociologists writing about "the ordinary affairs of ordinary people" is to be able to discuss ideas without resorting to convoluted jargon (see also Becker, 1998; Silverman, 1998). This, Erikson argues, "allows them to be understood outside the narrow precincts of the discipline and yet with sufficient precision to allow for careful inspection and evaluation within it" (2008, p. 404). I have strived to present my ideas and 
arguments in writing that ascribes to these calls. More significantly, within my writing is a strong commitment to represent Brother's everyday experiences in ways that will stimulate not only compassion, but also critical reflection. Framing my work in this way is an attempt to raise both public and private consciousness about an individual who is representative of others from all walks of life who dare to do things differently.

I have presented the data in ways that emphasise Brother's agency, because the usual ways homeless people are portrayed within the literature are as passive victims of circumstances beyond their control. As Miller (1998, p. 423) argues, "Part of our dehumanisation of homeless people is to assume that they lack the ability to make choices". This approach follows Duneier (1999; in Duneier \& Back, 2006), who argues the job of a contemporary ethnographer, and a possible agenda for ethnography with regard to units of analysis, should be to recognise people as complex human beings. To do this, Duneier urges:

If you are going to get at the humanity of people, you can't just have a bunch of disembodied thoughts that come out of subjects' mouths in interviews without ever developing characters and trying to show people as full human beings. In order to do that it is useful to have a character that lives in a text from chapter to chapter and is recognizable (Duneier in Duneier \& Back, 2006, p. 554).

Aware of criticisms levelled at the way some ethnographic studies of homeless people adopt an 'innocent ethnography', which can serve "to perpetuate assumptions of the homeless as 'other"' (Radley et al, 2005, p. 277), my elected method of data representation strives to avoid emphasising Brother in ways that other him. In humanising him, I share Duneier's further concern:

...one of the tasks of ethnography is to disentangle what is the same and different about people who have been exoticized...It is part of the larger task of showing the ways in which people who start out like 'us' and become 'them'. Finding out how people go from being 'us' to being 'them' is one of the warrants of ethnography, especially in a sociological context where we're talking about members of one's own society (Duneier in Duneier \& Back, 2006, p. 558).

With my research framed in a commitment to everyday life studies, a central aim of this research is to provide insight into the mundane, routine, 'micro' aspects of 
the lives of individuals and groups and their social interactions. Therefore, presenting vignettes as "units of analysis" (Duneier in Duneier \& Back, 2006, p. 554) felt like the most potent way to show the particular "rhythm, syntax, and semantics" (Denzin, 2003, p. 484) of Brother's everyday street life. On this view, the banal and mundane are contextualised through rich description of people and places, which humanises the experience of a public life lived on the corner. By extension, this separates my study from the many broad analyses that exist in the literature, as I attempt to get inside the everyday nature of street life to capture the depth and nuanced complexities of Brother's experience. Portraying Brother in his complexity and individuality as a unique human being is further intended to avoid an 'ordinary versus extraordinary' binary.

A reflexive text featuring the ethnographer as a core actor in the ethnographic situation provides the means for finding "diverse ways of rendering negotiated realities" (Clifford, 1986). In this thesis, as I have shown already in this chapter, interweaving field notes from my personal research journal makes transparent the ways my researcher role was progressively repositioned as I was drawn into Brother's world on the street corner. Through highlighting particular issues encountered during my fieldwork, I am able to reveal what I learned from and about Brother over the course of our relationship. For example, as elucidated in this chapter, the research relationship that developed between us proved pivotal in shifting even my physical position when doing street corner sociology.

\section{Collaborative research}

During my first meeting with Brother, he had instructed I tell his story, "and not that bullshit media or courthouse story" (Fieldwork: 21/11/06). Yet Connelly and Clandinin (1990) propose that because:

Humans are story telling organisms, who, individually and collectively, lead storied lives (p. 2)...The thing finally written on paper (or, perhaps on film, tape, or canvas), the research paper or book, is a collaborative document; a mutually constructed story created out of the lives of both researcher and participant (p. 12). 
Certainly, in my study, once trust and rapport was established in the research relationship, Brother's directive changed to become one periodically reminding me to "tell our story" (emphasis Brother's own). From time to time, Brother would refer to me as 'the wordsmith' or he would tell me to include a particular event. A case in point occurred when he referenced an episode I had witnessed during the previous period of observation. It had involved police officers confiscating his drink when refusing to accept it was not alcohol. On next seeing me, he had been quick to check whether I had written about "the soft drink robbery" in "the book" (Fieldwork: 01/06/09). Brother's own writing, mentioned earlier, given to me by him for 'the book', can also be understood as having a collaborative role by giving Brother further voice in this research. Sometimes I invited Brother to collaborate with me more specifically. For example, I asked him if he wanted to have some input into naming the book/thesis. Telling him the temporary title was Street Life, he had responded, "That says it". Pressing further and asking whether he could come up with something a little more interesting, he had told me, "You're the wordsmith. It'll come to you. Though, possibly after the fact." (Fieldwork: 22/06/10).

\section{Applying Becker's 'tricks of the trade'}

So, how did I manage, and make sense of an accruing abundance of observational data? Howard Becker's classic Tricks of the Trade (1998) draws on theory-taming techniques developed during his four decades plus as a researcher and teacher. These techniques or 'collection of tricks', are simple devices that he intends will help social scientists when making sense of their data sociologically and formulating new questions based on what they have found:

What the tricks do is suggest ways to turn things around, to see things differently, in order to create new problems for research, new possibilities for comparing cases and inventing new categories, and the like. All that work. It's enjoyable, but it's more work than if you did things in a routine way that didn't make you think at all (p. 8).

Following Becker, interpreting my research data to create this thesis involved a fluid process of moving between field notes and the literature to develop ideas about how things fitted together or how they differed. Working back and forth 
between ideas and theories, a process of interpretation, analysis, and representation began to take shape. This involved methodically reading and re-reading through empirical data as they accumulated, highlighting key points while also attending to more ambiguous notions (Becker, 1998; DeWalt \& DeWalt, 2011). In keeping with an inductive approach, a general, abstract theory of a process, action, or interaction grounded in the observational data being collected was used to set data collection goals in later stages of the research (Becker, 1998; Duneier, 1999; Mills, 1959). For instance, in time I became aware of Brother's capacity to sustain a state of physical wellbeing and a consistently jolly disposition. The latter was observable in his prevalent use of humour underpinning the majority of his interactions with others, and I was initially surprised at such fortitude against the backdrop of austerity he faced in his living situation that is bereft of any 'home comforts'. To comprehend some of the things I was observing, I began to sociologically dig by extending my reading to include material deriving from a sociology of humour or emotions perspective, developing concepts in a continuous dialogue with my empirical data (see also Duneier, 1999). I watched and rewatched Errol and Abi's documentary Te Whānau O Aotearoa-Caretakers of the Land, which centred on a protest staged by homeless people at Parliament Grounds and featured Brother as the key character (Wright \& King-Jones, 2003). I aimed to further understand the contextual background surrounding Brother's street life preceding my study and to seek clarification about historical events Brother occasionally made mention of during our corner conversations.

To make sociological sense out of what I was seeing and hearing on the street, I began making notes during the process of writing up my initially scrawled field notes, formulating links where possible between observational material and sociological concepts and theory. The next stage was to confront more actively the interplay of more precise writing and thinking through writing drafts, a process E.M Forster sums up as, 'How do I know what I think until I see what I say?' (Forster, 1927). Indeed, given that doctorate dissertations are permitted to entail up to one hundred thousand (preferably well thought out) words, the exercise of draft writing becomes another intricate but important step in working with one's data. C. Wright Mills (1959) elucidated this process as initially presenting your work to 
yourself, 'thinking clearly', and then presenting it to others. At this stage learning it is still not clear, which propels you into the next stage - 'context of presentation'. Here, as C. Wright Mills proposes, new ideas move the writing into a new context of discovery, one that projects a higher level of thinking and is more socially objective (1959, p. 244). Like Forster, C. Wright Mills reasons one cannot divorce how one thinks from how one writes. Rather, the trick is to keep working back and forth until all the key elements are in place and continue to develop and order ideas around this framework.

Through these multiple ways of working with the data, three general ideas emerged and I began to thematically organise the material into three broad conceptual categories: the interactive nature and form of Brother's street life; how space is used; and the role of the individual body and its material objects. In order to further refine the large volume of data in each of these categories, subcategories were created. For example, data noting the interactive nature of Brother's street life was first sorted into five sub-groups, which distinguished the various types of social actors observed interacting with Brother. The first referenced the public-at-large: shoppers, walkers, commuters, tourists, children, and the elderly. The second referenced people patrolling or working on the streets in an official capacity: police officers, Walkwise and Parkwise wardens, street cleaners, refuse collectors, and those carrying out footpath or road maintenance. The third referred to 'other street people', including homeless people. Data in a fourth category related to the public's interaction with me, including their interaction with Brother vis-à-vis me, while data in a fifth category derived from Brother's personal communication with me. I then noted which interactions could be classified as random, that is, they appeared to the best of my knowledge to be one-off, sporadic interactions with Brother. Through this process I was able to distinguish which exchanges could be identified as more than a 'one-shot deal'. These interactions were then considered to constitute on-going, interactive relationships with him, albeit to varying degrees.

The form and nature of each interactional encounter instigated by others towards Brother was also noted, producing further sub-categories identifying seven broad 
types of social interaction: modes of address or simple greetings; brief interchanges; authoritarian; displays of public caring and sharing; celebrifying/iconicising; stigmatising; and harassing. Brother's various responses to social interaction or his ways of initiating social interaction were identified and similarly sorted within four broad categories: spoken communication including his frequent use of humour; bodily gestures; objects as interactional devices; and interaction avoidance methods and techniques.

Procedurally, this splitting and funnelling of data into explicit categories was also conducted with observational material relating to space, the body, and its material objects. Yet this was no easy task. As Thrift (2008) argues, the social and spatial are so thoroughly imbued that their analytical separation quickly becomes a misleading exercise. To be sure, observational data for this study could just as easily have fitted all three thematic categories of space, body, and interaction. Nonetheless, I endeavoured to make sense of the large amount of data involved, keeping foremost in mind the key issues of my agenda that sought to understand the intersection of how Brother found space, made it his own, and interacted with others in that space. Managing data towards this goal therefore inevitably involved organising and forcing data into categories as I have described. Ultimately, though, my concern was to not explore these three categories in isolation, but to conceptually conceive of my data as an entity to further understand how a nexus of the three was able to bring forth an experiential sense of city-as-whare for Brother.

\section{Conceptual saturation}

I recognised I was reaching conceptual saturation when I was able to observe Brother's interactive street life with others or observe his interaction with his environment and fairly accurately predict how he might act or respond next. I was also able to identify sociological ideas and concepts carried into the field in the action and talk unfolding on the street. For example, Duneier's (1999) conceptualisation of the 'Fuck it! mentality' (mentioned in Chapter Three and conceptualised in Chapter Seven) and the three observable stages leading to that state were not only transferrable to the Wellington context but were contestable in my analysis of data collected. 


\section{Concluding comments}

This chapter has explained the research process used in this thesis for doing street corner sociology. Drawing from fieldwork notebooks and my research journal I have critically appraised issues encountered as a novice ethnographer when recording at the micro-level of face-to-face interaction (and when in close body-tobody proximity) Brother's routines, activities, and interactive relationships with others in his everyday life. Discussion has pointed to the ways my fieldwork venture required me to be intuitive, open, flexible, negotiable, and even vigilant when working in a one-to-one research relationship in public space among a sporadically unpredictable public. I further elucidated how the subjective nature of our developing research relationship had significant bearing on shaping and reshaping my method. Detailing the ways in which Brother taught me 'the method within the method', I also highlighted the many benefits gained when allowing my research to become participant-led to a degree. I also suggested that the researchers' own body should not be overlooked within the ethnographic enterprise, but rather it can be understood as a research tool for making pragmatic sense of mundane moments as they are lived.

Ultimately, this chapter has endeavoured to illuminate and make transparent the humanity experienced when 'getting the seat of my pants dirty' doing microsociology on the street corner. A crucial concern in this chapter has been to impart an early sense of Brother's autonomy and agency. This is important because as Brother once told me, "Between your writing and the documents at the courthouse, we will do it...academia can change things" (Fieldwork: 24/09/09). As Duneier (in Duneier \& Back, 2006) argues, we actually need social research that shows how human resistance allows individuals to build their own social capacities in spite of their marginalised status. So, in reiterating Duneier's point presented earlier, one of the many possible agendas for ethnography should be to work harder at showing people as people - using ethnography as a means of trying to talk about how meanings are understood by individuals. Because, as Duneier (in Duneier \& Back, 2006) further contends, change is not necessarily affected through a dialogue with a theory or social policy, but rather change can occur through awareness, understanding, and dialogue at the human level. The research methods discussed in 
this chapter were used to procure data and build a study aspiring to this end. By extension, this research aims to improve our understanding of people who do things differently, and to stimulate critical sociological reflection regarding different modes of being, and achieving belonging in the world. 


\section{Chapter Five Interpreting Wellington's street scene}

\section{Introduction}

This is a chapter about people living on the street, what they do, how they use space, and how others also sharing the space respond to them and understand their presence. Two key aims sit behind this exploration of the interactive and spatial dynamics of the inner city street scene in Wellington, Aotearoa New Zealand. The first is to set out what is distinctive about Wellington's geography and the city's street people, including some key players in the Wellington street scene. Drawing from fieldwork observations, the task is to provide an ethnographically informed exploration of the local setting, focused on how people use available methods in a shared public space to construct everyday social realities. As part of this aim, I locate Brother within the street scene and identify both what is unique and ordinary about his particular way of doing street life in the autonomous realm of social action that Goffman (1983) referred to as the 'interaction order'. This chapter provides a socio-spatial and political backdrop contextualising the broader street scene within which Brother belongs. This will pave the way for close examination of how space matters, the role of the body and objects, and the nature and form of social interactions between diverse individuals in the remainder of my thesis.

A second interrelated aim is concerned with exploring the classification or categorisation of people as 'human kinds' or 'types'. Philosopher Ian Hacking (2002, p. 8) argues, "We live in a classified world which might be deconstructed in a playful way, but whose structures we will need in order to think until they are altered not by deconstruction but by construction, by creation." Here, Hacking taps into that most basic of sociological questions: How do we conceptualise and realise who we are and what we may be, in particular moments and spaces? Applying Hacking's five-part analytical framework to the category of homelessness and to those categorised as homeless people, I explore, via news and social media representations and face-to face street interactions, how a new kind of 
person can be brought into being, both in the way they are perceived by others and by the way they experience being a person. I am also interested in exploring Hacking's 'looping effect' (2007). Hacking argues:

We think of...kinds of people as given, as definite classes defined by definite properties. As we get to know more about these properties, we will be able to control, to help, to change, or to emulate them better. But it is not quite like that. They are moving targets because out investigations interact with the targets themselves, and change them. And since they are changed, they are not quite the same kind of people as before. The target has moved. That is the looping effect...That is making up people (p. 293).

Methodologically, Hacking's (2007) framework is focused on "classifications of people, in how they affect the people classified, and how the effects on the people in turn change the classifications" (p. 285). His framework comprises five interactive elements: a) classification; b) people; c) institutions; d) knowledge; and e) experts. In this chapter, Hacking's five elements can be succinctly understood in relation to my work as follows: a) The classification is 'homelessness'; b) Within this classification, the classified people are 'the homeless'; c) The institutions involved include the media, Work and Income New Zealand (WINZ), homelessness agencies, the New Zealand criminal justice system, the police; d) Knowledge - both popular and expert - that is generated about the classification, identifies causational factors of homelessness such as addiction or unemployment, and pathways in and out of homelessness. For Hacking, the two forms of generated knowledge shade into each other and both work within institutions that then reinforce legitimacy, authenticity, and 'status as experts'; e) Experts - including lawyers, medical professionals - accounts for the way in which professional intervention can loop back to affect the everyday lives of homeless people.

Though knowledge and intervention can bring about positive outcomes, for example, homeless people are assisted out of homelessness, as Hacking (2007, p. 289) observes, "classification tends to invite stereotypes". Consequently, as knowledge about a classification increases and the classified become recognisable by definitive properties, this can leave them open to interventional measures that can control, help, and organise. 
In addition, Goffman's concept of looping which refers more to an 'unmaking of the person' and understood by Goffman to apply at the level of face-to-face interaction will further allow for an examination of how the cyclic affects of stigmatisation, marginalisation, and humiliation processes are given life in everyday encounters and are experienced by street people. Goffman's looping resembles Hacking's, insofar as his work explores how people are made up and constituted within institutional settings (for example, Stigma (1963b), how patterns of normality and deviance work on individual agents, and how the agents can change those norms, by way of a feedback effect. However, as some critics have pointed out, in Goffman's work it is not always clear just how the agent can react back to affect discourse (for example, see Jenkins, 2008; Shilling, 2003). Although this raises empirical questions about the ways in which human resistance to discourse might challenge and transgress the boundaries of taken-for-granted social norms (Shilling, 2003), his work nonetheless remains essential for coming to understand how people are made up day-by-day within institutional and cultural settings and structures.

Central to this chapter is the question of how Wellington street people, using city space as 'home space', are singled out or collectively grouped, named, and categorised. I reveal how these sorting and naming processes are observable not only at the local scale of the street in everyday social interactions, but also within news media reportage, and more recently, in online social media commentary. The broader relevance is that these occurrences signal a shifting of attitudes that serves to not only reinforce stereotypical attitudes regarding homelessness and homeless people, they can paradoxically also challenge prevailing thinking in new and specific ways. These processes, when conceptualised in light of Hacking's (2004, p. 280) "realism in action" emphasising "the making and moulding of people that occurs as events are enacted", illuminates how Hacking's five elements can influence definitions of homelessness, laws about homelessness, and practices designed to curb homelessness. 


\section{Conceptualising and categorising homelessness}

The question of who we are is often answered in reference to where we come from. Moreover, contemporary understandings of home are generally understood as the concretisation of a particular moral order, as among the things we learn and practice in the home are social rules that protect the common good (Pascale, 2005). Set in this context, homelessness is best understood in terms of what is lacking. To be homeless means to be without a place. Yet people without homes do not just lack a roof over their heads but are understood to lack a hold in the whole social topography. In lacking a home, they are perceived to fall outside the moral order and are universally alienated as "losing all one's possessions raises the suspicion that a person is somehow out of control in every way" (Ablow, 1991 cited in Pascale, 2005, p. 260). Being homeless then, makes problematic many of the taken for granted assumptions about how we live our everyday lives. Whether by choice or not, homeless people are not assimilated, they are commonly thought to be dislocated from social networks and a sense of belonging, less able to sustain their self in society and less likely to be bounded by society's rules (Pascale, 2005). As a consequence, homeless persons are more likely than those with homes to be seen as the 'dangerous other' and are excluded, repressed, and displaced in all sectors of everyday life - experiencing punitive policing and city zoning practices, as well as negative stereotypes.

\section{Representing homeless people as 'other'}

Representations of homeless people as the 'other' are clearly evident in news media reports. International studies on homelessness consistently argue that the mediated discursive meanings ascribed to the homeless as a social group directs attitudes and activities in everyday encounters with homeless people (Amster, 2003). Research suggests that public representations of homelessness, such as media stories, can generate and reinforce views of otherness, which creates a polarising effect, with homeless people constructed as being 'less' than housed people. Certainly, while representations of homelessness vary, they do tend to revolve around a small number of tropes and stereotypes and these are important when considering how the media might report on homelessness (Phillips, 2000). 
Depictions in mainstream academic and journalistic publications that are intended to be sympathetic have been argued as negatively construing homeless people by emphasising filth and decay (Amster, 2003).

However, Phillips (2000) found that although such simplifications and misrepresentations have been identified by academic critics, they remain in circulation. These generally construct and position homelessness through discourses relating to categories differentiating between home and away, rural and urban, sexuality and sexual deviance, innocence and corruption, and street life, rooflessness, and above all - vulnerability. Although rooflessness is the most stigatised form of homelessness, it is by no means the most common form (Phillips, 2000). Similarly, Pascale (2005) argues that language used by the media when reporting on homeless people emphasises and reinforces their position as 'other'. She cites the tendency by newspapers to use the word 'we' when establishing identification between the speaker and the reader and argues this serves to isolate homeless people outside this circle. She further notes that the media are inclined to report on homeless people in ways in which their unhoused status precedes all other information about them. This extends to them usually remaining nameless as they are commonly identified foremost as 'the homeless'. Similarly, sleeping bags and other common possessions of homeless people referred to as 'paraphernalia', and sleeping sites favoured by homeless groups referred to as 'encampments', draws attention to the few possessions homeless people might own. By giving emphasis to the sleeping rough element of homelessness, the differences between housed and unhoused people are reinforced. In contrast, the newspaper media describe housed people as living in communities, which implies living together within society's moral social order (Pascale, 2005). The media play an important role in shaping broad social definitions through accumulation of media portrayals that suggest what is 'normal' and 'deviant'. When homeless people are included in media reports, they are often framed within what Croteau and Hoynes term "a spectacle of the bizarre" (2003, p. 163). 


\section{How media representations affect the everyday experience of doing homelessness}

A study by Amster (2003) explores what it is about homeless people that inspires such overt hostility from mainstream society and why their difference evokes such vehement and aggressive responses to their presence. Pointing to the numerous studies on societal reaction to deviant behaviour which continue to find that negative attitudes seldom relate to any actual or credible fact, Amster observes mainstream attitudes and behaviour towards the homeless derive more from a perception of deviance, than from reality. Amster (2003, p. 4) argues that it is the media, and its stereotypical media depictions portraying homeless people as dangerous, disordered, diseased, and criminal, "a sort of street trash... who are vile and malodorous", that perpetuates homelessness mythology.

These types of depictions are argued by Amster (2003), to feed a general consensus that dirt is a precursor to disease, and so just like homeless people themselves, the public places they occupy are in turn perceived by the public as defiled by their inhabitation. Amster contends that this perception leads to processes calling for the "exclusion, eradication, and erasure" (p. 197) of the homeless, which in effect signifies a desired "spatial cleansing" (Ferrell, 2001) of those perceived to present a threat to the social order and health of the dominant group in society. Ferrell (2001) points out that spatial cleansing includes a simultaneous cultural sanitation as when “...economic, political, and legal authorities work to recapture and redesign the public spaces of the city, they work to control public identity and public perception as well, to remove from new spaces of consumption and development images of alternative identity" (p.175).

Similarly, Phelan, Link, Moore, \& Stueve (1997, p. 325) observe that because many people have limited objective knowledge regarding homelessness, their perceptions are:

...likely to be influenced strongly by a small number of highly visible homeless individuals - visible either in the media or in their local community - who become salient because of their unusually dangerous, disruptive, or unaesthetic behavior or appearance...[which] may cause 
people to overestimate the prevalence of these characteristics in the homeless population.

Studies have found that poor public attitudes and intolerance of homelessness impacts upon the way the homeless are dealt with by authorities and leads to social distance between housed and unhoused persons, as homeless people find themselves stigmatised, excluded, and persecuted by informal and formal social control mechanisms (Amster, 2003; Lee, Farrell, \& Link, 2004; Lee, Lewis, \& Jones, 1992; Phelan et al., 1997). Within this process, homeless people are dehumanised and understood via ready-made categories rather than as individuals. Responses to homeless people perceived as a problematic societal category include anti-homelessness legislation and laws that attempt to monitor, control, and curtail the activities of homeless people in social space by targeting activities associated with homelessness for example, public sleeping, begging, or being intoxicated in public. The result is that an everyday concern for the homeless becomes one of balancing the tension between 'home' territories they regularly frequent (Wilkinson, 1980), and these public spaces, which are simultaneously open to all persons, and also regulated by the institutions of social control (Amster, 2003; Lee, Farrell, \& Link, 2004; Lee, Lewis, \& Jones, 1992; Phelan et al., 1997).

Mitchell (1997) contends that hand-in-hand with constructing the other as disorderly, it becomes necessary to locate some aspect of their behaviour and make it illegal. Despite assertions that this, in a positive sense, does not target the 'status' of individuals but the 'conduct' of such individuals, targeting behaviour nonetheless becomes the vehicle used to marginalise people perceived to be undesirable from public view. In the case of homeless people, this has seen a spate of laws passed in the United States prohibiting activities such as pan handling, pavement sitting or sleeping in public (Duneier, 1999). In fact, Duneier dedicates an entire chapter of Sidewalk (1999) to the frequent dilemma faced by homeless men when simply needing to use a toilet. He claims that as a consequence of ostracisation from public rest rooms, there have been cases when homeless individuals have then been arrested for urinating in a public place. Such laws, in forbidding the homeless any place to be, are argued to make survival itself illegal, and thus attempt to criminalise a whole class of people (Duneier, 1999., Mitchell, 
1997). Nonetheless, San Francisco's former Mayor Frank Jordan attempted to justify such action when reportedly saying:

...homelessness is not a crime. It is not a crime to be out there looking like an unmade bed. But if criminal behavior begins then we will step in and enforce the law (Howland, 1994 cited in Amster, 2003, p. 200).

\section{Constructions of homelessness and homeless people within New Zealand media}

As mentioned, in New Zealand where direct exposure to street homeless is far less frequent than that experienced overseas (O'Brien \& de Haan, 2000; Wellington City Council, 2004), media organisations may play a greater role in influencing public attitudes and perceptions of homeless people. Research by Lee et al (2004) usefully evaluates public perceptions formed both from first-hand exposure and via information received about homeless persons and homelessness. In examining the ways in which various forms of media consumption impact on public attitudes in the continental United States, the authors reported that any type of media consumption -including reading the newspaper- did not improve attitudes when it was the only form of exposure. It was found that information gleaned from the television, a passive activity requiring little critical thinking, had less affect than when reading about or discussing the topic of homelessness. Furthermore, mediaonly respondents were more likely to view homeless people as dangerous, and were less likely to support the rights of homeless people to public space or express a personal willingness to help homeless people (similar observations were made by Lee et al., 1992; Phelan et al., 1997). However, the authors also found that when face-to-face exposure to homeless persons was repeated or prolonged, anxiety, discomfort, and other negative responses were lessened, indicating processes of desensitisation. Pascale's (2005) research similarly observes that for most housed people in society, it is the news media that provides knowledge about homeless people and homelessness, rather than seeing homelessness on the streets.

So, how are representations of homelessness constructed within the New Zealand newspaper media, particularly in Wellington's newspaper reportage? Equally, how are homeless people categorised in this reportage on homelessness? 
In an earlier project (McGovern, 2005) I examined whether the newspaper media in Auckland, Wellington, and Christchurch could be seen to consistently represent homelessness and homeless people in negative ways. Findings confirmed that the New Zealand media overwhelmingly construct homeless people in the public imagination as 'dirty', 'diseased', and 'undesirable', as readers glean familiar messages underpinning the majority of accounts on homelessness.

The Wellington newspaper media, especially, reported on homeless people in ways emphasising them as an unwanted and dangerous presence in the central city. For example, Wellington's daily newspaper, The Dominion Post, included abundant reportage over several years surrounding a group of homeless people living in an inner city park. Among this coverage, one article reported that their long-term habitation in the space disgusted the Wellington City Council whose initiative was quoted as one that planned "to cleanse the streets of human detritus" ("Bylaw tweaking is a risky business," 2004). Likewise, retailers in the area, the police, and members of the public were reputed to share a similar view. The group, categorised by the Wellington newspaper media as the 'Glover Park homeless', were described as a mix of winos, glue sniffers, the mentally ill, and derelicts (Smith, 2005). Headlines admonished the group as Unreformed, unrepentant - the city's hard-line homeless (Johnson, 2003), while the Council's plans were said to be aimed at evicting the park residents ("Vanquishing the vagrants," 2004).

Wellington's Mayor at the time, Kerry Prendergast, was quoted as saying, in response to the loitering, drinking presence and behaviour of this group in public, "We cannot have that sort of behaviour happening in what is the front door to our city" (Allen, 2004). The article further details that Mayor Predesgast pledged that a stronger police presence would be put into force, and that local retailers and business owners were also petitioning for increased police support, as well as for closed circuit television cameras (CCTV) and a total liquor ban on the street. Another article informed that the homeless people in Glover Park had been given a port-a-loo, paid for by the Council, which had been forced into acting, given the area had become a public health hazard (McDonald, 2003). This was to be only a temporary measure, and a year later, it was again reported in The Dominion Post 
that there had been complaints about vagrants urinating and defaecating in Glover Park, as well as complaints about people sleeping and urinating in stairwells of inner-city Wellington City Council flats ("Vanquishing the vagrants," 2004). Glover Park was now described as off-limits by many members of the public; so too were other areas frequented by groups of homeless people who were said to be intimidating workers and residents through their presence and behaviour (Johnson, 2003).

By the following year, The Dominion Post was reporting that Wellington Police's Strategic Response Group had shifted to Cuba Street in a bid to step up their fight against offending by inner-city vagrants (Haydon, 2004). This was said to have occurred in response to concerns over the level of vagrancy and offensive behaviour of street dwellers (concerns raised by pedestrians, retailers, and residents). It was also reported that there had been about two hundred arrests in or around Glover Park in the first six months of that year. Readers were further informed that officers would hand-deliver letters to all retailers in the area, urging them to report any crime or anti-social behaviour by this group as soon as it happened. The majority of crimes committed by this group of homeless people were said to relate to issues of trespass, as bylaw legislation attempted to erase visible signs of homelessness by controlling the presence of homeless people in city parks and other public spaces (Haydon, 2004). ${ }^{18}$

\footnotetext{
${ }^{18}$ While it is not in the scope or interests of this chapter to offer a comparative analysis, two other newspapers examined in my earlier project (McGovern, 2005) also included some reportage on this group. For example, the Auckland-based newspaper The New Zealand Herald twice reported briefly on specific developments associated with the homeless people in Wellington's Park. The first article referred to the group having been moved into council flats ("Flats found for Wellington homeless," 2003), and the second informed that a Wellington human rights lawyer had won a case on behalf of five Glover Park homeless persons accused of breaching a trespass order ("Homeless win park trespass case," 2004). Conversely, Christchurch's The Press reported that their city councillors were aghast at Wellington City Council's proposed bylaw, which they believed was tantamount to "...bullying tactics from the chardonnay set", adding that sleeping rough was not yet an offence in Christchurch as being homeless was not thought to be chosen as some kind of career path (Tiffen, 2003). Christchurch City Council's policy was said to involve liaison with social services agencies working with the homeless rather than shoving the homeless out of sight, as was Wellington City Council's intention, evident in its proposed bylaw (Tiffen, 2003). In another article, Christchurch's then Mayor, Garry Moore, told The Press his Council believed, "A society is judged on how it treats our most vulnerable members. Christchurch rates well” (Claridge, 2005).
} 
However, not all Wellington homeless people were thought to constitute a social problem. As noted by Tonkiss (2003, p. 297): “...urban contexts have also been the primary sites for imagining and re-imagining forms of community, especially on the basis of shared social spaces or elective identities." In Wellington, an opinion piece in The Dominion Post by one journalist displayed a fondness for people he affectionately identified as 'loners', 'eccentrics', and 'itinerants', living in a city he considered non-conformist:

From lost wanderers to wayward geniuses, Wellington has always harboured people who don't fit the mould elsewhere...many identities from the 'Pigeon Lady', 'Upright Smoking Man' and 'Cowboy Braxton' to long term homeless men 'Bucket man' and 'Blanket man'. Streets, corners, and parks have all been arenas for social engagements of all kinds - with all kinds of people - in Wellington where no amount of rule making including: '...the council's hygiene police' has managed to flush out non-conformity (Kitchin, 2006).

Another column, written by a Londoner new to New Zealand and Wellington, remarked upon the unusual way homeless people are known by name, or universal nickname, to every other fellow citizen in Wellington (Fergusson, 2006). Fergusson, like Kitchen, pointed to how key players in the Wellington street scene are identifiable by names attributed to them by the public, which generally reflect some activity or item of clothing unique to the individual. Fergusson (2006) also alluded to how the identity of some 'vagabonds' attracts sympathy, while others attract a different form of attention entirely:

...Blanket man; he raises a head of steam whenever conformists spot him. His near-nude presentation and footpath address in Courtenay Place even raises hackles at the city council where good order and decency are said to be important motivators in the conduct of the capital.

Views like these exemplify a continuum of attitudes expressed via 'letters to the editor' and opinion columns of Wellington newspapers. Likewise, media reportage exhibits a dichotomy in attitudes, which can be seen in the reporting about two homeless men, Robert Jones and Bernett Hana (Brother), constructing them as two competing faces of homelessness. 


\section{Wellington newspaper media's homeless poster boys ${ }^{19}$}

Robert Jones (Figure 5:1) was known simply as 'Bucket Man'. The Dominion Post reported extensively on Jones after his sudden death in 2003. Within its reportage, Jones was portrayed as having been a private, quiet, gentlemanly figure who had chosen to live as a recluse. He was said to have been a humble, quiet, tea-drinking chap who had kept to himself and harmed nobody. It was further reported that Jones had lived rough in Wellington for over 20 years until he had walked out of his bush hideaway that morning; bedroll tucked under arm, birth certificate, bank statement, and will in hand, and knelt down in a city gutter, and died (Haines, 2003a). ${ }^{20}$ This posthumous construction of Jones fits with Laurenson and Collins (2007, p. 663) contention that 'good' homeless people are those who "largely abide by the written and unwritten rules of appropriate public behaviour". Moreover, as Laurenson and Collins have also observed, "sentimental "hobo" characters...while they are still "othered" - by virtue, for example, of their unusual appearance... and lack of conventional shelter - they tend to illicit sympathy and curiosity as opposed simply to fear and distrust" (Laurenson \& Collins, 2007, p. 663). Indeed, media reportage on Jones' funeral dominated the front page of The Dominion Post (Haines, 2003b) and informed readers that 600 people, from paupers to politicians, had attended his funeral. Mayor Prendergast spoke about what a 'good' homeless man he was (while the Council was simultaneously planning to slip through an amendment to the Wellington Consolidated Bylaw 1991 , prohibiting camping in public places). ${ }^{21}$

\footnotetext{
${ }^{19}$ New Zealand national television news providers also included news stories and footage of the funerals of each of these Wellington homeless men at the time of their deaths. National Radio and other independent radio stations also provided radio interviews with people working with the homeless. In Brother's case, radio interviews included the legal and academic voices from his lawyer Maxine Dixon, and myself as street researcher. Additionally, views and opinions surrounding the lives and deaths of these two men, though much more prominently so in Brother's case, were the subject of much talk back radio from time-to-time over the years.

${ }^{20}$ Renowned New Zealand author Maurice Gee later named Bucket Man as the source of inspiration for the leading character in his award-winning novel Blindsight (2005).

${ }^{21}$ The media also included reportage on this development planned by the Council (published the day before Robert Jones died). Readers were informed that, "The Wellington City Council are considering a bylaw that would sweep homeless people off the streets and arrest anyone sleeping in public. The bylaw, now being drafted, bans sleeping, camping and 'residential activities' in 94
} 


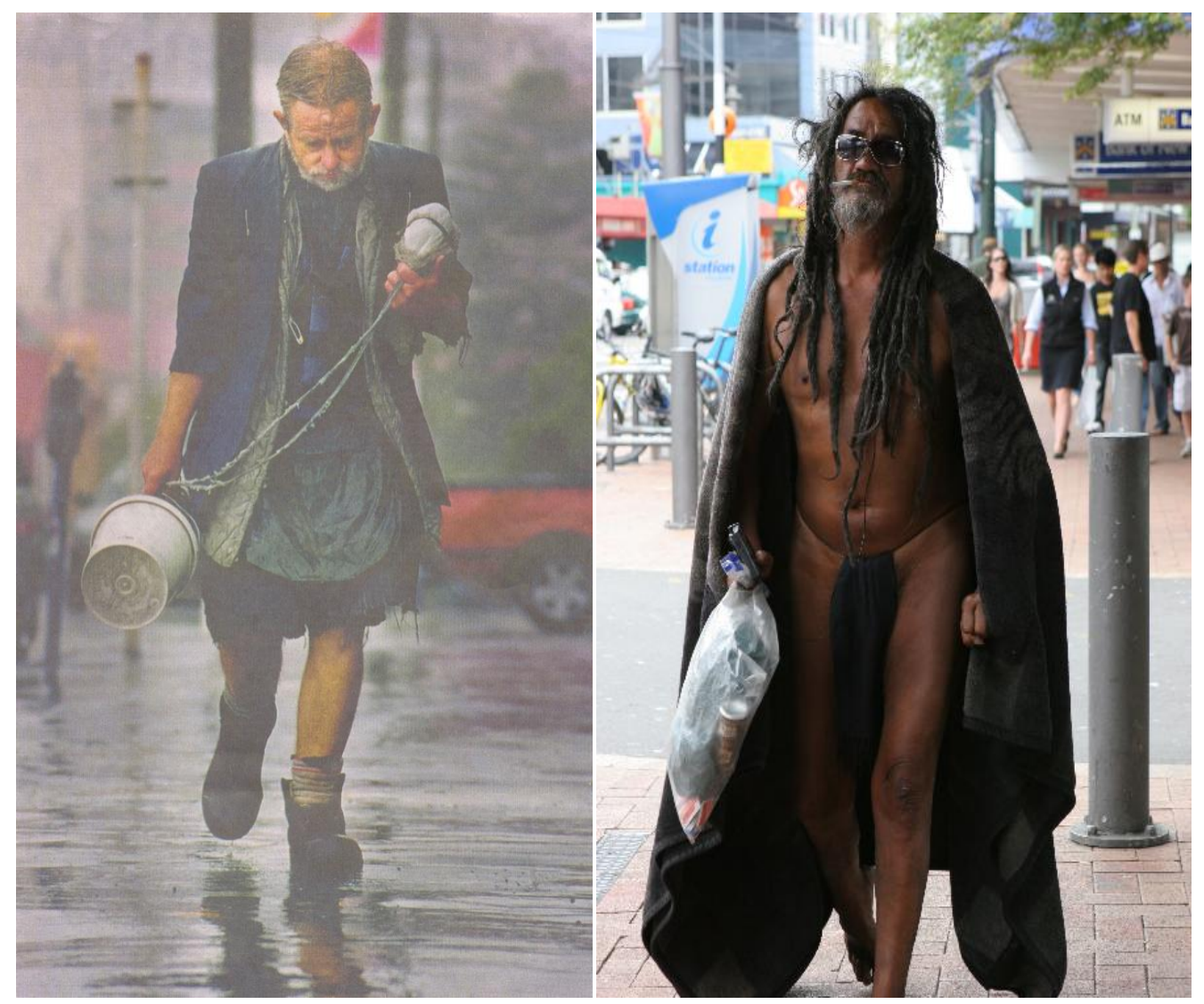

Figure 5:1 Wellington's Bucket Man and Blanket Man (Brother)

Sources: Haines, 2003b; Belinda Brown Photography, $2008^{22}$

In stark contrast to Jones, who was depicted as a harmless 'roving character', media reportage on Brother almost always focused on his law breaking behaviour. Further, language used by the media variously described him as a "manky nomad" (Tratt, 2005) or an "urban Tarzan" ("Urban Tarzan," 2007), ${ }^{23}$ reinforcing his status

public spaces and means the homeless can be moved on if people feel intimidated by them (Haines, 2003c).

${ }^{22}$ While the image of Bucket Man is from The Dominion Post, the image of Brother aka 'Blanket Man' was taken by Belinda Brown. Though The Dominion Post published a comparable image of Brother walking a city street clad only in his loincloth, it was taken from behind depicting a rear view of him. I have therefore chosen to substitute it with one of Brown's which shows each man face on to more clearly emphasise the visual difference between these men. Moreover, as will become evident in the chapters that follow, photographers from The Dominion Post do not shy away from opportunities to take raw imagery of Brother that in the extreme leave nothing to the imagination of its' readers'.

${ }^{23}$ In 2007, The Eastern Press, a weekly newspaper produced for Wellington's Chinese community (and published in Chinese) included reportage about Brother and his choice to live on the street, despite New Zealand having a welfare system in place. The article included a front page photograph of Brother, and four others within its pages. 
as feral and posing a menacing threat to the public. Because Brother presents as an anchored presence through his choice to dwell '24/7' on busy city street corners, everything he does - from smoking cannabis and drinking alcohol, to sleeping or basking near-naked in the summer sun - is highly visible to others, including the intrusive lens of the media's camera. Consequently, media reportage and accompanying images of Brother are usually focused on his illegal behaviour that occurs in public.

In the simplest interpretation, respective media constructions and associated images relating to these two long-term Wellington homeless men (only briefly sketched here) project a notion of 'good' and 'bad' homeless people. The work of Hodgetts et al. (2011) and Laurenson and Collins (2007) has also picked up on the media's tendency to contrast reports of 'bad' homeless people with portrayals of 'good' homeless people (see also May, 2003). This juxtaposition by the media produced a whimsical Bucket Man impression on one hand, with an ominous Blanket Man impression on the other. The media elected to refer to these men mostly as Bucket Man and Blanket Man, ${ }^{24}$ and so too did many people I observed interacting with Brother at the face-to-face level of the street. Though such naming may seem innocuous and while "Naming alone is never enough to create" (Hacking, 2002, p. 8), it nonetheless objectifies these men and draws attention to their frugal belongings. Crucially, as Hacking further notes, "naming occurs in sites, in particular places, and at particular times. For a name to begin to do its creative work, it needs authority. One needs usage within institutuions. Naming does its work only as a social history works itself out" (2002, p. 8).

${ }^{24}$ The voices included earlier which exemplified public opinion surrounding the city's more colourful folk, including the homeless and published in The Dominion Post, exhibit this practice of 'naming' through their use of colloquialisms identifying street people according to their clothing, activities, or gender. Likewise, my fieldwork, including casual conversations with members of the public, unearthed: Camo Lady, Two-Dollar Lady, Silver Sleeping Bag Lady, Kenny Rodgers, The Poet, and Balloon Man, among others who are similarly named and identified within the housed public's recitals of anecdotal stories about them. 
Language used by the media in more concerted efforts to construct these 'poster boys' epitomising 'good' and 'bad' faces of homelessness more clearly fulfils and achieves such an agenda. As Hacking points out, "Names do not work alone, as mere sounds or signifiers. They work in an immense world of practices, institutions, authorities, connotations, stories, analogies, memories, fantasies" (2002, p. 9). Hacking provides an example of the child that is called 'fatso' in the playground, citing the way such naming would bring hurt and possibly shame as 'fat' is despised. He expounds how 'fat' acts in a world of meanings connecting fat to "physicians, insurance companies, lovers, diets" (2002, p. 9). For those who know they are fat, their "world is invaded by instruments, scales, measuring tapes, tables prepared by actuaries" (p.9). The point that Hacking nicely illustrates here, is that 'fat' is no mere word. Just as the name 'homeless' is no mere word. It too, is 'inference rich' (Sacks, 1989) with the classification of 'the homeless' revealing social definitions of phenomena and 'social kinds', good and bad, but perceived predominately as the latter. Certainly, in the case of these two Wellington homeless men, media organisations played a pivotal role in naming, constructing, and categorising - contributing to 'good' and 'bad' homeless people becoming synonymous with the names Bucket Man and Blanket Man. Indeed, categorisation practices were and are occurring within the bureaucratic space of local politics. This was made evident in Laurenson and Collin's study of local government regulation of homelessness in New Zealand, with one city planner lamenting, “depending on what the context is we have lovely homeless and don't we care about them, don't we love them, and ghastly homeless, and we get awfully muddled" (2007, p. 663). 


\section{Tramps on the Net}

Exceeding the reach of newspaper readership is the world of the Internet, an alternative, interactive sphere, with social media platforms such as Facebook ${ }^{25}$ offering a 'tool and terrain' for 'making up' people. As a communication forum, the Internet enables the harsh condition of homelessness to be recast and even romanticised. One example of this light-hearted approach is manifest in the take below, suggesting technology might also be changing on-the-ground experiences of those 'doing homelessness'.

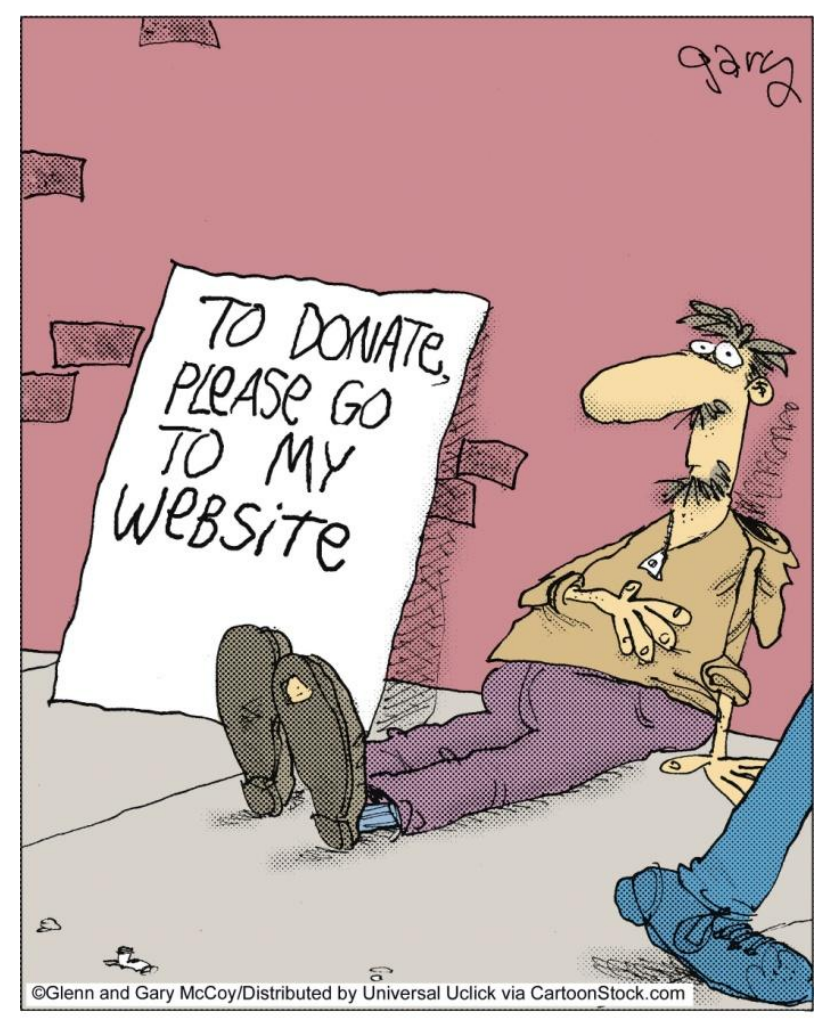

Figure 5:2 Internet wit

Source: www.CartoonStock.com (used with permission)

The phenomenon of Internet social media can exploit those without any private space of their own. That is, the virtual public that makes up the audience of the World Wide Web can voyeuristically peruse profiles of homeless individuals from around the globe at the click of a mouse. At their discretion, members of this

\footnotetext{
${ }^{25}$ www.facebook.com 
virtual public can pass comment, judgement, or even jest about a particular homeless person.

In 2006, The Dominion Post informed readers that Blanket Man had gone global via the online encyclopaedia Wikipedia, where he was described as an "iconic and integral part of Wellington's urban fabric" (Blanket Man, 2006). Various links were provided for public perusal, including an account of his judicial hearings and convictions relating to his past and ongoing conflicts with authority. Opinions expressed online by visitors to this site ranged from describing him as James K. Baxter's 'Māori Jesus'26 to denigrating him as a 'village idiot'. Today, Brother's Internet fame supersedes the Wikipedia page with which it began. His Facebook page has 28,000 'Likes' (Blanket man, 2009) and he has 1,300 'friends' on Myspace (Blanket Man, n.d.). Figure 5:3 shows a sample of posts on Blanket Man's Myspace page, reflecting public sentiment surrounding his choice to live in the open.

\footnotetext{
${ }^{26}$ James Keir Baxter 29/06/26-22/10/72 was a well-known poet and celebrated figure in New Zealand society.
} 


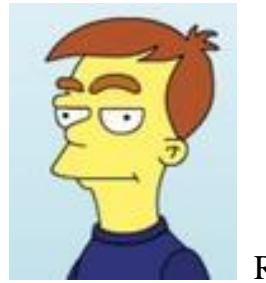

Read about you in the Dom-Post this morning, man. Press releases

AND Myspace? You're well sorted. But give us a call if you need a media rep, eh?

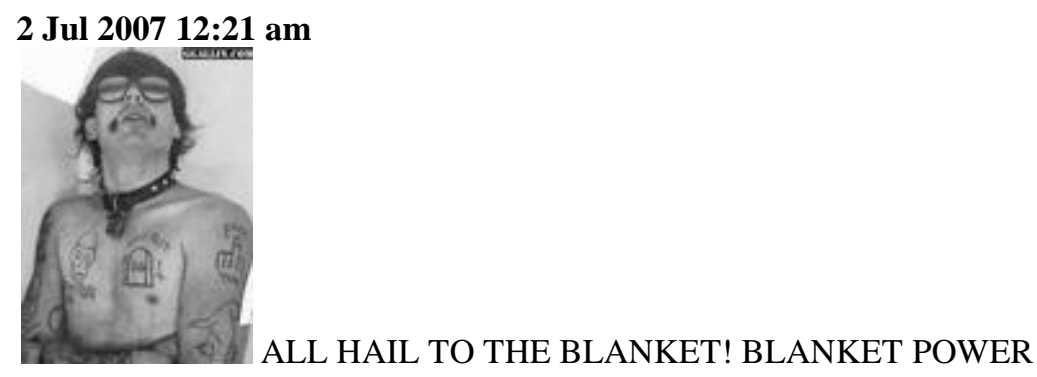

16 Jul 2007 6:02 pm

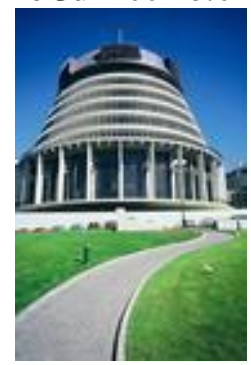

From one capital city icon to another. I feel you bro. I really do. It's a tough life being on centre stage 24-7. Keep it real blanket man. :D

Figure 5:3 Comments posted on Blanket Man's Myspace page

Source: Blanket Man, n.d.-a

Besides Brother, a surprising number of homeless people have Web presence. A New Zealand website, Tramp Stories (www.trampstories.co.nz), profiles a dozen homeless people from around the country, projecting images and information globally, into the lives of housed people. Another website, Top Tramps ${ }^{27}$, part of the comedy website www.funnyordie.com, profiles homeless people from around the world (dubryferkin, 2011). Among these people is Gordon Robert, a wellknown character and resident of Bournemouth, United Kingdom, who is better

${ }^{27} \mathrm{http} / / / \mathrm{www}$. funnyordie.com/lists/4aebb83a80/top-tramps is a website that profiles a selection of 'top tramps' or homeless people from around the world. Each person's real name and geographical location is provided. This is followed by a list of other information under the following headings: famous for, rumours, Facebook page (link provided), video (link provided to any videos), DoA (dead or alive status), fame rank, and skill rank. 
known as 'Gordon the Tramp'. His fame rating on Top Tramps is four out of five and Gordon is described as famous for always knowing the time despite not owning a watch. In 2011, thousands of Gordon fans responded to an advert calling for people in Britain to nominate local heroes to the London Organising Committee for the Olympic Games as potential Olympic torch bearers (Pyatt, 2011); the Facebook page set up for this cause has over 18,000 'Likes' (Gordon Roberts (Gordon the Tramp) for Bournemouth's Olympic Torch Bearer, 2011). Figure 5:4 shows how this social phenomenon was reported on by the British newspaper media.

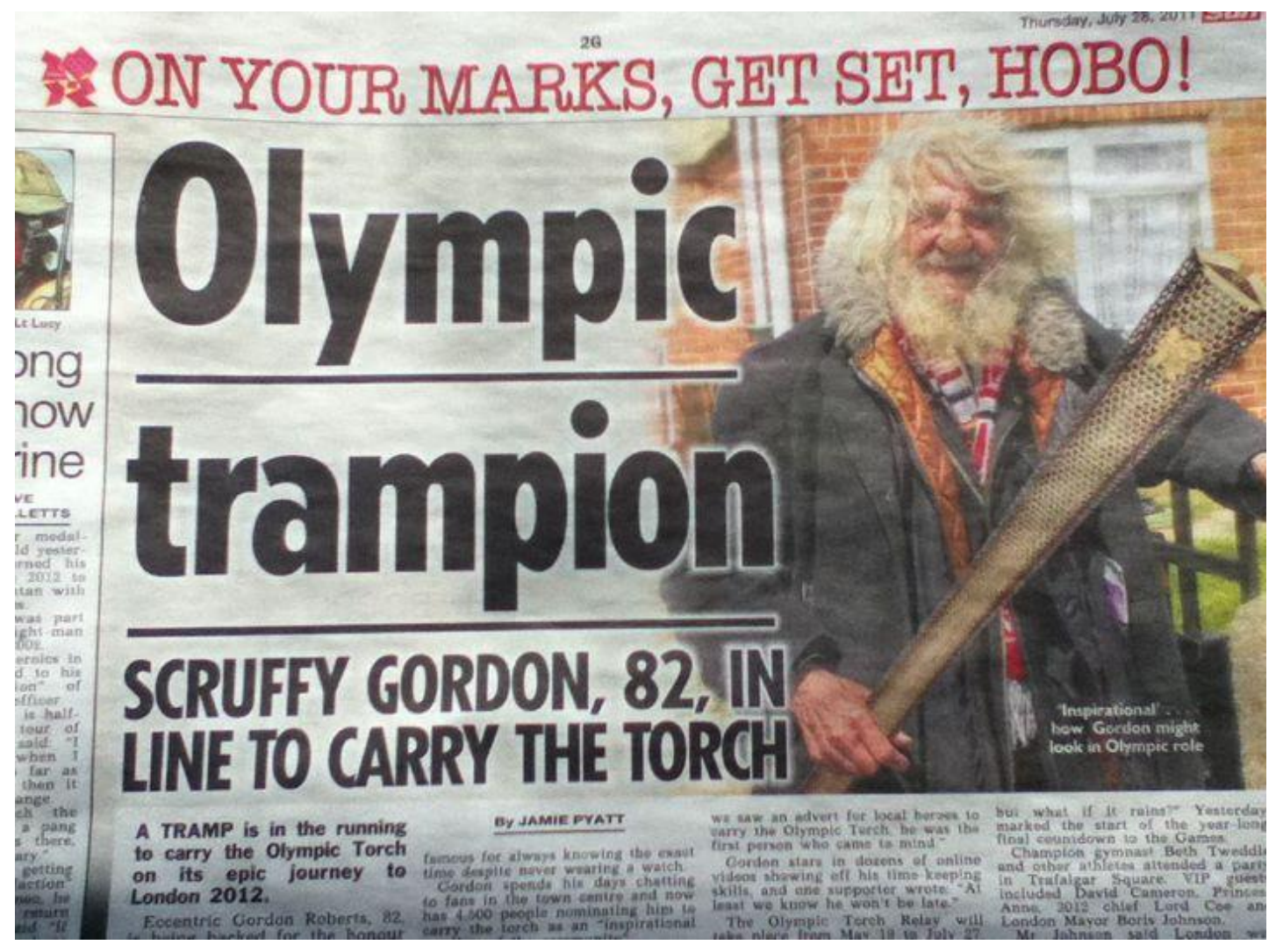

Figure 5:4 A British example of the championed 'tramp' status of an individual

Source: Pyatt, 2011

Toying with language is evident in Figure 5:4 - including referring to this homeless individual as an 'Olympic Trampion' - challenging normative understandings and playfully connoting new status to an individual who is otherwise understood to belong at the bottom of the social hierarchy. The inclusion of a doctored image portraying Gordon holding the Olympic Torch with the news 
media reportage on this individual invites the reading public to imagine how this 'new person' being propelled into being might look.

Surpassing Gordon's ranking on Top Tramps is a Chinese man, referred to as 'Brother Sharp', and also known as 'The Beggar Prince' and 'The Handsome Vagabond'. This man's real name is Chen Guorong and he had a top fame ranking of five out of five on this website. His top rating is attributed to his status as, "the hottest homeless man that ever walked the streets. Certainly in China anyway" (dubryferkin, 2011).

Chen Guorong was photographed (by a professional photographer) on the streets of Ningbo in China, and his image was posted on the internet. Not long after, fashion designer Vivienne Westwood's Menswear Fall 2010 collection, which first showed at Milan Fashion Week, featured the theme 'Homeless Chic'. ${ }^{28}$ Figure 5:5 below shows Brother Sharp on the street juxtaposed with one of Westwood's models on the Milan catwalk emulating his layered 'look'.

\footnotetext{
${ }^{28}$ Westwood's presentation of models styled to look like stereotypical rough sleepers was a move prefigured by Ben Stiller's (2001) satirical film Zoolander, which featured a similar fashion show called Derelicte.
} 


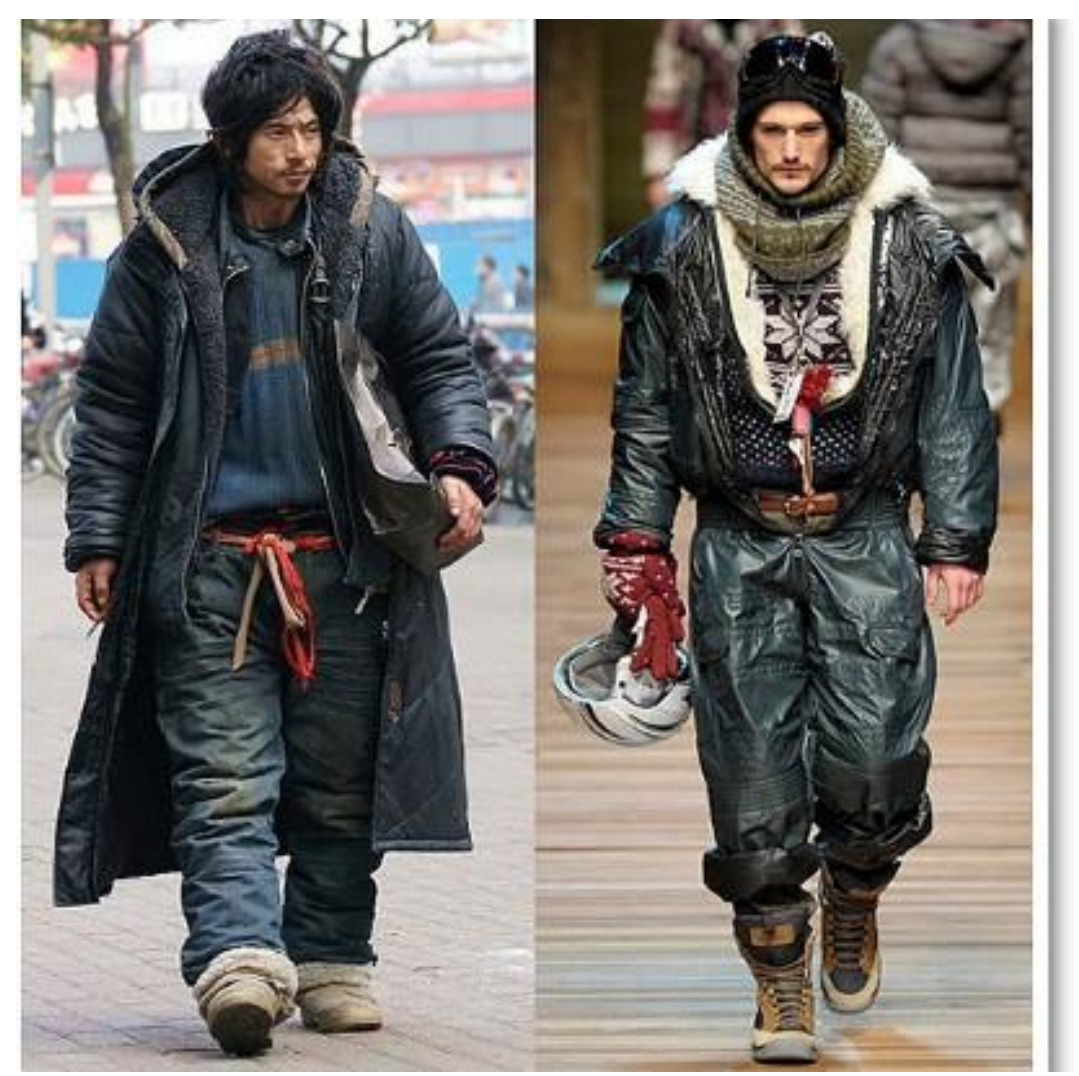

Figure 5:5 Brother Sharp and one of Westwood's 'Homeless Chic' models at Milan Fashion Week

Source: Nicholls, 2010

An article reporting on Westwood's use of the homeless man as a fashion icon was published in Wellington's The Dominion Post newspaper ("Homeless chic on Milan catwalk," 2010). The article states that several-hundred fashion experts had burst into rapturous applause and cameras had flashed when her collection opened with a dishevelled model emerging from a cardboard box. Styled upon the notion of the roving vagrant, Westwood's display included a catwalk carpeted with cardboard, upon which models with unkempt hair, dirty faces, and sporting faux frostbite, sashayed or pushed shopping carts while carrying sleeping bags or bedrolls. Her stereotypical depiction of belongings homeless people are commonly thought to possess similarly accords with Pascale's (2005) point made earlier that referenced how the value of homeless people's possessions can be disregarded through particular language that is used to describe them. At the same time, her focus on the objects homeless people are understood to have both emphasises the rough sleeping element of homelessness and the way homeless individuals are often poorly attired. Westwood's show symbolises the way representations or 
symbols of homelessness can be adopted when transporting homelessness into something hip to be adopted by 'the beautiful people'.

Duneier (1999) denies there is any romance to be found in the experience of homelessness. Westwood's approach, which reduces the serious issue of homelessness to a fashionable condition, ultimately joins an emerging shift in attitudes romanticising the harsh condition of homelessness. Betensky's (2004) essay, Princes as Paupers: Pleasure and the Imagination of Homelessness, for example, evaluates the practice of people in positions of power deliberately opting to experience homelessness. According to Betensky, by impersonating the poor in their own milieu, they supposedly seek to draw sympathetic media attention to the plight of those sleeping rough. A city street corner dubbed 'the grate American sleep out' in reference to heat that permeates from street vents (grates) remains a popular choice. Betensky notes the survival and acting techniques to volunteers wishing to take the 'urban plunge' and survive a weekend on the streets. However, the novelty factor intrinsic to 'roughing it' over a weekend is made transparent by certificates that are awarded to successful 'plungers' when they complete the weekend.

Furthermore, while Westwood's collection suggested homelessness is an issue mostly affecting men, she nevertheless distinguishes various types of homeless men. For instance, a man in an orange boiler suit, likely intended to represent someone who has been jailed for vagrancy, and another wearing a crown and army ribbons, supposedly intended to portray the homeless war veteran. It is through an emphasis on stereotypical caricatures of homeless men via clothes and props that Westwood was largely able to extend a notion of homelessness as a playful concept to a privileged audience.

Processes that elevate the status of some homeless people to that of loveable rogue, can, paradoxically, lead to the 'unmaking' or 'unravelling' of the homeless person. While Gordon the tramp was described as 'well chuffed' and enjoying the attention of the masses in his everyday street life (Kevan, 2007), Brother Sharp did not fare so well with unwanted fame. Images and tales of Brother Sharp spread 104 
rapidly through Chinese image boards and chat rooms, turning him into an overnight Internet sensation and bringing much attention from people who saw him in public. Brother Sharp was reported to react by "shed[ding] tears and even yell[ing] at the heavens" ("Leave Brother Sharp alone," 2010) whenever people photographed him or attempted to interact with him on the street.

Brother Sharp's response fits with Goffman's theorisation of 'looping' - the unmaking of the person which, to reiterate, encapsulates the cyclic affect of responses to humiliation that are experienced at the interpersonal level of face-toface interaction. Though for Brother Sharp, an unprecedented degree of unwanted attention and public interference in his daily life allegedly tipped the balance, turning his street life existence into an untenable invasive experience (China Daily, 03/08/10).

Quite apart from the ability of the newspaper and online social media to pick up and amplify the nature of a person or group, an abundance of stories propagated via word-of-mouth by housed residents of Wellington often speculate about various individuals living in open space. Often these tales contain information about what these people may have been seen doing or they claim to profess knowledge about various homeless people's biographies. If one were to buy into this abundant local lore, then, 'Bucket Man' was a millionaire when he died, 'Blanket Man' has a law degree, and 'Blanket Man's' daughter was seen riding a train while heavily intoxicated and eight months pregnant. ${ }^{29}$ Indeed, there seemed no end in regard to the sheer volume and diversity of 'Blanket Man' - and to a lesser degree - 'Bucket Man' stories - that were told to me in casual conversation whenever I divulged I was studying street life in Wellington. People often shared

${ }^{29}$ It was not uncommon for such stories to also include information about homeless people's families, which is suggestive of the influence, families are understood to play in creating people. Moreover, as exemplified in the anecdote surrounding Brother's daughter, whether 'true' or 'imagined', a notion of bad is extended and applied to one of his offspring highlighting immoral behaviour in the case of his pregnant daughter. Conversely, what role families might also have had in contributing towards the unravelling or 'unmaking' of the person is also evident in ordinary people's sense-making, which attempts to contextualise and identify circumstances that might be responsible for precipitating a demise leading someone into homelessness. 
their views with me when I was in situ with Brother during fieldwork. On one occasion, a middle-aged man's view was not verbally expressed, but rather was shared via the small written note that he silently handed me as he passed us by in the street (Figure 5:6).

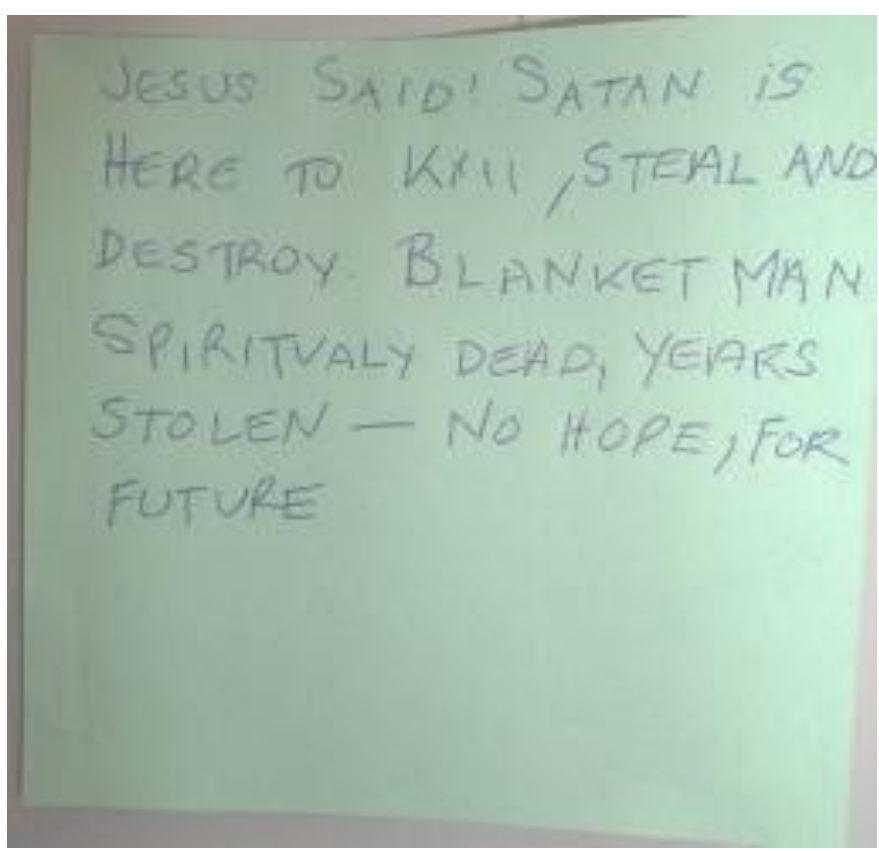

Figure 5:6 One pedestrian's view, expressed in a note

Source: Author, 2010

So far I have discussed some of the ways homeless people are made up in the media, on the 'Net, and in the everyday talk of individuals, with the latter briefly illustrated through letters written to newspapers and in local lore that identifies, names, and categorises. The role of language in making and unmaking people also occurs in other, novel, more subtle or opportune situations. When passing the Wellington Night Shelter one evening, for example, I noted that the letter ' $\mathrm{K}$ ' had been added to the Shelter's sign, prefacing the word 'night' (Figure 5:7). 


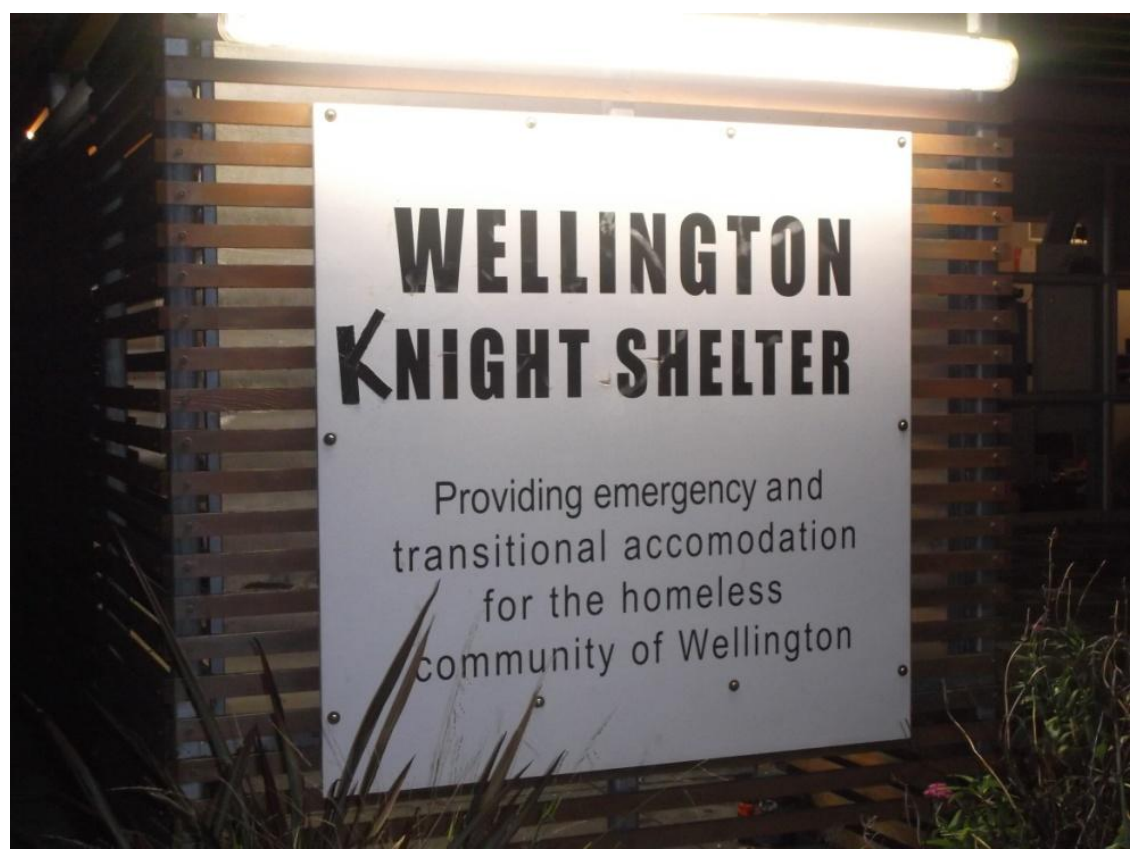

Figure 5:7 A letter added to signage outside Wellington's homeless men's shelter playfully elevates the status of the city's poorest, most marginalised citizens

Source: Author, 2012

The simple but effective inclusion of this letter playfully elevates the status of the shelter's homeless inhabitants, a group otherwise commonly understood as occupying a low social position. Turning 'night' into 'knight' could have been intended to stimulate other challenging propositions in the public's imagination. Perhaps aligning homeless men's status to that of knights plays with suggestions such as that found in the proverb foretelling that 'the meek shall inherit the earth'. Alternatively, transforming 'night' to 'knight' could have been intended to imply that for homeless men, it is only within such shelters that they are able to 'remove their armour', let down their guard, and rest in the relative privacy provided by the Shelter's respite at the end of each day. At minimum, a shelter for knights extends a light-hearted attitude of worthiness towards shelter users - men that the hostile city ordinarily shrugs aside. Conversely, the toying with language evident here, can also be interpreted as a form of public 'piss-taking' or mockery of people that are commonly perceived to have low social status in society.

Recapping briefly, this chapter has explored how discursive processes contribute towards creating dominant constructions of homelessness and homeless people. In particular, the media has been shown to be a key player in actively interpreting 
homelessness in a predominately negative light. I have further shown, in the Wellington context, the important role media constructions have in shaping broad social definitions regarding homeless people themselves. As a 'given kind' (Hacking, 2007), homeless people are generally perceived as 'dirty, diseased, and undesirable'. In turn, a classification of homelessness is predominately viewed through a social problem lens. As outlined earlier, Hacking's analytical framework identifies that as knowledge increases, the classified become defined through definitive properties, which loops back to affect those classified through measures designed to control, help, organise, and so on. So far, I have alluded to how this 'looping back' can affect 'on the ground' experiences of homeless people in public space. I have also highlighted how media reportage encourages the public to believe that policy and law can eradicate society's scourge, and subsequently influences further calls for the implementation of punitive but often futile measures. Further, I have demonstrated how The Dominion Post constructed competing faces of 'good' and 'bad' homeless people through representations emphasising the 'lovable rogue' versus the 'manky nomad'. I have also considered the role online social media and a fashion designer can have in contributing to constructions of homeless individuals. I have clarified that classifications of homelessness have been found to manifest in established responses taken towards homeless people living in cities overseas (Amster, 2003; Ferrell, 2001). The next section will explore how the classification of homelessness impacts upon those classified as 'the homeless' in Wellington. In particular, I focus on how these people are dealt with by the authorities.

\section{Local responses to homelessness in Wellington}

In 2004, street dwellers became the focus of much public and political attention. Wellington City Council proposed a public places bylaw that would prohibit rough sleeping in the city, particularly in response to public distaste about people living in an inner-city park, Glover Park. The very next day, Robert Jones, a familiar homeless figure, died on the street, which was front page news. The synchony of these events acted to heighten awareness and concern about rough sleeping, which eventually saw the establishment of a Council-led taskforce charged with 
developing a strategy for responding to homelessness (Wellington City Council, 2004).

The resulting Homelessness Strategy (Wellington City Council, 2004) was a strategy in name only. Much of the document covered what the Council and other agencies do that relates to homelessness, with no suggestion of a comprehensive strategy for what would or should be done in the future. The 'strategy' did, however, lead to the establishment of Project Margin, a project between the Council and a social service agency to assist homeless people into and help them manage social housing. At the same time, the public places bylaw was quietly passed. While the Council used a broad definition of homelessness, including all people without access to safe, secure, and affordable accommodation, their subsequent actions - focused on street dwellers and control of public space revealed that their actual definition of the population of interest was much narrower, focusing on those who were thought to 'make the most trouble'. The Deputy Mayor, in a speech delivered at a public forum, made clear that in the Council's "fight against homelessness", protection of the environment was their principle concern (Ian McKinnon, speech at homelessness forum, 2007). This illustrates that the 'working classification' used by institutions of social control is not necessarily the one enshrined in their official documents. It is worth noting that Wellington City Council is currently developing a new homelessness strategy, $T e$ Mahana, with the stated target of ending homelessness in Wellington by 2020 (Wellington City Council, 2013).

Focusing on the case of Glover Park, in the next section I demonstrate an example of the Council in action as it managed its 'fight against homelessness' by reclaiming public space for the people. I begin by briefly considering how a concept of public space can be understood here in relation to homeless people. 


\section{The case of Glover Park}

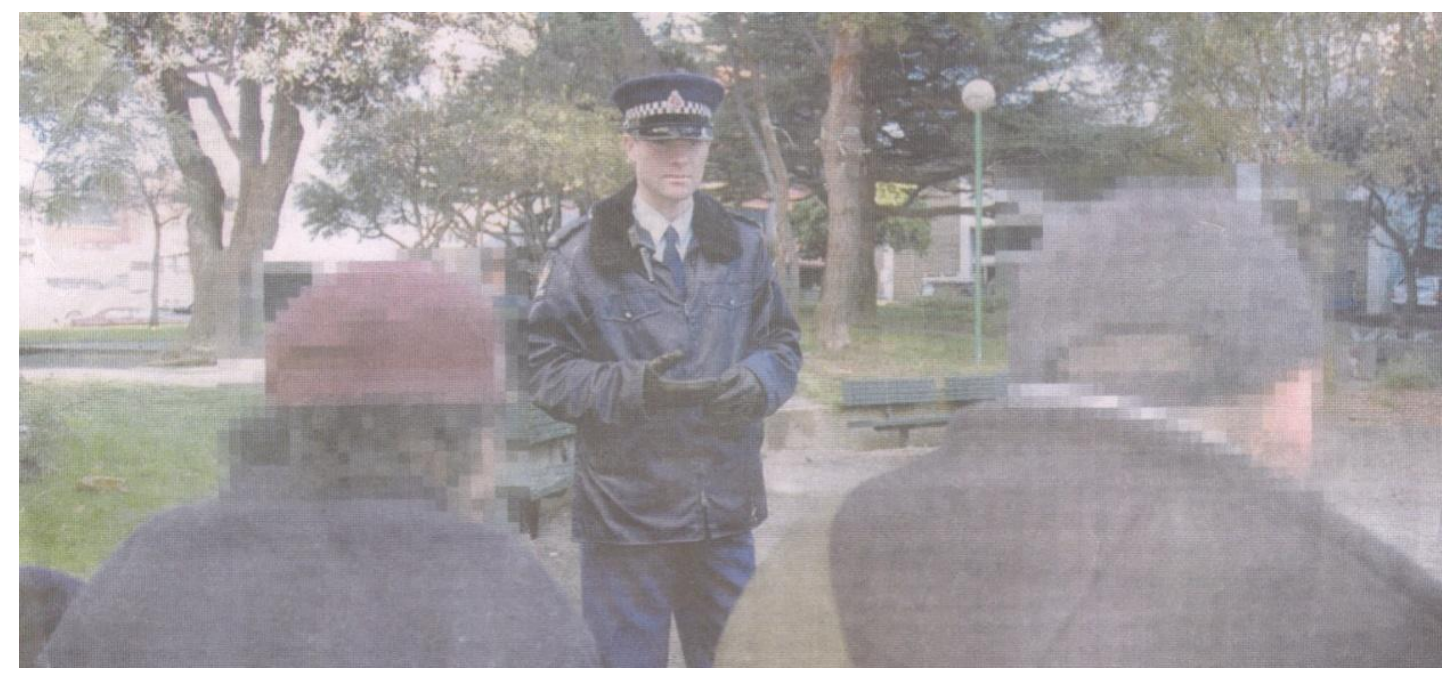

Figure 5:8 Glover Park

Source: Smith, 2005

Public space is conceptualised as being far from a neutral construct (Lefebvre, 2000, Mitchell, 2003). Instead it becomes a contested space over who has right to the city (Ferrell, 2001, Sibley, 1995). As street dwellers have no private space of their own, the effects of public space becoming more exclusive (excluding them) are further marginalisation and displacement (see Cooper, 2001).

On a similar note, Kawash (1998) considers the homeless problem as it appears today in the dominant discourse of media and politics is not seen as a problem of the economy or the society that produces homelessness. Rather, as Kawash argues, it is viewed as a problem that the homeless create for the economy and society in which they live. Accordingly, the problem confronting policy makers becomes not so much how to help the homeless but one that is more concerned with how to protect the public from them.

Laurenson and Collins $(2006,2007)$ investigated local government responses to homelessness in New Zealand and found that broadly speaking homeless people were reported as generating discomfort as opposed to outright fear. This was said to lead some people to avoid places where homeless people were known to gather. Indeed, conflict between homeless people, housed people, and who has the right to use public space and how, is highly evident in Wellington where homeless 110 
persons' activities conducted in public space are often targeted and criminalised (see also Duneier, 1996). In this vein, though public space is simply defined in New Zealand as spaces which are intended for public use and may be publicly or privately-owned (Ministry of Justice, 2007) and though New Zealand has no formal anti-homelessness legislation per se, it is here that homeless people often face exclusion as a result of other informal and formal social control mechanisms. Within such mechanisms, homeless people are not ascribed moral or legal subject status but rather, as made transparent in Wellington City Council's admission earlier, they become "unsightly rubbish to be removed, objects with limited aesthetic value" (Walby \& Lippert, 2012, p. 1029) who are hidden from view through dispersal strategies.

The images below show Glover Park as it underwent transformation in 2005. Though the hoardings surrounding it prohibited access to all while under renovation, local artists were invited to create murals upon the construction hoardings as an attractive alternative to otherwise plain barricades. Several of the works recognised the parks former inhabitants as illustrated below.

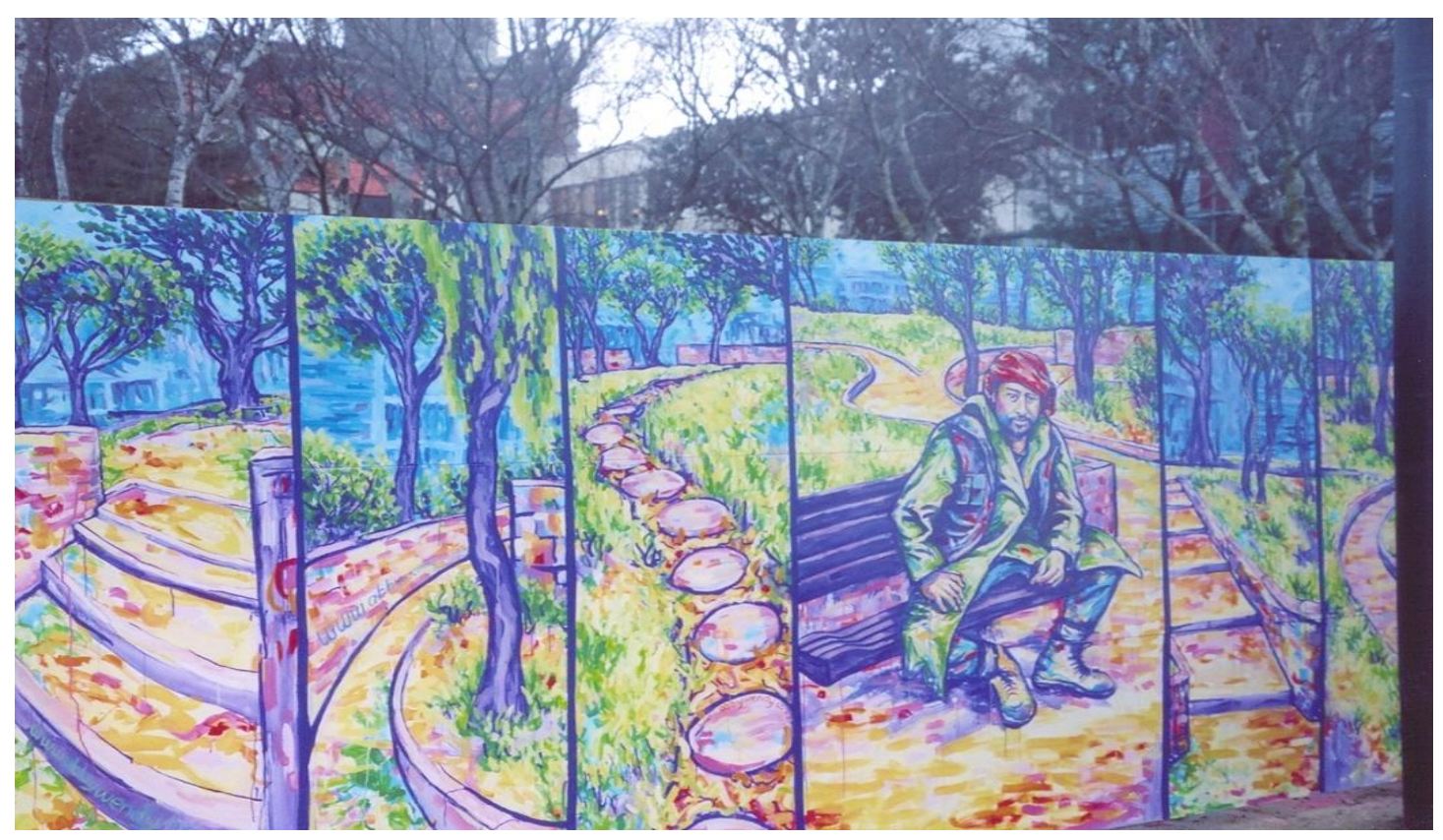




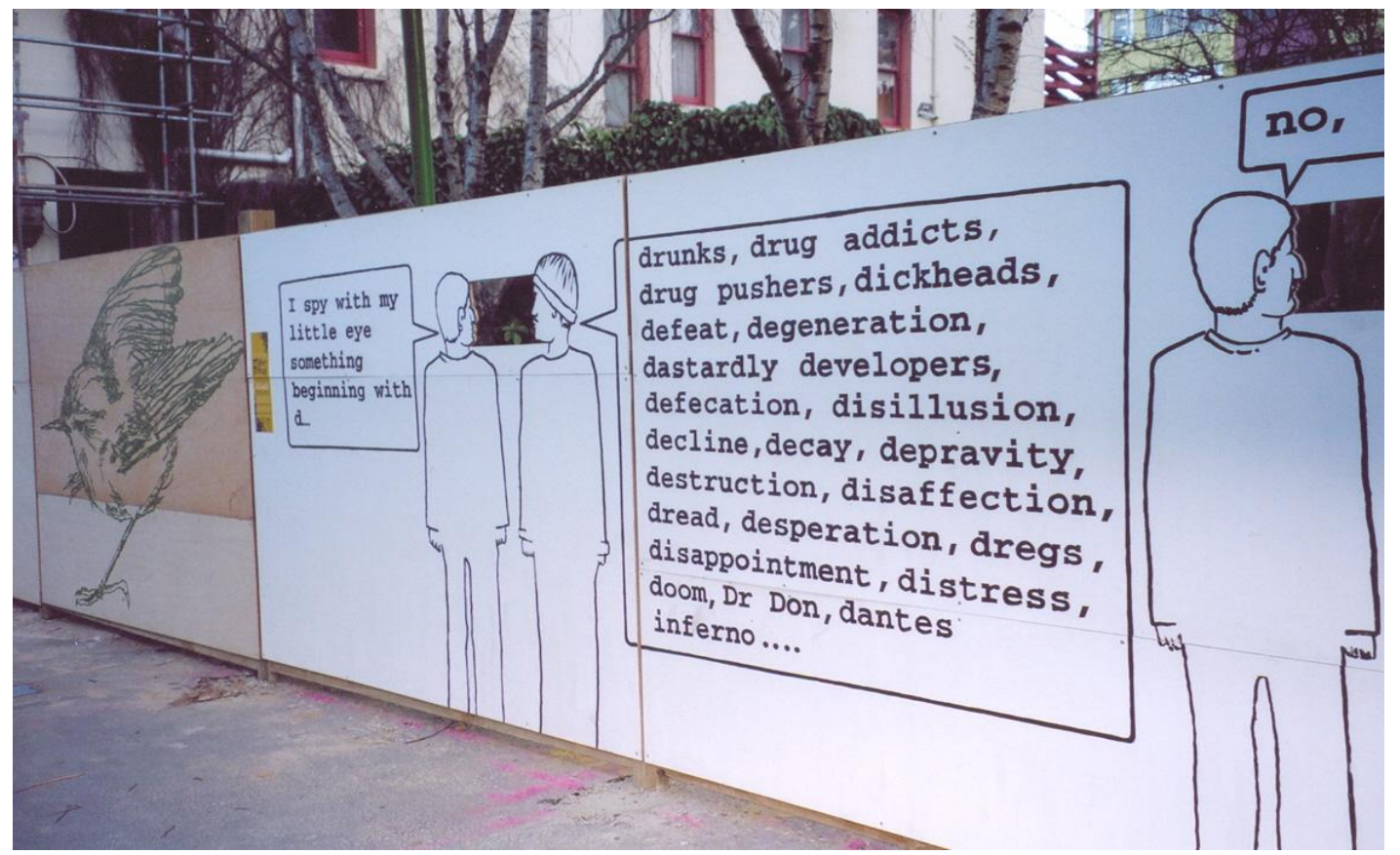

Figure 5:9 Hoardings erected around Glover Park, showing a yesteryear tramp and referencing homeless occupants

Source: Author, 2005

While the first panel nostalgically depicts a solitary tramp resting on a park bench, the second, by artist and concrete poet 'Nia', clearly references the gloomy underbelly of urban life as the newspaper media had repeatedly portrayed it over a long period of time. The panel shows a game of 'I Spy'. Suggested answers for something beginning with ' $\mathrm{d}$ ' included: "drunks, drug addicts... degeneration... defecation... dregs". The negative reference to the park's former inhabitants evident on this hoarding reinforces stereotypical imaginings of 'dodgy' homeless folk commonly understood as addicted, diseased, and undesirable.

Following the $\$ 1.5$ million upgrade of Glover Park and during the subsequent official opening day formalities of the restored park, Mayor Prendergast publicly acknowledged that Wellington City Council's goal had been to strategically renovate the space in such a way that the park's former homeless people would not want to return. Confirming that the Council had sought expensive international health and safety advice when planning the new look park, Prendergast had explained:

This space was previously taken over and privatised by a small group of people who lived in it 24 hours a day...the council's initiative has been to 
redesign a park that is brighter and better for us all...a sanctuary and safe place for people to use and reuse, one that is welcoming for everybody (Mayor Prendergast, speech at Glover Park opening, 2006). ${ }^{30}$

Prendergast - unwittingly perhaps - confirmed that a process of "exclusion, eradication, and erasure" (Amster, 2003, p. 197) was undertaken by the Council in order to rid the space of homeless people who had, for many years, inhabited the park as a home in open space. Proclaiming that the space was intended to be inclusive for everybody's use and enjoyment was contradicted by the Council's recent actions. Simultaneous with the furore unfolding in response to homeless people inhabiting Glover Park, and the eventual strategies employed by Wellington City Council to successfully remove them as I have described, were other processes designed to purge visible manifestations of homeless people from other city spaces. For instance, a process began to remove and replace old wooden bus shelters around the city known to be providing temporary homes for homeless people. The glass-sided shallow replacement shelters in existence today do not provide adequate protection from the elements and therefore deter anybody from wanting to live in them.

Other developments saw the introduction of a liquor ban, enacted in 2003, which criminalised public drinking in a designated city zone during specified hours. While not aimed specifically at homeless people, it was implemented in an effort to control a perceived public-place drinking problem, of which the media were reporting homeless people were a significant part ("No quick fix," 2005; Scott, 2004). By 2006, a general perception held the liquor ban was having very little effect, with police themselves admitting they tended to resolve liquor ban breaches by way of a cautionary warning initially, with enforcement not given high priority (Sim, Morgan, \& Batchelor, 2005). Nevertheless, The Dominion Post informed

\footnotetext{
${ }^{30}$ A United States study (Mitchell, 1995, p.110) examining reactions surrounding the proposal, closure, and subsequent redevelopment of People's Park in Berkeley, California, found similar language was employed by joint City-University stakeholders to justify developments to protestors. For example, a university spokesperson described how the "space had to be reclaimed and redefined for 'an appropriate public"'.
} 
Wellingtonians that Wellington City Council was being pressured by retailers and business owners, who were described as feeling "fed up to the back teeth" by the street drinkers who had been congregating daily in Cuba Mall ever since the closure of Glover Park (Scott, 2004). Complaints were instrumental in the ban eventually undergoing review, leading to the Council's 24/7 Liquor Control Bylaw coming into effect in July 2008. This includes a far greater geographical scope prohibiting the consumption of liquor at all times.

During 2005, closed circuit television cameras were introduced at junctions and known gathering points around the inner city. In addition, the Council created roles for safety officers who were tasked with a street patrolling responsibility. These Walkwise officers are described by the Council as 'city ambassadors', whose role was designed to prevent and reduce crime and anti-social behaviour through their visibility (Sim et al., 2005). While it is also the role of Walkwise officers to notify police about any concerning behaviour exhibited by street people, during my fieldwork, I noted that Walkwise people (along with parking wardens and street cleaners) were considered by Brother in mostly friendly terms. That is, from my street observations, their working the streets was interpreted, at least from where Brother sat, as their also being 'of the street'. Field notes recorded ongoing interactive relationships observed between Brother and various street workers. These casual but consistent relationships can be likened to those that occur between neighbours with much of the banter reflecting the type of exchanges one might otherwise expect to hear passing 'over-the-fence'. For example, remarks about the weather, the immediate environment, or any disturbances or events having recently occurred or that were occurring, were often ruminated upon in brief conversations.

Evident within these discursive practices I have described is an evolving body of popular and expert knowledge. As Hacking (2007) claims, these two types of knowledge can appear to shade into each other regarding understandings about classifications and those classified. I have revealed how people categorise and name, distinguishing at a most basic level notions of 'good' and 'bad' homeless people. Significantly, discussion has pointed to the interactive relationship 
between human categories and specific locations in social space such as Wellington's Glover Park. To progress this further, I next attend to the role of material conditions and concrete social exchanges observed between individuals at the interpersonal level of face-to-face interaction. Drawing from fieldwork observations conducted in a range of city spaces involving various homeless people, including Glover Park's former residents (who were labelled the 'unreformed, unrepentant, hardline homeless' in media reportage), I discuss how people are made up 'on the ground' within mundane everyday social interactions. The aim is to understand more specifically how Wellington street people are constituted and defined socially and spatially. Attending beyond just what we 'say' to include what we 'do' allows for an alignment with Hacking's (2004) assertion that we live in a classified world where naming alone is never enough to create; therefore, we must concentrate on the interaction between classifications and people classified. Moreover, for Goffman, it is within the ordinary dynamics of social interaction that people are constituted and defined. In the next section, I follow in the tradition of Goffman's method, described by Hacking (2004, p. 278) as 'bottom up', given that Goffman's idea of 'looping' was concerned with understanding how forms of discourse affect the social relations and the lives of ordinary people in everyday situations.

As my discussion on methods clarified, fieldwork was conducted in a range of city spaces where street people gathered - from paved pedestrian malls to grassed parks - in order to achieve clear first-hand understanding of street life in the city. Once fieldwork was established, I began to formulate ideas about the ways street life is lived out in the city. I was initially struck with the way homeless people were able to be observed leading highly visible lives as they hung out in popular city locations. Sometimes these groups were made up of twenty or more people. Their way of inhabiting space contrasts markedly with portrayals of homeless people overseas. Increasingly excluded from public space, they spend their time in exile, often existing in perpetual motion not because they have somewhere to go but precisely because they have nowhere to go (for example see, Kawash, 1998, Waldron, 1999). In the main, studies from the United States and the United Kingdom describe homeless people as occupying peripheral or marginal spaces 
identifiable as those "spaces outside the marked and named space" (Chiu, 2009, p. 32) of the inner city. Consequently, these spaces can generate a sense of isolation, exclusion and boredom. Alternatively, occupancy of prime spaces, when it does occur, is said to happen mainly during off-peak or marginal times when the space is not as heavily occupied by mainstream members of housed society (for example see Mitchell, 2003).

'Hanging out', regardless of whether it occurs in prime or peripheral space, is an importantly recognised feature of street life that is characterised by Duneier (1992) as a socio-spatial practice capable of concretising group dynamics. Similarly, Chiu (2009) argues day-in and day-out routine spatial practices inscribe the physical domain with alternative and profound meanings as a lived space is carved out. Sennett (1990) articulates a similar argument in his conceptualisation of "narrative space' becoming a physical domain invested with emotional and symbolic meaning through human agents embodied and emotional experiences.

The first fieldwork vignette describes a group of homeless people who, on other occasions, formed part of a larger contingency frequently observed in Cuba Mall hanging out in this busy pedestrian space. Consequently, the banal scene accords with Duneier's (1992) assertion that it is routine, repetitive practices that characterise individual autonomy and engender collective solidarity:

The same people are usually present at similar times each day or week. But gatherings do not necessarily occur among them with that same regularity. Collective life does not consist of a continuous flow of interaction among all the members. It is, rather, a now-and-then phenomenon that occurs with some unpredictability, in varying arrangements, from day to day (Duneier, 1992, p. 35).

\section{Street living room}

A clear brisk winter's day, I observe people loitering or traversing the space of Cuba Mall. On my right, two Gothic women wearing layers of black clothing and dark lipstick stand rolling cigarettes and talking. To my left, a group of five middle-aged, bearded, beanie-wearing males are seated beside Wellington's iconic Bucket Fountain. At their feet a sleeping couple lie entwined around each other. 
"It's quite busy around town today" one man says. "Yip" agrees another. "Where's Granite these days?" he asks. "Walking around" explains another. A bottle of white methylated spirits passes from man to man. One man gives the neck of the bottle a cursory wipe with the cuff of his coat before taking a drink. Another man coughs and splutters. He now makes a desperate gasping sound as he looks wildly about struggling for air. As his coughing subsides for a moment he leans forward bowing his head as saliva dribbles from his mouth to pool at his feet. As another coughing fit now quickly engulfs him, the man beside him pats his back soothingly, perhaps to aid loosening phlegm or simply to provide him some comfort. Another of the group comments "He needs to go home, that's what he needs". The group laugh at the irony of this statement given they use the night shelter for sleeping and various city spaces as a living room during the day. The ill man now twitches and jerks as he tries unsuccessfully to quell the relentless coughing. Spluttering, he tips sideways, and a pile of coins spill from his pocket jingling to the ground. The man next to him stoops picking them up saying "Keep them in ya fucking pocket will ya".

The couple on the ground begin to stir. Waking, they are greeted by the group. "Top of the morning to youse" says one of the men cheerily. The woman tries to maintain her balance as she attempts to stand up. Making it to her feet she staggers away haphazardly down the mall. Another woman, short and round with long lank hair arrives and kisses the sick man's cheek and announces to all "Coppers walking up the road, they' re coming now". All but the sick man and one other get up quickly and disperse as they depart up the mall. Within moments, two police officers approach and look the remaining two men up and down very slowly as they pass them by (Fieldwork: 11/08/07, 1.05pm - 1.30pm).

Despite Wellington media and the Council framing homeless people as threatening to the ordinary everyday lives of others, the fieldwork above reflects how the group life nonetheless survives in the face of controversy. It further illuminates the group as quietly gathered and posing no threat to the public or to the public space. Although some street people were seen posing a nuisance factor, occasionally squabbling loudly amongst each other or asking a passerby for money or cigarettes, ${ }^{31}$ more commonly this innocuous presentation was the dominant

${ }^{31}$ For example, having completed the observation above, and when walking away from the mall, I had recognised the woman who recently having woken on the ground and drunkenly walking off, was now being physically restrained by police officers in the process of arresting her. Though I could only speculate, I assumed this was due to her state of intoxication in a public place. As she began spitting, I overheard one officer caution the other "Careful mate, she's Hep C". His succinct expression nevertheless conveys the health and safety issue homeless people are also commonly understood to pose to others. 
impression formed throughout fieldwork. Moreover, in depicting the habitual way Wellington's street people were observed to use this particular inner-city space on a daily basis, their relaxed presence and informal routine activities of talking, eating, drinking, and even sleeping suggests the repetitive use and familiarity of this space, evokes an embodied sense of Chiu's (2009) 'lived space' and Sennett's (1990) 'narrative space'. Indeed, a sense of private 'living room' space within a public mall.

For people living on the street, usual familial links are said to be more disjointed than those among mainstream society (Pascale, 2005). Therefore, substitute kinship ties can develop between street people, which fulfil many of those functions usually taken up by traditional family (Duneier, 1992). Certainly, in the fieldwork under discussion, we hear a casual inquiry made into the whereabouts of an absent group member. In the street life context, the reply that, "Granite is walking around" would imply all is well with that individual. Also evident are the attempts by others to show care and concern for one of the group who is patently unwell. Inherent with those efforts, one also hears ironic humour used - "He needs to go home" - which both makes light of the situation and points to the glaring shortcomings of a life lived in the open. A sense of camaraderie is also observable in the warning issued about approaching police officers. On this note, both the vulnerability of the group's openness to police scrutiny and their knowledge surrounding their own susceptibility to potentially more direct police intervention is made apparent. Though this vignette depicts the police not stopping, overall I found that the bigger the group, the greater the likelihood of police intervening to ask questions, move the group on, or make arrests.

Furthermore, noting the way hanging out consists of activities resulting in "predictable and desired amounts of companionship, conviviality, and solitude" Duneier says it is also common for people to alter the conditions of passing time (1992, p. 37). People achieve this by either moving away from the group to sit alone for a period of time or by sitting with 'outsiders' where they might attempt to engage them in conversation (Duneier, 1992). The following passage validates this claim, describing how on another occasion, one man's actions led him away 
from the larger group to try to initiate interaction with me - an 'outsider' and supposed 'member of the public':

"Go on", he instructs me. "Now when they're looking, kiss me on the cheek". Ignoring him and instead working to actively project a distracted air by looking away from him and into the distance, he nevertheless persists. Nudging me in the waist with his elbow, he prompts me to now acknowledge him. "Well if you won't kiss me, hit me then, slap my face, go on just do something", he tells me, adding, "I want to rark them up. I want them to see you giving me some attention, any attention". He indicates with a quick head movement that by 'them' he refers to the rest of his group who sit some six to eight metres away, opposite us. I note a couple of his friends are watching his interaction with me and grinning. I decide he is becoming too much of a nuisance as he oversteps the boundaries of how people usually behave in public with strangers. Getting up, I tell him it is time for me to go and meet somebody (Fieldwork: 22/02/08).

While this exchange does point to the nuisance factor street people are capable of producing, particularly when bored, intoxicated, or both, the man's request nonetheless brings to mind a reversal of sorts of Goffman's 'wise persons', discussed in the previous chapter. That is to say, the man's inference suggests that any attention from me - a 'normal' - towards him - a 'stigmatised' (see Goffman, 1967) would engender a moment of elevated status or social validation for him in front of his peers. In this context, a slap is understood to provide as much social elevation as a kiss. For the man in question, successfully engaging an ordinary member of the public in any form of interaction was enough to score points in challenges men set each other when attempting to stymie the inevitable boredom that comes with life lived on the street.

What are the social effects of being a very small but very visible group of people, and what difficulties arise through this in the negotiation of everyday life? The next fieldwork segment exemplifies police officers intervening and conversing with another homeless group in a city park. It reveals that the line between friendliness and harassment remains a precarious one for homeless people living their lives in the cityscape. The interaction, rich with innuendo referring to the men's low status, addictions, and daily activities, is demonstrative of how homeless people are commonly understood, treated, and 'made up' in social 
interaction. The interactive exchange has further utility for setting the scene for Chapter Eight, where I focus on how humour can play with boundaries and create distance. In that chapter, it will become clear that illegal activities can be used to make humour, and that breaking the law can be something to laugh about. However, note that the fieldwork describes a scene I observed before the liquor ban was extended. Therefore, it was not yet illegal to be consuming alcohol in this particular location at the time.

\section{An arresting sense of humour}

From my position on the park bench, I observe three police officers standing interspersed among four homeless men who are park regulars. I hear an officer ask one man whether he is currently sleeping at the night shelter. 'Nah', he replies. The officer looks at the man's water bottle and comments, "That waters fucking great isn't it. What is it, meths?"32 A ripple of laughter sounds as both groups respond to the officer's jest. The man now offers, "Nah Country Wine or Steinlager for me". "You might need to go back to Rimutaka [prison] mate", replies the police officer. "Fuck that", says the man, "I ain't going back. I'm on me best behaviour, reporting to probation". The officer retorts, "We've been told you've had a few problems", to which the man counters back, "I took a bottle of beer, it was a misunderstanding." Again, everybody laughs. Another police officer interjects, "Yeah, what were you doing, looking in the fridge for a job?" prompting more laughter to break out.

The group now starts conversing, and with two people sometimes speaking at once it is difficult to pick up specifics. I am struck, however, by the show of camaraderie directed towards the men by the police who are engaging them in jovial banter, heavily punctuated by police use of the 'F word'. I now hear the third police officer telling the man he should not be drinking because 'no alcohol' is a condition of his bail. The second police officer intervenes, asking the man three times in quick succession whether he has an address, prompting another of the men to say they are just drinking in the park and not hurting anyone. The first officer ignores him and keeps his attention on the first man saying, "Yes, but you're not supposed to drink [uses his name], doesn't agree with you". He now tells the man he is under arrest for breach of bail and begins reading him his rights.

\footnotetext{
${ }^{32}$ Here, the police officer is referring to methylated spirits.

${ }^{33}$ The man refers here to New Zealand brands of wine and beer respectively. 
Meanwhile, the other officers are continuing to enrol the men in light hearted banter and so it is amid another outbreak of laughter that the arresting officer now leads the arrested man away towards one of two police cars parked nearby. One of the remaining officers stands with his arms crossed at chest height as he watches a man running through the park carrying a car jack. He asks the group, "What are we jacking up fullahs, shopping for wheels?" As everyone laughs at his joke, he reaches and takes a glue bag off one of the men while chiding him, "You need to be doing weights brother, big boy like you, not doing this rubbish." Holding the glue bag suspended in his gloved right hand held extended at chest height, he now walks off with the other officer towards the police cars. One of the homeless men calls to the departing officers' backs, "I'll give youse a call on my cell phone later when I'm ready for a lift to court." The two remaining homeless men standing beside him chuckle at his cheek (Fieldwork: 05/06/08, $1.00 \mathrm{pm}-1.20 \mathrm{pm}$ ).

Coser writes, "to laugh, or to occasion laughter through humour and wit, is to invite those present to come close" (1959, p. 172). Yet Coser's research, a study of humour in the hospital setting, is limited to jocular talk between patients and does not explore humour across status lines, for example between patients and staff. My data involve two groups where a marked status distinction clearly exists. The above scene is illustrative of the way police, on the basis of their authority, can intrude on the privacy of civilians any time they wish. Mechanisms of humour are used by the police with a group of men who simultaneously experience invisibleness and scrutiny from both official and unofficial others in daily life. Goffman's 'looping' is a useful concept to bear in mind here as it encapsulates the cyclic affect of responses to humiliation experienced at the interpersonal level of face-to-face interaction.

Readily identifiable in this encounter is an unexpected degree of joking relations. Yet much of the banter described in the encounter can be understood only in terms of the common concerns of participants (Kuipers, 2008). This is evident in the way the interaction between the two groups does not miss a beat. For example, though the dialogue presented begins by revealing an exchange taking place between one of the officers and one homeless man, it would seem all participants understand the shorthand, such as the episode of theft implied and the subsequent joking retort about looking in the fridge for a job. More specifically, however, what form and function does humour have? 
From the perspective of the police, though they appear to maintain a tone of enjoyable sociability while using copious expletives in their communication with the men, they are nonetheless the group holding power. The humour used by the police is nuanced and complex. It combines an implied denigration of the homeless men with a subversive cynicism thinly disguised by a show of camaraderie. Furthermore, the police dialogue exposes the limitations of the men's lives. That is, the many examples of word play displaying police knowledge is evident in sarcastic comments about the homeless men's status, their unemployment, their lack of address (home) and their perceived idle existence, including even a patronising and personal comment about the body of one homeless man. In not having any private space to call home, it would seem the police view such individuals or groups in rather cynical terms. Moreover, as Terry (1997) has noted, "mockery serves as a humorous tool whereby moral and social boundaries are defined, often at the expense of individuals or groups perceived as being lower in status by those instigating the laughter" (p. 34-35).

Similarly, Lindesmith, Strauss, and Denzin (1977) have observed the way “"naming' refers to the process by which police classify people as social objects having certain stereotypical attributes and then act toward them on the basis of the identifying label" (cited in Pogrebin \& Poole, 1988, pp. 194-195). While Hacking's argument draws a similar conclusion, his framework allows for exploring further the way names do not work on us in isolation but rather they work "in an immense world of practices, institutions, authorities, connotations, stories, analogies, memories, fantasies" (2002, p. 9). As my fieldwork suggests, the police had acted in relation to the group in the park drawing on their institutional knowledge (generated 'police' knowledge of these particular homeless people in Wellington). As the encounter unfolded, the police officers' talk reveals they treated the men by 'ribbing' them in a playful way, while at the same time, belittling and controlling them. This fieldwork example powerfully brings to mind Hacking's (2007) 'classified world' which he argues "might be deconstructed in a playful way, but whose structures we will need in order to think until they are altered not by deconstruction but by construction, creation" (2002, p. 8). 
The appropriateness of joking is also argued to usually depend on the situation (Pogrebin \& Poole, 1988). Therefore, as an observer, the action of one man being placed under police arrest amid jovial group banter appeared incongruent with the seriousness associated with such an act. That is, for most ordinary people in Wellington, being arrested would no doubt signify a memorable life event. By contrast, to put it in the context of the participants observed, arrest is a mundane activity within police work itself, while for homeless people being arrested can also become a fairly commonplace experience.

From the perspective of the homeless men, the encounter reveals that a humour "of the underdog as well as the humour of the top dog" (Coser, 1959, p. 172) is nevertheless present. The underdog humour could be interpreted as having a role of defiance, a playful form of rebellion against authority and again, another means by which to alleviate boredom and relief from mechanical routine. Additionally, humour could function as a means of allaying anxiety because the stigmatised group are unable to control the outcome of an encounter in which they have little power.

Subsequently, the men's responses render police dialogue comical by laughing along and keeping the interaction on a playful beat. Yet the men do make fun of 'the system'. For example, the jocular comment to the police officers' departing backs could be interpreted as one man's attempt to regain agency on behalf of the group through collective triumph. As argued by Anderson (1996, p. 196) "liberties that are taken with others are not necessarily spelled out but are often negotiated during social interaction between participants who keep their eye on their audience". Despite the police in this interactive encounter holding discretionary power and making subtle and not so subtle jokes at the men's expense, culminating in the homeless group becoming one member down, ultimately, the last word was uttered by one of the homeless men and as such was immensly appreciated by his comrades. 


\section{Concluding thoughts}

While there remains much more that could be said about each of the fieldwork vignettes presented in this section, and my brief treatment here has undoubtedly raised more questions than it has answered, this has been partially my intention. The aim has been to introduce empirical data in this chapter to paint a picture of the street life scene in Wellington as it was able to be observed during my study. In the planning stages of my thesis this chapter's title had been earmarked "Setting the Street Scene". Yet in hindsight, with more understanding of the way the ebb and flow of structural constraints affects the scene, I concede any efforts in 'setting' the scene would have been futile given the street and its properties, including its' people, remain 'dynamic' within a scene of flux and change. Even during the initial stages of my fieldwork the so-called scene altered quite radically largely in response to structural change within Wellington City Council bringing tighter social control around drinking in the street. By extension, this significantly altered the way Wellington's street people could be observed to 'do street life'. That is, while the scenes I have described all involved street drinking, these observations were conducted prior to the original liquor ban being reconstituted extending its jurisdiction. Following the revised legislation, Wellington's street people began to migrate to new locations outside the scope of the liquor ban so that they could consume alcohol without so readily inviting police intervention and criminalisation of their drinking activity. In effect, the inner city emptied of the street drinkers who had formerly congregated in its malls and parks over many years.

Today these people are visible spending their time in the city traversing the streets in motion. Accordingly, Wellington's street people now 'do street life' in a similar manner to that described in the literature reporting on how homeless people exist in cities overseas. Any loitering and its associated activities including street drinking by these individuals and groups is now generally conducted in new "lived spaces" existing in zones not (yet) under the jurisdiction of 'no liquor' rules. Over time, however, fluidity, change, and migrational movement endures. For example, though many street people initially migrated to Newtown - the nearest suburb at the time outside the no drinking legislation - within months Newtown locals began 124 
to complain about the presence of street drinkers in their community prompting a further extension of the liquor ban to then encompass Newtown within its scope. Ongoing responses to the 'social problem' perception regarding the presence of homeless people can be summed up in attitudes calling for 'not in my backyard'. ${ }^{34}$ To be sure, following Newtown's inclusion as a no liquor zone, I have noted the emergence of several homeless people sleeping in various bus stops in my own neighbourhood of Kilbirnie bordering Newtown. ${ }^{35}$ Further, I recognise several faces of one-time Cuba Mall drinkers among a particular group that often congregates to hang out on the main shopping drag of my suburb. Their regular presence suggests a new lived space is presently in the process of becoming. Therefore confirming that despite the non-existence of formal anti-homelessness legislation in Wellington, to be homeless here is progressively becoming even more of an experience of moving through time and space as street people attempt to keep apace or out of radar of increasing social control measures.

Despite tighter social control mechanisms criminalising the consumption of alcohol on city streets, Brother perseveres in his choice to live life 24/7 on busy city street corners. Consequently, his daily activities and routines include blatantly drinking alcohol within metres of "No Liquor" street signage. Brother's persistence in breaking the law has in turn been met with some rather unusual legal responses that he himself prefers to call 'tactics'. Moreover, his resistance to these responses realised further developments of a medical interventionist nature. I argue Brother is simultaneously caught in a cyclic web where he is 'made up', 'unmade' and 'remade' again by legal and medical knowledge processes, within media reportage, and in the public's imagination.

\footnotetext{
${ }^{34}$ This attitude was particularly prevalent in the public response that rallied against a proposed wet house initiative (a place where homeless people can live and drink in a controlled environment), which had earmarked a site in a South Wellington suburb. The media reported profusely on the local resident's unwillingness to having these people in their community. To date, a wet house in Wellington is yet to eventuate.

${ }^{35}$ In line with this migration to Kilbirnie, the local media reported that Kilbirnie retailers were pleased with a three-month trial that had seen two Walkwise officers assigned to the suburb. A bookshop owner was said to be grateful for the presence of Walkwise officers in the neighbourhood given that some "highly agitated" clients from a neighbouring social agency were loitering outside his shop (Wright, 2007).
} 


\title{
Chapter Six Space matters
}

\author{
We Breathe, Love, Peace, Harmony, Equality At The Top \\ Further Towards "Peace Amongst The Working Class, We Approach Both \\ Govt \& Local Govt To Sign Over To Us Lands "Not Being Used" For \\ Buildings, Roads, Footpaths, Recreation, Sports In Amongst Cities, \\ Towns, Prisons And Other Similar Institutions, The Roof Of Buildings \\ Can Be Used To Collect Water \\ We Shall Carve A Vista, More Than A Sense Of Being, "More" Than a \\ Feeling \\ Belonging - Participation - Involvement
}

(Brother, 2008)

\section{Introduction}

The above prose expresses Brother's personal philosophy and politicking on the matter of space. For Brother, unused (Crown) land would be put to good use if it were made available to those without land, those without homes, and those without optimism so that they might then live on and off the land. Within Brother's vision, Papatuanuku (Mother Earth) belongs to all people and as such, each of us, are, to use his words, 'caretakers of the land' in Aotearoa New Zealand.

In other writing Brother states, "We have a 'Great Need, an Urgency' for an affiliation with the land. Thus we want all the dormant flat lands laying fallow around Wellington City to begin with" (Brother, 2008, original emphasis). Without access to land, Brother considers that the people he claims to represent are likely to remain homeless, destitute, idle, and cast out. ${ }^{36}$ He considers 'fallow' unused land

\footnotetext{
${ }^{36}$ In line with this vision, during one corner conversation with Brother, he told me that following his arrival in Wellington in 2001 he had approached Work and Income New Zealand (WINZ) and requested a small grant so that he might buy a spade "to dig up the land and feed the poor". Though the request was at first declined, a small grant was later given and a spade was duly purchased. Yet within two weeks, the spade had been confiscated off Brother by the police who viewed it as constituting a weapon when carried about the person in city space (Fieldwork: $01 / 11 / 09)$. 
should be made available to disadvantaged or homeless people existing in a state of exclusion and poverty so that collectively they could put it to productive use. This, he argues, would realise for such people, a sense of inclusion, productivity, and wellbeing. ${ }^{37}$ Ultimately, his writing reflects a belief that land matters. By speaking of land issues, Brothers' stance metaphorically reveals how spatial matters matter.

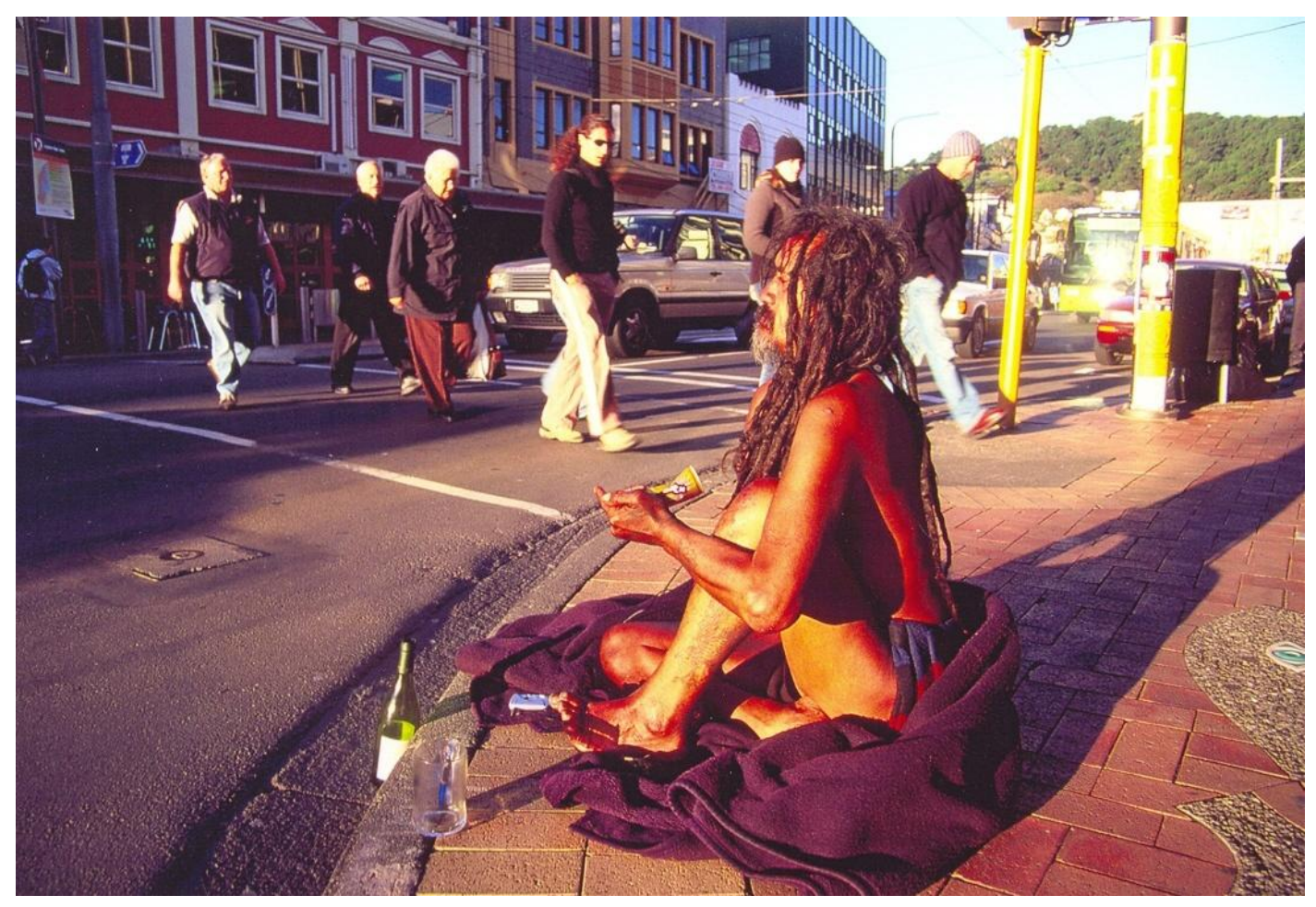

Figure 6:1 Brother domestically appropriating a city footpath as home space

Source: Belinda Brown Photography

Figure 6:1 shows Brother at home in the city as he cuts a familiar sight occupying space on the cityscape. For a person living in public space, spatial concerns factor greatly in daily life. As previous chapters have established, homeless people's use

${ }^{37}$ In 2011, WINZ thwarted unemployed Invercargill man Kevin Middleton's plans to grow a large community vegetable garden in a section of public reserve land earmarked for the project by the Invercargill City Council. Although WINZ acting regional commissioner, Sue Rissman, commended Middleton's plan to contribute to the Invercargill community by feeding the unemployed and teaching others to become self-sufficient, she argued WINZ were unable to support his participation in any unpaid activities that interfered with his ability to be actively looking for paid work. Middleton was therefore told to concentrate instead on getting a proper job (Harding, 2011). 
of space, along with the activities they conduct in these spaces, are contentious issues in many cities around the world. In Chapter Five it was demonstrated that street people in Wellington are increasingly being subjected to socio-spatial control measures, premised on a dominant perception holding that homeless people pose a social problem for others in the city.

To live one's life in the tough terrain of the city street is undeniably a physically and emotionally difficult existence. Indeed, battles of daily hardship are abundantly evident in the fieldwork observations. From the '\$2 lady' observed over several months when she bunked down sleeping in a city bus stop to other destitute people reduced to sitting at street level with signs declaring their homelessness and asking passersby for cash donations. So, this begs the question: Why would someone choose to live a difficult, uncomfortable, and contentious existence? And, how are people sorted spatially into categories based on how they use space?

This chapter asks 'how' questions to explore Brother's everyday use of space and his routine activities within his places of habitation. These questions seek to understand how he manages to achieve domestic appropriation of footpath spaces in the public domain of the city street and its corners. I examine how his occupancy of footpath space is in turn understood and responded to by both the authorities and other Wellingtonians. Central to this aim, Brother's choice to live on the street is conceived of as an 'elected lifestyle' set against a conceptual backdrop of Sennett's (1990) 'narrative space' and Sundstrom's (2003) idea of 'social space'. Sennett's (1990, p. 184) articulation of 'narrative space' maintains space and place are similarly related terms because while space is a physical domain, it becomes invested with emotional and symbolic meaning through human agents embodied and emotional experiences. Yet for Sennett, in order for a space to become "pregnant with meaning", there does not need to have been some particular special happening, as rather, "it is enough for a place to seem rich with the history of place habitation" (p. 196). Sundstrom's (2003) 'social space' resembles Sennett's idea of narrative space as it refers to the spatiality of 
everyday experience and action. It is the social spaces moved through in everyday life that "are infused with social use and meaning" (p. 84).

Bringing space to the forefront of analyses in this chapter will demonstrate how processes of social relations and action 'on the street' are 'ordered and organised in and across space' (Pellow, 1996) by Brother, and how these are interpreted by others. As Sundstrom (2003) recognises, the relationship between human 'categories' and social space is crucial, given that social space can be understood to symbolise "the spatial component and result of social organisation" (p. 84), which influences how we spatially sort people into social categories. However, as Sundstrom has also noted, recent discussions have placed emphasis on the intention of language while not giving enough attention to the role of material conditions. I agree with Sundstrom's assertion that this oversight represents a serious omission as although materiality can inhabit our understanding of human categories, and even our identities, as Sundstrom (2003, p. 88) points out "sheer matter" on the other hand, "can do more than affect us, it can inhabit us".

Space has long been critiqued as a secondary topic within sociology with sociological theory often indifferent to space and spatial considerations (Crang \& Thrift, 2000; Giddens, 1984; Gotham, 2003). From this perspective space is viewed as mundane, inert, and neutral, it is "a setting, backdrop, stage, or context for something else that becomes the focus of sociological attention" (Gotham, 203, p. 466). This view has been identified as 'bracketing out" space and missing a elemental point that space is a social relation involved in the production and reproduction of social structures, social action, and complex relations of power, resistance, and difference (for example, see Giddens, 1984, Gotham. 2003, Sibley, 1995). However, the spatial turn in sociology (Gotham, 2003; Thrift, 1996) has seen space become an important topic of concern with sociologists increasingly emphasising agency as a complex spatial dynamic in shaping situations in the lives of the marginalised poor people. For example, Gotham \& Brumley (2002) have examined how public housing residents construct a meaningful attachment to place and challenge stigmatised identities and negative stereotypes associated with project life. McNaughten Nicholls (2009) suggests 
that by conceptualising transgression as 'an act of agency', the social and structural factors which impact upon the material world in which homeless people are embedded, are revealed. In a similar vein, Cresswell (1996, p. 23) considers transgression, "does not, by definition, rest on the intentions of actors but on the results - on the 'being noticed' of a particular action".

As I am also interested in "the dynamism of social construction, classification, and enactment of who is a member and who is not, who belongs and who does not, who has the right and who does not" (Pellow, 1996, p. 2), this chapter explores Brother's daily spatial mapping and use of space. As proposed by Gotham (2003), conceptualising marginalised people as 'using space', enables the researcher to explore how different strategies of adaptation and resistance can "function as a means of neutralising externally imposed social identities on the one hand, and cultivating and asserting autonomous identities on the other" ( $p$. 731). Brother's key locations in social space that have become sites of conflict through monitoring and surveillance are identified and explored to reveal the way interventions not only control his use of space but also criminalise his actions in these spaces. In doing so, I demonstrate how spatial regulation produces cycles of temporary fracture and displacement from various spaces that affects his lived sense of place. However, by exploring Brother's strategies of adaptation and resistance, I also consider the way space "as a system of meaning" (Gotham, 2003, p. 732) does not only constrain but can facilitate how he chooses to 'do' everyday life, his way.

The concept of space has also been identified as "an abstract, complex notion that is difficult to pin down" (Merrifield, 2000, p. 173). Therefore, spatial metaphors of inside or outside space, free space, safe space, dirty space, empty space, and lived space are useful means for thinking or writing about socio-spatial relations (for example, see Gieryn, 2000; Valentine, 2001). Within such spatial terminology, Wellington's Glover Park could be labelled a 'hot space'. Methaphor and imagery used to describe boundaries in a spatial context exist in synonyms and other metaphors, for example "edges, borders, frontiers, margins, boundaries...verges, transitions, filters, halls... and zones" (Rodman \& Cooper, 
1996, p. 94). In my examination of how space matters in Brother's everyday life, his 'primary locations' for example, are conceptualised as 'home space' but I also use other metaphors, 'corner space' and 'boundary space', when identifying, interpreting, and explaining the meanings of particular spaces and how they function in Brother's spatial mapping of the city.

My exploration of how space matters in Brother's street life is also elucidated using a spatial map illustrating Brother's locale. Photographic images depicting a variety of street scenes, signs, art, and public commentary are also included to show how other people interpret and attach meaning to Brother's home spaces. Including a range of materials for analysis is an approach endorsed by Latour (2005, p. 55), who argues that only by constantly comparing complex repertoires of action, will sociologists "become less wooden, less rigid, less stiff in their definition of what sort of agencies populate the world". In order to best interpret the city street and articulate the social, Gieryn (2000) similarly urges sociologists to become "more adept with maps, floor plans, photographic images, bricks and mortar, landscapes and cityscapes" so as to render "a set of empirical findings or an explanatory model” more visual (Gieryn, 2000, pp. 483-484).

Analytically, the aim is to examine how Brother, as city-street dweller is able to 'make up' himself while simultaneously resisting others attempts to categorise him. This raises key conceptual questions regarding how this individual is able to maintain his choice to live on the street in the face of controversy surrounding his presence. Firstly, what are the institutions and actions that monitor, regulate, and criminalise Brother's occupancy of city space as home space? Secondly, what role might space have in engendering a lived sense of city-as-whare despite the opposition this individual faces in his daily life? Ultimately, through closely examining many of the day-in and day-out trials and tribulations that are 'observably the case' (Sacks, 1992), this chapter aims to contribute new conceptual understanding to how space matters when one lives without conventional shelter in public spaces. 


\section{Public space: whose space?}

Public spaces occupy an important ideological position in everyday life. Nonetheless, understandings of public spaces change over time and every society has some mixture of normative public and private boundaries. Consequently, physical, social, economic and political factors all come into play when considering the way public spaces created by societies reflect a balance between dynamic public and private values or divides (for example, see Carr et al., 1992; Sennett, 1990).

As I noted in Chapter Five, public space in New Zealand is simply defined as spaces which are intended for public use and may be publicly or privately-owned (Ministry of Justice, 2006). However, New Zealand's Urban Design Protocol (2005) also recognises the temporal dimension to public space, noting cities are shifting towards a $24 / 7$ way of life, and how within this process, the management of public space may likewise be shifting. This is evident in Wellington with implementation of initiatives such as Walkwise wardens, installation of CCTV cameras, and changes to the liquor ban in Wellington. Interestingly, because many homeless people's lives are, by necessity, lived 24/7 in public space, the move towards this 24/7 way of life is impacting on spaces homeless people use. As a result, it is becoming necessary for homeless people to adjust their way of life not only because of increased monitoring but also in response to the city's round-the-clock popularity that is now interfering with a once relative degree of privacy formerly afforded when the city had 'shut down' overnight.

Public spaces are full of tensions surrounding the acceptance and exclusion of people. The concept of public space, however, is often imbued with notions of acceptance and diversity (Iveson, 1998) with Mitchell (1995, p. 116) concurring that "ideals like "the public", public space, and the public sphere" in their very articulation, implies a notion of inclusiveness in the modern Western city. Yet as Mitchell (1995, p. 118) argues, public places have always been places of exclusion and inclusion, and "although homeless people are nearly always in public" and constitute residents of public space, "they are rarely counted as part of the public" (see also Kawash, 1998; Sibley, 1995). It is in the public realm that 132 
homeless people often face exclusion as a result of punitive regulations (Kawash, 1998). As shown in Chapter Five, homeless people can face a conundrum as in not having private homes they nonetheless find themselves "precariously positioned in the ongoing battle over who belongs to the public, who has access to public space, and who has the right to decide what uses of space are within the public interest" (Kawash, 1998, p. 320). As Amin (2006, p. 1018) observes, it is within such a context that 'urban marginals', including the homeless, "are quickly tracked, gathered and shunted on as threats to public space valued increasingly for its worth as a consumer and corporate space".

In the New Zealand context, my review of the literature revealed that while punitive bylaws can target homeless people, they are not widespread and are sometimes accompanied by efforts to support social service providers (Laurenson $\&$ Collins, 2007). However, to reiterate, the authors also found that the attitudes of city authorities can be subject to political whim, articulating an exclusive vision of public space that is linked to concerns for public safety and city image. These arguments were shown to be valid in regard to the small case study profiling local government responses to the homeless people that inhabited Glover Park and the subsequent reclamation of that particular city space by Wellington City Council.

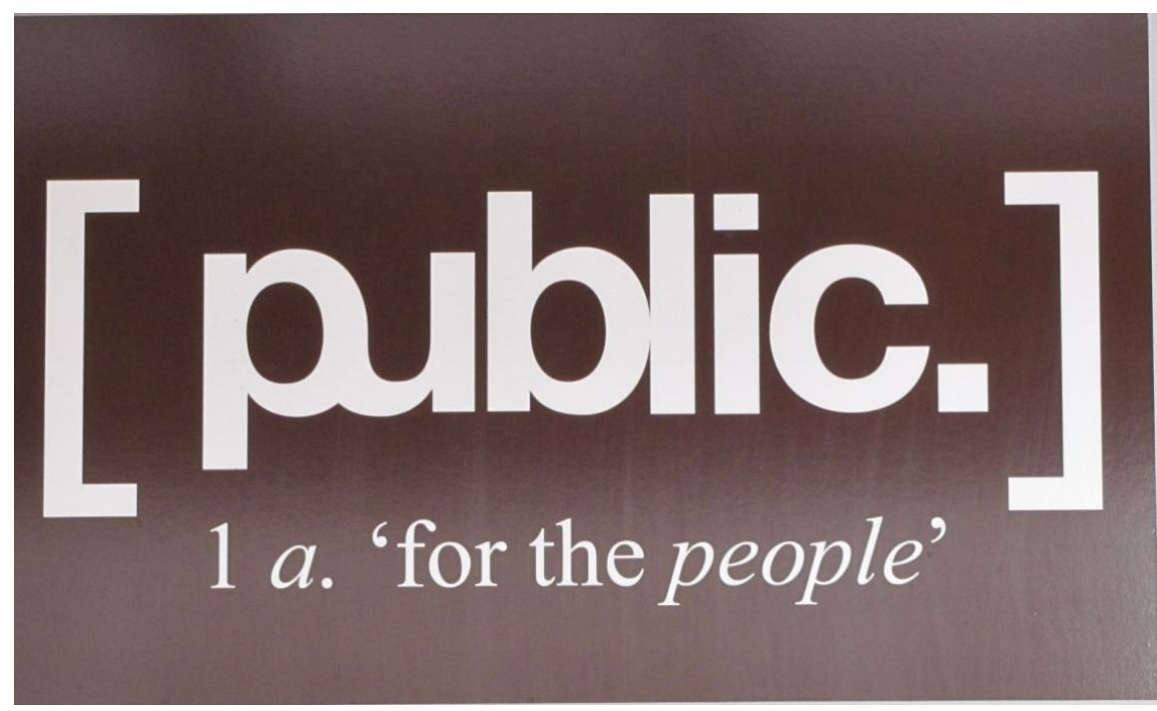

Figure 6:2 Signage outside Wellington's Public Bar, located on one of Brother's primary home corners

Source: Author, 2012 
Wellington's Public Bar (Figure 6:2) borders a highly favoured corner within Brother's daily spatial mapping. It is therefore symbolic of one of several key footpath (home) sites where conflict arose through Brother's occupancy of the kerb as he basked in the afternoon sun - sometimes drinking alcohol or smoking cannabis, or both, sometimes taking an afternoon nap. This particular corner location will feature strongly throughout the remainder of this chapter as a representative site for exploring the roles of 'cornering', 'guttering', and 'ATMing' in Brother's everyday use of public space. I reveal how through these sites Brother secures the 'five S's' crucial to his life: safety, sun, shelter, social interaction, and support.

The particular social problem that Brother is considered to pose is one that can be spatialised, with both his presence in and use of public space as a home upsetting assumptions about how such spaces should be used. Cresswell (1996, p. 22) writes, "We can think of "out-of-place events as "spatial Garfinkeling" because they breach taken-for-granted assumptions that ordinarily serve to dictate appropriate social action. Certainly, in directing focus back to Figure 6:1, it is suggested this photograph subtly supports Cresswell's claim. The image signals how we are spatially aware beings existing in a world of meaning as we go about “our ordinary everydayness of being-in-the-world" (van Loon, 2002, p. 94). Particularly, I point to the way the city scene invites us to imagine what those crossing the road - most often conventional housed members of society - might be thinking as they see Brother leisurely enjoying the sun at a busy city junction. The image clearly reflects Brother explicitly transgressing boundaries of appropriate behaviour: he is smoking cannabis, has a wine bottle propped in the gutter, he is wearing little clothing. Therefore, using pavement space as living space in this way clearly challenges notions of public/private divides as well as what is considered suitable or legal behaviour in a public place. Numerous transgressions between, clean and dirty, ordered and disordered, normal and deviant, legal and illegal, safe and dangerous, rationality and irrationality, healthy and diseased, dressed and undressed, are all therefore too easily possible. However, as Cresswell (1996, p. 26) proposes: 
Transgression is important as it breaks from "normality" and causes a questioning of that which was previously considered "natural", "assumed", and "taken-for-granted...they disrupt the patterns and processes of normality and offend the subtle myths of consensus...that which is usually considered "the way things are". The way the world is defined, categorized, segmented, and classified is rendered problematic.

Certainly for Brother, his life lived in public does attract controversy by others who judge his lifestyle choice as transgressive and his daily activities as a series of transgressions. However, I argue his 'choice' to live on the street, despite the hardship, constitutes a form of protest or activism rooted in his philosophy holding Aotearoa belongs to all people. Yet Cresswell (1996, p. 23) further suggests that, "Transgression is judged by those who react to it, while resistance rests on the intentions of the actor(s)". In this vein, could Brother's public life be explainable as an act of resistance as Cresswell's work suggests? In short, can his domestic everyday life be viewed as a constant act of resistance? For Cresswell (1996, p. 23), "Intentional transgression is a form of resistance that creates a response from the establishment - an act that draws the lines on a battlefield and defines the terrain on which contestation occurs". Given Brother's occupancy of public space as home space, and common preconceptions held regarding public space, Cresswell's proposition is relevant when exploring Brother's daily mapping of space, his activities in space, and the public responses that unfold in response to this. In light of these arguments, while space clearly matters to Brother, equally, it matters to others who seek to defend common sense assumptions about how public space should be used.

\section{Agency in action}

In this section I explore human agency as a phenomenon shaped by space. I focus on how Brother uses city space to illustrate how mundane moments in time are both framed in themselves and also within the wider socio-spatial context of the street setting in which they occur. I begin with a fieldwork vignette detailing Brother's morning routine on the street. 


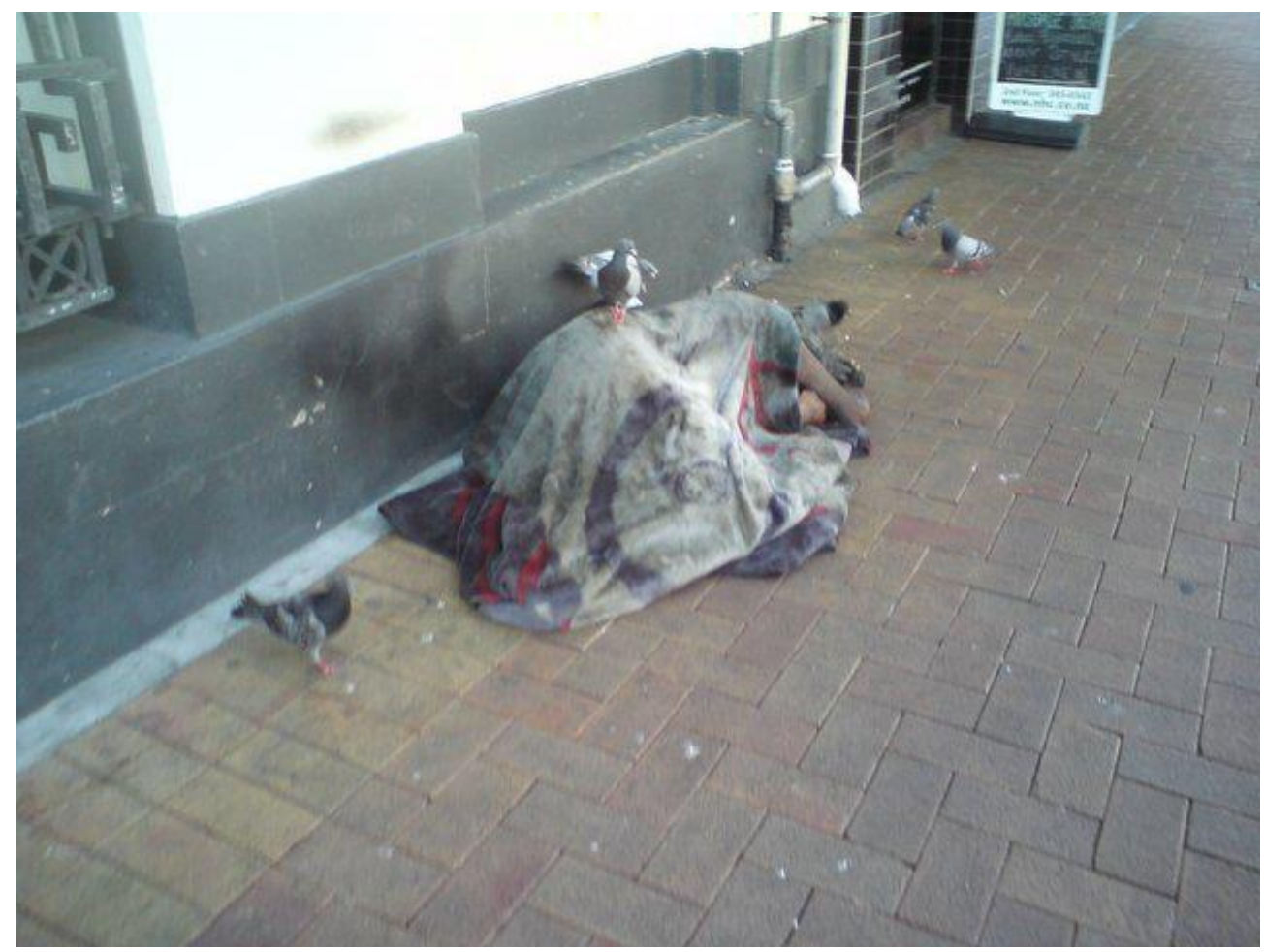

Figure 6:3 Street sleeping ${ }^{38}$

Source: Google image search, keyword 'Blanket Man', photographer unknown

The dawning day reveals a dull, bleak sky overhead. At ground level the road shines wet from heavy rain that pelted the city throughout the night. On the footpath the sleeping body of Brother lies diagonally across the centre of the pavement, lying curled on one side, ropes of long dreadlocked hair partially obscure his face. A semi-unravelled sleeping bag lies strewn across the ground behind him. Around him, bright orange burger rings litter, contrasting brightly against the dull grey of concrete.

A rubbish truck inches slowly along as a man runs behind, ducking and diving collecting up bags from the gutter and heaving them two at a time into the cavity at the rear of the truck. Suddenly, the relative quietness of this early morning scene is violated by the ear piercing noise of a concrete cutter bursting into action across the road. Men in hard hats and overalls

${ }^{38}$ While Figure 6:3 was not selected for its clarity, it has been included for its candid capturing of Brother's street sleeping presence. It depicts pigeons, which were an ever-present part of Brother's street existence. Despite pigeons being commonly perceived as disease-carrying pests or 'sky rats', Brother was observed to care for these birds in a similar manner to how one might ordinarily care for household pets, sharing food with them and allowing them to constantly hover in his personal space. On one occasion, I noted Brother sharing a mince pie with a pigeon. Having removed the pastry topping, he then proceeded to scoop out mince using the inside of one very long fingernail as an eating utensil. Each time he removed his finger, the pigeon would peck directly into the pie, having its share. 
pick up their shovels as Brother stirs in his sleep. As the sound of the machinery quickly reaches a relentless pitch, Brother awakens. Shifting himself into a sitting position, he corrects his headphones that have gone askew on his head during sleep. Standing to adjust his blanket, he scatters some burger rings to several pigeons fussing nearby.....

Reaching under the folds of his blanket, he removes a plastic bag and appears to check its contents. He now withdraws an empty cola and bourbon can used to smoke marijuana and removes a six-pack of cans from a plastic bag also under his blanket. Opening one, he takes a swig just as two joggers pant past. Crumbling marijuana into the groove doctored at one end of the makeshift pipe, he now hunches forward bringing it to his lips and lighting the contents. Deeply inhaling, he attempts to hold in the smoke for as long as possible. His body writhes and twitches as he struggles to stifle a coughing fit. Mission accomplished, he takes a second toke as a man in a business suit bristles past, eyes fixed straight ahead.

Though not quite 7am, it is clear Brother's morning routine is now underway and I leave my car to join him. "Ah," he grins, "thought I might see you today, what day is it today?" Lifting his foot, he points to his toe which is bruised and swollen, "It's broken, irritating me, need to anesthetise myself with Doctor Vodka, every cunt will be out tonight." Giving his foot a wriggle he concedes, "Ah well, at least we're breathing, bit of a monotonous everyday activity but gotta breathe. I'm not going to worry about no toe".....

A bus slows and stops, waiting for the traffic signal ahead to turn green. Faces peer at us through steamy windows. Meanwhile the pedestrian traffic is rapidly increasing as other commuters walk to work. I note Brother is beginning to eye up those out and about, turning his head from left to right as he surveys the street. As a succession of commuters hurry past, he tells me, "They're all just playing by the rules and they subject their kids to the same bullshit [pause] ah well, they've gotta work I spose, gotta feed their tamariki [children]." A moment passes. He continues, "Boring lives, same old, mundane everyday".....

A grey haired man strides past, prompting Brother to remark, "He's looking very smooth, can walk with confidence when you look like that." A moment later he adds, "It's all in the way you portray yourself." Next, two tourists, cameras slung around their necks and huge packs straddling their backs, causing their bodies to lean forward under the bulky weight, stare openly at us as they walk past. One continues to look, back over his shoulder, for some distance. Brother tells me he sees a lot of people carrying their houses on their backs. A street cleaner in a bright orange vest pushes his bulky cart towards us. Reaching us, he stops and asks Brother how he is. "I'm a dumb cunt, the last dumb cunt left in the universe," Brother tells him. Pointing to the sleeping bag, the cleaner asks, "What's with that?" "Ah, some cunt gave it to me last night but I don't 
want it, what would I want that for?" Brother says, before throwing his head back and laughing raucously. Shrugging, the cleaner tells him, "Here, I saved this for you," and places a full but open bottle of wine on the ground. "I' $\mathrm{d}$ better get on with checking my turf. The public have made a right mess of things last night." An older couple walk by hand in hand. The woman smiles at us before muttering "Poor man" to her partner.

Now acknowledging most pedestrians in his customary way by lifting his chin towards them in greeting, people, in fairly equal measure, either respond by smiling or greeting, or they avoid acknowledging his presence by looking the other way. The minutes pass and as we sit companionably together, Brother offers, "People think they watch me, but I am the watcher".... (Fieldwork: 27/04/08).

This excerpt highlights the 24/7 nature of Brother's life lived on the street and emphasises the contrast between his presence and the lives of the 'housed others' using the space to commute or exercise. Equally apparent is the way his ordinary routine is prompted by the sounds of the city. Sleeping on the footpath brings a unique experience as is revealed in other field notes which capture Brother's own reflection, "The foot traffic of the inner-city pulsates 24/7" (Fieldwork: 05/05/09). His querying what day of the week it is fits with van Doorn's (2010) finding that people who have been homeless long-term lose their sense of linear time, adopting instead a cyclic perception of time where simple points of reference are tied to nature - the position of the sun, distinguishing day from night, summer from winter, and so on. Beyond cyclical adaptation, as the fieldwork reflects, Brother was tuned into the rhythms of the city that includes the alarm clock of the waking city each morning.

In the absence of usual dressing, cleansing, toileting, or breakfasting routines, Brother was observed as attending, instead, to adjusting his bodily attire, blanket and headphones, and conducting a quick stock take of his few belongings. These personal activities conducted in full view of the public emphasise the social nakedness that permeates his particular way of street living. Also clearly

\footnotetext{
39 This regular cleaner would tip dregs of wine from bottles he collected littering the street into another until he had accumulated enough to fill a bottle to give to Brother when his rounds reached his part of the street. Receiving the alcohol, Brother would often make jest about getting 'room service'.
} 
observable are Brother's law-breaking activities of consuming alcohol in a no liquor zone and his use of cannabis.

His response to my arrival indicates that I too have become part of his everyday. On this note, his dialogue with me is also useful for the insight it reveals about the street and its people. Brother's comments about passersby are representative of a rich body of 'corner conversations' I had with Brother which revealed his thoughts as both the 'watched' and the 'watcher' as he in turn looks out on others. His comments referencing his observations of others living conventional lives noted the rut of going to work, the way other people are able to portray themselves through the way they dress, and how those on holidays burden themselves by the weight of their possessions that accompany them.

The brief exchange with the cleaner reflects the type of neighbourly relationships spoken about in the previous chapter. To be sure, the cleaner's comment regarding 'the public' messing things, positions the public as 'other', an entity distant from him. Instead he aligns himself with Brother, another person 'of the street', who must regularly deal with 'the public' and their various doings. In turn, Brother's mockery regarding the sleeping bag, clearly gifted, reinforces how he is able to assert his autonomy, despite his need. That is, while he did not want the bag, he will accept wine from the cleaner. In this way he is able to maintain face by showing his 'staunch' persona; by not needing home comforts he reveals his ability to endure a hard daily existence in the cleaner's eyes.

Having established how Brother routinely starts his day as represented in the vignette, I next explore his use of city space throughout the day. The aim is to examine the interplay of space and agency to understand how the concrete spaces of the urban street can provide a sense of rootedness and connectedness to place through the regular commandeering of public space for everyday personal use. It is specifically Brother's day-in and day-out repetition of inhabiting regular spaces and conducting routine activities in these spaces that I argue enables him to claim and remake city space. 


\section{Daily spatial mapping}

Ethnographic research by Rowe and Wolch (1990) recognises the importance of spatially fixed stations and paths in the everyday lives of homeless people and argues these are crucial to homeless people's social networks and coping strategies. Daily mobility paths are observed by the authors to accumulate over time to "form a life path or 'time-space biography' for the individual" (p. 116). Spatially fixed stations are identified as revolving around key points of return in the round of routine activities and social interactions within the mobility path that can typically involve traversing long distances. However, the authors report that the homeless existence can bring about an erosion of spatially fixed stations in the daily mobility paths of homeless people, disrupting homelessness networks, and profoundly affecting the ability of homeless individuals to obtain material goods, access shelter, and receive emotional support. In next outlining Brother's routine use of city space and by distinguishing primary spaces, corner locations, afternoon and evening spaces, and sites of frequent visitation, I show that Brother has firmly established spatially fixed stations within a daily round of 'small' movements that are purposefully chosen to allow him to reap sun, shelter, safety, sociability, and support. Brother's use of space illustrates a departure from the way Rowe and Wolch have discussed mobility paths to function in the lives of homeless people living in Los Angeles. In Wellington, where it is 'street legal' to live in public, there is no need to exist constantly in movement in order to avoid the authorities (although as was discussed in the previous chapter, changes to the liquor ban are spatially regulating where street people can now hang out). Moreover, in Brother's case, his mobility path does not have any need for factoring in visiting service facilities, which were identified in Rowe and Wolch's study as providing substitute homes for clients. Rather, Brother's stoic use of space and his routine movement between these spaces that are mainly situated within one city block will be demonstrated as not leaving him wanting the social contact of others. Conversely, he is constantly 'visited' by others in his 'home spaces' where he is backed by an informal support network that also ensures his basic material needs are met. By extension, habitual occupancy combined with the repetition of everyday activities is argued to produce for Brother, a particular sense of 'place'. That is, 140 
as Gieryn's (2000, p. 471) idea of 'lived in' space articulates, “ordinary people extract from continuous and abstract space, a bounded, identified, meaningful, named, and significant place". Yet even though his fixed stations and paths have augmented a firm grounding within his locale of Courtenay Place creating an experiential lived sense of city-as-whare, the objective is to also expose that this is reliant on how he socially organises himself in relation to the space itself.

Figure 6:4 illustrates the Courtenay Place precinct that is Brother's locale. His regular spaces of habitation or visitation are marked on the map reflecting Brother's use of space in his home territory. Also included on the map for contextualisation purposes are other regular spaces for example Glover Park (Brother's former home turf prior to its closing down and my research commencing). 


\section{Brother's daily spatial mapping around his locale}

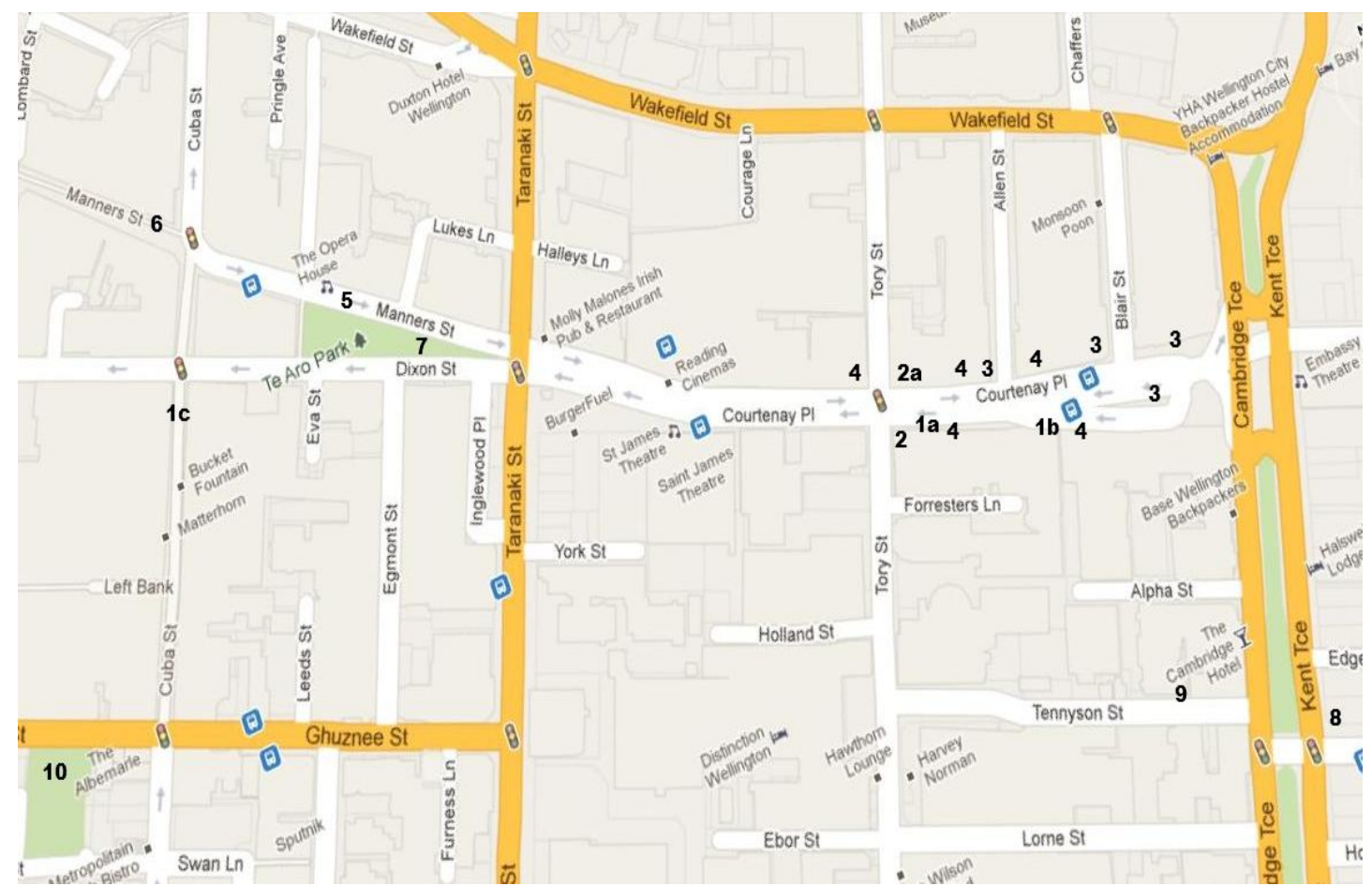

Figure 6:4 Courtenay Place and its immediate environs, marking Brother's city-as-whare spaces

Key

Primary locations

1a. ANZ Bank

1b. United Video

1c. Cuba Mall

\section{Primary corners}

2. Burger King corner

2a. Public Bar corner
Other city-as-whare spaces

3. Late afternoon locations

4. Evening locations

5. Manners Street alcove

6. Manners Mall

7. Te Aro Park

8. Liquor King

9. Phantom Print

10. Glover Park

Primary locations are defined as those 'home base' sites where Brother sleeps, spends the first couple of hours of each day and where he will remain if the weather is poor. During my time in the field, he inhabited 1a, 1b, and 1c. However, the 1a site was where the majority of observations in primary sites were carried out as other factors disrupted long term occupancy in the others. At times, Brother's habitual routine use of space, engendering a lived sense of city-as-whare, was 
disrupted by others. For example, court orders periodically prohibited him from occupying the Cuba Mall site, while the frontage area he had occupied outside the former boarded up video store was later made unavailable when it underwent redevelopment and became home to a restaurant. However, even when occupying the Cuba Mall location, Brother would return to his home locale of Courtenay Place and to one of his primary sites. He explained to me that, "Courtenay Place is my default emergency. If some cunt pisses me off, I will still go there even if bail conditions forbid it" (Fieldwork: 11/02/08). Here, he alludes to Courtenay Place as providing a safe space in homely territory. Certainly, Brother's long-standing affiliation with the Courtenay Place quarter is often commented on by others, for example in social networking sites discussed earlier in Chapter Five, and in other novel ways, such as that illustrated in Figure 6.5.

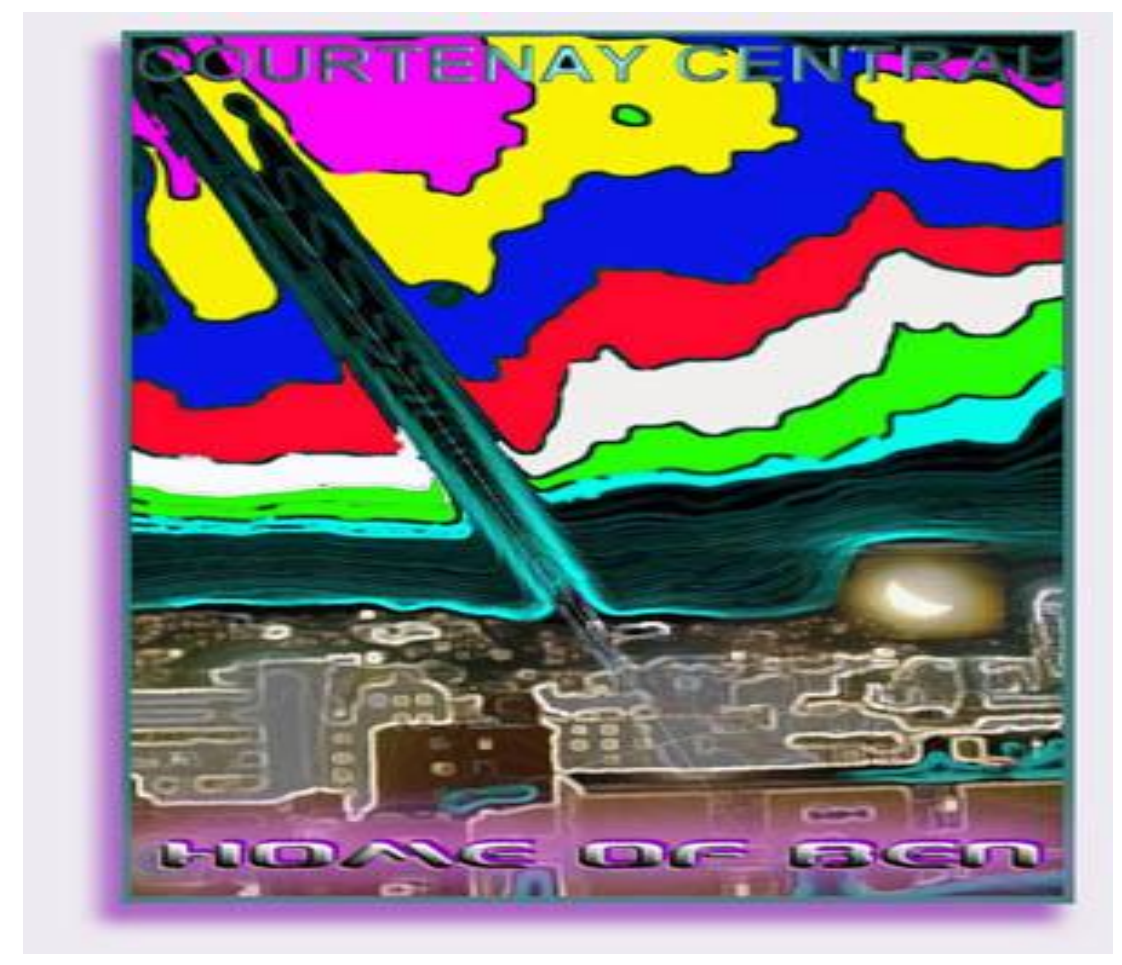

Figure 6:5 'Artist's' impression of a laser illuminating the 'Home of Ben'

Source: Google image search, keyword 'Blanket Man', artist unknown

However, during one two-week period, Brother utilised an alcove between two shops in Manner's Street (location 5). This was because he was simultaneously prevented from occupying any of his primary locations and other back-up locations (for example location 6) because of bail conditions. That particular space 
did not receive anywhere near the degree of foot traffic experienced in other locations of Brothers' choice and coupled with the fact that it was mid-winter at the time, I observed that period as being a comparatively bleak time for Brother.

Te Aro Park exemplifies another 'back-up' space that was observed (and experienced through my researcher role) as a transitional 'waiting' space. That is, when Brother temporarily left his Cuba Mall primary patch to shop or toilet himself, others would sometimes move in to utilise the vacant space he had left behind to eat their lunch or to rest their legs. Without his physical presence and through his habitual practice of always carrying his small sum of possessions with him whenever he travelled, he left no visible claim or marker on the space. Sometimes, however, other street people 'knowingly' took over his Cuba Mall patch in his absence as they loitered to socialise and drink in this prime location with its clear view of all who entered, exited, or passed by the mall. Regardless though, of whoever used the space, Brother would wait in Te Aro Park where he could observe the space, and could then move back once it was vacated. It was interesting to observe that whenever others had stepped in to occupy Brother's Cuba Mall space in his absence, he never once reacted by exerting his ownership over the space. Instead, waiting it out, he was observed in-action to practice his egalitarian view about public land in Aotearoa belonging to 'all people'. Although, when physically ensconced in a space, as the chapter to follow will argue, he is nonetheless able to claim and remake space when appropriating space through strategically using his body and objects in particular ways.

Brother's movements during the day are striking in the way street space is used to achieve similar ends as others might utilise house space to reap sunshine or shelter, relax, pursue entertainment, or access material resources like food. His primary space can be likened to bedroom/living space, his street corners evoke a sense of outdoor leisure space, while his evening locations position him among the immediacy of socialising others, bringing him lively distractions from monotonous routine. Brother often analogised aspects of the street scene to activities or objects normally associated with the house or home, for example, likening the outlook to watching the television: "Boring today, pity we can't change the channel" 144 
(Fieldwork: 07/05/09). Similarly, when a ruckus broke out among a group of young women one evening, he had responded, "Uh oh, time to press mute" (Fieldwork: 04/01/09), as he had turned up the sound on his FM radio to listen to other sounds that were more to his choosing.

Brother's spatially fixed stations are centred on providing him sun or shelter. In good weather, his habitual movement in space around his locale of Courtenay Place begins with movement away from primary location $1 \mathrm{a}$ or $1 \mathrm{~b}$ to primary corner 2 where he is able to sit in full morning sunshine. In the late morning or early afternoon, he crosses the road to the Public Bar corner, where he receives full afternoon sun. Later, as the sun begins to set below the western hills that backdrop the city, he migrates eastwards - sometimes in a succession of movements - to capture the last of the day's sun in locations not yet in shadow. As nightfall approaches, he performs a reverse migration, moving westward to occupy one or the other of several favoured evening locations. There he remains until returning, often in the early hours of the morning, to a primary footpath location for sleeping, until the cycle begins again the following day. However, as mentioned, during inclement weather, Brother remains in one of his primary locations, where he is able to take shelter at least from the rain under the protection provided by building awnings overhead.

While this trajectory portrays his 'usual' everyday movements, there are variations in his construction of space to create a whare-in-the-city. He may decide to spend an evening in his primary location outside the ANZ bank, therefore alternating which side of the road he sits in and slightly changing the experience given that the ANZ side is slightly less populated with bars and the number of revellers moving from one bar to the next is reduced. On most days he also leaves his immediate locale to shop at Liquor King or one of the many 24-hour convenience stores in the vicinity. He may need to appear in the District Court, visit WINZ, or do business with Phantom Stick Ups (the print business where he takes his writing). Or, he may simply want to hīkoi around his locale to stretch his legs. On this note, when walking with Brother in the context of his 24/7 street life, and when moving between a primary location (1a, b or c) and perhaps Liquor King (8) for example, 
an appreciation of how it is possible to experience a broader lived sense of the city-as-whare can be understood. For instance, within Brother's daily spatial mapping, Kent Terrace (see map) is symbolically experienced not just as another street, but rather it is negotiated as an extension of primary spaces. Within this analogy of the city-as-whare, such arterial routes of the city are used as links or transition zones, or 'hallways' (as would become the case within an analogy of the conventional house/home) in a trajectory of movement. In this way, the hîkoi from his primary locations to Liquor King becomes an experience akin to travelling from living room $(1 \mathrm{a}, \mathrm{b}$, or $\mathrm{c})$ to the fridge $(8)$ for alcoholic beverages.

His choice of primary spaces relates to receiving money and support. Brother's ANZ site, his morning and afternoon corners, and each of his evening locations are all situated in the immediate vicinity of ATMs (automatic teller machines). On numerous occasions I observed people withdrawing their cash from an ATM and slipping him a ten or a twenty-dollar note before leaving. Brother's locale situated in the city's nightlife hub brings the concept of the 24-hour city to the forefront of lived experience, as throngs of people converge on Courtenay Place for the restaurants, shows, and perhaps most commonly, the bar scene that extends long into the night. Participating alongside Brother within his locale over the 24-hour day, I found that there was no let up from others interacting or attempting to interact with Brother, regardless of the hour. In many of these interactional encounters, money was not only given, but also food, alcohol, cigarettes, drugs, and other items, such as the sleeping bag mentioned in the morning routine vignette. Brother is strategically positioned 'in place' to secure social connectedness and material resources (if and when he chooses them). Brother's interactive relationships and the specific roles they fulfil will be examined in Chapter Eight.

The following section considers Brother more explicitly within the particular street space of the street corner, as I draw from field notes made when observing Brother residing 'in place' on his Public Bar corner (Primary location 2a). Before providing a brief vignette depicting the way Brother routinely occupies this urban space, it is worth briefly pondering the corner as a unique physical location in the 
city. For ordinary people traversing city space, the street corner is a transition zone marking the interface between road and pavement. It functions as a 'boundary space' (Pellow, 1996, Rodman and Cooper, 1996). The city street corner is also where people converge and mingle as they wait for traffic signals indicating when they may cross the road. As such, street corners are often places of pause in one's movement around the city. Commonly understood as junctions, corner sites often become nominated as designated places where people arrange to meet one another on 'such and such corner'. Brother's choice to spend the bulk of his day inhabiting the transient boundary space of the street corner is then of analytic interest.

Rodman and Cooper (1996) observe boundaries in a spatial context may be especially revealing when the housing is unambiguously unconventional. To be sure, Brother does not shirk away in dark corners. Rather, his 'corners of choice' mark two boundaries of a lively four-way intersection rendering his physical presence in these spaces as highly visible to the public-at-large. His decision to occupy corner spaces is a strategic choice as it advantageously positions him to successfully 'corner the market' both socially and materially. To reiterate, ATMs are located on each of his chosen corners and as suggested above, corners are both transitional zones and places of pause. These factors ensure heavy foot traffic of a nature different to the more continuous passing-by nature of pedestrians that occurs in other sites. This can heighten the likelihood that he is given material support from pedestrians on which his daily survival depends. Moreover, Brother's 'cornering of everyday life' situates him literally 'road side' in close proximity to motorists who also must pause to await traffic signals at the busy thoroughfare intersection. Consequently, Brother is able to 'corner' not only pedestrians but motorists too. Indeed, motorists were often observed greeting him, or throwing money, cigarettes and other items to him from their car windows. Yet, the positioning of self - mid-centre within each corner site - is also argued to afford him some margin of control. Not only is he able to commandeer more space for himself, but he is well placed to either engage or disengage with others in his presence as he sees fit (the intrinsic role of social organisation in finding and managing place, and contestable territoriality will be examined in the following 
chapter that focuses specifically on the spatial body and objects in street life). Last but not least, because the street corner is geographically open, Brother's cornering of everyday life enables him as a prolific sun worshipper, to reap and receive full sunshine. The following fieldwork excerpt describes a representative moment in time 'hanging' on Brother's primary corner 2a.

\section{Whiling away another afternoon}

The intense heat bears down, burning into my skin. The air is stifling, exhaust fumes linger. Yet next to me, Brother sits seemingly unaffected. His outstretched legs leisurely encroach into road space, making an already tight left hand turn for motorists even more difficult. His feet are speckled with sticky black tar from the melting road. A couple of large salamis given to him earlier by a passerby lie in the gutter sweating inside their clear vacuum packaging. His Te Māori book showing its usual page depicting a Māori carving rests on the edge of the pavement facing pedestrians crossing towards us. Next to the book, a sheet of paper, also placed to face on-comers, advertises the upcoming general election and reminds people to check that they are enrolled to vote. Every now and again, as passersby cross the road towards us or stand around us waiting for the traffic signal to cross, Brother tells them, "Register to vote, hold that vote." A group of 10 or so pre-schoolers and their teachers now mill around us waiting for the green man signal to cross the road. Paired together, holding hands, most of the children stare openly at Brother as he loads new batteries into his radio. "Hi Blanket Man," says one child solemnly, his thumb half hanging out of his mouth. Several other children follow suit while another comments, "He hasn't got any clothes on." A motorist, negotiating the tricky left hand turn, only narrowly avoids Brother's outstretched legs. He calls through his open passenger window, "Keep ya legs in bro or they'll get run over". Brother, who has resumed listening to his small FM radio, appears oblivious to any warning (Fieldwork: 16/01/09).

This fieldwork description is reflective of many other observations of Brother in his routine settings. It reveals his resilient acclimatisation to weather extremes and alludes to the role of certain objects that were part of his street life from time to time. While Chapter Seven specifically examines the significance of the body and material possessions, here I point to Brother being physically embedded in public space among others, including small children. On this note, his 'recognisability' as a prominent person who is well known on the Wellington cityscape is evident even among pre-schoolers. A pre-schooler comments on his near naked appearance in public while his physical presence is also illustrated as posing a potential problem 148 
for motorists. Yet overall, the vignette captures a fairly benign picture of Brother as he whiles away an afternoon enjoying the sun, listening to music, and watching the street. In fact, not long after he had loaded new batteries into his radio, he had taken an afternoon nap in the setting. Arguably however, it is predominately this presentation of the self and the undertaking of these simple activities that are interpreted by others as transgression and defilement of public space.

\section{Agency and structure collide}

Brother's routine use of space, as fieldwork excerpts illustrate, is often disrupted by official views on the use of public space and is subjected to legal interventions that monitor and criminalise his commandeering of public space as personal home space. Figures 6:6 and 6:7 are representative of the times I observed Brother being arrested on the street. In Figure 6:6 he is being led away by police (presumably to the police station, where the usual practice is to detain him in custody overnight, and if charges are laid, he is taken from the police cells to appear in the District Court the following morning). Note that the officers are wearing black leather gloves and using handcuffs with rods attached for ease of leverage when managing him, while also removing the need to touch him. Of note, as Figure 6:7 illustrates well, Brother was only ever observed to exercise passive resistance during police arrests. In opting to remain seated on the ground, arresting police officers are required to lift him onto his feet. Sometimes he was observed managing to remain cross-legged in a seated position as he was carried away to the police car. 


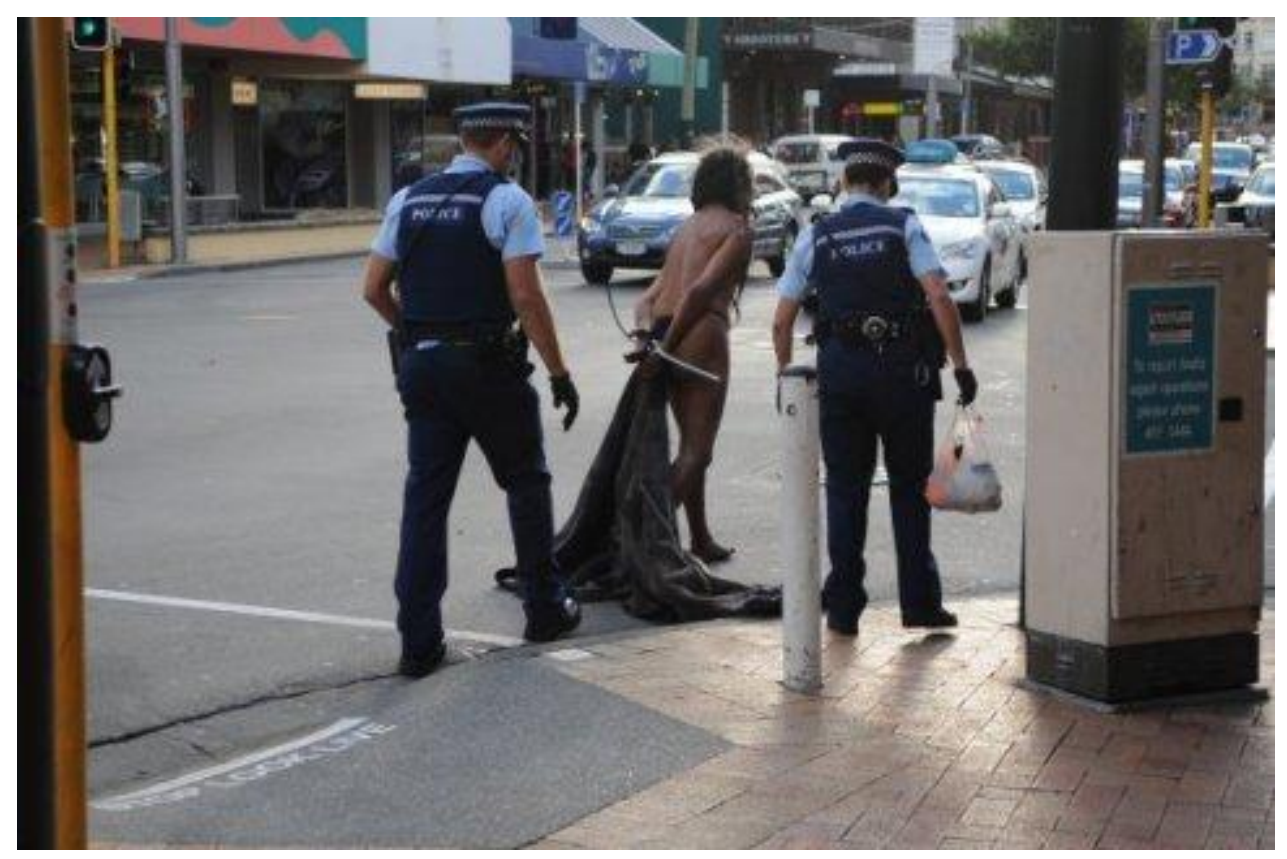

Figure 6:6 Brother under police arrest on the Public Bar corner

Source: Google image search, keyword 'Blanket Man', photographer unknown

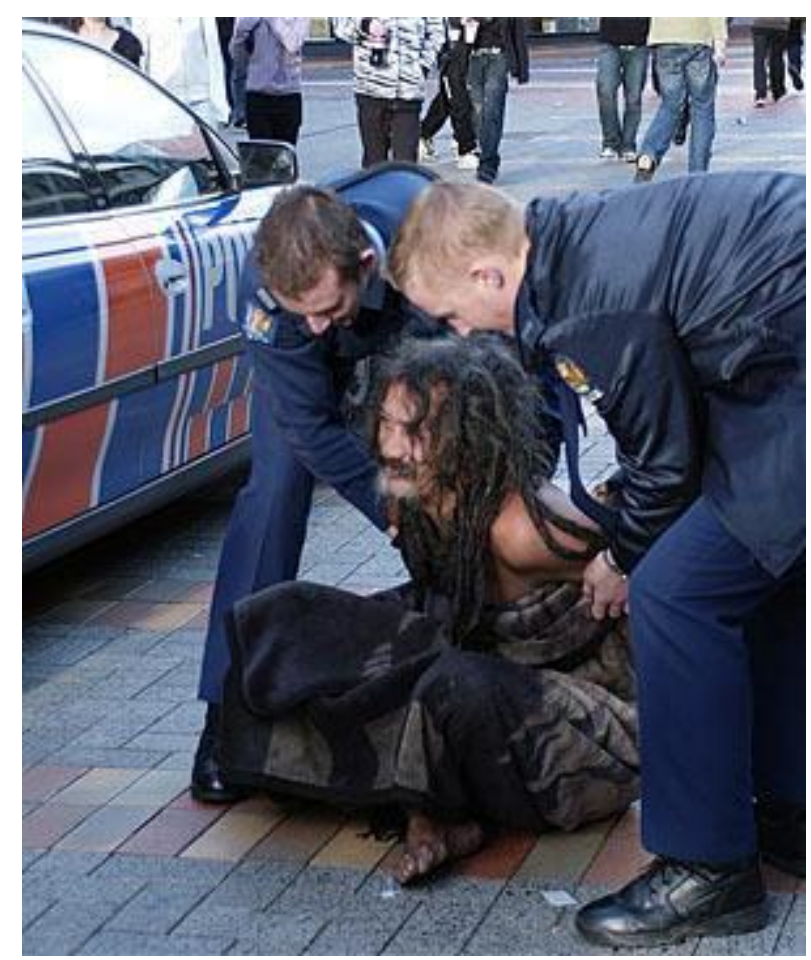

Figure 6:7 Brother exercising passive resistance

Source: Google image search, keyword 'Blanket Man', photographer unknown 
It is within such incidents that the interplay between (spatial) agency and structure becomes especially amenable to examination. It has been suggested that an emancipatory critique of a notion of homelessness as a form of freedom from conformist control is possible (Cresswell, 1996; Sibley, 1988). Yet the mappings of Brother's ordinary everyday fit within Sibley's (1995) framing of a 'geography of exclusion' which elaborates the way negative feelings about people marked as different may also be associated with, and projected onto objects and spaces perceived as polluted by the presence of non-conforming people. Consequently, public space is a site where difference is contested and where territoriality becomes "an intrinsic part of the organisation of power, and the control of resources and people" (Cresswell, 1996, p. 12).

Hacking's (2007) framework conceptualising the way classifications of people and people classified loop back changing the classifications, as discussed in the previous chapter, clarified that two forms of generated knowledge - both popular and expert - shade into each other and work within institutions to reinforce legitimacy, authenticity, and 'status as experts'. This, Hacking asserts, accounts for how professional intervention can loop back to affect the everyday lives of people. The remainder of this chapter will explore these claims within a trajectory of legal responses evolving in reaction to Brother's life lived in city space.

As has been explained previously in this thesis, to be a homeless person living on the streets in Aotearoa New Zealand is not an illegal state of being. However, as was also discussed, homelessness is overwhelmingly negatively constructed in ways that emphasise homeless people as dirty, diseased, and dangerous, and as posing a nuisance threat to the lives of housed others. The previous chapter further clarified that although there are currently no formal anti-homelessness laws in New Zealand, in Wellington, various informal and formal social control mechanisms do operate to monitor and criminalise the everyday activities of homeless people in public space. Consequently, homeless people's presence within public spaces was shown to be often implicitly or explicitly contested. 
In Brother's case, court documents dating back to his arrival in Wellington portray a relentless trajectory of legal action that has occurred in response to his activities in public space. The majority of charges relate to Brother's cannabis-smoking and alcohol consumption in public places. Less frequently, other charges relating to offensive behaviour such as public nudity and alleged urination in public, as well as driving offences (driving a motor vehicle with excess breath alcohol and careless driving). While these behaviours undisputedly constitute criminal offences under New Zealand law for anybody committing them, relentlessly penalising Brother through the criminal justice system realised a futile cycle of arrests, bail conditions, and sentencing such as fines, community service, and incarceration. While numerous court documents detail the nature of offending, sentencing decisions and so on, the following example represents a conundrum created for Brother through many sentencing decisions.

In 2006, a District Court judge, noting that Brother had accrued $\$ 6000$ in outstanding fines, acknowledged that as he was of limited means it was becoming abundantly clear that he could not pay court issued fines. He also acknowledged that Brother had been previously assessed as unsuitable for community work. Nonetheless, he considered community work was the appropriate sentence, and if he did not do it, he warned Brother would go to prison. Brother's lawyer, Maxine Dixon, appealed against the sentence, advising the Court that she had accompanied Brother on the three previous occasions that he had reported for community work, and he had been unable to partake as he had not worn shoes for about seven years. Therefore, she argued, it was unlikely he could ever wear them again and walk without severe blistering resulting. The nature of the community work required shoes to be worn, thus, on appeal, Brother was once again assessed as unsuitable (Mallon, 2006).

Other judicial rulings imposed conditions that affected how Brother used city spaces. These conditions included trespassing Brother for periods of time from 'primary locations' therefore disrupting his lived sense of space in regular habitats. For instance, during one District Court appearance in June 2007, a bail condition was imposed on Brother trespassing him from Manners Mall. At that time he was 
currently dwelling in Manners Mall because he had previously been trespassed from both Courtenay Place and Cuba Mall (where each of his other primary locations are sited). On appeal, Dixon had argued on his behalf that conditions prohibiting him from various locations in this way breached his right of freedom. She also argued that the latest conditions would not alter Brother's type of offending, given his offences were not location specific. Duneier (1999) makes a similar argument in Sidewalk when recognising because street dwellers do not have private homes, this means that their activities conducted in public space, are often perceived as inappropriate or as constituting illegal offences. Though the judge had replied she was not convinced, she had quashed the condition and had instead imposed a condition of bail forbidding Brother from using any drugs unless they were of the prescription variety (Fieldwork: 27/06/07).

By 2008, other court documents deriving from another appeal Dixon had lodged on Brother's behalf revealed bail conditions were once again prohibiting him from entering Courtenay Place. Yet the court documents also recognised that given Brother's reoffending rate (by then dozens of times over several years), it was apparent he was going to continue to offend. While it was also noted that remands in custody and sentences of imprisonment were not going to stop him offending upon his release, it was agreed that "at least while he is in custody the opportunity to offend publicly disappears" (Young, 2008). Although the condition preventing him from going to Courtenay Place was overturned, it was replaced with another condition that aimed to banish Brother from the city altogether. The judge's ruling stated, "That Mr Hana not come within 3 kilometres of the Wellington Town hall, save to attend Court and save to attend a pre-arranged appointment with his counsel." Despite the judge recognising that such a condition placed a significant restriction on Brother's right of movement by acknowledging, "that it may be $\mathrm{Mr}$ Hana is incapable of obeying these conditions". The judge also ruled that if Brother breached these conditions, "then he can expect a remand in custody" (Young, 2008).

Perhaps the most unusual bail condition placed upon Brother was one in which he was ordered by a District Court judge to wear underwear in public. This unique 
bail condition was subsequently reported on the front page of The Dominion Post on New Year's Day (Fawkes, 2009) and was accompanied by an image of Brother wearing underpants that were just visible under his loincloth. ${ }^{40}$ The corresponding article informed readers that Brother was again back on the streets having spent a week in prison for cannabis possession and indecent exposure. Lawyer Maxine Dixon was reported as having told the judge that allegations that Hana had exposed himself would be contested. Dixon then offered the following interim defence: "He wears high-risk clothing. It's a way of life rather than a deliberate attempt at lewdness." Although this example further suggests that Brother's presentation of his self in public space was also becoming subject to surveillance and criminal justice intervention, in the following chapter, I chronicle the way court ordered underwear, later became quite literally a case of 'medically prescribed boxer shorts'. This development emerged as Brother's rebelliousness and his persistence that continued to claim city space as lived space saw a shifting re-categorisation of him from 'bad' to 'mad'. This was to bring intervention of a different nature in order to rein him in and curb his activities. I introduce this development next.

During 2009, in response to Brother's continued offending, legal interventionist processes began to include a monitoring of Brother's mental health with the courts directing he undergo psychological assessments along with physical tests. These were undertaken at Wellington Hospital, and it is my understanding that these were done to explore the possibility that some problem of a pathological nature might be responsible for Brother's insistence to live and offend in city spaces, despite the numerous punishments that had been meted out by the courts. For example, when once again in the District Court observing another of Brother's court appearances on charges of smoking cannabis in a public place, the judge asked the court, "Do we have the results from Mr. Hana's CAT scan?" A court official had shuffled through papers before responding, "Yes we do and all normal

\footnotetext{
${ }^{40}$ Note here how Brother resists at least partially by continuing to wear his loincloth over the underwear.
} 
your honour" (Fieldwork: 28/11/08). Later, back on the corner, Brother had asked me "Did you see them trying to pull that mental health CAT scam [sic] thing on me again?" (Fieldwork: 28/11/08).

Then in 2010, during another corner conversation, this time on a relatively quiet 5am street, Brother offered, "I've seen the psycho [psychiatrist] down at the court house again. Full capacity was the verdict even though they're trying to say I'm mental - that nutter guy" (Fieldwork: 28/05/10). He paused before lamenting, "I can't even get arrested anymore, the rest of them are still going to the slammer but I haven't been in the big house (prison) for ages." ${ }^{41}$ Indeed, by now, I too was observing a notable shift in the way police were beginning to largely turn a blind eye in regard to Brother's illegal activities conducted in public space. This evolving shift bringing a period of relative in-action is to be explored in the following chapter, which examines what transpired next as a 'medicalisation of deviance' began to take precedence.

\section{Taking the path of most resistance: concluding thoughts}

In light of Brother's actions and authoritative reactions to his actions as I have discussed them, Cresswell's (1996, p. 23) assertion that "[t]ransgression is judged by those who react to it, while resistance rests on the intentions of the actor(s)" can be understood to take on relevance. Brother's activities in public space are intentional and because of this, can be understood as acts that constitute resistance (and persistence). The clearest elements of resistance are seen in Brother's day-in and day-out determination to live his life as he sees fit, despite the consequences of criminalisation he experienced as the authorities reacted to his persistence. As discussion has also revealed, another form of resistance is equally evident in his relations with police. Certainly, his relationship with the police does not constitute one of avoidance. On the contrary, it appears to take on the form of a defiant game.

${ }^{41}$ As my understanding of Brother grew, I came to appreciate that for him, going to prison every now and again offers him some respite from the street, especially during the long harsh winter months. In fact, going to prison is an event he has come to expect and on this note, he accepts that prison becomes, as he describes it, "an occupational hazard" and an unavoidable part of the territory which surrounds his chosen way of being in the world. 
As the police began to ignore much of his blatant rule-breaking behaviour, Brother's talk with me started to reflect a sense of pride that he was 'winning the battle' in doing things his way. Yet, sometimes a parallel tinge of loss, recognising it could now be 'game over', was also evident in his everyday talk. These types of comments generally lamented the way he was no longer attracting the same police attention.

As a transgressor and resister of the rules that surround Wellington public space, Brother's everyday acts can be understood to take the path of most resistance. As such, he commits a blatant form of 'spatial Garfinkeling', challenging taken-forgranted assumptions surrounding the proper use of public space, appropriate public behaviour, and commonly understood notions of home. This chapter has contributed new conceptual understanding about how Brother's particular form of 'spatial Garfinkeling' also positioned him 'in place' even as he is perceived 'out of place'. I have also endeavoured to impart a sense of how his execution of spatial agency enables him to 'make himself' while at the same time unsettling others. Inevitably, others' attempts to understand why someone would choose to live as he does have been shown to involve categorising and re-categorising processes as Brother becomes what Hacking (2004) identifies as a 'moving target' within the looping effect. As professional knowledge about a classification increases and the classified become known by definitive properties that can leave them open to interventions, changing the everyday lives of the classified, the changed people can also cause classifications themselves to be redrawn or modified.

I move toward closing this chapter by presenting three views of a street poster that appeared in Brother's primary space (1b) after he had been removed from the street following a court directed committal to Wellington Hospital's psychiatric unit (Ward 27) in 2010 (Figures 6:8, 6:9, and 6:10). Wellington City Council removed this street poster within 24 hours of its appearance. At the bottom of the poster, various logos reflect the creator's opinion about particular (knowledge) organisations that may have played a hand in his committal (Figure 6:9), and to the 
right of the image someone wrote "Stop stealing Ben" $" 42$ in black tip pen (Figure $6: 10)$.

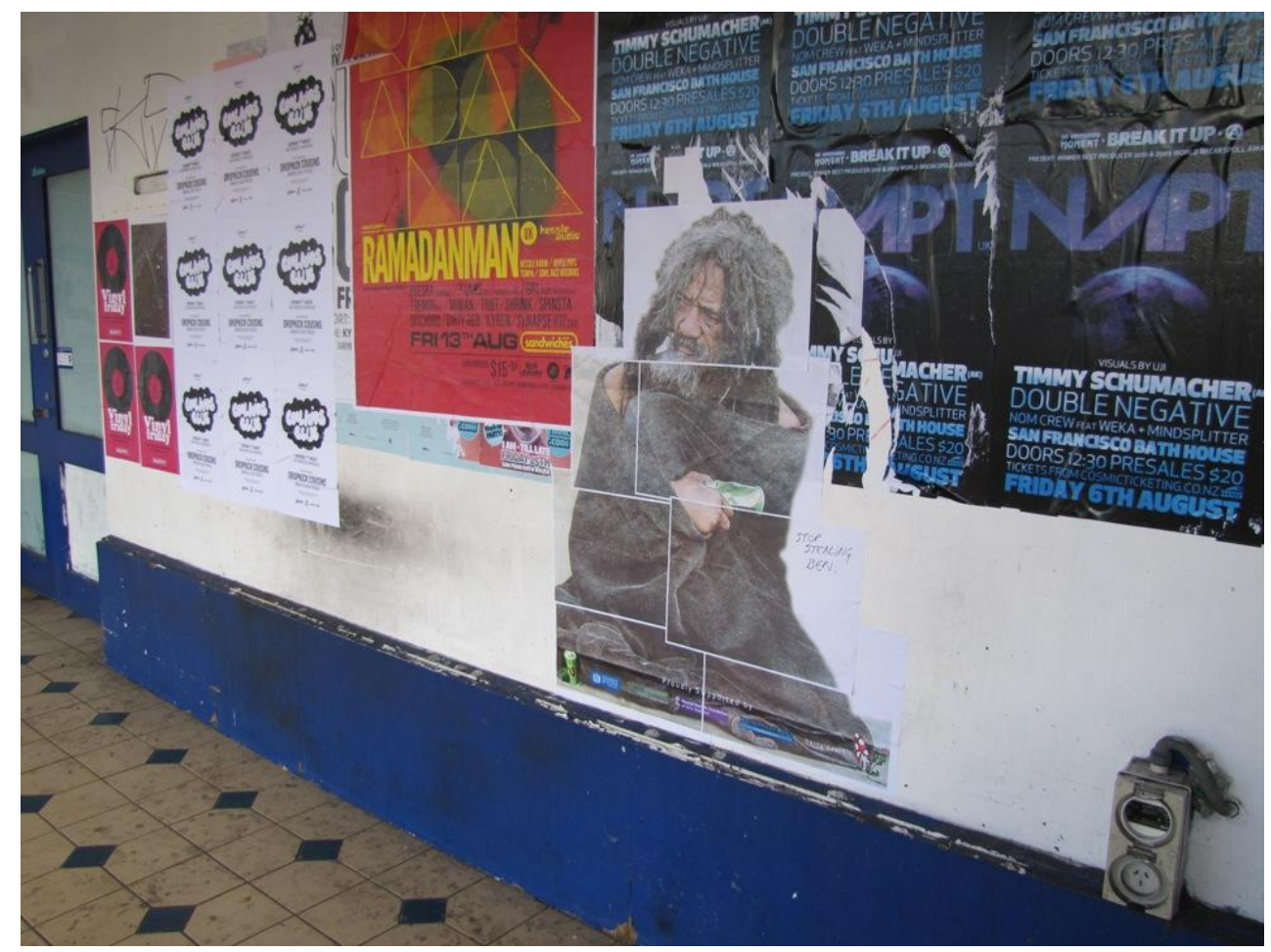

Figure 6:8 Representational 'narrative space'

Source: Author, 2010

${ }^{42}$ While I was taking the photograph (Figure 6:8), another street dweller had approached me to ask whether I was the person who had stolen his 'street brother'. 


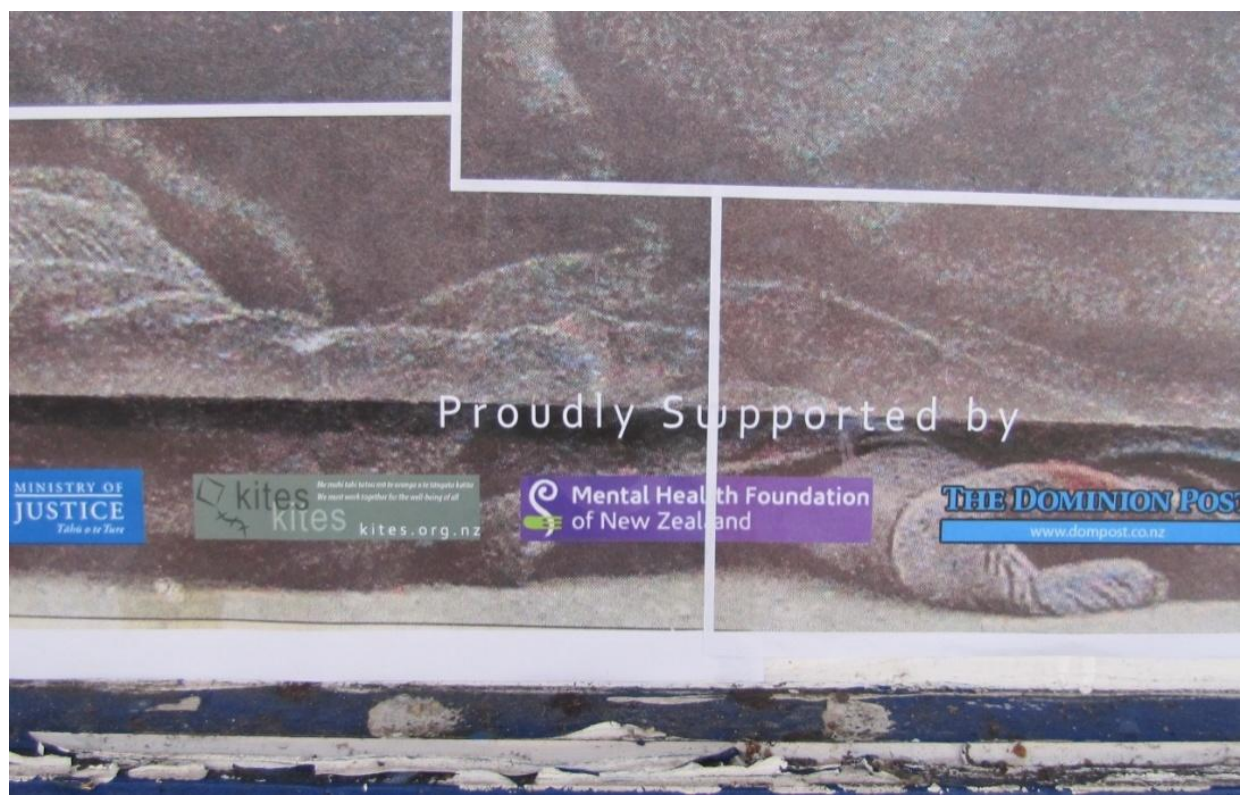

Figure 6:9 Logos of the organisations that the poster's creator considers played a role in Brother's committal

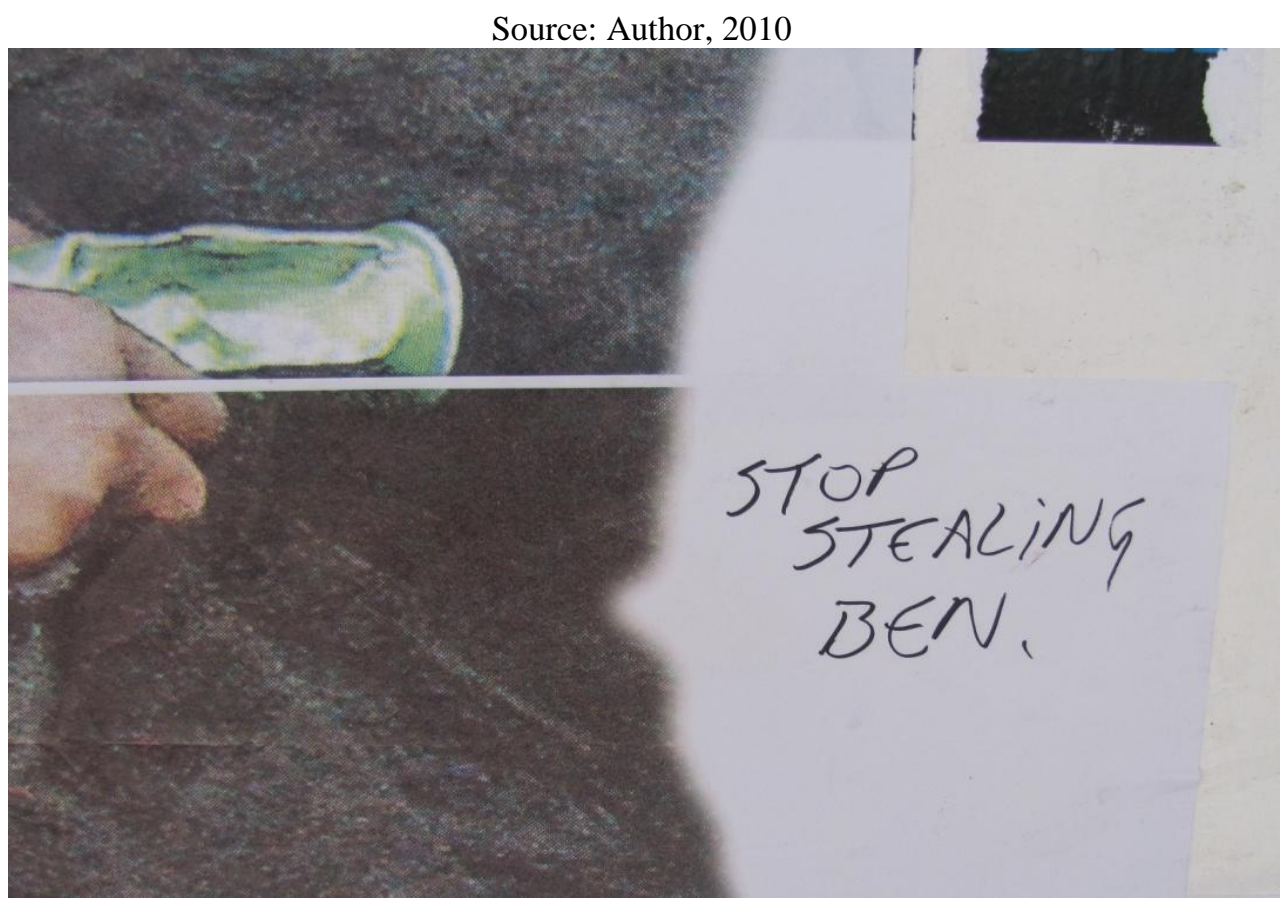

Figure 6:10 A message that was later added to the poster by another member of the public Source: Author, 2010

This anonymous gesture can be interpreted to symbolically reposition Brother back in his 'rightful' lived space. Moreover, this action by a member of the public bears testimony to the way many people admire and respect Brother's stance to live life his way. This street-based expression arguably resonates with Sibley's 158 
proposal that "the social self can also be seen as a place-related self which applies to stereotypes of the other which assume negative or positive qualities" (1995, p. 19). Sibley suggests a place stereotype can be a romantic representation of a particular location to which a person or social group are seen to belong or not. The street poster further reflects Sennett's 'narrative space' which to recall, observes, "it is enough for a space to seem rich with the history of place habitation" (p. 196). Despite the legal retaliation occurring in response to Brother's use of city spaces, a corresponding level of acceptance is also made evident through small mundane acts that recognise 'Brother's place', such as the street poster. Another example showing public acceptance of Brother's 'homely spaces' is found in Brother's retelling to me one day about being "dropped off at home" (to this location) earlier that morning by a prison van following his release from prison (Fieldwork: 03/07/09). Sennett's articulation of narrative space can be understood as taking on another dimension if one looks to the left of the street poster (Figure 6:8). There, Brother's bodily imprint can be seen as a black smudge on the white wall of the building. It marks the space where his head and shoulders usually pressed as he rested against the building's facade. It too also tells a story of past habitation in this space.

To end, I also return to Gieryn's (2000) articulation of 'lived in' space to propose this primary location along with Brother's other places of sustained habitation bring him an experience of place in 'homely spaces'. The sequence of spaces/places that I have identified as marking the core cartographic features of a subjective city-as-whare for Brother clearly fits with Gieryn's (2000, p. 472) contention that "[p]laces are made as people ascribe qualities to the material and social stuff gathered there: ours or theirs, safe or dangerous, public or private, unfamiliar or known...". This claim can perhaps be understood within Brother's own 'sometime' directive to me as I was leaving the field having observed it. This directive was heard to invite me into his lived space of home-within-the-city-aswhare as it told me to "make sure you 'drop in' again later" (Fieldwork: 08/04/2009, for example). Finally, it has been the overarching aim of this chapter to demonstrate the numerous ways in which space and spatial issues are central to 
somebody like Brother, where home is a place that must be maintained and managed in busy urban space. 


\section{Chapter Seven}

\section{The socio-spatial body made meaningful}

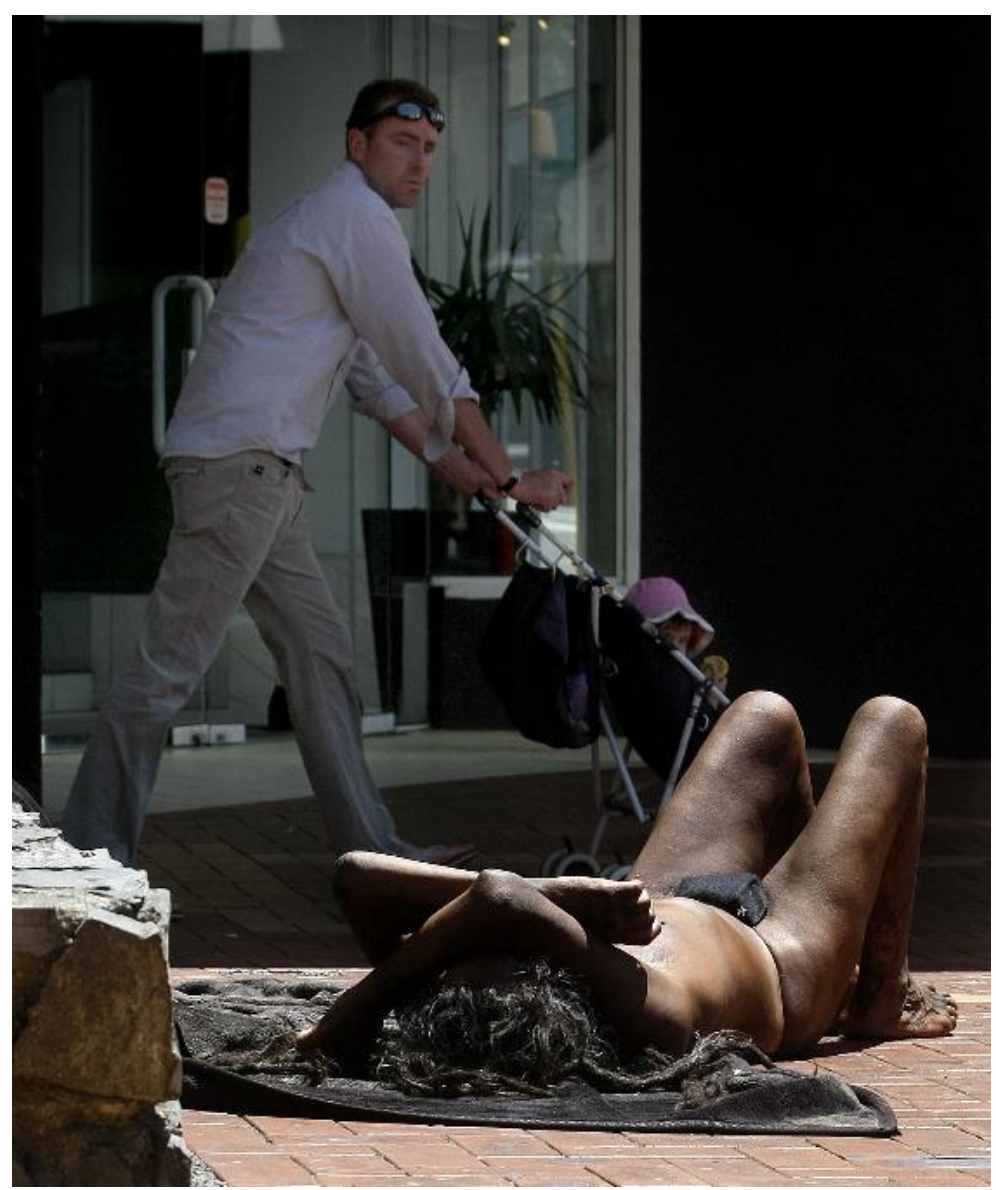

Figure 7:1 Occupying city space as intimate 'sunning space'

Source: Copyright Fairfax Media

\section{Introduction}

Just as we fill our jails with those who transgress the legal order, so we partly fill our asylums with those who act unsuitably (Goffman, 1961b, p. 248).

We medicalise kinds of deviant people relentlessly, not always with success...In many cases, we try to make unfavourable deviants as close to normal as possible (Hacking, 2007, pp. 309-311). 
The preceding chapter established how Brother's use of public space as personal (home) space is monitored and how his activities within those spaces are often criminalised. A trajectory highlighting some of the responses taken towards his presence and actions in public spaces exemplified the way in which legal interventions can prohibit him from occupying regular locations not only within his locale of Courtenay Place but also within the wider city. By extension, Brother's breaching of trespass orders, together with some sentencing decisions resulting from other offending committed through his routine activities, were shown to culminate in his temporary removal from the streets for periods of time as he was incarcerated.

I also introduced how a parallel surveillance of Brother's mental health was beginning to infiltrate court decisions and rulings. As discussed, this involved psychological testing and medical procedures that probed whether any pathological or physiological reason could possibly underpin Brother's continued resistance to being housed, despite ongoing opposition and punishment resulting through that choice. Despite all tests finding Brother to be in good mental health and operating in 'full capacity' of his mental faculties, a District Court judge still ruled to have Brother committed into Wellington Hospital's psychiatric unit. However, the street poster that anonymously appeared on the wall in one of Brother's primary locations immediately following that committal (Figures 6:8, 6:9, and 6:10) reflects that some ordinary members of the public understood that most recent action to be ungrounded. Indeed, Errol Wright, a Wellington filmmaker whose 2003 documentary film centred on a protest staged by homeless people, and featured Brother as the key character (Wright \& King-Jones, 2003, first introduced in Chapter Three), posted the following comment on 'Blanket Man's' Facebook profile just after Brother was sentenced and committed:

Despite two psychiatrists testifying that he is in good health Brother aka Blanket Man has been imprisoned by district court Judge Paul Barber to Ward 27 at Wellington Hospital for psychiatric treatment. This is not the first time they have tried this exact tactic to lock him away, but every other time the psychiatrists have said the same thing - he's not mad or crazy. This time however Judge Paul Barber has used his judicial powers to lock him away despite the evidence produced to the court to the contrary. "I think it's for his own interests" Barber said, however that's for 
psychiatrists to decide, not a district court judge. The system is unwilling to engage with people who have radically different ideas about society and the status quo, and when they are challenged the State seeks to lock them away by any means possible. FREE BROTHER! (Wright, 2010)

This chapter builds on the preceding discussion by exploring the way the body and its objects can be included as an integral part of spatial analysis. Specifically positioning the public body of Brother and his two material objects - blanket and loincloth - central to my analysis, I examine the various ways in which the homeless body is said to intrude into everyday awareness and is made meaningful (Kawash, 1998). A primary aim is to understand within such battles that seek to reclaim public space, how the "microlevel of the individual body" (Kawash, 1998, p. 326) emerges as the site of contestation as those holding differential power can intrude upon the personal space of 'troublesome' bodies. The task is to show how the material fleshy body, "by occupying public space, becomes itself the threat" (Kawash, 1998, p. 325). I demonstrate that new knowledge about 'the criminal' (Brother) that is brought to light from the 'community of experts' (Hacking, 1986) coincides with a re-categorisation of Brother. I argue these developments were to mark an end point for Brother severely altering his lived experience.

As Hacking (2007, p.311) observes, "Kinds of people who are medicalised, normalised, administered, increasingly try to take back control from the experts and the institutions". Similarly, as included in Chapter Three, de Certeau (1984, p.xix) points to how ordinary people can find ways to use tactical and spatial resistance so as to resist the strong, or that of an imposed order. Ultimately, then, even as Brother's body and his attire are subjected to informal and formal social control mechanisms, they are equally demonstrated in this chapter to have key spatial roles in enabling Brother's continued expressions of agency and his ability to persevere in living his elected lifestyle in the face of conflict.

In order to best achieve these goals, it becomes necessary to sociologically deconstruct the body of Brother in order to understand how its parts and actions are understood to 'make trouble' in public space for (housed) others. However, I want to stress that taking this reductionist approach does not intend to imply 'the 
homeless body' of Brother is an entity of objectification. That is, to borrow from Kawash (1998, p. 324), "the homeless body is not the same thing as the homeless person or the human body that homeless people necessarily possess or inhabit", but rather "it emerges as a particular mode of corporeality in contingent circumstances through which the public struggles to define and secure itself as distinct and whole".

Structurally, this chapter begins by briefly outlining the theoretical influences underpinning my conceptual approach to the socio-spatial body. Following this, is an examination on the role Brother's body plays in enabling him to socially organise himself among others in daily public life. Key findings represented in the data are then summarised and contribute to my analysis in the remainder of the chapter. Focus is then directed on how (housed) others sense-making processes perceive Brother's body to be socially disorganised and 'troublesome'. Three main areas of contestation then explore the horizontal, dirty, and semi-naked body of Brother to conceptually understand why his socio-spatial presence is so problematic for others and the effects of this construction.

\section{Conceptualising the socio-spatial body}

As was explained in Chapter Three, Garfinkel (1967) encourages analysts to study mundane actions and everyday practices of people without privileging sociological categories. Rather than seeking to produce 'laws' of general behavior, this approach seeks to understand human behaviour by examining the methods that people employ to make sense of the social world. This chapter (concerned with the nature of social action, everyday structures of surveillance and control, and how knowledge is socially constructed) draws on Garfinkel's breaching processes which, to reiterate, constitute a type of empirical inquiry where normal interaction is interrupted. By specifically exploring the homeless body as a particular mode of embodiment, I am able to elaborate on how the socio-spatial body is made up and categorised through spatial practices.

Erving Goffman positions the body as the dominant vehicle of social interaction and focuses his attention on the immediacy of the more personal and physical 164 
aspects of face-to-face interaction and mutual observation in daily life (Jenkins, 2008; Shilling, 2003). Given a distinctive feature of Brother's everyday life determines that all of his actions and activities are socially situated in the immediate presence of others, incorporating Goffman's insights into the body as a component of human agency, allows for understanding the way the body is shaped by society and how the existence of the body as a corporeal phenomenon can itself affect how people experience their bodies (Roberts, 2006, Shilling, 2003).

For Goffman, agency is located in the way we choose to act and manage our appearance within different circumstances. In particular, Goffman's works The Presentation of the Self in Everyday Life (1969) and Behavior in Public Places (1963a) are especially useful for interpreting how Brother presents and conducts himself within his routine everyday activities and social interactions with others. Moreover, central to Goffman's argument in Stigma (1963b) is the idea that everyone has at one time felt stigmatised in the presence of others. This work is particularly useful for understanding the way we categorise others during social interaction by assessing characteristics that may be read as tainting the individual. Goffman describes discrediting traits of stigmatised individuals as "blemishes of individual character" (1963b, p. 3) and observes the way these are often assigned to people who are homeless, unemployed, addicted to alcohol, drugs, or both, imprisoned, or mentally ill. As opposed to others that Goffman terms 'normals', stigmatised persons face discrimination and reduced life chances.

Following Goffman and placing emphasis on the "embodiment and spatiality of interaction" (Jenkins, 2008, p. 91), questions can be asked of the data about how human resistance to categorisation processes might challenge and transgress the boundaries of taken-for-granted social and bodily norms. Conceiving the body as a corporeal phenomenon and exploring the physical and social characteristics of Brother's body as both the medium and raw material through which he navigates the world, further enables examining the body as an entity invested with meaning that can also place restraint on actions (Shilling, 2003). To achieve these aims, I explore the dirty, horizontal, and semi-naked body to examine the specific character of Brother's body in the setting of the streets of Wellington to understand 
how it is socially constructed and constrained, and to identify how Brother exercises agency in responses to this.

\section{The homeless body in motion}

Following Garfinkel (1967), I show that knowledge of a context is important as it is by knowing a context that social actions can be understood. The first fieldwork excerpt in this chapter contextualises Brother's socio-spatial presence in the city, detailing some of Brother's encounters with others as he went on a hīkoi, attending to mundane chores. Given these data derive from several hours spent on the trot capturing the spatial footing of Brother's experiences and noting what was 'observably the case' (Sacks, 1992), this observation is included at some length. This move is warranted given the data not only contextualises, it evokes in the analytic vein, several important ideas that are to be developed throughout the remainder of the chapter. In the broadest sense, this fieldwork stresses the ways in which ordinarily simple tasks were observed as often being made difficult for somebody, who, to paraphrase Duneier (1999), lives on the wrong side of traditional normal dichotomies, but is nonetheless still tied to the institutions of control and rehabilitation. Consequently, this material describing Brother's activities and the mundane characteristics of his social existence has utility for understanding where these fit within larger schemes or the wider social order.

An elderly Māori woman and her adult son are sitting on the ledge to Brother's right. Noticing me arrive, he tells them, 'Oh oh gotta go to work now'. The woman says, "where did you say you were going'? "To work" he repeats in a tone suggesting the activity is an ordinary everyday routine. Looking puzzled for a moment she then turns her attention to me saying "Me and my boy stop most mornings to say hello. This is the first time I've ever seen this, someone living on the street. I'm not from Wellington". As she speaks, Brother is busily gathering up his plastic bag of belongings. "Just getting my briefcase sorted" he chortles. As I wait, a commercial van pulls up and a man leaps out to spray disinfectant around the entrance to the bank to Brother's right. Giving it a cursory mop, he grabs a shirt tie someone has strung above Brother's space, tosses it into the gutter and without acknowledging any of us, hops back into his van and drives away. "Ah good to have the whare [house] cleaned" says Brother who is clearly full of good humour this morning. He is now performing a series of movements shifting his self off the ground and onto his feet. It is quite a process as he pauses and stretches, grunts and groans; 
"Ah" he says arching his back and cursing his body, "Bloody old fart bones". The woman watching him asks, "What's the matter does your bum hurt"? Now on his feet and adjusting his blanket more firmly around his body, he chooses to ignore her question. She asks me, "Does he not have a house. Does he not want to live in a house"? I answer no and no as Brother interjects telling me "Come on let's hīkoi".

Walking at a fair clip, Brother barely bothers checking on traffic before stepping out to cross any roads. I opt to wait until it is safe to cross and then have to jog a little to catch him up. As we near a busy six-lane road I tell him that one day he's going to get hit by a car if he's not careful. "You're wasting energy on fear" he replies. Reaching the kerb, he makes an exaggerated point of waiting for a break in the traffic before stepping onto the road and walking alongside several moving cars. Looking back over his shoulder at me, he calls "these are for you". A big truck is approaching from the right and Brother stands still in its path calling again "what about a truck, you never said anything about a truck". The truck slows almost to a stop so as to avoid hitting him. Brother resumes crossing the lanes of traffic. We arrive at Downtown Community Ministry and dropping his bag at my feet he now enters the building alone. Within moments he is back and as he sits himself down on the ground, he says he'd forgotten he's banned from the premises because he does not wear a shirt. After smoking a cigarette, he stands saying "They'll see me outside though" and disappears around the side of the building. Heading back towards me a few minutes later, a patched gang member breaks from the small group milling nearby to intercept asking, 'You gotta smoke brother'? Brother tells him "I don't help others die of cancer". The man shrugs and asks me instead. Handing him one, I note this is the first time I've ever heard someone ask Brother for anything. Brother gestures with his head for me to follow him. Walking away he states "To WINZ now".

A chilling wind whips around us as we walk up Dixon Street and turn into Willis Street. Brother seemingly unbothered by the bitter cold and squally rain chats away about his court appearances and how much he thinks his many arrests may have cost the system. Entering WINZ I note a short queue of people waiting at reception. Brother goes and sits on the floor away from the queue. I suggest that if he wants to be seen we need to wait in the queue. When it is our turn, he puts his release form from Rimutaka Prison on the counter to show he is there to collect his 'Steps to Freedom' cheque. ${ }^{43}$ When the receptionist goes off to check something he returns to resume his earlier position on the floor. Within seconds he is approached by two burly security guards who inform him he is trespassed from WINZ. They now come and tell me the same thing. We are joined by a clerk who tells me his cheque will be taken to him outside before appealing to me "if

${ }^{43}$ Inmates who have been in prison for more than 31 days are eligible on release for the steps to freedom grant, which is administered by the New Zealand Income Support Service. 
you can just get him out". Telling Brother that we have to wait outside, he follows me and sits down on some steps outside near the entrance. Three Parkwise Wardens stop "are you just out of jail bro" one asks. "Yeah" says another "we haven't seen you for ages". "Ah it's all bullshit in there" Brother says gesturing instead to the WINZ office behind us. They all laugh. Eventually the clerk comes out and tells Brother, "just scribble your acceptance here" and then hands him a cheque.....

Walking down Willis Street now, a toddler being pushed towards us in a buggy stares openly at Brother and says loudly "That man doesn't have any clothes on". Passing a construction site on the opposite side of the road, several workers - at least four floors above us - holler down their greetings to Brother who pauses for a moment to laugh up at them. Turning into Lambton Quay we are suddenly thrust into the midday congestion of corporate workers. As we walk shoulder to shoulder amid the throng of pedestrians, Brother's blanket brushes the suits of men who pass us walking the other way. I note ahead the regular presence of the zealous street preacher who hands out religious tracts to passersby. On seeing Brother, he becomes animated and tries to thrust several leaflets at him as we pass by while rambling about sin and being forgiven. Brother tells him "Keep breathing and shuddup". Continuing on down Wellington's 'Golden Mile' many people acknowledge either him or the pair of us by smiling or saying hello. We enter a bank and I follow Brother to the teller. Handing the teller his cheque, he asks could he put his cash in a bag. Leaving the bank he tells me he will get us some kai [food]. I follow him into a fresh fish shop where he is treated like a regular customer. He simply has to point at the display in the window and the man retrieves two punnets of raw oysters. "Here you go boss" the fishmonger says passing him his oysters. Brother gives him a crisp fifty dollar note and receives ten dollars change ${ }^{44} \ldots .$.

The day's business now complete, we turn and begin to walk back to Courtenay Place. A small boy walking towards us utters "Hi Blanket Man". One of my daughter's and her flatmate also approach us. "Hi Mum" she says as they pass us by. In Manners Mall many teenagers try to engage Brother by calling out to him. He nods at some and ignores others. Those acknowledged, grin and seem pleased. One youth lets out a whoop and high fives his mates. Several minutes later we are now on the 'home straight' striding back to Brother's ANZ location.....(Fieldwork: 23/06/08).

${ }^{44}$ In New Zealand, where oysters are an expensive delicacy, 'Bluff' oysters purchased on this day by Brother would be considered a luxury by most people. 


\section{What does this vignette reveal?}

This vignette illustrated an ordinary member of the public attempting to make sense of Brother's life lived on the street. Her questions are fobbed off by Brother, who, instead of answering them seriously, combats her curiosity with nonsensical retorts. His explanations about going to work, packing up his briefcase and getting his whare cleaned, challenge any suggestion that he is 'homeless'. Rather, he playfully aligns himself with activities normally associated with house dwellers and conventional obligations normally associated with that lifestyle. The woman still searching for sensible answers had then turned to me therefore interpreting my position within Goffman's role of 'wise person' as was discussed earlier in Chapter Four. Further, the swift but specific clean up conducted by the commercial cleaner directly around where Brother dwells, points to the way spaces inhabited by the homeless are in turn considered defiled through their presence. The data also show Brother's risk taking behaviour and rebellious actions that challenge the taken-for-granted social order or 'the rules of pedestrian traffic' (Goffman, 1971) by not managing his body in pedestrian and vehicular traffic in adherence with these rules. Moreover, the data illustrate the way in which informal and formal social control mechanisms attempt to regulate 'the other' in social life while illuminating how, because of this, simple tasks such as accessing a homeless advocacy agency become difficult. For example, Brother's treatment at DCM that saw him dealt with outside the building, raises concerns regarding the way in which applying moral sanctions surrounding such things as acceptable dress codes can exclude the very people the agency is there to support. Similarly, next at WINZ, Brother was asked to leave because a trespass order taken against him prevented his physical presence in the building, highlighting another case where barriers hinder accessing services. As Brother himself put it to me once he had finally received his cheque, "At least with you here, I'm not going away totally empty-handed". In the WINZ situation, security guards and a WINZ employee singled me out, - this time to take responsibility for Brother. A toddler can also be heard to comment on Brother's appearance. Despite Brother being encased in his blanket on that day, even a small child did not consider it to be 'normal' attire. However, also evident, is much friendly recognition of Brother. Construction 
workers holler down, a fishmonger clearly familiar with Brother's purchasing needs, calls him 'Boss', and teenagers vie to be singled out by his attentions.

Having provided but just the briefest of summaries, it is nonetheless clear that Brother's body set against the background of the daily round is a very visible body that is disconcerting to many. As the field notes show, Brother's embodiment within inner city spaces also compels people to look at the spaces he occupies differently. The woman in the vignette exemplifies that for many people, seeing such an overt manifestation of homelessness is a new experience. The excerpt is illustrative of how Brother was observed throughout my fieldwork responding docilely to obstacles, and that while his appearance and some of his activities might 'make trouble', his conduct towards others whether neutral, friendly, or humourous, is nonetheless checked.

Kawash's (1998, p. 335) work on the homeless body asserts that despite public intolerance surrounding homeless people, "the body must have a place". Consequently, the material existence of homeless people cannot be denied. Kawash contends, "the homeless body must be seen as a specific mode of embodiment, one that requires its own specifications" (1998, p. 324). In order to explore these claims, I next consider how Brother embodies space in particular ways so as to demarcate lived in space while also creating some private moments for his self when dwelling in the street setting.

\section{The private body in public space}

In stark contrast to the experience of house dwelling where walls of the house afford privacy and the house itself is usually shielded and segregated from the one next door by boundary fences demarcating private territory, street living offers no such private or 'back stage' region (Goffman, 1959). Therefore, to manage at least some temporary respite away from the relentless demands of a life lived publicly requires individual resourcefulness and strategic planning.

Julia Wardhaugh's (1999) work has explored how homeless people find ways of being homeless so that they might feel safe when living without any private space 170 
of their own. Wardhaugh identified two opposing bodily responses of 'contraction' and 'expansion' adapted by homeless people when living vulnerable existences in the open. 'Bodily contraction', refers to the way homeless people, and particularly homeless women, typically choose the 'path of least resistance', confining themselves to interstitial city spaces where they can escape the stigmatising gaze of the public and avoid the attention of the authorities. Bodily contraction also refers to how homeless people can retreat behind a barrier of their own skin by preserving personal information as a way of attaining some degree of privacy in a publicly lived life. Wardhaugh argues that for homeless people:

The body is the most fundamental boundary for the individual...the skin serving to both define the person and separate them from their environment... the body assumes an increased or even paramount, importance. Lacking access to that second skin, the home, the homeless body becomes the first and often only line of defence against a dangerous world (1999, p. 102).

'Bodily expansion' refers to a more common and masculine way of managing the dangers associated with homelessness. Rather than disappearing into marginal spaces, home territory within a wider cityscape is sought. For these homeless people, safety is perceived to not "lie in the shadows but in claiming the streets as their own" (1999, p. 103). Nominating the street as a "quintessential male space", Wardhaugh further observes that home territories may be robustly defended by a "safety in numbers" presence claiming ownership over city spaces (p. 103). Yet, as also noted by Wardhaugh, the majority of homeless people desire individual territory in public space. Therefore, in these cases, when physically protecting the boundary of the body and defending the space it occupies, violence can become the only recourse for extending control over intruding bodies.

\section{Brother's 'tricks of the trade': staking out a personal boundary in public space}

Brother's mode of using space involves occupying city footpath locations and busy corner junctions and through these ways of using space, his actions represent a significant departure from the way homeless people are usually described using space (see, for example, Kawash, 1998). Furthermore, his use of space goes 
against Wardhaugh's notion of bodily contraction. Rather than retreating into his skin, Brother's near-naked appearance in public space literally flaunts his skin. To reemphasise, Brother's body represents a 'larger than life' public presence and so in contrast with Wardhaugh's 'contracted body' is more fittingly described as a very overt 'expanded body'. Yet even as his body stakes out a very visible visceral presence in urban space, it cannot easily be explained by Wardhaugh's concept of bodily expansion because Brother does not use violence, nor does he seek to exert control over other bodies. In this respect, Wardhaugh's dichotomies are somewhat restricting allowing only a simplistic categorisation of Brother's body into one form or the other.

Through repeated observations an idea began to emerge suggesting Brother's blanket could fulfil a symbolic role besides just providing a functional measure of cushioning or warmth for his near-naked body. That is, metaphorically the blanket acts as walls around his body serving as the front line of defence for him on the street in contrast to the skin of the 'contracted body' (Wardhaugh, 1999). In this way, it serves as protective 'bodily armour' enabling him to defend and manage unwanted intrusions and trespass from others. I also observed how alternatively his blanket allowed him to extend the limits of the body expanding the space over which he could claim a sense of 'temporary ownership'. Though this could align with Wardhaugh's conceptualisation of 'bodily expansion', it is important to distinguish here that Brother's bodily expansion is realised via a blanket that becomes an extension of his body, and not through violence or exerting overt control over other bodies.

To understand the symbolic agency of the blanket and its role in demarcating personal territory, I draw from Goffman's (1971) spatial and bodily metaphor 'bodily preserves'. This concept describes how the self governs or inhabits, or is subject to and active in a set of territorial preserves. These preserves refer to space taken or used by a physical body when either motionless or in movement and the body's ability to assert itself through associated material artefacts. Goffman's eight preserves - personal space, the stall, use space, the turn, the sheath, possessional territory, information preserve, and conversational preserve - are intended to be 
understood both serially and in terms of coexistence, and so they offer a system of reference for exploring and understanding the significance of Brother's blanket as a marker of personal and private territory in the public setting of the street.

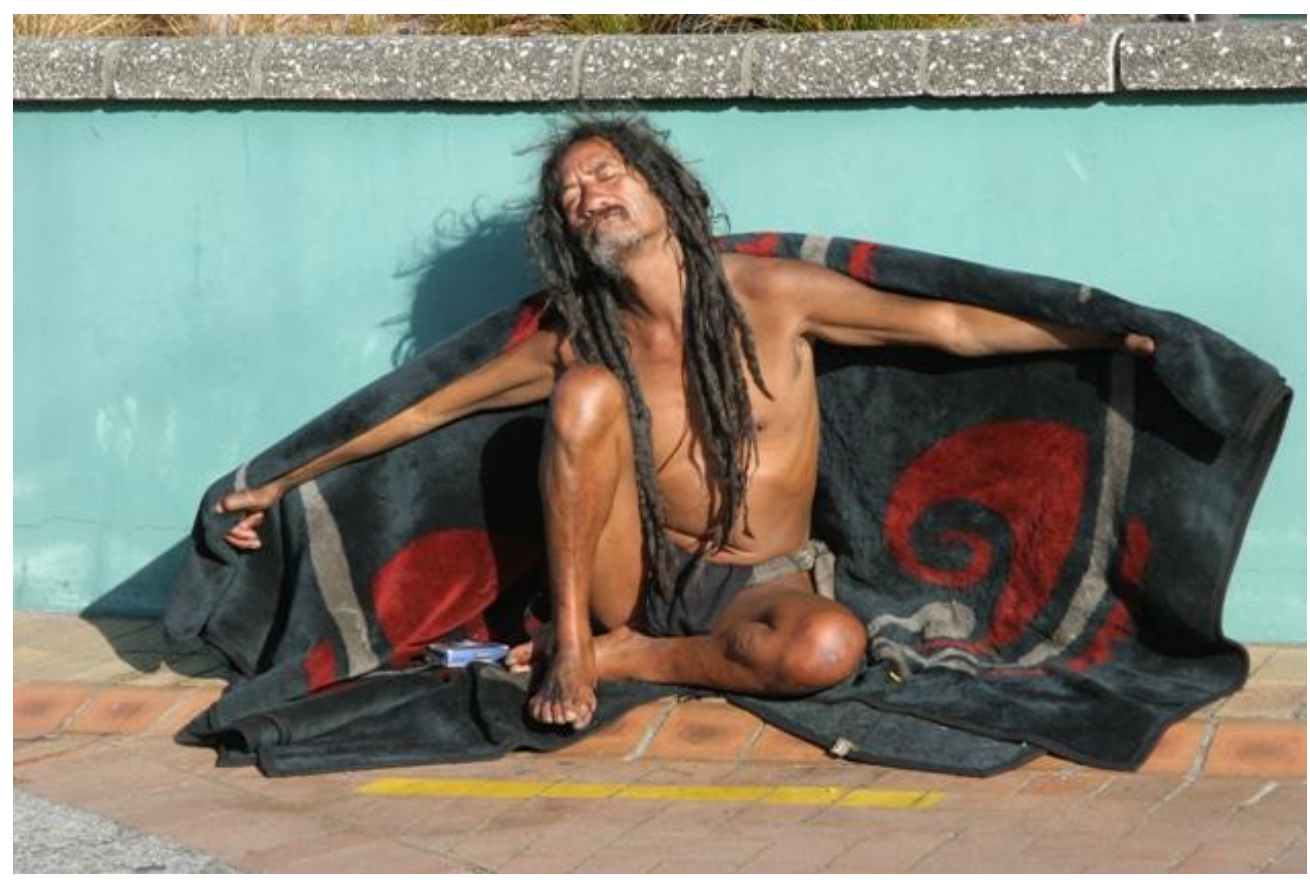

Figure 7:2 Expressing the self through a material artefact associated with the body ${ }^{45}$

Source: Belinda Brown Photography

For Goffman, at the centre of social organisation are 'claims' which are the entitlement to possess, control or use the 'goods' or desired object. The claim to a preserve is made visible by a sign of some kind, which Goffman refers to as a 'marker' of which there are three types - central markers, boundary markers and ear-markers. However, some territories such as a house are fixed and attached to an owner while others are situational and become 'claimed goods while-in-use' as for example, a hotel room. Consequently, temporary tenancies such as a park bench can function as a situational territory for homeless people. Finally, there are 'egocentric' preserves, which move around with a claimant, for example, a handbag or in Brother's case, a plastic carry bag. Such preserves are typically

45 Drawing on Goffman's dramaturgical metaphor, Brother's blanket as it is being used in this presentation of the self could also be perceived as a 'bodily prop' on street 'stage' space. 
claimed long term and the eight territorial preserves referring to the territorial functioning of the body are all of a situational or egocentric type.

To consider these preserves in regard to Brother's socio-spatial body, I will focus on personal, situational and egocentric territoriality. Starting with personal space, this refers to a temporary, situational preserve into whose centre the individual moves. Goffman views the skin that covers the body and the clothes that cover the skin as personal territory, terming these 'the sheath'. While he considers the sheath as the most basic minimal configuration it can nonetheless also function as a preserve in its own right, that is, as the purest kind of egocentric territoriality. Second, the spatial 'claims' Brother makes over footpath spaces can be understood as 'situational' preserves. As the claimant Brother avails himself of this public space over which he stakes a claim-in-use with his body marking the footpath as personal 'lived in' space. Although the footpath operates as a temporary tenancy, his blanket when laid out on the footpath, articulates and stabilises his claim to the space 'in use' providing him more room than would be ordinarily claimed as personal space by the body alone. In this way, his blanket becomes a portable 'stall' providing an external, easily visible, defendable boundary of a spatial claim. Not only does the blanket extend the limits of the body, it also acts as a 'boundary marker' in much the same way as lying on a beach towel does to claim 'temporary tenancy' on a section of beach. Accordingly, the blanket becomes an 'egocentric' preserve as it moves around with him. But because the blanket is identified with the self and also draped around his body, it is also a 'possessional territory' that allows him control as he moves across boundaries. In sum, the very notion of an egocentric territory suggests that the body is not only a preserve but also a central marker of various preserves as demonstrated by personal space, the sheath, the stall, possessional territory and so on.

So, how do Goffman's bodily preserves operate in practice in Brother's everyday street life? How does he claim space through his body, and how is this understood by the public? To answer these questions, and when keeping Wardhaugh's 'contracted' and 'expanded' body in mind, I draw from other fieldwork data 
exemplifying the role Brother's blanket has in achieving each of these opposing presentations of the self.

\section{The boundary of the blanket}

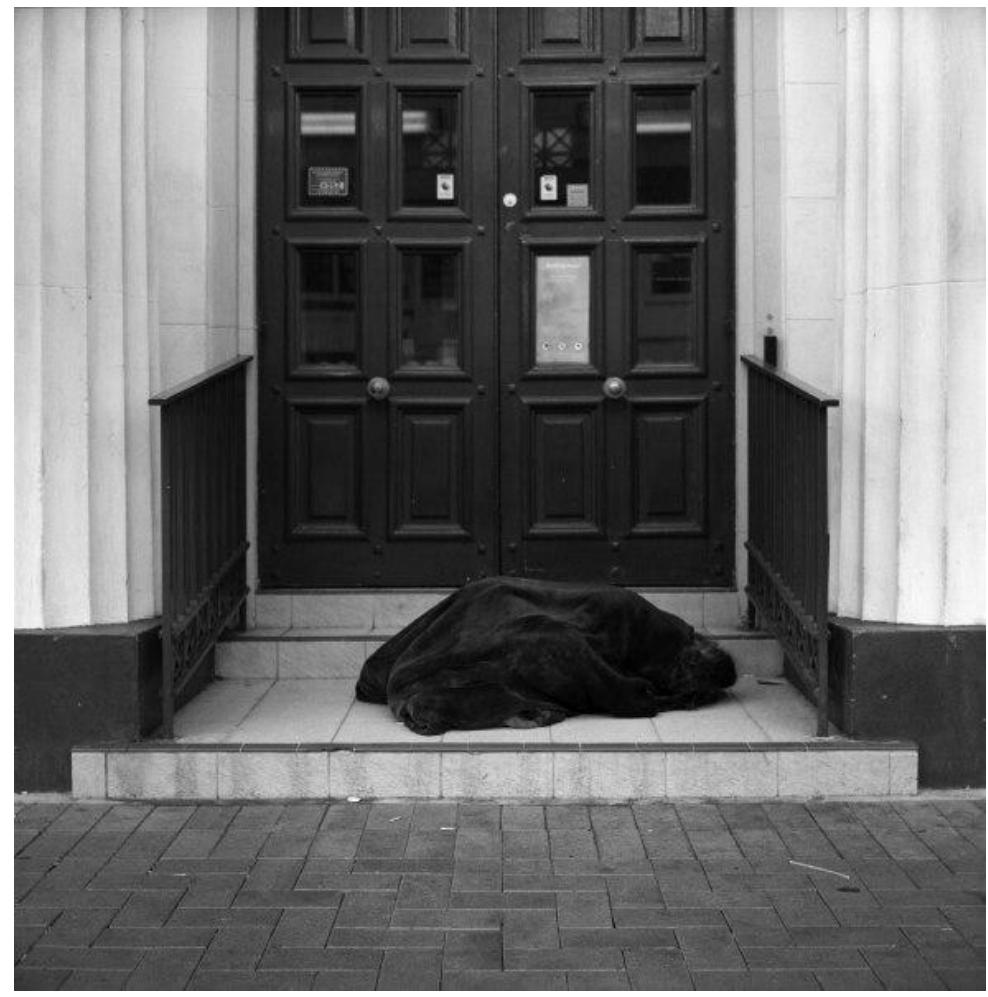

Figure 7:3 Brother's 'contracted' body outside the ANZ Bank

Source: Darkhalide - Simon Burrow

At times, especially when sleeping or during inclement weather, Brother's huddled figure curled or crouched within the cocooning confines of his blanket as he takes shelter in primary spaces, aligns him more clearly within Wardhaugh's (1999) notion of the 'contracted body'. That is to say, for those not conversant with Brother's long standing street dwelling visibility and various methods of using space, this placement of the self and use of the blanket, could, more than any other street presentation of self, prompt 'displaced' or 'marginalised' readings of the homeless body as 'matter out of place' (Douglas, 1966). Moreover, in the above image, the blanket shrouding Brother's sleeping form appears to represent what Wardhaugh would describe as a second layer of protective armour in the body's 
defence against a cold unsafe world (1999, p. 83). For onlookers, this contracted and insular bodily presentation could heighten an awareness of the extreme state of vulnerability within which someone living in the open must exist.

As fieldwork progressed, I began recognising the way in which Brother's blanket had a dual role beyond simply providing clothing, cushioning, and warmth for his body. The blanket served as a boundary marker delineating personal space on the footpath. To illustrate this, I draw from an observation (Fieldwork: 04/01/09) where Brother and I were watching the street in companionable silence when we were interrupted by the arrival of a postgraduate student also studying at Victoria University of Wellington. As she then stood over us instigating small talk, while casting looks at Brother, I had become aware of the way her presence was irritating Brother. Initially he had responded by turning up the volume on his FM radio and keeping his head turned to watch the street in the opposite direction from where she stood. Then, after a few more minutes as she had continued to loiter while failing to read my lack of reciprocated engagement as a cue prompting her to move on, I became aware of Brother attempting to create physical distance to further signal his disassociation from her presence. He achieved this through a gradual series of bottom shuffles that shifted him to the edge of his blanket furthest away from where she stood. These movements created an island of blanket extending between him and us sending a clear statement of his annoyance to her intrusion. In registering this more pointed show of disapproval, I had verbally suggested she leave and had then exercised damage control through remaining silent and waiting to see what Brother would do or say next. After several minutes passed, Brother had reversed his movements in one big shuffle shifting himself back to the centre of his blanket. While repositioning his body through the material space of the blanket in that case could be read as a powerful bodily cue signifying dissociation, it was not understood as such by that particular bystander.

At other times, however, some people were able to loiter at the blanket's perimeter for short durations. For example, that same day, the arrival of a small group of recurrent pedestrians - young adult punk rockers who lived in the vicinity - and their brief stay as they exchanged banter with me, went uncontested by Brother 176 
who maintained his watch on the street in front of him while remaining in his midblanket position.

Figure 7:4 below shows Brother's 'expanded body' on Burger King corner. In contrast to the huddled body, this routine presentation of the sunbathing self in the city emphasises how Brother extends the limits of the body in public space when using his blanket as a possessional territory. The image also shows two Walkwise officers standing over the sunning snoozing Brother whose loincloth has slipped revealing his genitals.

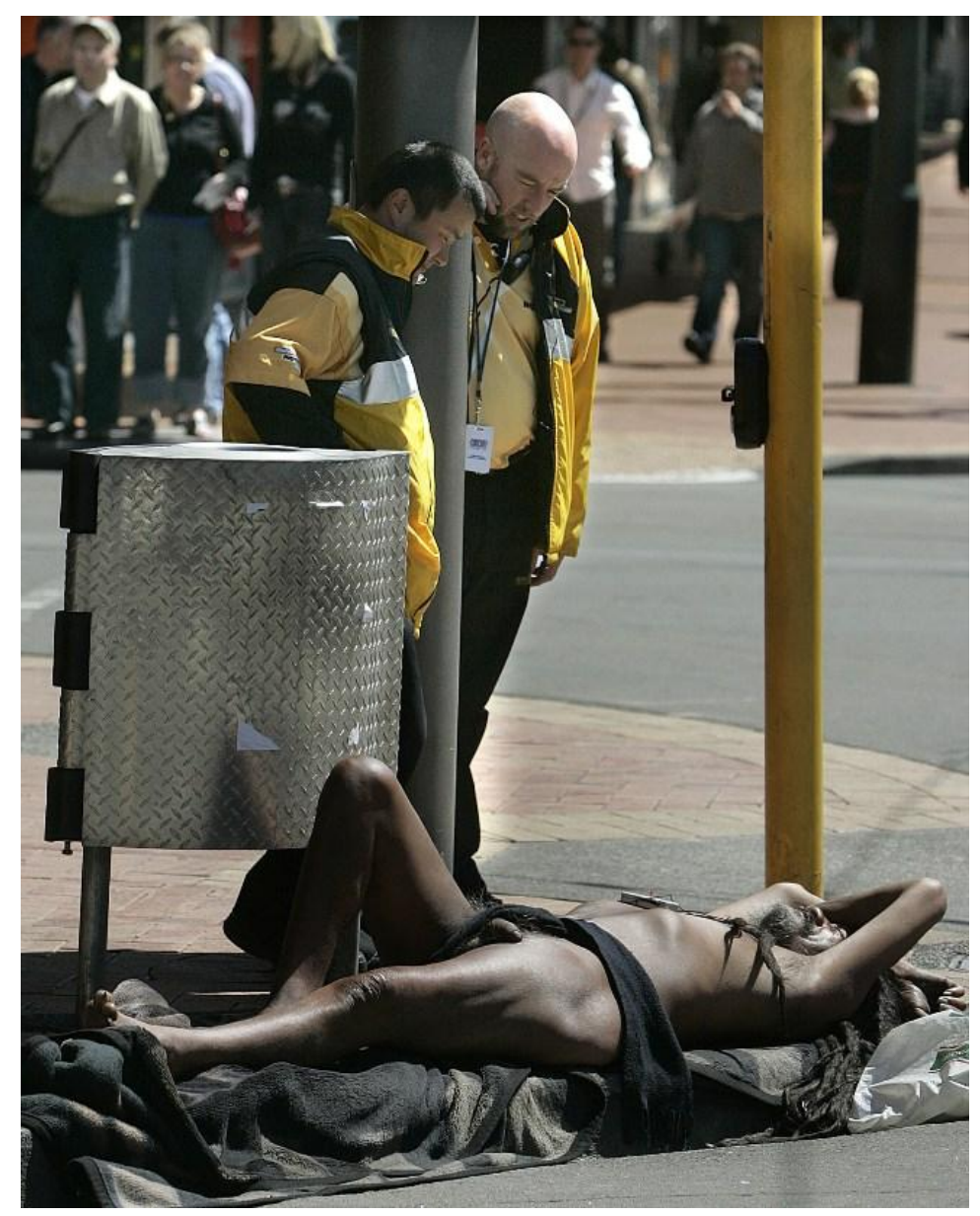

Figure 7:4 The horizontal, dirty, semi-naked presentation of the body in public Source: Copyright Fairfax Media

So, where the 'contracted body' of Brother is more likely to be read in ways fitting dominant public categorisations of homelessness and the category of homeless people themselves as marginalised and subjugated, it is perhaps in these situations 
where Brother's spatial presentation of the 'expanded body' makes most relevant Garfinkel's (1967) idea of breaching experiments. That is, this spatial presence 'makes trouble' disrupting taken-for-granted societal rules surrounding understood behavioural codes in the setting of the city street (see also Goffman, 1961b). The above image shows Brother making trouble in several ways. First, he is not behaving like a 'good' homeless person as was discussed in Chapter Five. Rather, he is blatantly occupying prime social space as lived in 'home' space. Second, he is horizontal in public, dirty, and he is asleep. Third, his body is semi-naked and his genitals are exposed.

Compared with the way his body is rendered small when huddled cocooned within the blanket's confines for warmth, and beyond simply sitting on his laid out blanket staking a larger spatial claim than ordinarily would be taken up by the body alone, it is within this other prone and relaxed presentation that the body itself is rendered most large. Arguably, it is most saliently through the placement of his body in this way that his body becomes a statement; in Brother's own words, "Home is wherever you feel most comfortable" (Fieldwork: 28/03/10). Certainly this horizontal stance could suggest to outsiders that his is a body that is quite at home on the street.

Yet for many onlookers it is this particular deportment of the spatial public body that is most readily interpreted as 'troublesome'. Interpretations based on this precept, are more inclined to contest Brother's body as socially disorganised and lacking in any self control, and therefore view it as potentially threatening to those living by mainstream values and morals. To begin to unpack why people are intimidated the most by this particular stance, just as the street corner as a particular space was given consideration in Chapter Six, it is apt to firstly consider more broadly the footpath itself as a specific space.

To paraphrase Pope (2008), footpaths can be metaphorically thought of as the pedestrian arteries of the city. Entered, exited, and traversed by pedestrians, footpath space is associated with the outside and with dirt. Put simply, the footpath is the ground beneath our feet. So although in the most pragmatic sense, footpaths 178 
are transitory spaces used by people as they move from place to place, on a more conceptual level, because of this, footpaths are also as Goffman's (1971) and Duneier's (1999) work suggests 'social structures'. Consequently, as an integral part of public space, others informally and formally regulate people's footpath use and behaviour.

In her book The Death and Life of Great American Cities (1961), Jane Jacobs argues that sidewalk safety is not primarily kept under control by the police, but that the order of the sidewalk is mostly maintained by a complex intangible but well-functioning network of human action arising from ordinary people going about everyday life. This, she says, occurs within a framework of rules encouraging peaceful cooperation over violent aggression. However two decades on from Jacobs's writing, Duneier suggests that by the early 1980s, the police were essential to the maintenance of order as the voluntary informal social control enforced by the people themselves was no longer enough "because the eyes upon the street were no longer conventional" (1999, p. 157).

My fieldwork accords with these arguments finding that the regulation of homeless people in the urban setting of Wellington is in fact reliant upon a broader circuitous policing network that includes Walkwise officers' interceptions, and Walkwise officers' working in concert with the Wellington Police, as well as citizen complainants reporting the behaviour of homeless people to both Walkwise and the police. Furthermore, it is through Brother's mode of inhabiting footpath space as 'home' space that the embodied contrast between his body and those of pedestrians is most strikingly marked. Similarly, it is here within the social space of the footpath that differences between Brother's 'misbehaving' body and the conforming upright bodies of others is most viscerally emphasised.

In order to make sense of Brother's body from the subjective position of ordinary (housed) people, from within a context where most people adhere to a commonly understood social order, I next explore what counts as 'troublesome' in a given context. Placing the embodied agent at the centre of analysis, I examine three bodily breaches that are regularly committed by Brother in city space and which 
are observable in the image: the horizontal body, the semi-naked body, and the dirty body. I also discuss how these bodily breaches contribute to formal and informal scrutiny and intervention that have today become another integral part of Brother's daily experience.

\section{The horizontal body}

Pope (2008) views the body as a social symbol giving off messages about a person's self-identity arguing that the body symbolically becomes an arena of oppositions: "It is lovely/filthy, noble/common, vertical/horizontal, public/private, and legal/illegal" (p. 76). Moreover, Pope (2008, p. 80) suggests that in spite of the supine body being synonymous with pleasurable activities, "lovemaking, birth, resting and play", to publicly prostrate one's self sends a signal to other - vertical, busy, powerful, more fortunate - bodies that they are not just physically lower in stature but in status too. He writes:

The supine body symbolises indolence, passivity, sickness, and death. As long as the horizontal body stays indoors, in the hospital, in the bedroom, or in the coffin, we are fine, but once it takes to the sidewalk, to the public, alarms go off. In shifting 90 degrees the body is suddenly misbehaving (Pope, 2008, p. 78)

Lying horizontally in the street or on the street corner, Brother takes up footpath space that is usually used by other pedestrian bodies in a vertical position. ${ }^{46}$ During my fieldwork I saw how people avoided Brother's blanket laid out on the pavement, with not one incident observed in which another person walked over his blanket. Instead, people were seen to keep to the footpath space outside the territorial perimeter delineated by the blanket. Sometimes, however, Brother's prone body extended the blanket's boundary, as Figure 7:1 at the beginning of this chapter illustrates. Yet again, pedestrians were observed avoiding Brother's personal use of this space by slightly altering their course creating more distance

\footnotetext{
46 Kawash (1998) similarly noted the way a horizontal body of a homeless man was folded impossibly small in order to lie and sleep on a train seat designed and intended for upright bodies. In Wardhaugh's terms, such a body would mark a case of the 'expanded' body albeit 'contracted' because of space restraints.
} 
between themselves and the sunning body of Brother. People approaching Brother, registering his prone body ahead, either opted to keep their eyes fixed straight ahead practicing what Goffman (1971) phrased 'civil inattention' or averted their gaze elsewhere until they had passed him. Others openly stared as they waited at the traffic signals on the street corner or walked on by him. Figure 7:1 captures this reaction with both father and toddler looking at Brother's presentation of self on an inner city pavement. Sometimes people's disdainful expressions clearly showed their reaction of disgust on seeing his horizontal body displayed in this manner. Some passed comments, affirming their views, such as: "Ah Ben, not a care in the world eh", "Hey bro, you need some shoes?", "Should feed you to the dogs" (called out by a passing taxi driver), and "That's disgusting, shouldn't be allowed" (one woman pedestrian to another) (Fieldwork: 2008/2009).

From Brother's perspective, as an avid sun worshipper, lying on the footpath is just another mundane pastime and an enjoyable experience. Yet, he is well aware of societal rules that govern public space, particularly through his own brush-ins with the law when telling me, for example, "Rimutaka [prison] full of rules, don't do this and don't do that, but out here there's more rules than in there...rules everywhere" and "for every action, there's a reaction" (Fieldwork: 20/09/09).

Significantly, Brother's use of his body and blanket in public space can also be interpreted as a form of ongoing protest befitting his philosophy underpinning his campaign Te Whanau $O$ Aotearoa: Caretakers of the Land Incorporated, as introduced earlier in Chapter Five. To restate, Brother argues that his street vigil, ongoing since arriving in Wellington in 2001, is a passive protest highlighting the need for vacant land to be made available so that he and other dispossessed people, whom he claims to represent, can nurture, plant, and live on the land independently of others. By interspersing Aotearoa with 'Ourtearoa' across his scripts, he intends to convey his vision that (Crown) land should belong equally to the common people. On this view, Brother's embodiment in public space can be understood to challenge a situation he considers amounts to 'an invasion' which he describes as "The taking of land by ignorance and order". Within the context of many corner conversations with Brother, this latter claim is interpreted to relate 
back more specifically to the confiscation of Maori lands that occurred during European colonisation in the $18^{\text {th }}$ Century.

In addition, one piece of Brother's writing further suggests his blanket holds a certain symbolic and political relevance in public space:

This certain Blanket Represents the land of

\section{"Our Tea Raw"}

Has been confiscated, yet again by the New Zealand police outside the bank on Courtenay Place.

Eye witnessed by respectable persons of the Metropolis.

We have been dispossessed of any lands in reality terms. We have no Represent[ative] land.

We can do nothing else but keep getting arrested if not daily, weekly

(Brother: 2006)

Viewing his blanket's role as representing the land, he further alludes to an experience where he was stripped of his blanket by the police in full view of housed members of the public. The police, neither at the time, nor afterwards, gave any explanation for their removal of Brother's blanket. He also argues other people, including the homeless, are especially vulnerable to this type of police intervention which can culminate in police arrests. Elsewhere, in his writing, again playing with the name Aotearoa, he offers the following translation:

\section{Our - T-R-Raw (pronounced Aotearoa) (Translation) OUT - SIDE}

(Brother, 2007)

By outside, he aligns his self once more with marginalised others that live outside the establishment arguing:

Legally, we DO NOT Exist in New Zealand however We are on record with "THE POLICE, THE COURTHOUSE, THE PRISONS and SOCIAL WELFARE

(Brother, 2007) 
It is also feasible to interpret Brother's translation of Our - T-R-Raw as incorporating more specifically, those who literally live outside on the streets, that is, other homeless people who exist and struggle as some of the most marginalised people in cities. Indeed, Brother's writing in 2011 is still restating his vision he considers will benefit the destitute people living in exile in Wellington: "We want to create our own land with the help of the local council" (Brother: 2011).

As Pope (2008) observes, given both public and authoritative forms of treatment afforded towards street people, it is no surprise that they do not always accept their circumstances passively. He writes:

No wonder people on the street lie down in protest, territorialising the sidewalk with their obstinacy, their visibility, their presence and their bodies, as if to say: Fuck public policy, fuck the police, fuck urban planning, fuck decency (p. 77).

While Brother's sustained presence on the street can be understood in part to symbolise a one-man protest that now exceeds a decade in time, my discussion has nonetheless shown how Brother uses his body in particular spatial ways to achieve this. I have also demonstrated how he materially maps out personal space through ascribing other roles to his blanket beyond it merely providing cushioning and warmth. Intrinsic within his very presence and routine actions is an ongoing rebellious show of agency that challenges everyday laws and conventions surrounding the proper use of public space and how bodies are supposed to look and act. To develop these points further I next explore the dirty body of Brother.

\section{The dirt of the matter}

Could someone please clean him up a bit? Despicable filthy creature who is ruining our streets... Needs a fire hose. And a manicure. And rehab. And a haircut... Send him away (Anonymous: 20/01/08). ${ }^{47}$

\footnotetext{
47 This view of Brother's body was expressed in a 'comments book' left by Belinda Brown at her photographic exhibition Brother (Dec 2007-Jan 2008) at the Paramount Theatre in Wellington. This public book encouraged viewers to share their thoughts on the images exhibited.
} 
Mary Douglas' (1966) anthropological argument challenges Western ideas of pollution. Tracing the meaning of dirt in different contexts, Douglas identifies that dirt in any given Western society is matter that is cognitively 'out of place'. Dirt, therefore, is threatening. Sibley (1988, p. 409) articulates a similar argument, writing, "the purification of social space involves the rejection of difference and the securing of boundaries to maintain homogeneity". In light of such arguments, Brother's dirty presentation of his self in the sterile setting of the city street marks his body as a 'body-out-of-place'. The anonymous quote above offers several solutions as to how he can clean up his act but, more pointedly, it indicates an urge that exists among clean-bodied people to exclude his dirty non-conforming body considered to not belong in the shared public setting of the street (Cresswell, 1997).

The differences between Brother's unwashed body and those of pedestrians who must share the space with him are clearly noticeable. Both body and blanket are deeply ingrained with dirt emphasising the way dirt does not just happen; it accumulates, sometimes over many months depending on how long the stretches of freedom between one prison sentence and the next are. Others often comment on his unwashed presence. For example, a group of security guards at the District Court were observed flicking their fingers in front of their noses and pulling disgusted faces after Brother had walked past them. One said, laughing, "Eau de cologne Blanket," and another replied, "Blanket aftershave" (Fieldwork: 25/06/08). During my fieldwork I also saw one retailer in Brother's home locale of Courtenay Place, who is referred to by Brother as "Mrs. Fastidious" because "she is always doing the cleaning" (Fieldwork: 05/01/10), contest Brother's spatial presence in her vicinity. On one occasion, she had thrown a bucket of water, wetting both him and his blanket, while yelling, "Go on, shift, get outta here" (Fieldwork: 11/02/08). A liquor store clerk also showed ongoing hostility towards Brother's unclean presence, and resented him coming into the store. The following vignette captures one incidence of this contestation while also referring to the way in which Brother's body is understood as a contagion to others:

Entering the store, the regular sales clerk casts a disapproving glance our way. As Brother makes his way to the fridges at the rear of the store, the 184 
clerk challenges me, "You know you'll get Typhoid or Tuberculosis hanging around with him". Standing with his arms folded across his chest and leaning back slightly, lips pursed, he stares at me waiting to hear how I will respond. Realising I have no comment, he tells me "Every time he comes in here, the shop stinks for three hours after he's gone". He removes his spectacles and begins giving them a quick clean with a tissue. I suggest that if it troubles him that much he could buy a can of air freshener from the nearby supermarket. Seeing Brother walking towards him, liquor in hand, he mumbles about how the purchase would take three months to clear through the outlet's petty cash system. The clerk serves him grudgingly but silently without making any of his usual reproaches regarding the liquor he knows will be consumed on the street (Fieldwork: 22/06/08).

People's treatment towards Brother's unwashed and soiled presence resonates with Sennett's proposal that a 'character' (person) in urban space, like a character in a novel, develops through displacements that encounter resistance. Sennett says this happens "in much the same way that the most intense activities in the wild happen at contested borders where field animals come into contact with forest animals" (1990, p. 197). Yet, to think about dirt in terms of order and disorder, Brother's dirtiness can be understood as part of a 'repertoire of rebelliousness' that is not dissimilar to the way I understand the 'dirty' hippies of the 1960s flaunted their filth in resistance to the mainstream counter culture. From this perspective, dirt is affirming and liberating. However, on a more practical note, because Brother's elected spatial style incorporates sleeping rough, he does not have access to the homeless night shelters' showering facilities. Nor does he avail himself of public washroom facilities other than for toileting purposes.

Perhaps then, it is also possible to explain Brother's bodily disorder in line with a form of retreatism identified by Duneier (1999), which he calls the 'Fuck it! mentality'. This term accounts for when people working or living the streets reach a point when they say, "I don't give a fuck" (p. 61). According to Duneier (1999), there are at least four distinct features leading a person to this mindset. First, this resigned way of thinking begins to consume most areas of a person's life. Second, the person becomes indifferent to behaviour once considered basic and natural, for example, sleeping in a bed or using a toilet. Third, the person feels intense embarrassment or shame for having hurt their families through self-destructive 
addictive behaviours and therefore they wish to avoid being seen by them in their reduced state. Fourth, the person experiences freedom having given up any sense of accountability to others.

While the 'Fuck it! mentality' reflects an indifference to basic standards that may offend others, Duneier argues "it is not a wholesale retreatism from society itself, nor does it eradicate every social emotion" (1999, p. 62). This was illustrated in my fieldwork one evening as we sat in one of Brother's late night locations in the hub of the nightlife crowds. I had mentioned to Brother that I might see one of my own daughters' who was at a birthday celebration nearby. He responded, "Your daughter might get embarrassed seeing you sitting here with me" (Fieldwork: 27/02/10). Clearly, while Brother's presentation of his body in a filthy state in full view of others could fit with Duneier's 'Fuck it! mentality', he does however, still 'give a fuck'. At least if not so much for his self, then ironically in how my association with him could in turn bring shame upon my family members.

Brother's choice to present his body in a filthy and pungent state while lying and living on the street in full view and close proximity of others could appear to fit on several levels within Duneier's 'Fuck it!' framework. For example, field notes include repeated observations of Brother's deliberate practice of spitting directly onto his blanket before rubbing the surrounding sections of blanket together so as to absorb the discharged mucous into the fabric. However, Duneier further argues the four phases symbolise a particular type of retreatism attributable to the individual interacting with a particular situation, including depression, addictions, and an indifferent society. I argue that what could 'appear' as an established 'Fuck it! mentality' in Brother's case, actually represents a preferred way of living that has physically and mentally manifested through his sustained embodied interaction with the physical environment. That is, over many years, Brother has become so acclimatised to sitting and sleeping on the hard surface of the street day-in and day-out that he is no longer able to sit comfortably in a chair or sleep in a bed. My observations repeatedly confirm this claim, for instance, he chose to sit on the ground outside Star Bucks (while I sat beside him in a chair); and opted to sit on the floor of the District Court as he waited to be called to the dock. Even when 186 
later visiting Brother in Ward 27, I was not surprised to find that initially he slept on the hard floor beside his hospital bed.

Through this acclimatisation process, Brother developed a preference for all things 'outside' as is also made apparent in his account one afternoon of his son's visit to him on the street corner:

"You just missed the young fulla," he told me, "He was here wanting me to go and stay at his house". "Oh" I asked, "What did you say?" $\mathrm{He}$ replied, "I said no." After a brief pause, he looked at me with a surprised expression asking, "What would I want to go to a house for?" (Fieldwork: 22/06/08)

Here, Brother's response does not indicate that his son seeing him in his street dwelling surroundings was an issue - as might be evident if his response fitted neatly within Duneier's model of the 'Fuck it! mentality'. Rather, his reaction can be understood as fitting with his aversion to things 'inside'. In fact, he often commented on the way housed people "liked to bring inside stuff outside" as they sat in parks using laptops and so on. In a similar vein, he once observed after an elderly chap had deposited a container of home baking for him on the street that "people do like to bring me produce from their domestic environment" (Fieldwork: 08/06/08).

Regardless of whether a form of the 'Fuck it! mentality' is reached through situational or environmental factors, the net result can appear similar. Brother persists to exist in an unwashed condition and a key difference to Duneier's categorisation is that he does not give a fuck about others' reactions. In exhibiting no outward sense of internal shame whatsoever, Brother's dirt, associated stench, horizontal posturing, and the way in which he flaunts his body, leads me to argue that in his particular case, his actions stem more from a "I do not give a shit what they think" attitude and established mindset. However, he clearly cares in another way because he is concerned that people see him in a particular way, one that has not succumbed to 'softness', is not attached to comfort, and maybe, one that is also 'immune' to fear. This became clear when during my later fieldwork observations I saw an acclimatisation process in reverse was possibly occurring in the psychiatric ward. That is, Brother was again interacting with material objects or 
'indoor things' that were once more able to give him bodily comfort. For example, although I initially observed that Brother chose to sleep on the floor beside the bed in his hospital room immediately following his admittance, after some weeks, he had moved the mattress off the bed and onto the floor:

Arriving this afternoon, I am momentarily stunned to find Brother dozing on his mattress, which is now on the floor in the middle of the room. The difference between the usual dirty body adorned by an equally dirty blanket as observed on the street with this body tucked into a proper bed, starched white hospital linen starkly contrasting with clean brown skin, is decidedly marked. My chaperone today, yet another helpful patient, calls, "Ben, your friend is here to see you." On seeing me, he leaps out of the bed and onto his feet. Grappling for his blanket that lays heaped in a corner, he quickly wraps it around his body in its usual fashion and says, "Smoke", gesturing for me to follow him. Once in the courtyard, he assumes his cross-legged street position upon the ground (Fieldwork: 25/08/10).

Later, I had added a reflective note regarding this visit describing in particular the way Brother had seemed almost sheepish when being 'snapped' succumbing to a proper bed - albeit on the floor - and the domesticity with which that change represented. He had been quick to restore the status quo impression; blanket, outside, ground. Moreover, when in Ward 27, he was made to bathe regularly and his blanket was often simultaneously washed through the hospital's laundry system. On this note, another visit with Brother in the psychiatric ward coincided with an approaching scheduled first bath for him. Not having long arrived, he had announced with a wry grin on his face, "News flash! I'm having a bath tonight. Apparently." (Fieldwork: 20/06/10).

To an extent, Brother's cavalier attitude is picked up on by those observing him living day-to-day life on the city street. Impressions people form based on what they see and how they interpret or socially construct what they understand to be happening in a given context, contribute to the ways in which we make up people. In this vein, he very much cares that people see his resistance to 'the shit' he has to put up with and it is important to Brother that others see he has not given in, at least not in the manner of Duneier's 'Fuck it! mentality'. Rather, he fights antagonistic responses that challenge or oppose his way of doing things. Moreover, 
as Hacking 2002) would argue (and Goffman would agree) even the unmaking of people has been made up in this way. Significantly, however, with new styles of reasoning that develop from changing common consensuses, new ways of treating the perceived problem or 'person' are introduced.

So, keeping the horizontal, dirty, 'I do and I don't give a shit' ambivalent body and attitude in mind, I now extend discussion with an examination of the third and last dimension; the semi-naked body.

\section{The semi-naked body}

Our attitudes to body exposure are a set of jumbled attitudes and contradictions (Goffman, 1965, p. 50).

Figure 7:4 represents one of Brother's routine activities of afternoon napping. The image depicts what pedestrians can regularly observe for themselves on the street corner: the horizontal, dirty, semi-naked body of Brother. Two Walkwise officers are peering down and appear to be summing up 'what to do' about the sunbathing sleeping body lying in the street. Although not present when the image was taken, my observations suggest that in other situations when Brother is similarly presented, unless some public complaint had instigated the arrival of Walkwise officers then they generally did not interfere. Police officers however often intervened. For example, on one occasion, when again asleep and inadvertently exposing his genitals, I had observed three police officers' wake and arrest him. He had been charged with indecent exposure. On the other hand, public concern regarding Brother's wellbeing sometimes led people to notify the police. This often happened in response to when he was having an extended nap and people reported he had not moved for several hours. Basically, these people sought reassurance from the police that he was in fact 'just sleeping' and had not become unwell or died. ${ }^{48}$

\footnotetext{
${ }^{48}$ I was fortunate to glean another perspective through my employment as a university researcher working within space at Wellington Central Police Station's watch house, where I was privy to jobs being dispatched over the police radio. For example, one evening a call was put out
} 
On multiple occasions in the field I heard comments from passersby when registering Brother's prone, dirty, and semi-naked appearance. For example, waiting to cross the intersection myself one day, a middle-aged woman waiting beside me had turned to me and echoing the voices of children already mentioned, had simply stated, "Wow, he hasn't got any clothes on". From where we stood, although wearing his loincloth, Brother, asleep, knees drawn up towards his belly, indeed appeared naked. When sitting with Brother, I also noted many pedestrians comments, and again public opinion was varied: "There he is the naked fella", "Too cold mate, too cold" and "Wear some pants man, no one wants to see your smelly arse ya alcoholic bum". Moreover, a brief exchange between two matronly women stopping one evening just as the sun was setting went as follows. Speaking in a slow exaggerated tone, one woman had asked Brother "Aren't you cold without your blanket on?" As Brother ignored her, the other woman also speaking as if Brother could be simple, had piped up "Come on you need your blanket, it's cold and you can't sit there with almost nothing on, it's not right". Prompting a response this time, Brother had snapped back, "You can fuck off". "No Ben" the first woman had then replied, "It's Jesus you need, Jesus loves you" (Fieldwork: 10/09/09).

These comments highlight the way people referenced his semi-nakedness in terms of the need for clothes to combat the cold and in the interests of public decency. The comments also associate his semi-naked state with the need for intervention, sometimes even in the form of divine intervention. Such comments entail moral judgments about codes of behaviour and what is deemed proper and right when presenting oneself in public space. To recall Pope (2008, p. 80), to prostrate one's self in public sends a signal to other more powerful fortunate bodies that the supine body is lower in status than vertical bodies. However, the implicit assumption that Brother was not 'quite right' in the head as evident in the patronising way in which the women had spoken to him also reflects how other

requesting any police officers in the vicinity of Courtenay Place "to check on our friend Ben and give him a prod to see if he's still breathing" as a member of the public had reported he had not moved in over four hours. 
categories such as 'mentally unwell' can be attributed on the basis of outward appearance. Overall, underpinning the majority of comments expressed by ordinary people, are connotations implying Brother's 'private' activities are not acceptable in public spaces.

In this vein, Brother's horizontal, dirty, and semi-naked body is read by other people's sense-making processes in ways which draw upon opposing binaries of horizontal/vertical, dirty/clean, and clothed/unclothed. Furthermore, Brother's bodily actions are also made sense of in terms of opposing binaries of public/private, illegal/legal, and normal/deviant. In short, and as Barcan (2004) points out, at either end of this continuum the non-complying body is implicitly understood differently. Undeniably, in the context of the street, Brother's embodied existence involves exhibiting excessive flesh, which also has a contributing role in constructing ideas of bodily mess, disorder, and deviance. Importantly, for people like Brother, doing things differently can have serious implications. As noted by Goffman, "persons who come to the attention of the psychiatrist typically come to the attention of their lay associates first" (1972, p. 137). Therefore, Goffman argues that what psychiatrists see as mental illness, the lay public have usually first seen as offensive or inappropriate behaviour worthy of negative social sanctions. In light of these arguments, Barcan's (2004) work has further analytical relevance.

A key argument in Barcan's Nudity (2004) holds that nakedness operates as a corporeal sign allowing humans to be divided into types or kinds. For Barcan, because categories of clothing and nakedness are tied up with categorising different types of people as criminals, perverts, deviants and 'normal' people, "the dialectic between nakedness and clothing is... a potent cultural site for a tussle between sameness and difference" $(2004$, p.12). This, she says, takes place among a welter of binary oppositions constituting sense-making categories for Western thinking about human identity such as invisible/visible, pure/corrupt, antisocial/social and public/private (p. 14). Within such binary oppositions, Barcan (p. 181) argues "certain forms of naked behaviour can be understood as signs of psychological disturbance, social rebellion, or criminal activity, and can be seen as 
in need of correction, control or punishment". In this vein, ascribed categories "of deviance, legal categories of criminality and moral categories of right and wrong explore nakedness as both symptom and a problem to be fixed" with Barcan also noting the way in which popular stereotypes of danger, crime and perversion particularly pervade male exposure (p.143).

Therefore, as noted by Grosz (2004), to be naked places one in a vulnerable condition where one is unprotected and more prone than usual to the affect and the impact of the other. Without doubt, Brother's semi-nude appearance often lands him in trouble with the law. In Chapter Six my description outlining the law and order responses to Brother's daily activities and presentation of self in public, reported how one solution attempting to regulate Brother's unruly semi-naked appearance resulted in a court ruling forcing him to wear underwear in public. Though Brother complied with the order, he nevertheless maintained some agency in the process regarding what he prefers to wear and what he prefers to be seen wearing. This is achieved through continuing to wear his loincloth, albeit over the underwear. As also discussed, around the time the court ordering of underwear was introduced, other interventionist measures of a more medical nature began taking on renewed precedence. I next outline this trajectory to identify how an unmaking of the person can be understood to occur in the 'remaking of the person' in Brother's particular case.

\section{Sameness versus difference}

In 2009, investigations into Brother's 'difference' which discussion has shown is notably visible in his presentation of the horizontal, dirty, semi-naked self and his regular private-in-public activities, began to more actively probe whether any physiological or psychiatric condition could account for his different way of being in the world. In line with this development, Brother sometimes made a mockery of the questions he was asked by health professionals. For example, he had told them, "I listen to dead people" and "I boogie with the dead" in response the question, "Do you hear voices?" (Fieldwork: 16/01/09). Yet, while he was making fun of the assessment process, he was also giving answers that made logical sense to him given he was referring to his regular pass time of listening to music including 192 
many favourite (deceased) musicians - Jimmy Hendrix, Bob Marley, Jim Morrison, Janis Joplin, and so on. During one corner conversation, and after he had recently undergone another court ordered assessment, Brother had relayed "Have seen another psycho (psychiatrist) down at the court house. I told him I time travel and that I'm currently enjoying 1984". He had laughed heartily and said, "I play with madness". Then, after a brief pause he had turned to me smiling and dryly added, "That'll give them something to think about with all their surveillance tactics eh" (Fieldwork: 04/11/09).

Then, in March 2010, Brother mentioned that the police were no longer interested in arresting him but that 'the psychos' had assessed him again. In May 2010, during another conversation had on a quiet 7am street where Brother talked about the ongoing "tactics" of those in authoritative positions who "are still trying to CAT scam [sic] me", he had also commented, "I can't even get arrested anymore. The rest of them (street people) are still going to the slammer though". Understanding that on one level Brother almost welcomed the odd brief night spent in police custody, or even a short prison sentence that also helped combat the cold and bleak winter experience, I nonetheless sensed he was beginning to feel unsettled now that the police were turning a blind eye towards his public offending - chiefly his smoking of cannabis and street drinking. I had talked to him about the medicalisation of deviance process, also explaining that those in authority - the justice system and mental health professionals - were now collaborating more frequently on what to do about the 'social problem' that he continued to pose by living and acting however he chose in public space. Brother, listening intently and understanding the simplified (non-academic) sociological reasoning I was offering, had told me that at least he knew where he stood when under the radar of cops and courts but that he did not trust the "tactics of the psycho's and their CAT scamming [sic] bullshit". ${ }^{49}$ I also cautioned him that his humour - "playing with

\footnotetext{
${ }^{49}$ Here, Brother is referring to a court-ordered CAT scan. CAT is an acronym for a Computed Axial Tomography (brain imaging) scan that is increasingly applied in psychiatry both for clinical evaluation and as a research tool. Sometimes a CAT scan is used to look for any organic abnormality or problem such as a brain tumour or bleed that could be treatable and could be causing behavioural issues in some people (www.netdoctor.co.uk).
} 
madness' - to the psychiatrists could potentially backfire. He replied that he had told the court that he did not want to be medicated or treated and that he was being careful playing them at their own game (Fieldwork: 22/05/10).

Towards the end of May 2010, when again sitting with Brother observing, he had randomly asked me whether I had ever been to the South Island. He told me that he had not made it there himself yet (Fieldwork: 28/05/10). Several days later and Brother's talk about the South Island was to gather significance when I read in The Dominion Post that he had travelled by ferry to the South Island and was to appear in the Blenheim District Court on charges relating to his public cannabis use on the ferry (Wong, 2010). Accompanying the story was an image of Brother sitting on the street outside the court. His court appearance in Blenheim resulted in his being flown back under police escort to appear in the Wellington District Court. Remanded at large afterwards and catching up with him on the corner several days later, he had seemed pleased with his break in routine which had given him experiences of getting to the South island, sailing on "the big waka [ferry]", and flying in a plane for the first time (Fieldwork: 10/06/10). When next reappearing for sentencing in the District Court in June 2010, District Court Judge Paul Barber, despite hearing the assessments of two psychiatrists finding Brother mentally fit, committed him under Section 34 of the Mental Health Act $^{50}$ to Wellington Hospital's Ward 27 (Hunt, 2010).

So, how is it possible to understand why Brother became a subordinated person incarcerated within a psychiatric ward when all psychological and physiological testing prior to that had consistently found him mentally fit?

To begin to answer this, Hacking's (2002) theorising about how people are made up identifies the way the "community of expert knowledge" can create a reality from above. In contrast to this, Hacking also recognises that the vector of the

\footnotetext{
${ }^{50}$ Section 34 refers to the Mental Health (Compulsory Assessment and Treatment) Amendment Act 1999 which, as the explanation suggests, gives judicial power to the courts to impose compulsory treatment orders on people.
} 
autonomous behaviour of the person that is labelled can press from below and create a reality that every expert must face. These claims are useful for understanding the longstanding battle of the wills that persisted between lay people and the authorities versus Brother, a street dweller flouting an "I do and I don't give a shit" mindset as he 'lives it up' at times doing things his way in prime social space.

Until Brother's committal (and beyond) I observed how he pushes normative and acceptable boundaries between commonly understood codes of appropriate public/private and illegal/legal behaviour. As discussion has further illustrated, he does not always do things his way in a quiet or discreet manner. Indeed, at times his actions seem to invite controversy. Yet, as I have demonstrated, much debate and action arises in response to his use of public space and the activities he routinely conducts as he embodies these spaces. Brother was first ordered through the courts system to undergo a mental health assessment in 2003 and as was documented in the film Te Whanau Aotearoa: Caretakers of the Land (Wright \& King-Jones, 2003), the assessment found him functioning within 'normal mental capacity'. Investigations into Brother's mental health did not then gather any notable momentum until 2009. In the interim, the standard official response to Brother's breaching behavior was to arrest him, charge him and punish him which, as discussed in the previous chapter, included him spending periods in prison. Hacking (2002, p.11) suggests however, that as people become aware of how they are classified, their behaviour can change in conjunction with the classification. In Brother's circumstances, my observations repeatedly found that he remained rebellious to the labeling of him as 'a criminal' and the associated consequences meted out by those with the power to enforce law and order responses that came with that label. Contrary to Hacking's articulation, Brother did not alter his ways or clean up his act. Instead when conflict did occur, it seemed to buoy Brother along in his steadfast resolve to live his life as he saw fit. As he put it to me after one such confrontation, "They persist, I resist" (Fieldwork: 30/05/09). However, even as he maintained his street life in the face of sanctions, as Chapter Six also discussed, he also complied at times with court orders temporarily forbidding his 
presence in certain spaces. Moreover, he is also committed to the wearing of courtordered underwear.

Over time, as the trajectory has highlighted, the 'community of experts' - justice personnel and health professionals - renewed their earlier concern by more actively questioning the mental health status of Brother. The growing idea that mental impairment could be affecting his ability to make 'proper' decisions, triggering a process wherein the Brother as 'criminal' classification was deconstructed and replaced with a new classification of Brother as 'mentally ill'. Consequently, this trajectory can be seen to align with Hacking's observation that the 'community of expert knowledge' can create a reality from above.

On the other hand, as the data have simultaneously shown, Brother's aberration from fairly predictable monotonous routine of almost ten years standing, that saw him leave his home locale and travel South also accords with Hacking's (2002) observation recognising the way "people who are medicalised, normalised, administered, can increasingly try to take back control from the experts and the institutions" (p.12). Put simply, as Brother became increasingly aware of mounting scrutiny deployed by 'the community of experts' seeking to reclassify him, he resorted to taking more radical action himself in order to avoid the net he sensed closing in around him. In doing so, however, he extended his body in an unprecedented way, which signalled trouble to the 'community of experts'. Why? Because Brother, now geographically removed from his locale of Courtenay Place and the site of sustained monitoring, became what Hacking would describe as a moving target at which intervention then must aim (Hacking, 2002). The swift legal response that intervened to return Brother back to Wellington certainly supports this claim. Further, the judicial decision-making that subsequently committed the 'bad/mad' homeless body into psychiatric care fits with Kawash's view: "if the homeless...[body]...cannot be eliminated or erased, then at least it can be shrunk down, isolated, and contained so that the public need not feel the pressure of its presence" (1998, p. 330).

Central to Hacking's (2002) 'making up people' is a concern with the way classifications, when known by those classified or those around them, get put to 196 
work in institutions changing the ways in which individuals experience themselves. Hacking goes further saying that such classifications (of people and their behaviour) are 'interactive' as the classification and the individual classified may interact once the individual becomes self-aware of a particular classification, if only through being treated or institutionalised in a certain way therefore experiencing themselves in that way. Moreover, for Hacking, this can create a situation wherein current systems of diagnosis and treatment themselves help to produce the kinds of disturbed behaviour characteristic of the illness. He writes, "...the classification and diagnosis is constructed, and this very construction interacts with troubled people and helps to produce their behaviour which in turn confirms the diagnosis" (2002, p.10). In light of these arguments, one final question remains: Could Brother, as a committed psychiatric patient, be observed to interact with his new classification and did he come to fit his category?

I made several visits to Brother while he was in the hospital with the following vignette providing an insight into one of my earlier visits:

"This is what happens when other people think for you", Brother tells me as we sit in the cold barren courtyard of the psychiatric unit. Aside from us, there is only one other person out in the yard who has chosen to sit right beside me on one of the wooden bench seats. Brother, wrapped in his blanket, sits to my right assuming the cross-legged stance he adopts on the street. The woman beside me starts coughing, a violent phlegm filled attack. Leaning forward now and gasping for air, she splutters spittle while stamping one foot up and down on the ground as she struggles to gain control. As the coughing fit subsides, she sits up straight and soothingly pats her chest before turning her attention to the unlit cigarette held in her other hand. The three of us sit in silence as pigeons meander at our feet pecking fruitlessly at the concrete surface of the yard. As I absorb Brother's insight concerning his present situation and wait to hear whether he will elaborate, the woman patient beside me spontaneously breaks into song. I am immediately struck by the sheer power and beauty of her voice as her rendering of Green green grass of home quickly reverberates filling the air. Brother continues now "Their rules, this is not my life I'm living". He pauses, now adds, "They say I'm a transient" (his emphasis as he tries out a new classification). That makes me a nutter in their thinking". Spoken within this bleak secure place known simply by many as 'Ward 27', I silently wonder if this latest confinement, which, is far removed from home as he chooses it out on the street, will become his final stop. As the woman's poignant longing for home continues to sound, he echoes my thoughts saying 'They'll never let me out'. I decide, “They can't keep you here forever. All you can do for now is keep keeping it real". "Ah" he 
replies, "We'll just have to wait and see what their politically correct way says next" (Fieldwork: 20/06/10).

Striking within the vignette is how Brother is rendered impotent under what he identifies as their thinking and their rules. Clear within his utterances, is an acute awareness surrounding an almost total loss of agency experienced as a confined patient in Ward 27. By virtue of his new status, he is now deprived of many of his legal rights. His freedom of movement is severely restricted, his personal hygiene is monitored, and, his body is injected with psychotropic drugs. In terms of the latter, and as he put it to me on more than one occasion, the medication interacted with his sense of wellbeing with Brother identifying "the pills make me morbid" (Fieldwork: 02/07/10). Crucially, the vignette identifies how a new classification and the associated responses which led to the confinement of the now 'mad' transient body can be seen to impact on Brother's ability to live life how he would choose it. Ultimately, he clearly and keenly feels the effects of the reclassification of Brother as mentally unwell, as they interact and change his daily experience.

Overall, however, whatever the 'community of expert knowledge' tried to do with their categories, that is, whether they criminalised or medicalised Brother's expressions of agency, he is nevertheless able to retain his grip on acting autonomously. For example, my discussion has also alluded to how my visits to Brother in the ward found him maintaining his way of doing things wherever this was possible. He elected to spend his time outdoors sitting on the ground in the courtyard; therefore only returning indoors when evening lock up dictated. $\mathrm{He}$ continued to wear his blanket as clothing. And although he eventually relented and slept on a mattress upon the floor, he never availed himself of the conventional bed option that was on offer in the room.

Brother's case and in particular his desire to hold onto his sense of self as described here within the psychiatric setting, exemplifies the ongoing relevance of Goffman's work for contemporary scholars. In particular, Goffman's articulations of stigma and total institutions are useful for they observed the way, after admission, patients strived to retain the image of oneself that one wanted to present to others, even as this came under attack by the institutions rules. For 198 
Brother, though he had strived to maintain his usual image of the self, he could do very little about the trembling of his hands that was caused by the anti-psychotic medication he was required to take. When ruminating about this, on several occasions, it became clear to me that he was experiencing what Goffman conceived of as a violation of the territories of the self. That is, through the medication, his body let him down: Goffman's (1961a) 'mortification of the self', manifested.

After some months spent solely within the confines of Ward 27, and then when eventually released on day leave, he picked up on established routines of his choosing by walking the 30 minute distance from the hospital back to his locale of Courtenay Place to again resume his city-as-whare life. He spent these days as he had always done by gradually moving from one favoured corner to the next to enjoy the sun, sociability of others, and a regular afternoon nap. He also continued to smoke cannabis and consume alcohol in public. On the other hand, in complying with stipulations setting the terms and conditions granting him day release, he had kept to his curfew returning to the ward by night fall and he had worn what could now be more aptly described as 'medically prescribed' boxer shorts in public.

\section{Conclusion}

This chapter has concentrated on the interface between spatial control and bodily control. In doing so, the analytical emphasis shifted from a concern in Chapter Six with how Brother's use of space can be understood to matter to him and how his spatial styling is in turn interpreted by others, to one which has examined here, the embodiment of his social action. In some respects this has been a difficult chapter to write. I have endeavoured to draw from observational data to understand how exactly the homeless body is said to take on increased significance when one is without a conventional home. I have also attempted to show Brother's own expressions of agency in the way he manages to socially organise himself on a socio-spatial footing among others who must also share the social setting of the street where he makes his home. By extension, Brother's ever-present blanket was shown to have a significant role in enabling him to not only claim space but to also 
procure boundary creation and maintenance in the context of the busy city street. Through closely examining Brother's presentations of the self and his routine activities I have proposed that a particular mind set has developed through an enduring embodied acclimatisation and connection with the physical 'outside' environment. I have further argued that in Brother's particular case, his actions can be understood to stem from an "I do give a shit what you think of me" established attitude which on a conceptual level presents a noteworthy departure from Duneier's discovery of the 'Fuck it! mentality' among the men he studied in Sidewalk.

Countering this, I then examined why Brother's material fleshy body in public space is perceived as troublesome and threatening. Drawing upon observational data, I explored three key bodily breaches to tease out just what it is that the body does that 'makes trouble' in the context of the street. In doing so, I have demonstrated how even the 'dormant' sleeping body of Brother constitutes an activity that breaches the social 'order'. Therefore it too was shown to be equally open to the scrutiny and control of others. I further demonstrated how the body can be understood to provide a potent metaphor for social (dis)order with opposing binaries of legal/illegal, private/public, cleanliness/dirt, vertical/horizontal, clothed/unclothed informing common consensus about what is thought to constitute the symbolic (dis)ordering of the individual body in public. In this vein, I have established the 'good' homeless body is indeed one that minimises its surface, its extension (see Kawash, 1998 and Wardhaugh, 1999). Without doubt, Brother's horizontal, dirty, and semi-naked posturing of the self was shown to cause offence to others and is commonly interpreted as presenting a contagion to housed people. Various methods to reign in or control the ' $\mathrm{bad} / \mathrm{mad}$ homeless body' of Brother have been shown, including a bucket of water being thrown, medically prescribed boxer shorts, and his bodily containment within both a prison cell and a locked down psychiatric ward.

The final part of this chapter then explored the consequences of sameness versus difference with a trajectory whereby Brother's longstanding classification of 'homeless criminal' evolved into a reclassification of him as a 'mentally ill 
individual'. Here, I specifically examined whether the salient characteristics that lead to diagnosis reside in the patients themselves or in the environments and contexts in which observers find them (see Rosenhan, 1974). I have argued that in Brother's particular case, a 'battle of the wills' played out to some extent both behind closed court room doors and on the street corner as the institutions of control and rehabilitation continued to collide with Brother's expressions of agency. However, a significant aberration from Brother's longstanding routine was shown to resonate with Hacking's articulation of the 'looping effect of human kinds'. Moreover, this deviation from routine in symbolically representing Brother as a 'moving target' was exposed to have had an important role in bringing the problem of 'what to do about Brother' to a head. Lastly, I explored whether or not Brother could be understood to interact with his new classification and whether he could be seen to fit his category. I concluded that even as a committed patient in Ward 27, Brother was nonetheless able to retain his hold on his independent former self through socially organising himself 'his way', where possible, within the confines of the psychiatric setting. Even so, the actions of housed society have also been shown to constrain Brother in a number of ways including where he must live at times -ranging from which street corner, to a prison cell, and a psychiatric ward- and what he must wear. Though the latter saw his loincloth replaced by court-ordered underwear, which were later replaced by medically prescribed boxer shorts, Brother, maintained the wearing of his loincloth over the top of each. Therefore, again, the circuitous battle of structure versus agency is rendered visible in his autonomous action that maintains some free will, wherever he feasibly can, in reaction to the sanctioning actions of others. 


\section{Chapter Eight \\ Maintaining 'elbow room' in a publicly lived life}

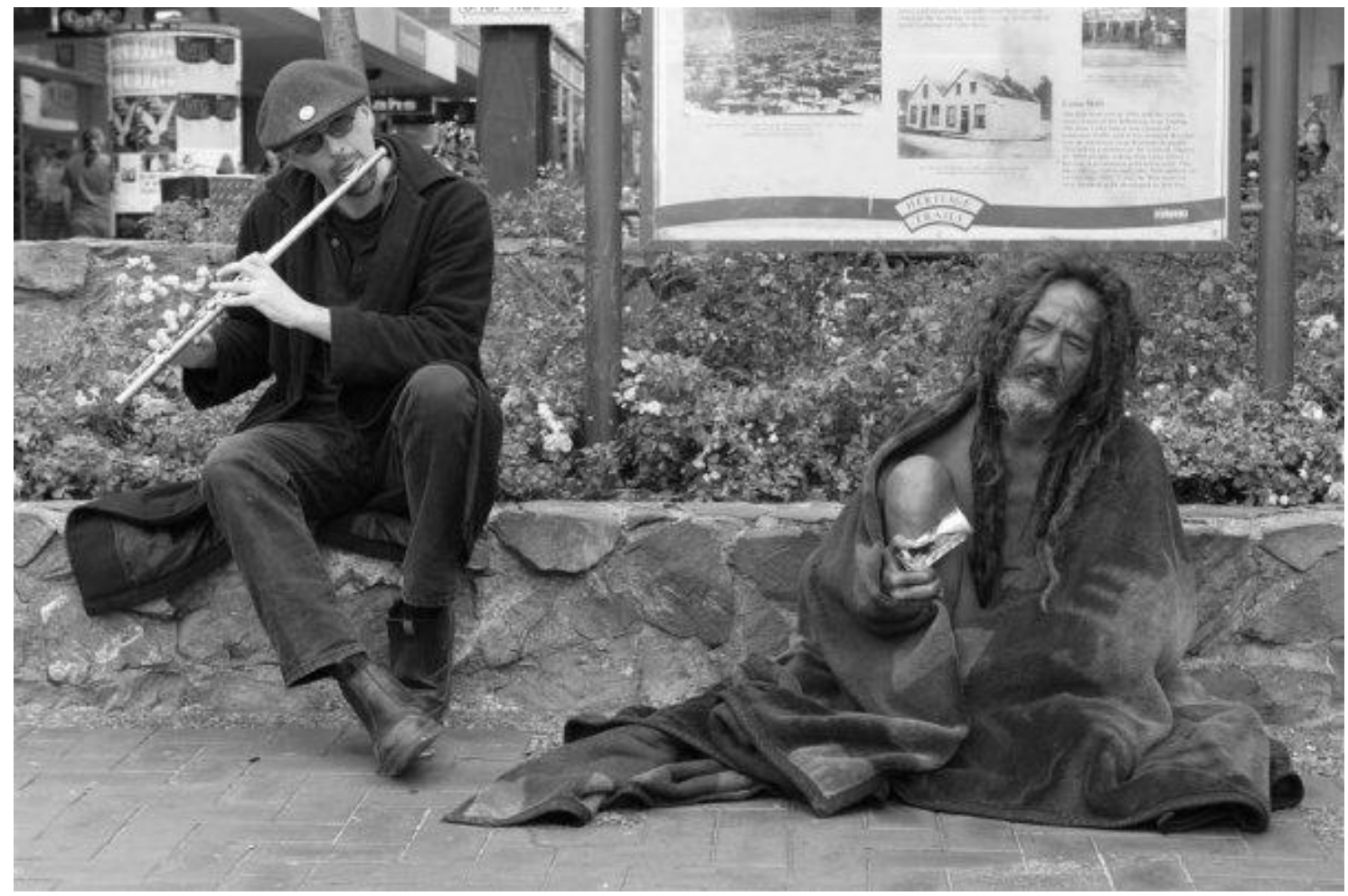

Figure 8:1 A man plays his flute in Cuba Mall beside Brother

Source: Belinda Brown Photography

\section{He aha te mea nui o te ao? \\ He tangata, he tangata, he tangata!}

What is the most important thing in the world?

It is people, people, people!

Old Māori proverb ${ }^{51}$

51 This whakatauki (proverb) defines the human person as the most important element in the universe. It is quoted often in speeches and whaikōrero (formal speeches) to emphasise the mana (authority, prestige) and tapu (sacredness) of humankind (Calman \& Sinclair, 2001; Ryan, 2008). 


\section{Introduction}

In the previous two chapters, I examined how space matters and the significance of the body in Brother's everyday street life lived night and day on a busy city footpath. Survival mechanisms crucial to Brother's management of daily life were shown to be contingent on the ways he is able to socially and materially organise himself in public space in particular ways to secure safety, sun, and shelter. I also touched on the important role the socio-spatial body plays in procuring support and sociality in daily life. I further established that informal and formal social control processes responding to Brother's use of public space, his activities in public space, and his presentation of self in public space, had contributed to a classification of Brother as a (homeless) criminal and a subsequent reclassification of Brother as a mentally ill (homeless) individual. I also revealed Brother's resistance to social control mechanisms and classification processes.

Extending these arguments, this chapter focuses on the situatedness of everyday talk and social action to understand how Brother, a well recognised city street dweller, is 'made up' by people who observe his activities or stop to interact with him on the street. By positioning the thinking, acting, talking, and laughing individual at the centre of my analysis, I aim to further understand how Brother, in turn, 'makes himself up' as he lives his everyday (and everynight) life in the visible presence of others.

My discussion in this chapter is framed around a repertoire of talk and actions that belong to an interactional toolkit developed by Brother. These interactional techniques and methods work to invite or shut down interaction with him, and to interrupt or distance the intense flow of interaction occurring within his unusual living situation, so that he can experience 'down time' and have opportunity to pause and gather reserves, so that he can cope better with the periods of intense contact that follow. Within this cyclical process, Brother maintains some control over what he defines as another particular "occupational hazard" (Fieldwork: 27/02/10) that is, the 24-hour presence of other people. van Doorn's (2010) qualitative study on the way perceptions of time and space change gradually in the lives of homeless persons similarly showed how homeless persons find themselves 
continually in surroundings full of stimuli where they are confronted by an incessant flow of impressions from which there is practically no escape.

My fieldwork material presents a significant departure from the way homeless people are often discussed within the homelessness literature as predominately experiencing marginalisation in daily life among housed people (see Lee, Farrell, \& Link, 2004; Snow \& Anderson, 1993). Within such accounts, homeless people are usually described as suffering "non-person" treatment, that is, stigmatised individuals are often treated by others as if they are not there at all, as 'objects' not worthy of even a glance (Goffman, 1963a, p. 85). Contrasting with that dominant portrayal, Brother has a marked presence on the street and in the public imagination of many Wellingtonians. In fact, he is a street person who has become something of a legend, at least in the Wellington environs. ${ }^{52}$ Moreover, despite Brother's homeless status and consequent 'membership categorisation' (Garfinkel, 1967) within a subordinate group, my street level gaze found clear evidence of varied and complex forms of social interaction occurring between Brother and the public. A striking feature was the unexpected prevalence of humour in Brother's talk and actions. This humour stood out as a vibrant social process and raised empirical questions about how the fundamental processes of humour could be observed working-in-action in the interactive street life of Brother.

Humour, as Kuipers observes, is a "quintessentially social phenomenon" that is often quite particular to a specific time and place (2008, p. 361). The role of humour as a coping strategy providing a cohesive function in the lives of marginalised and stigmatised groups has been examined in the daily lives of people experiencing social nakedness when undergoing total surveillance (see Coser's (1959) study among hospital patients and Terry's (1997) study on prison inmates). These studies share a focus on the form and nature of collective humour among people of equal status who share common concerns and generalised anxieties. Although a search of the broader homelessness literature

\footnotetext{
52 See Lloyd and McGovern's (2007) discussion on the importance of the spatial routines and faceto-face interaction of everyday life in the construction of this locally identifiable person.
} 
revealed that humour in the everyday lives of homeless people has not been studied, a small 'humour' study by Ritchie (2011) has examined the role humour plays in reducing tension in ordinary housed people's conversations about homelessness. For example, humour was found to have a facilitating function in the introduction of "otherwise embarrassing or awkward topics" (2011, p. 507) in relation to the complex issue of homelessness. While some humour was found to combine an implied denigration of homeless people with a subversive cynicism, some humourous stories also celebrated the humanity of homeless people, including stories in which homeless people were able to beat 'the system' in some way (Ritchie, 2011). This chapter contests that view and provides a challenging alternative examination to argue that Brother has strategically developed a jocular boundary which enables him to maintain a back stage self during front stage projections when interacting with others on the street.

Previous research has also identified humour as a symbolic resource used by occupational groups. For example, Pogrebin and Poole (1988) explored the strategic use of humour among police in the briefing room where humour was found to be a valuable resource for testing attitudes, perceptions, or feelings of group members while promoting social solidarity of the group, strengthening group norms and reinforcing the integrity of the occupational working group. The role of humour in the sex industry has also been examined. Arguing that prostitution is an extreme profession where bodily contact is intense, direct and commodified, Sanders (2004) identifies humour both as a business technique and a psychological distancing strategy in order for sex workers to manage the emotions of selling sex.

While there is much talk within sociology about patterns of inclusion and exclusion of stigmatised groups and persons, and many studies on homelessness address this very issue (see Amster, 2003; Clapham, 2008; Ferrell, 2001; Miller, 1991; Phelan et al., 1997), a review of the literature clarified that, aside from a few notable exceptions (Duneier, 1999; McNaughton Nicholls, 2009; Parsell, 2011), insight into the agency or intentional social actions of homeless persons 
within the contextual setting where they are enacted has been marginal. Also absent from existing discussions is any notion of wellness among homeless people or suggestion that playful elements could infiltrate the day-to-day business of "doing life on the street life" (Fieldwork: 14/08/09). In short, academic writing on the experiences of homeless people proposes that street life existence is essentially 'no laughing matter'.

I begin my examination of talk and action by detailing a mere thirty-minute period observing in Brother's primary $1 \mathrm{~b}$ location, near a fast food restaurant in Courtenay Place. It represents the type of notes that I made in the evening when the street scene became lively with late night revellers. My intention is to provide a window into the comings and goings surrounding the social interaction with Brother to emphasise his particular situation and the way public interaction and inclusionary practices significantly infiltrate his everyday life.

It is 11 p.m., and like most Thursday nights, the locality is pumping with late night revellers. Beside me, Brother muses, "Gotta breathe, bit of an everyday event, monotonous, but I've seen a few people forget and it didn't get them very far." Erupting into raucous laughter, he catches the attention of two men walking by. One asks, "Hey Blanket, how ya doin?" Now, a solitary male in his forties stops and sits himself on the ground to Brother's right. He smiles, revealing missing teeth and removes a tobacco pouch from his pocket. Taking out a small metal pipe he loads it with cannabis and gestures it towards me. Shaking my head, he shrugs his shoulders and takes a couple of tokes himself. He then deposits a bud into the groove at one end of Brother's recycled can that he uses for smoking and which he is holding close to his body at chest level. Brother laughs again and the man follows suit, perfectly imitating the loud coarse sound for a few moments before getting to his feet and walking off.....

A couple in their thirties stop and the man says, "Hey buddy, I've heard about you in Oz, here's some change for ya." He holds out a palm of small coins towards Brother who ignores him and his money. Bending to deposit them on the ground next to a few others scattered about, the woman captures the act on her mobile phone's camera. Brother laughs and tells him, "Nah your ancestry says get that bloody vote out".....Hot on their heels, three young guys now stop and one drops some marijuana on to Brother's pipe, telling him, "Cave Man, you blow my mind you do, this'll get you smashed." A minute passes and I see four police officers approaching on my left. Reaching us, they stop and one male officer steps forward, standing over us, putting on black leather gloves. He points one foot towards a bag on the ground containing empty cans and bottles and 
questions me, "You been drinking that?" I shake my head. ${ }^{53}$ He looks at us both, "Whose is that, whose been drinking that? Bernard, what are you doing, that is an illegal V can you have." $" 54$......No sooner do the officer's depart than a young man stops and extends his hand towards Brother. Ignored, he asks "You alright bro?" He raises his hand and attempts to pat Brother on the head, evoking a reaction this time. Brother simultaneously recoils his body to avoid the intended contact while glaring up at the man and snarling, "Fuck off". Taking the hint, the young man now leaves. Two men in their twenties step in to occupy the space directly in front of us. One places an unopened bottle of beer on the footpath, saying, "Sup up Bro and enjoy." Straightening to leave, he nearly bumps into two girls who have stopped and are standing behind him. One girl shrieks, "Blanket Man, you're my idol, yeah aye." Giggling to each other and linking arms they walk off.....

Next, and in equally rapid succession, a young girl offers a can of premixed vodka, which Brother accepts, a man tries to give him some change and is ignored, and two guys offer him cigarettes. Taking the cigarettes he says, "Cancer, yum yum".....A man approaches, slowly negotiating his way on crutches and trying to keep up with his mates. Noticing him, Brother loudly announces, "Bugger," and laughs. The man's friends laugh too.....An open air taxi pedals past on the road and one passenger yells our way, "Oi, get a vaccine." Two drag queens flounce to a stop and ask Brother for the use of his lighter. He tells them, "I don't help others die of cancer"..... (Fieldwork: 24/10/08, 11.00 pm -11.30 pm).

This material accentuates Brother as a well-recognised and familiar public figure who is open to the attention and whim of others. It captures the constant stream of pedestrians stopping to interact with Brother within a 30-minute period. A total of 54 people were observed interacting with Brother in 26 separate instances, ranging from simple greetings and trying to touch him or give him things to official interventions. These interactions involved a variety of people: men of various ages acting alone, in pairs or in groups; two couples, two sets of young women and a

53 Throughout fieldwork, the police questioned me on several occasions about my activities alongside Brother on the street. One time, an imminent joint arrest seemed likely when an officer had remained unconvinced that I was not participating in Brother's drinking session despite my drinking a cup of tea from a polystyrene cup at the time. The accusations and questions that developed had become increasingly hostile until eventually the female officer had directed me to pass her the bottles and for Brother to pass her the black rubbish bag explaining that in doing so we could avoid spending the night in the police cells.

${ }^{54}$ The police officer is referring here to an empty energy drink can that Brother has manufactured into a make-shift pipe for smoking cannabis. 
solitary woman; one street person, and two groups of male and female police officers. During these interactions, Brother had his photo taken twice and was addressed by seven different names, none of which were his proper name, Bernett. Brother was twice given marijuana (and in another interaction, he was promised some next time the young woman was around), he was given food three times and alcohol twice, cigarettes once, money three times, and was spoken to or had property removed from him by two groups of police officers over three separate interactional episodes. While all but two of the interactions were positive or friendly in nature, the donning of leather gloves by the police officer before he dealt with a material byproduct of Brother's life (the pipe that Brother had handled) indicates the contamination risk he is perceived to present, aligning with notions of dirt and disease expressed in the call to get myself vaccinated.

The fact that Brother did not instigate many of the interactions is not remarkable. First, he had no need because his lived experience in public space told him he could anticipate much social attention from the incessant flow of passing pedestrians. Second, by Brother's own admission, he is not much of a conversationalist (Fieldwork: 11/08/08). This does not mean he did not actively seek out social interaction when the mood took him, as indicated in the above fieldwork excerpt by his jovial quips and his engagement with the social life occurring both directly with him and around him. Before moving on to examine Brother's methods for managing the steady stream of interlopers he confronts in everyday life, I engage other empirical data to illustrate the nature and form of social encounters that involved members of the public seeking what I came to identify as 'Blanket Man thrills'. These interactive encounters highlight a more intrusive level of interaction within which others act in their own interests, and sometimes at the expense of Brother.

\section{Blanket Man thrills}

While these types of interactional encounters involved various people of differing ages from all walks of life, here I draw on two examples to describe this interaction. Firstly, 'Blanket Man thrills' are interpretable as a form of interactional encounter where young people seek to achieve kudos in the eyes of 208 
their peers. Part of Brother's mana stems from his transgression of 'ordinary conventional life', including his open law-breaking - this appeals to a youthful generation for whom marijuana smoking is common and 'cool'.

Approaching Brother is an act that involved nerve on the part of some young people. My street observations found that teenage boys would sometimes egg one another on (from a short distance away), before one would inevitably take up the challenge and approach Brother to talk to him or offer him a burger or cigarette. During these 'priming of the other prep talks', some interesting comments were overheard. For example, dares expressed between boys were heard to include, "Go on, ya big girls blouse, do it," and "Don't be a girl, ya wuss." A sociological study by Kuiper (1990) examined male New Zealand rugby players' use of gendered language within the context of changing rooms both prior to, and following, their rugby matches. Finding that men's banter often equated men with women and girls, Kuiper proposed that hinting at effeminacy acted, "as a coercive strategy to maintain solidarity and discipline in a group which is involved in physically dangerous activity" (1990, p. 292). While I do not propose others perceived Brother to pose any physical threat to their person, trepidation in approaching Brother was certainly observed. For example, people sometimes paused as they appeared to weigh up whether or not to make an approach, with some then abandoning the idea and walking on. Teenagers' unease can be understood as not wanting to 'lose face' by experiencing a humiliating reaction from Brother. Brother's responses were unpredictable - I observed a range of reactions, from the 'middle-distance stare' ${ }^{55}$ and open insult, to friendly acknowledgment, as he saw fit. Not knowing what to expect likely put some youth off. Those whom took up the challenge and met a favourable response had their status momentarily enhanced in front of their peers, as they had successfully braved a 'Blanket Man moment'. Sometimes, however, even an unfavourable response from Brother snarling, expressing profanities, or even the middle-distance stare - temporarily

\footnotetext{
55 I borrow Lofland's (1973) term, 'middle-distance stare', to refer to an interactional technique used by Brother to ignore other people. I explain this later in this chapter.
} 
enhanced the status of a young person in the moment. This was evident in the groups' bravado, back-slapping, laughter, and chatter as they left the scene.

\section{Poked, prodded, and photographed}

Secondly, young adults acting collectively in groups made bolder approaches in their interactional attempts with Brother. Buoyed along by the camaraderie of the group, they were often seen stopping to poke, prod, and photograph Brother, seeking a brief interlude of fun and games either with him or vicariously through him. The following two images encapsulate such moments in Brother's life, reflecting what he must sometimes tolerate when others got 'in his hair' in this way. ${ }^{56}$ Both photographs were taken during New Zealand Rugby Sevens tournaments, an annual, much anticipated affair on the national sporting calendar. These tournaments last two days and attract large numbers of both local and international tourists. Though a sporting event, the Rugby Sevens is equally renowned for producing a party atmosphere that spills from the sports stadium onto the streets and into the bars of the capital. Contributing towards the carnival atmosphere are the fancy dress costumes worn by spectators, with many costumes representing occupational groups (police, fire service, and armed forces personnel are popular), recent blockbuster movie characters, or the various rugby teams supported.

The first image, Figure 8:2, was taken during the Rugby Sevens in 2006 when several groups contributed to a two-hundred strong presence of 'Blanket Man' impersonators around the stadium. One group held an enormous purple banner reading, Kerry Beware: Blanket Man For Mayor, in dual reference to Wellington's Mayor (at the time) Kerry Prendergast, and her campaign against homelessness

\footnotetext{
${ }^{56}$ Though Figure 8:2 predates the commencement of my research and Figure 8:3 was taken in my absence, meaning I was not privy to the particular circumstances surrounding these encounters, this does not detract from my objective in this discussion as my intention is not to analyse these interactional encounters per se but rather examine what such social phenomenon depicted represents.
} 
(previously discussed in Chapter Four) and Brother's infamous purple blanket. Figure 8:2 captures one group of impersonators as they pay a street visit to Brother on their way to the sports stadium.

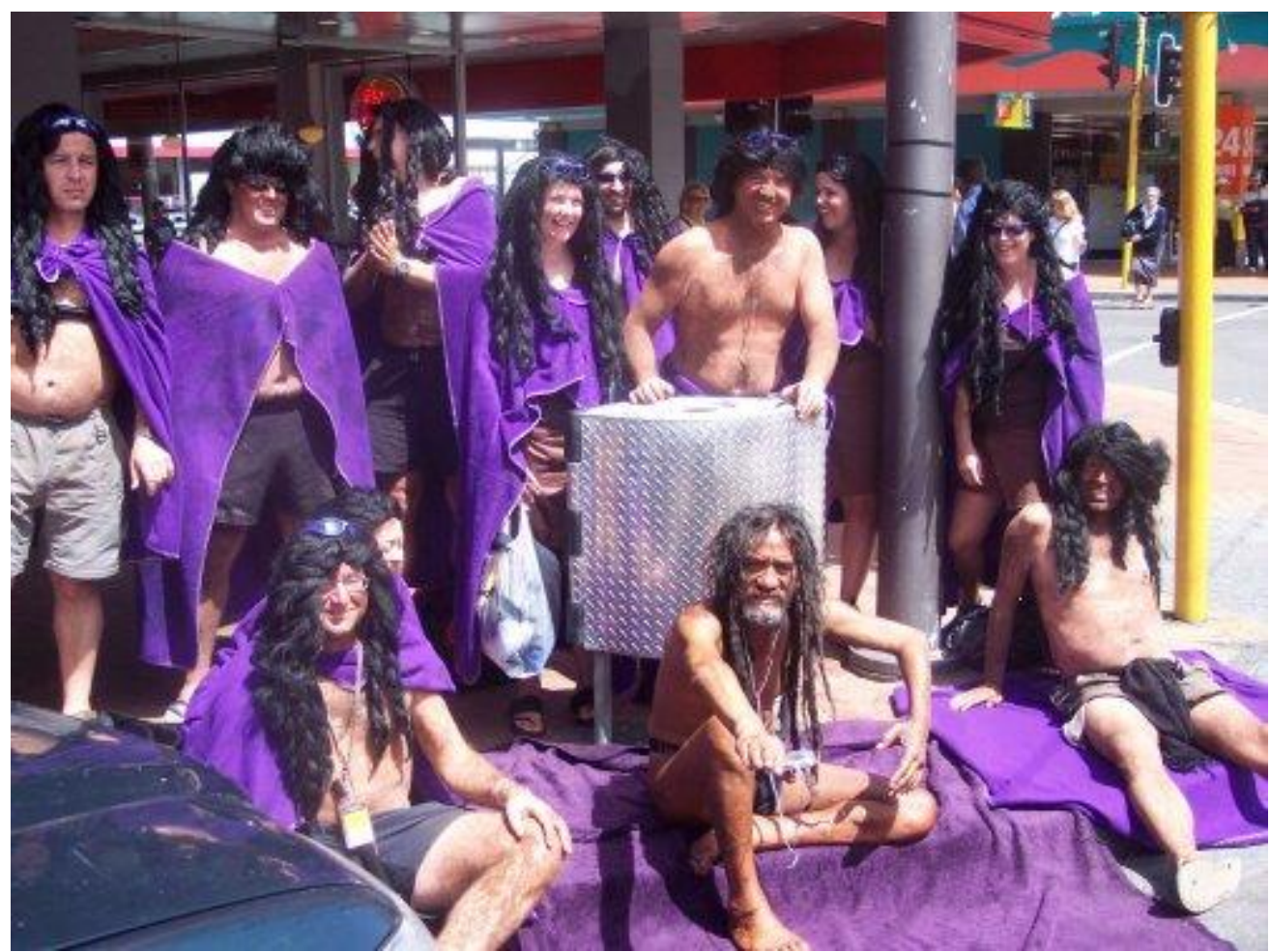

Figure 8:2 'Blanket Man' impersonators paying Brother a street visit as they make their way to the sports stadium

Source: Blanket Man, 2006 (Wikipedia)

While not present for this event, my knowledge of Brother's actions and life deduces the following. Figure 8:2 depicts a slightly bemused Brother surrounded by folk impersonating his personal identifiers: dreadlocked hair, loin-clothed body, and ever-present blanket. Brother grooving to his sounds indicates that he is at least tolerating what is happening. However, it would be difficult even for Brother, a street savvy strategic interactionist, to have much sway or authority over this particular occurrence. For one, he is clearly outnumbered. Given his healthy sense of humour and the fact the impersonators were part of a larger contingency of Sevens revellers well known for their partying antics, I venture it is likely he appreciated this particular encounter, in the 'good sport' way it was no doubt intended. But, for whom, do interactional episodes like this create a sense of fun and games? 


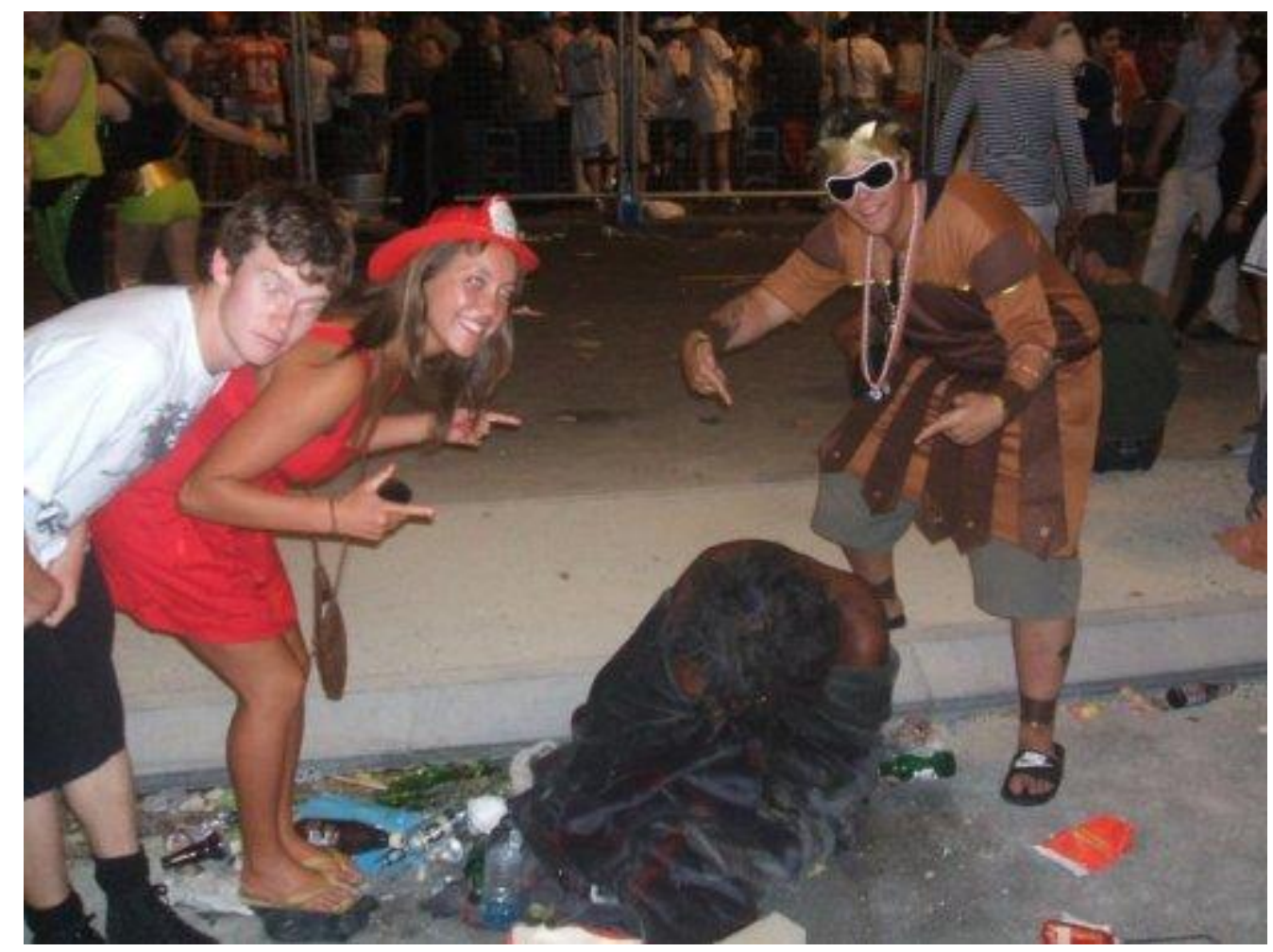

Figure 8:3 Sevens revellers prodding, poking, and photographing Brother as he sleeps Source: Google image search, keyword 'Blanket Man', photographer unknown

Figure 8:3 reflects a group of Sevens participants drawn to the city's primary nightlife hub following the end of the day's matches. It shows young people posing for the camera around a sleeping Brother in downtown Courtenay Place, Wellington. These images were sourced via a Google search of 'Blanket Man' images, where many others of a similar ilk are also available. They illustrate a form of encounter where the behaviour of others pesters him. Striking in Figure $8: 3$ is the juxtaposition of Brother in the gutter and the debris he is huddled among, which represents other people's 'good times' - empty bottles, food wrappers, and so on. This particular image reflects a desolate base condition of Brother's street life, rough sleeping. It portrays that for Brother (and rough sleepers generally), there is no such experience as feeling 'safe and sound' in one's sleep, or securing privacy while one sleeps.

Interactional episodes involving those looking for short-lived status enhancement or some quick fun and games on the street, often at Brother's expense, can be explored in relation to a concept Duneier developed in situ as he observed the 212 
interactions between homeless men and white middle-classed women. 'Interactional vandalism' explains a type of behaviour or 'vandalism' that occurs against propriety (Duneier \& Molotch, 1999). Interactional vandalism describes what can happen when interactional attempts fail and 'go wrong'. In his study of homeless street vendors, he identified interactional vandalism accounted for when "a subordinate person breaks the tacit basis of everyday interaction of value to the more powerful" (Duneier \& Molotch, 1999, p. 1288). Exploring the formal indicators identifiable within the men's interactional attempts with women passersby, Duneier and Molotch were able to pinpoint the signals and methods used by the men that attempted to entangle women into conversation with them. These included sexual come-ons as greetings and using the women's dogs as interactional openers. These interactional intrusions treated the women as objects or 'interactional toys', and because they were upsetting to the women, many women were forced into rudeness themselves when attempting to shut the men down. The women's faraway gazes or their silent responses to men's greetings treated the men as though they were not there, that is, the pragmatic non-person response usually given towards homeless people as was mentioned earlier. Ultimately, Duneier and Molotch proposed that despite the men's lower socialclass position, they were instead able to draw on the privileged position of men in the public sphere, to try and influence what they would have liked to see happen on the street.

In light of Duneier's arguments, several implications can be drawn from the 'Blanket Man thrills' interactional episodes I have discussed. Though Brother is a homeless person, thus connectable to natural reactions of risk, dirt, and deviance, there is considerable public 'knowership' (Goffman, 1983). He is a locally recognisable identity, who has taken on considerable notoriety, and to some extent adulation. Therefore, he is not representative of 'typical' homelessness and he is rather, a non-intimate who nonetheless is open to interaction by strangers as they pass by on the street. As I have intimated and will demonstrate below, he is not immune to molestation attempts to poke, prod, or photograph him. 
Brother has comparable social status to that of the men which informed Duneier's observations, however, his situation breaches the strongly normative interactive environment often experienced by homeless people. It is argued that housed people commit a reversed form of interactional vandalism when treating Brother as public property and as an 'interactional toy' when seeking their type of 'Blanket Man thrills'. That is, these members of the housed public were observed to breach interactional norms that are normally adhered to between unacquainted people, in order to achieve what they would like to experience on the street. Crucially, as this social phenomenon exposes, Brother's elected mode of dwelling on busy public thoroughfares can bring an extreme experience of everyday existence. Moreover, his every action, and reaction, is circumscribed 'front stage' in the fullest Goffman (1959) sense, not just in space, but also in time.

Brother's methods for dealing with difficult others were not always 'fool-proof' with the clearest elements of his resistance observed within social encounters where others attempted to touch him, as the following fieldwork excerpt exposes:

A man loiters in a doorway with his mates as they smoke cigarettes. He calls out, "Blanket Man", which gains no response. He walks over and reaches out to touch his arm. In response, Brother leans back, trying to create some distance. The man counters by taking a step further into his space; undeterred by Brother's obvious recoil, he pats his arm. At this, Brother jumps, yelling: "Fuck off ya queer cunt, ya always trying to touch me." Still ignoring this, the man touches his shoulder. This time the response is physical: Brother lashes out with his foot, his blanket flies open revealing his loin-clothed body, and in the ruckus his stash falls to the ground. The man swaggers back to his mates, one of whom comments, "He's almost an icon you know" (Fieldwork: 18/06/07).

Given my discussion so far, Brother's reaction highlights what could happen when Brother reached the end of his tether and had what Goffman (1961b, p. 56), would call his "ignition point" roused. Clearly, in order to deal with a constant, and at times, difficult public co-presence, but also wanting to engage the sociality of others at times, requires individual resourcefulness on Brother's part, and a keeping of his wits about him, as much as possible. However, through deploying his 'tricks of the trade', he is able to maintain some control over whom and how others may interact with him, and achieve some middle ground between too much 
and too little public attention. In the next section, Brother's interactional techniques are outlined and examined to consider what role and function they might have in allowing him to manage others and to also 'make himself up' on the street.

\section{Surveyor and contemplator of the street}

Brother's lived experience clearly affords him knowledge of the city's rhythm and tempo, revealed by his statement, "I am the contemplator of the street" (Fieldwork: 28/03/09). As a result, he can often anticipate times that could prove particularly problematic for him as far as interfering others are concerned. The following two quotes reveal how certain days of the week and even the weather could influence what he anticipated. The first quote reflects his ironic humour when playing down a horrendous storm that had battered the capital throughout the previous night and no doubt had affected him, "I heard it was freezing last night [Friday], the weekend party starts now"57 (Fieldwork: 11/06/08). On another occasion, he asked, "What day is it today?" On telling him, "Thursday", he responded, "Ah, every cunt will be out tonight trying to gate-crash my party for one. I'd better get myself some Doctor Vodka" (Fieldwork: 22/08/08). The second quote refers to the way other people, fuelled by alcohol, became more bold, and how they became more tolerable to Brother if he too had been drinking. However, unwanted pedestrian contact and acts constituting interactional vandalism did not only emerge through major events staged in the capital (which could see the night population swell from twenty to seventy thousand in the city, during the Rugby Sevens, for example) or during average weekend evenings. Brother confronted unwanted forms of pedestrian interference often, in mundane, rather benign forms, when pedestrians (sometimes inadvertently) breached interactional norms, even when endeavouring to be inclusive or helpful.

${ }^{57}$ Ordinarily the 'weekend party' period he refers to commences Thursday evening and continues through to the early hours of Sunday morning. However, given the inclement weather mentioned, the city had not been busy and therefore Brother had experienced a reprieve from the usually very busy normal Thursday evenings. 
As mentioned earlier, one effective technique used by Brother to signal his reluctance to others was managed through his utilisation of the 'middle-distance stare', identified in Lofland's (1973) work on behaviour in the public realm. This particular technique revealed how accomplished Brother was at the art of avoidance. In keeping his face impassive, he gave no acknowledgement of the presence of others, feigning the impression of looking out into the street, without looking at anything in particular.

People were consistently observed not knowing what action to next take when ignored by Brother through this technique. For example, a young woman's perseverance was recorded over a number of consecutive days as she had attempted to give a hot pie to Brother. He had used the middle-distance stare to ignore both her and food. As she failed for the fifth time to get any acknowledgement of her presence, she looked my way and shrugging, told me, "It's a really weird feeling always being rejected by Blanket Man" (Fieldwork: 18/05/09). Brother's (non)-reaction to the 'hand that wanted to feed' is a reversal of the "passive meek homeless person" observed by Parsell (2011, p. 451), who is described as actively striving to appear worthy and grateful by downplaying any assertive or capable aspects of themselves, projecting instead only those aspects of themselves that suggested humility and docility during their receipt of donations.

Closely attending to Brother's responses within those interactions involving food and other goods, it was discovered that good donations for Brother comprised donations that were simply deposited without any fanfare on the pavement. Through this more detached mode of giving (which many people practiced), he was able to exercise passive disregard and was not required to acknowledge every benevolent person or their offerings. Crucial to Brother, was a desire to be known for his rugged tenacity to tough it out on the street so pavement deposits can be seen as allowing him to avoid casting himself into a role of powerless codependency. The woman with her pie was therefore ignored because she committed a common error made by people who, electing to stand over Brother when making their offerings, inadvertently cast him into the role of a lowly receiver of their generosity. Brother not only resisted being positioned as lowly 
receiver, in effect he re-directed the feelings of rejection commonly aroused in homeless people back onto the gift-givers. This feeling of rejection was seen in people's awkwardness, as they appeared to hover and weigh up what action to take next. Should they offer the item again or leave? Some people resorted to leaving with their intended donation; some chose to place it on the ground before leaving; while some people asked if I could give it to him on their behalf. In the case described, the woman's posture had further signalled her eventual resignation. After speaking to me, she had moved slightly away to put the pie into her bag, had wrapped her coat tightly about her and had walked quickly away, avoiding any eye-contact with a small group of people seated nearby that had witnessed Brother's rejection of her donation. By extension, Brother's nonchalance served to evoke a reversed form of indifference that treated higher status individuals almost as non-persons, as was heard in the woman's expressed feeling of rejection.

While surveying the street and when feeling sociable, Brother's customary way of greeting or acknowledging those in his presence was to perform a quick upward thrust movement of his chin while making eye contact. Often this greeting was performed in quick succession, or conversely, in slow motion whenever he attempted to greet several people approaching or passing at once. I once overheard a young male on the receiving end of this gesture, delightedly telling his mates that, "Blanket Man always gives me the ups" (Fieldwork: 13/01/10). 'The ups' is a good colloquial description to describe this friendly gesture, which was the most common form of communication instigated by Brother with those walking or driving by him.

Another routine interactional opener inviting public acknowledgement, attention, or engagement were Brother's one-liner statements. A frequent one-liner was his reminder to other people to "keep breathing". The significance of this comment can be interpreted in two ways. On one hand, for Brother, breathing is a metaphor that recognises the busy and purposeful way other people use city space, in stark contrast to him, as they transition between one task to another, one bar to another, or commute to and from work. On the other, breathing also references the hard conditions that he must sometimes endure in the street life existence, where 
continuing to survive can become an ongoing feat dependent upon individual resourcefulness and resilience. For example, following a period of intense southerly storms, followed by a particularly spectacular thunderstorm, he told me, "We've moved on from surviving, now we just gotta keep breathing" (Fieldwork: 02/06/08).

Another frequent, if not daily, one-liner was the self-mocking proclamation, "I am the last ugliest dumb cunt left in Aotearoa." Though this self-depreciation humourously conveys that he is an endangered species, it also refers more seriously to his perceived 'otherness' brought about through his choice to live on the street. In this vein, Ungar (1984) notes, self-mockery is commonplace when individuals' performances are open to the scrutiny of others because when one reveals one's weaknesses or faults in a humourous manner, one is able to retain dignity and status. Therefore, a person cast into a demeaning role such as homelessness, could, whether intentionally or inadvertently, take refuge in selfmockery. Self-depreciating banter in this sense can be understood to allow Brother to get in first so as to diffuse anticipated responses to his stigmatised identity. As Ungar further claims, through using self-depreciating banter, individuals can also call attention to "their own faults or failings in order to enlist sympathy, seek reassurance or engender forbearance" (1984, p. 128). He suggests that selfmockery can create an ironic distance from admissions:

By viewing their shortcomings in a nonserious fashion, they are inviting others to take less account of their deficiencies, In effect, they are simultaneously providing others with privileged insights and disarming them by requiring them to discount the import of what they have learned (Ungar, 1984, p. 129).

In Brother's case, self-deprecation served to shut down caring afforded by others or their attempts to enhance his status. This allowed Brother to create and maintain distance, as by not taking himself seriously, it was then difficult for others to do so. Field notes referenced his quick inclination to use ridicule to shut down well meaning attempts by others through mocking his self or situation. A young woman that had approached Brother late one night to give him money and tell him that he was a Wellington icon, that she cared about him, he was like family to her, and 
that he needed to take care of himself, illustrates a case in point. He had responded by laughing and shooting back, 'Nah, I'm a dumb cunt, the last dumb cunt left in Aotearoa" (Fieldwork: 18/06/07). This type of self-effacing response by someone aware they do not always occupy an esteemed status in the eyes of others, when uttered in response to momentary enhancement, aims to disrupt sympathy or sentiment by projecting an air of autonomy (see Ungar, 1984). It is intended to suggest to others that he does not need their care and concern.

At other times, an incongruent use of humour was revealed when he would joke loudly that his life was the same or better than that of housed societal members. Interestingly, this form of humour was also used to jokingly deflect both differences and similarities between his life and those of conventionally housed people. His use of language was pivotal in his projection of this. One example, included earlier in observational material presented in Chapter Six, revealed him telling a woman that he was getting his whare cleaned before heading off to work. Then, there were the incongruous comments to me that indicated his ability to take whatever was thrown at him, for example, one morning following a night in police custody at Wellington Central Police Station, Brother had told me, "Ah Hilton Central, just another occupational hazard that comes with the territory" (Fieldwork: 11/08/08). Sometimes pedestrians themselves made good natured comments referencing the differences between their lives and his, for instance, one male commuter had smiled and told him, "Ah, Blanket Man, I pay rates you pay nothing" (Fieldwork: 16/01/09), while an elderly man once commented, "Eh, look at you, not a care in the world, eh" (Fieldwork: 24/09/09). Meanwhile, Brother would occasionally offer brief explanations to passersby who stared at us or stopped to take photographs, such as, "We're trying to think outside the square here" (Fieldwork: 08/04/09).

Brother's command at turning an extreme existence into one of jest can be understood to simultaneously subvert the ascribed membership category of homelessness and its associated category-bound behaviours by troubling their normative understandings. That is, his tendency to amp up a pleasurable state in the face of obvious hardship portrays his resistance to and rejection of, a 'down 
and out' self. ${ }^{58}$ Jocular behaviour can also be understood as an attempt to brush off public sympathy and challenge stereotypes often associated with homeless persons. The data reveal how Brother's repertoire of one-liner statements often came to the fore when his own actions made aspects of homelessness stereotypes most salient. One stereotype often associated with those who are homeless, is that homeless people perform degrading activities such as ferreting in rubbish bins or asking passersby for money. As was illustrated in the fieldwork material earlier, Brother had jovially quipped, "Cancer, yum, yum", as he received cigarette donations from strangers. Likewise, when walking with Brother, we would occasionally pause for a moment here and there as he bent to pick up discarded cigarette butts (wonderfully captured in the street scene of Figure 8:4). In doing so, he would make light of this activity saying to me, "Our generation, we should have learnt about cancer." He also downplayed other actions that were likely to be read as from someone of lower social position such as when lurching to catch cigarettes that were tossed to him from passing car windows, "Ah cancer", he might say, while cheerily giving donors 'the ups' (Fieldwork: 08/04/09, for example). Joking quips used by Brother were intended to downplay his dependent acceptance of material goods by deflecting attention instead onto health risks associated with smoking activity itself, something all smokers subject themselves too, whether housed or unhoused.

${ }^{58}$ Other field note data support this claim with documented quotes from Brother in his personal communication with me. For example, he told me on several occasions that he did not consider himself to be homeless as the city was his home (Fieldwork: 09/04/09, for example). Sometimes he elaborated on this claim, telling me that his life on the street commenced as a choice because he had made the decision to live free therefore removing any need for continuing to commit crime in order to pay house-hold related bills and so on (Fieldwork: 27/02/10, for example). At other times he would muse about how society was unable to think outside the square and thought everybody should live in a house (Fieldwork: 22/06/08, for example). 


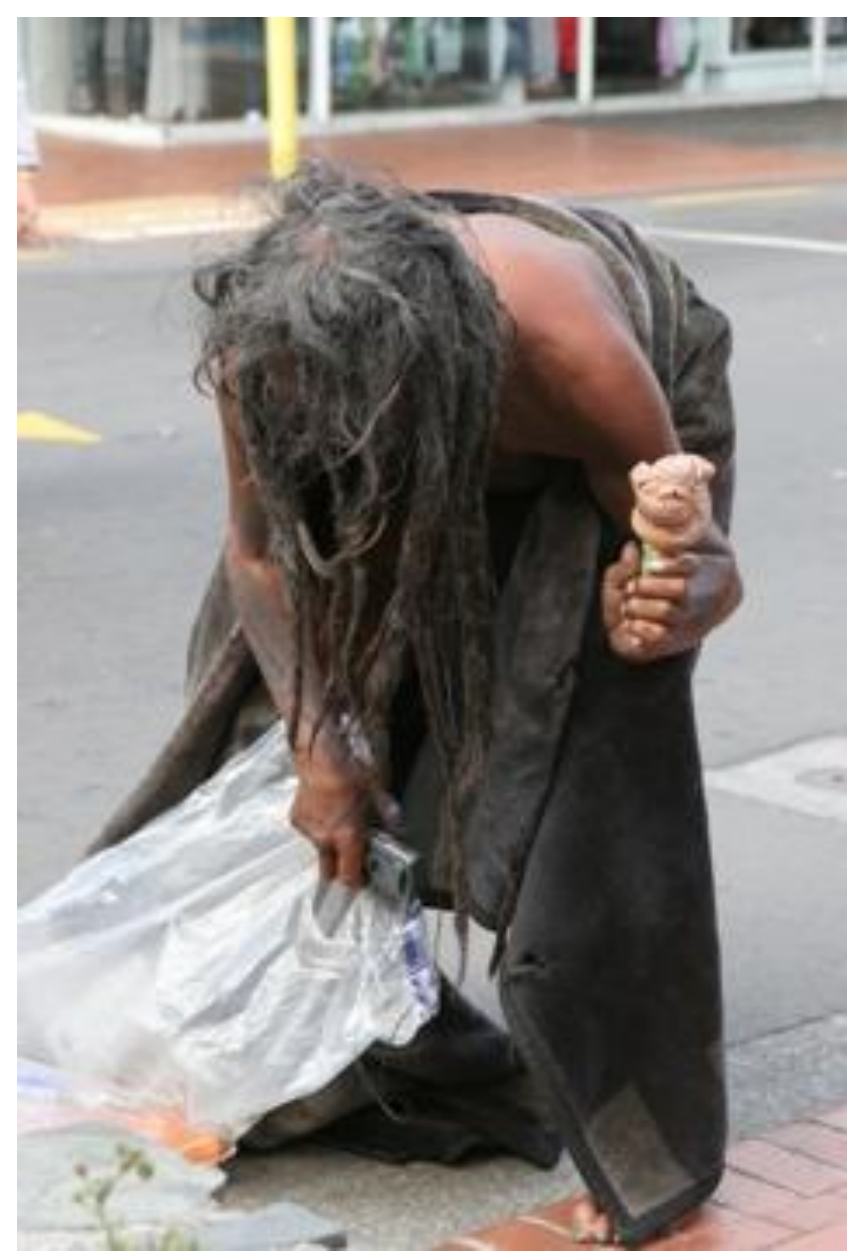

Figure 8:4 Stooping to pick up a cigarette butt

Source: Belinda Brown Photography

On one occasion, when sitting on the corner with Brother who was absorbed in his music, the male occupants of a car waiting parallel at the traffic signals, had amused their selves by throwing coins at Brother from an open car window. As he was pelted by the small change, one coin had hit him on the face before pinging to the ground. Unable to ignore the physical consequence of their actions, he had gruffly reacted by telling the car's occupants to "Get to work, you will need to earn some more of that now". Here, his comment can be understood as intending to mock the men's actions by reminding them they needed to earn their money in conventional ways (Fieldwork: 24/09/09).

As well as using greetings and one-liners to show his receptivity to sociality to brush off homelessness stereotypes, objects also served as interactional devices and were used in greetings that referred to his use of cannabis, tobacco or 
premixed alcoholic drinks by using specific terms - 'peace-pipe', 'cancer' and 'sugar diabetes - to describe these habits. In referencing his manufactured drink can as the 'peace-pipe' he indicated his alignment to Rastafarian principles ${ }^{59}$ and by citing known illnesses in relation to his heavy cannabis, tobacco, and sugar consumption, he intended to disarm other people's disapproving glances or ward off disparaging comments.

The 'peace pipe' had a dual function besides being just an implement used for smoking cannabis. The peace pipe was also used as an interactional device to rebelliously deride the prohibition of alcohol in public space and to flout a prohibited drug. Brother would hold it outstretched above his head as he thrust it in time to music and yelled out one-liners illustrating his defiance through provocative statements "Liquor free zone at all times" or "Let's get him with the liquor ban, they persisted, I resisted" (Fieldwork: 05/12/08). My field notes also report many instances where Brother may not have been actually smoking cannabis at a particular time, but on noticing people watching him or taking his photograph would then quickly load the pipe and toke on it. On such occasions he would often say "Hang on, we better give them what they want eh". Other times he would call out to those watching "Confucius says peace pipe, mon mun" (Fieldwork: 08/04/09) or "The smoke signal of peace" (Fieldwork: 28/03/08). More often than not, this promotion and consumption of cannabis served to elicit a great deal of encouragement from members of the public through their affirmative hand signals - the 'peace' or 'thumbs up' signs - voiced endorsements and donations of cannabis. Many people also passed comments. One middle-aged well-to-do looking couple, for example, stopped one day to ask me whether Brother always so blatantly smoked cannabis in public. The woman had then cocked her head in Brother's direction and had smilingly added, "oh well it must be good. I'll have what he's having" (Fieldwork: 04/01/09). Yet not all people responded positively to Brother's open cannabis use as the following comment

59 Although the peace pipe is associated with the tribes of North America for Brother it aligned with his understanding of Rastafarianism. 
loudly made from a passing motorist reveals, "Get a real life and get a job ya stoner why don't ya" (Fieldwork: 11/04/09).

Less frequent but of valuable cultural and personal significance to Brother were hongi ${ }^{60}$ - interactional greetings he expressed as 'tihei mauriora' (translated for me by him as 'the breath of life') - that were often used in his interactions with other Māori. Whereas Brother consistently exhibited aversion to being touched by others in public, the hongi was permitted and can be understood as an element of the encounter that is tied to cultural scripts and emotions. Cultural scripts utilised in interaction can be interpreted as prescribed emotions appropriate to the interaction and as preserving dignity of the self and the dignity of others (Goffman, 1972). For Brother, hongi are part of his cultural identity and therefore offer him a meaningful felt connection with his roots and other Māori while affirming self-identity. One Māori man, with a full facial moko ${ }^{61}$ and waist length dreadlocked hair, was observed periodically stopping by to hongi Brother in greeting. One day he told me, "I always hongi my brother" before pressing his nose to the side of mine and doing the same to me (Fieldwork: 18/09/09).

Another form of interaction that can also be understood as tied to cultural scripts and emotions, and having important cultural and personal significance for Brother, were pukana ${ }^{62}$ expressions. Goffman's concept of face-work has utility when interpreting the symbolic role pukana fulfills in Brother's engagement with others:

The positive social value a person effectively claims for himself by the line others assume he has taken during a particular contact. The choice of

${ }^{60}$ Māori philosophy holds that the hongi is to share life breath in face-to-face connections with other people to signify kinship. The practice of the hongi is to press the side of one's nose to the side of another's nose and hold firm for a moment. During fieldwork, I observed Brother accepting the hongi from three different Māori men and one Māori woman.

${ }^{61}$ Tā moko is a traditional Māori tattoo - a visual language that connects the wearers to their whakapapa (genealogy).

${ }^{62}$ Pukana are the facial expressions that accompany the dance performed during the haka (traditionally, the Māori war chant dance) that are performed today at the start of sporting matches or during kapa haka - Māori performing arts. Pukana means to stare wildly, dilate the eyes to show the whites and poke out the tongue. 
face is determined by the situation and is thus determined by culture (1972, p. 5).

One example of pukana operating as an interactional greeting was observed when a van of Māori women pulled up in front of Brother one day and one woman offered a blanket from a window to him. When noting he was ignoring the gesture, she had performed a pukana expression. Brother had then grinned and replied "Ah that's better" before responding in like manner. Before long, the tit-for-tat pukana expressions that were then exchanged between the pair had prompted the other women in the van to join in. Although brief, this had produced group fun and laughter on an otherwise bleak and cold day. In the next section, I closely explore an interactional stance, the 'Māori side-step', another tool in Brother's interaction toolbox, which I classified, along with pukana, as 'Aotearoa face-work' .

This section has demonstrated that the fine line that exists between friendliness and harassment is a precarious one. Having also set out how Brother's interactional techniques and methods that enable him to control or manage others interactions with him, the remainder of this chapter will now examine more closely other key roles humour can be understood to play within his everyday street interactions. Goffmanian micro-sociology, and in particular its insightful metaphor of the front and back stage dynamic, is central to the development of this section which explores two empirical examples. In the first example, I focus on one interactional technique in order to understand its unique role and significance. In the second example, I focus on an interaction between Brother and another man to examine how humourous exchanges, when managed strategically, can create shared solidarity and produce jolly good moments in the street life experience. 


\section{Sit-down comic or strategic interactionist?}

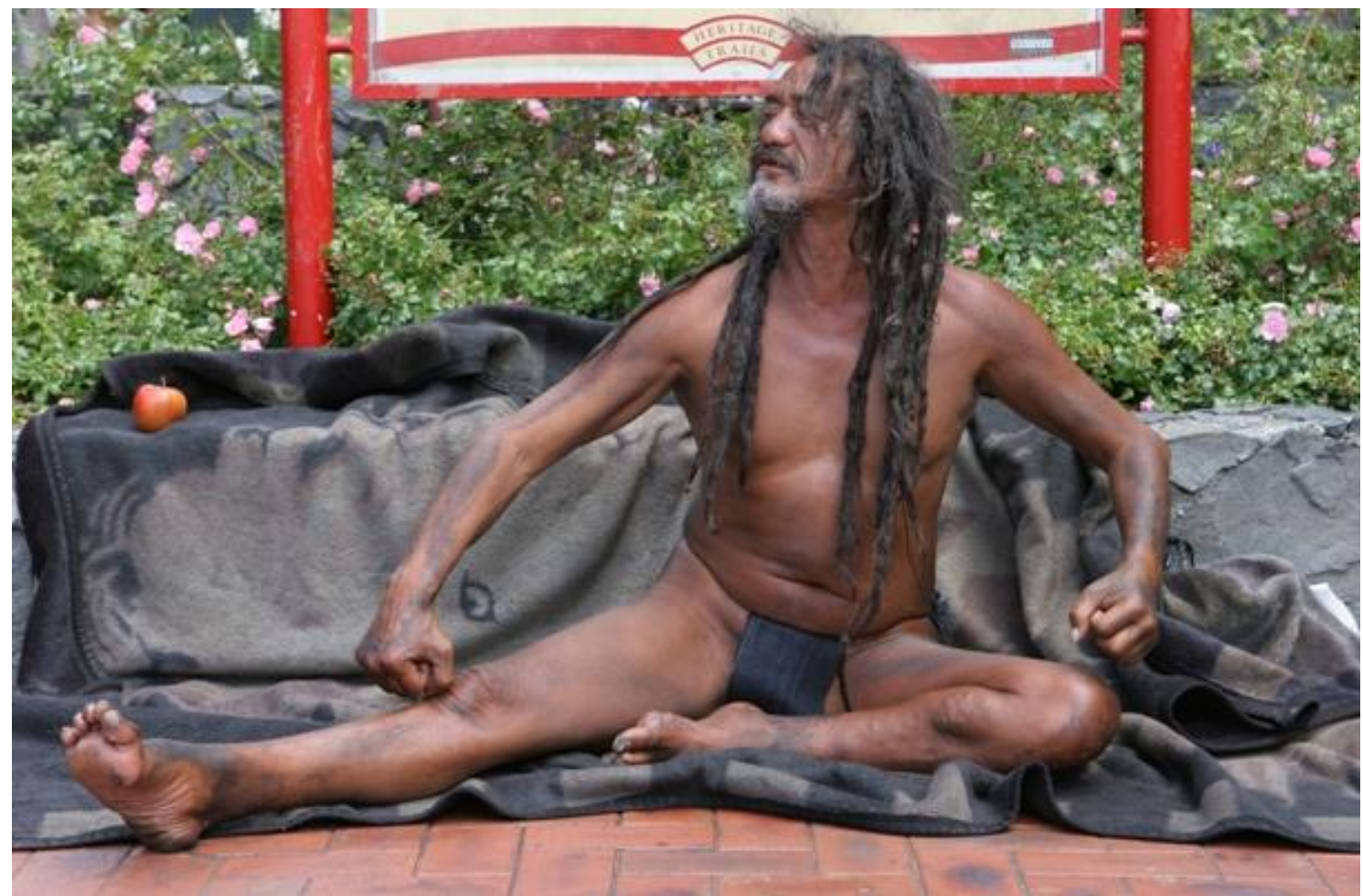

Figure 8:5 Brother's street enactment of the 'Māori side-step'

Source: Belinda Brown Photography

Figure 8:5, showing what Brother terms the 'Māori side-step', illustrates Brother in action on the street adopting one of his routine postures. While the image may not appear overtly humourous, as Kuipers (2008, p. 373) points out, "whether something is defined as humourous or serious is not a given, but something constructed in the course of interactions". Indeed, Brother's humourous intent was clearly discernible in his tone of voice, facial expression - often he would grin and nod to passersby or perform it in time to music - but above all in the laughing responses that it elicited (see Coser, 1959). Moreover, this particular stance was selected as it holds varied analytical utility given that its function fits several of the categories identifying different roles humour has in Brother's street interactions. Before going further, it is useful to first consider from a public perspective, how this, and other frequently assumed postures, are commonly understood purely from a spectacle perspective as the following comment from a District Court Judge attests: 
It is significant that all of Mr. Hana's offending is in the central city area. Having previously come across Mr. Hana in appeals against conviction and other appeals relating to bail, it seems to me more than a coincidence that his offending is in part a public performance (Doogue, 2008, emphasis added).

The judge's view suggests Brother's everyday routine activities and interactions with others are primarily provocative or exhibitionist in nature and designed to seek public attention. Similarly, prominent New Zealand columnist, Rosemary McLeod, describes Brother as "... a kind of attraction, the city's down-at-heel pet" (2011, emphasis added) and when referring to the way some people stop to talk to him, claims he is hard for people to understand. The performance aspect of Brother's behaviour is evident in McLeod's comments, which refer to the public interest in his presentation of self on the street. ${ }^{63}$ These views suggest Brother is a performing, rather than an interacting, individual and is therefore regarded as a social problem, that is, someone who needs to be managed as a symbol of the 'irrational' and 'colourful' aspect of urban life. ${ }^{64}$

So, how can this particular interactional stance enacted by Brother on the street begin to be interpreted besides being seen as funny or exhibitionist? The Māori side-step is a physical expression first used by New Zealand rugby players. This move occurs when a player charges a tackler head-on, bumping off the defender and generally trampling him as he runs over the top (maori side-step, 2011). Through lived experience in public, Brother knows that the police, on the basis of their authority, may intrude anytime they wish onto his or any other street person's personal lives. In view of the daily tribulations faced by Brother (including arrests and bail conditions that prevent him from occupying certain public spaces) the Māori side-step can begin to be understood as part of a repertoire of actions that have established a jocular boundary. Arguably, this stance is an attempt to impart a

${ }^{63}$ During fieldwork, this point was driven home with the inclusion of Brother's street location on the daily tour bus circuit. During these brief interludes, I observed tourists staring from windows or their cameras flashing as they worked to capture the scene on film.

64 Abelson (1999) makes a similar distinction when discussing attitudes that described the emergence of the bag lady's appearance on the streets in the early 1980s. 
sense of his own autonomy over his 'home' territory in public space. Indeed, other field notes document Brother telling me, "I better show em the old Māori sidestep" (accompanied by a mischievous wink) when he perceived imminent harassment from the police. Performing the Māori side-step is therefore also an indication of how he is not happy with what he must at times tolerate. However, it is also an attempt to project to the public at large that he staunchly intends to fend off any measures of social control that restrict his right of movement in public space or limit his participation in the social life of heavily populated city locations. Inherent in this action is his awareness that the public, too, are often knowledgeable about such events given that they are often reported on by the media or are able to be observed as they occur in real time on the street. It is suggested then, that one way this adaptation of a self-protective rugby move when adopted by Brother in an urban setting can be interpreted is as a form of rebellion against authority and stigmatisation processes often directed towards homeless people.

Another way to interpret the social significance of the Māori side-step as an interactional strategy in Brother's street life is found in Goffman's theorising of role distance and role segregation. From a sociological perspective, Goffman suggests:

When we closely observe what goes on in a social role, a spate of social interaction, a social establishment - or in any other unit of social organisation - embracement of the unit is not all that we see. We always find the individual employing methods to keep some distance, some elbow room, between himself and that with which others assume he should be identified (1961b, pp. 319-320)

While Brother's affiliation with members of the public connects him with conventional society, he still seeks some distance. Goffman writes that individuals enduring trying situations can produce a special kind of status symbol - a disidentifier - which they hope will shatter an otherwise coherent picture, "telling others not what he is but what he isn't quite" (1961b, p. 146). In this sense, he may actually be attempting to express some disaffiliation from the obligatory world of “formal, stiff and dead" (1961b, p. 152) social roles and norms by drawing on a 
store of conduct that is slightly unbecoming to a human being. That is to say, people in public space do not usually sit semi-naked on the ground defiantly clenching their fists. Brother sometimes referred to himself as 'a savage', and was observed snarling, barking and growling at the public at times. I observed on these occasions that individuals, not surprisingly, generally averted their gaze or acted as if they had not seen or heard these interactions. Although these episodes of disgruntled behaviour were in marked contrast to other interactional behaviour, it is here that we arrive at another key function of the Māori side-step.

Through this strategic method performed in the midst of city space, it can be argued he is able to express information about his resistance to 'the establishment' and housed society's way of life. Indeed, his mockery of the system and conventional everyday life could be read as defiance. This was sometimes revealed when he made his own observations about others, for example, "boring lives, same old every day, mundane" (Fieldwork: 11/07/08), "they're like working ants, locked in the system" (Fieldwork: 08/04/09), and "....always in a hurry to be somewhere, hope they remember to breathe" (Fieldwork: 15/12/08). At other times, he revealed insight into the way his choice to live on the street often met with resistance. A sampling of such comments follows: "I'm trying to live free, I'm nearly free but not quite, rules everywhere" (Fieldwork: 23/06/08) or "there's more rules out here than in the big house" (his term for prison) (Fieldwork: 01/06/09). On this view, the Māori side-step is a staunch and triumphal interactional technique used to convey autonomy and agency. It reflects that his life on the street has not eventuated through a series of unfortunate circumstances but, rather, through autonomous choice.

Although this line of reasoning is feasible it nonetheless creates a paradox. While the Māori side-step is intended to brush off notions of public sympathy which are sometimes afforded to homeless people, it could be counter-argued to exemplify a form of 'shadow work' (Snow \& Anderson, 1993). Shadow work falls within the domain of panhandling (begging) and is a term used to describe the ways homeless people can become skilled at accruing sympathy credits in order to receive money, food and other goods. Common methods employed by homeless individuals to 
attract a regular supply of contributors include fine-tuning their appearance, demeanour and pitch (Lee \& Farrell, 2003). However, in order to maximise chances of winning the attention or sympathy of passersby, shadow work can also involve interactions with the public such as offering a greeting, a story or entertainment (Lankenau, 1999). In this light, the Māori side-step (as only one of a repertoire of methods employed by Brother) has certainly contributed to gaining him notoriety. As was emphasised in the fieldwork description earlier, this has clearly put him in good stead as he receives a constant supply of money, alcohol, drugs and food. ${ }^{65}$ So herein lies the paradox. On one hand, Brother disaffiliates from the membership categorisation in which society places him (homelessness), yet on the other, he positions himself outside of conventional society through his choice to live on the street. Nonetheless, having carved himself a niche that tells others not what he is but what he is not 'quite', and by strategically giving primacy to one role or the other as he sees fit in relation to whatever he observes going on around him, perhaps perversely enables him to resist the exploitation of his private self while still enjoying the sociality of others.

The Māori side-step is but one of a repertoire of interactional techniques. As mentioned earlier, Goffman's concept of face-work examines how cultural scripts utilised in interaction can preserve dignity of the self and the dignity of others. In the analytic vein, the Māori side-step further brings racial difference into play as not only does it hold cultural and personal significance for Brother, it also allows him to have 'fun' when asserting and expressing himself on the street. In a conscious dramatisation of what Cowlishaw (2004, p. 86) identifies in her ethnographic analysis of performative racial agency among Australian Aborigines as "indigenous otherness", the Māori side-step similarly provides a visceral outlet through which Brother can share an element of his Māori cultural identity in a context where it has "the thrilling ability to shock" (Cowlishaw, 2004, p. 93). That is, given the broader contextual relevance of Brother's Māori ethnicity and his ascribed homelessness status, here his performance communicates where words

${ }^{65}$ In fact, the careful observer may have noticed an apple to Brother's right in Figure 8:5. It signifies one commuter's practice of delivering him 'an apple a day'. 
could not. Nonetheless, concurrent with this front stage presentation of self that can captivate the attention of passing others, a glimpse of the back stage self is detectable as he reveals multiple identities exhibiting his sense of self and who he is in relation to others under the guise of fun.

To this end, the playful element intrinsic to Brother's enactment of the Māori sidestep was observed to have a contagious effect on bystanders as he signalled interactional cues - making eye contact, smiling, and giving 'heads up' nods of friendly greeting - that this bodily gesticulation was also play. Moreover, this posturing, enacted "sometimes in concert with people, sometimes in opposition to them, but always in relation to them" (Hull \& Zacher, 2007, p. 75) by someone living on the margin without visible signs of material possession, brings the simple pleasure Brother experiences through this enactment poignantly into focus. Therefore, more often than not, this interactional technique was observed prompting others to ponder at the day-in-day-out level upon the human capacity for revelling in "bare life" defined by Thrift (2008, p. 70) as the simple fact of living itself which he argues has become heavily politicised. The following comments from by-standers support these claims: "Wow, he's awesome putting up the good fight day in and day out" (Fieldwork: 05/03/10); "I always see him and notice his presence - calm or not, mostly calm, but I bet he's never noticed me" (Fieldwork: 28/12/08); and "He seems very comfortable in his own skin despite the PC interference he has to put up with" (Fieldwork: 06/08/09).

While the Māori side-step represents an interactional stance that is often construed as simply funny or as an exhibitionist form of posturing designed to seek public attention, I have endeavoured to demonstrate the way several serious messages referencing everyday trials and tribulations as faced on the street by Brother are symbolically represented within this stance. I have also aimed to impart a sense of a fluidity of self and roles interpretable within this powerful bodily salutation, conveying how it was through this particular bodily expression that Brother was clearly observed taking a playful stand promoting his agency to onlookers. In light of these arguments, it would be an oversight to read the posturing of this stance simply as a semi-aggressive act or as some hollow form of public spectacle. 
Indeed, as Goffman once eloquently noted, it is within a personal capacity that, "An individual can be warm, spontaneous, and touched by humour. It is here, regardless of his social role, that an individual can show what kind of a guy he is" (1961b, p. 152).

\section{Street solidarity}

Gaming encounters provide us with fine examples of how mutual activity can utterly engross its participants, transforming them...in spite of the triviality of the game, great differences in social status, and the patent claims of other realities (Goffman, 1961b, p. 39).

In this last section, I draw from an event I observed during fieldwork to concentrate on a focused encounter between Brother and another man who was a frequent drop-in visitor. The role of humour is identified here, not only as a method to lighten the often boring reality of doing life on the street, bringing relief from mechanical routine, but as a means for producing a shared sense of social solidarity. In particular, this event illustrates that laughter, language, nods "and other playful gestures are not simply descriptive details of interaction. They are more fundamental parts of how interaction works" (Lee, 2009, p. 596).

A man squats on the footpath, exchanging light-hearted banter with Brother. Much laughter erupts as each man attempts to outdo the other with derogatory comments. "Cunt", throws Brother. "Arsehole", hurls back the man. With even more emphasis, Brother repeats his goodhumoured insult and laughs heartily. The man quickly joins in, perfectly imitating the distinctive laugh with equal gusto. I surmise the man is obviously known to Brother and well versed in engaging in this form of interaction with him. The man removes his shirt tie, flings it aside, and moves himself closer to Brother. He teases, "Ha ha ha, show us your undies then, have you got em on?" Laughing, he repeats the jibe, "Go on. Show us your undies." Brother grins, leans back, and opens his blanket to flash the loincloth he continues to wear over the underwear. ${ }^{66}$ More laughter ensues as they share mutual enjoyment at this display. Quieting down, the man tells Brother, "I respect what you stand for mate." Brother repeats his choice expletive, prompting another few rounds to pass between them. A group of pedestrians pause in their tracks, as one man

\footnotetext{
${ }^{66}$ The significance of underwear joked about in this exchange refers to the imposed bail condition that was discussed in Chapter Six which stated Brother must wear underwear in public.
} 
steps forward and says, "Stop the language, we're Christians." Immersed in their tit-for-tat banter amid much hilarity, Brother and his visitor appear not to hear him. After a few moments, the man stops swearing and asks Brother, "What does cunt mean to you, you say it all the time." With a deadpan face, Brother surprisingly cites a dictionary-perfect explanation, "It's the passage of the birth canal." The man turns to me, "I've been visiting this arsehole for years." Brother interjects, "I'm a bad boy", before laughing again and adding, "Don't get all pretentious on me." The man presses, "Where's your home town?" Brother points over the road to the recently closed and now boarded up video store, "My hotel's over there", he tells him. Seemingly spent, and with game over tonight, the man picks up his tie from the pavement and stands to stretch. Walking away, he yells a parting shot over his shoulder. This sparks a final string of expletives to ping back and forth, punctuating the night air until he moves beyond earshot (Fieldwork: 15/01/09, $9.14 \mathrm{pm}-9.35 \mathrm{pm}$ )

For Goffman, in daily life, moment-to-moment behaviour unfolding within fun and games provides a fruitful context, where the analyst is able to get as close as they are able to the "raw conduct" of individuals (1961b, p. 96). Within fun and games, as with any face-to-face interaction, there is enhanced possibility for communication and its feedback that is revealed through a wide variety of signs "for the damping and surging of response, and for the emergence of homeostaticlike controls" (Goffman, 1961b, p. 97). Goffman notes that though there is generally a normative framework for a given role, because of the complex forces at play upon individuals having fun, "roles may not only be played with but also played at" (1961b, p. 99, original emphasis).

Lee's (2009) stimulating ethnographic study of playful street corner rap 'battles' in Los Angeles elaborates Goffman's theories of 'keys' and 'limits' to understand how embodied and emotional cues are used to sustain the shared presumption that such battles are 'play'. For Lee, verbal duels are interactions that depend heavily on the successful communication that this is play. As my data illustrate, the playful interaction between the men began with obscene insults, which continued to underpin the interaction right to the end. Yet as Lee (2009) also notes, verbal duels have the power to turn into something else. Therefore, a central part of sustaining the playfulness can be observed in cues that signal when someone has acted outside the limits of the interaction. These cues are the rules defining which behaviours and activities are within the realm of play and which are not. 
In the fun and folly described, the first cue to signal this was play was evident in both men's use of language (swearing) followed by laughter. As momentum built, the visiting man signalled that this was in fact 'proper play' with the removal of his work place tie that further cued he was not only 'up for it' but 'in for the long haul'. A play-breaking cue occurs as the joking relations shift to a more serious form of talk with the visiting man announcing respect for Brother. Brother can be seen to work to preserve the playful frame - a form of exchange he is much more comfortable with than serious talk or questions - by strategically avoiding the break in play from gaining any purchase through directing the nature of the interaction back to exchanging expletives and joking relations. Back on a joking level, he 'plays the game', responding to jibes about undies and flashing his loincloth. However, moments later, the man is observed again attempting to shift the joking swearing relations, this time by asking serious questions. This 'game move' fits with Goffman's discussion on "opportune intrusions" accounting for what can happen next when one tries to access another's back stage self (1961b, p. 209). Nonetheless, Brother, in keeping his wits about him, again moved deftly to keep the interaction on a humourous level by signalling a cue to the man through voice inflection (mock stern), to not get pretentious on him. In managing the tone of the interaction on a joking level, he successfully managed to maneuver the man away from using the moment of solidarity to then get personal with him.

Effectively, the shift from joking to serious conversation or vice versa became an act of conversational cooperation which Kuipers (2008, p. 373) writes, "can succeed, be withheld, or fail, and this shift creates opportunities for specific types of communication". Indeed, several times Brother's visitor tried to break frame while simultaneously using the playful mood to his advantage in order to gather information about Brother he might ordinarily not have had a chance of getting. That is, anyone at all familiar with Brother would have learnt fairly quickly that questioning him usually served to only promptly shut down the interaction. Through having lived on the street for over a decade (at this time in writing) he has become very astute or 'streetwise' at pre-empting a plethora of interactional antics used by others in their attempts to commandeer light exchanges into ordinary conversation and, inevitably, into personal probing if given free reign. In the 
episode of play described, Brother's refusal to adhere to frame breaking cues, strategically dictates and maintains the nature of the social interaction at a gameplaying level by creating a jocular boundary. Brother's tactic resonates with Goffman's observation about the way individuals can act to say "I do not dispute the direction in which things are going and I will go along with them, but at the same time I want you to know that you haven't fully contained me in the state of affairs" (1961b, p. 133).

Ultimately, then, it is through maintaining his tactical use of humour that Brother can limit social interaction. In this light, joking relations for Brother can be understood to create and maintain distance and provide him a barrier in his everyday social relations. It is also interesting to reflect briefly on how being in Brother's presence, gave the man license to cross normative boundaries and breach behavioural codes by raucously indulging in obscene exchanges. Yet, as I have discussed, it was the very form of that jovial tit-for-tat swearing relations that effectively gave the interaction traction and enabled a period of solidarity to be enjoyed.

This section has demonstrated through two examples how Brother's everyday use of humour and ability to make light of often difficult situations is in fact far removed from McLeod's (2012) contention that he is "committing a slow willful suicide on the street". Rather, Brother 'lives it up' on the street, as he reminds others to breathe, exercises his autonomy and agency, tactically manages his responses to different situations and regularly enjoys a hearty good laugh. This section has further demonstrated how in a particular context, Goffman's (1959) 'front and back stage dynamic' can be conceptualised as a physical temporal dynamic. Certainly, as an interactional resource, the Māori side-step tactically employed and spatially managed by Brother was shown to provide a social conduit through which he is able to infer a fluid sense of his felt place-in-the-world through a form of playful mock aggression. The street solidarity scenario developed an analytical argument importantly illuminating the nuanced ways in which one can maintain role distance even as one is engrossed in the moment. As was exposed, Brother's interactional cues signalled to his visitor that though he 234 
had been 'let in', this did not then permit him to use the front stage play-inprogress to access Brother's back stage self. Instead, for Brother, the tit-for-tat exchange was jolly good fun to play, and fun alone was "the approved reason for playing" (Goffman, 1961b, p. 17).

\section{Concluding comments}

This chapter has critically engaged fieldwork material and the relevant literature to explore, interpret, and explain everyday talk and action in the social life of Brother. A descriptive account providing a micro lens into a short time spent observing Brother in his natural setting of the street emphasised the intensity of public interactions that is routinely faced by Brother. I have also demonstrated that within Brother's unusual domestic situation, managing his particular "occupational hazard" - the 24/7 presence of other people, realised the need for him to develop strategic interactional methods. Today, these methods evoke lines of conduct and modes of being that have established Brother's 'front stage self' as one firmly founded on a finely honed repertoire of humour. In particular, his jocular street persona has been argued to provide a protective boundary around his private self by providing a way for him to be among others without always having to commit himself to personal interactions. Indeed, this boundary has exposed a range of reactions, from open insult, to friendly acknowledgement, as he sees fit. This is important: Brother is his own man. He will tell others to "fuck off", accept their offerings, humourously indulge them, or even label himself the "last dumb cunt in New Zealand", if that is what he wishes to do.

This chapter has further argued that Brother has managed to mobilise much of his talk and actions to exhibit distance from the ascribed membership categorisation of homelessness. This has revealed that Brother's aptitude to reframe the serious incidence of homelessness within a jocular process allows him to resist the narrative of victimhood through defining his own identity as an individual who is in control and able to mind his self. However, in acting humourously, his conduct is complex as his command at turning an extreme existence into one of jest, creates a parody of the serious situation of homelessness which significantly challenges or 'troubles' common preconceptions about how street life can be experienced. 
Poignant is Brother's own expression of his lived experience: "this city is a great marae, it is my whare but without those in it, it'd be nothing" (Fieldwork: 08/04/10). This eloquently refers to his sense of belonging and home in the city among others especially when one also lives precariously under difficulty. Brother's description of the importance of people alluded to here reminded me of an old Māori proverb (provided at the outset of this chapter), where he conveys that for him, it is the presence of other people that breathe life into city space and help shape the daily flow that contributes to his lived sense of belonging. That is, open concrete spaces are, for him, homely spaces. Moreover, it is through other people's interactions with him, that he is able to socially interpret 'what kind of a guy' he is in relation to others.

This chapter has added another layer of understanding to the importance of finding equilibrium between space and body by examining how sociality can significantly enhance the experience of a publicly lived life. Brother's particular worldview as outlined earlier in this thesis is, to reiterate, one that expresses kinship with other people and a meaningful connection with the land. To further recall, for Brother, achieving this can transition a state of exclusion and mere existence into one of inclusion and a grounded sense of wellbeing and belonging. In this sense, sociologist Morrie Schwartz's (1997, p. 73) states, “[The] need to feel connected to other people is just as vital to human survival as food, water, and shelter." However, given these needs must be satisfied and learned in interaction with the environment and other people, these needs, as I have demonstrated, can only be satisfied by reaching some agreement with others as to how this can be done. For Brother, reaching this is attained through the process of building up lines of conduct or modes of being as I have elucidated in this chapter. Yet, as I have further shown, Brother's jocular boundary plays a pivotal role in allowing him to maintain some 'elbow room' or balance between his "impulse to embrace that which is public, and the drive to escape the discomfort of group demands" (Schwartz, 1968, p. 752). By extension, despite lacking the culturally acceptable signs of belonging, Brother has been able to carve a niche for himself in the thick of the pedestrian flow he calls his whare-in-the-city. 


\section{Chapter Nine Home street home}

Certain types of critics, by the way, judge work in the social science according to whether or not its conclusions are gloomy or sunshiney, negative or constructive. These sunshine moralists want a lyric upsurge, at least at the end: they are made happy by a sturdy little mood of earnest optimism, out of which we step forward fresh and shining. But the world we are trying to understand does not always make all of us politically hopeful and morally complacent, which is to say, that social scientists sometimes find it difficult to play the cheerful idiot. Personally, I happen to be a very optimistic type, but I must confess that I have never been able to make up my mind about whether something is so or not in terms of whether it leads to good cheer. First, one tries to get it straight, to make an adequate statement - if it is gloomy, too bad: if it leads to hope, fine.

(Mills, 1959, p. 89)

\section{Introduction}

This final chapter has two key aims. The first is to draw together key findings from the empirically focused chapters of this thesis to offer, as C Wright Mills urges, 'an adequate statement'. The second aim is to consider the contribution this thesis has made to sociology, homelessness studies, and everyday life studies. As to whether it is possible to conclude on a mood of 'good cheer' or not is a question best left for the Epilogue, which closes this thesis.

Throughout this thesis, I have explored the intersection between macro-forces (state and society) and micro-settings, exploring the interplay between private troubles and public issues. This thesis has demonstrated that while Brother's is a specific story, it is a story embedded within the local street scene. Consequently, it is a story that includes a diverse range of people commonly referred to as 'members of the public'. The 'ordinary public' captured in this thesis includes preschoolers, revellers, hurrying commuters, camera-toting tourists, and the lone pedestrian strolling among the pedestrian mass. Brother's story involves interactions with retailers, including Mrs. Fastidious, a friendly fishmonger, a disapproving liquor store clerk, and another who called him 'Boss'. Significantly 
involved in Brother's story were those working within the institutions of popular and expert knowledge and the institutions of social control: the media, legal representatives, judges, police officers, mental health workers, psychiatrists and psychologists. Other people infiltrating his daily life to interact with him did so as they worked the streets: cleaners, parking wardens, and Walkwise officers. The constant presence of a myriad of people emphasises that while none of us exists in a vacuum, some of us are more public and therefore scrutinised and judged more openly than others.

I hope to have done more than simply narrate Brother's story. My treatment, examination, and interpretation of Brother's corner life aimed to offer an in-depth temporal and conceptual account of social, spatial, and embodied action and organisation, of making do, naming, fragility, rebellion, conflict, dirt, bodies, transgression, humour, and resistance, set against the background hum of mundane routine activity propelling everyday life. Ultimately, it is a story of order in the disorder, and power in the resistance.

My study has emphasised that while Brother's is a particular story set on the street corner in Wellington, Aotearoa New Zealand, it nonetheless speaks to broader debates, and absences, within sociology. This story of an individual conceived as 'different' has revealed the ways in which perceptions around difference are open to contest and change. Moreover, Brother's story has provided a comprehensive snapshot-in-time account of what can happen to those at the margins who dare or are impelled to do things differently. Importantly, it is also a story about who is thought to belong, and who does not, and how we respond to those who are deemed not to fit.

\section{Chapter summaries}

In this section I provide a discussion of the empirically focused analytical chapters forming the main body of this thesis. I restate their aims and report the key research findings in each. I begin with a summarised conclusion of Chapter Five to draw out the main arguments and analytical conclusions. 
Chapter Five provided a grounding chapter, which interpreted the broader sociospatial political context pervading the local street scene to which Brother belongs. As part of that process, I located what is distinctive and ordinary about Brother's way of doing street life in the local setting described. This established the high profile nature of Brother's mode of living. Underpinning these aims, a pivotal concern was to grasp the social processes through which I argue homeless people are constructed as a 'given kind' (Hacking, 2002). A second interrelated aim was concerned with exploring the discursive processes through which Wellington street people have been singled out, collectively grouped, named, and categorised. Building on this endeavour, a third aim was to understand how we conceptualise and realise whom we are and what we might be, in particular moments and spaces. To this end, the dynamic relationship between popular and expert knowledge generated by the public, newspaper and social media, and the institutions of informal and social control, were explored to understand the "looping effect of human kinds" (Hacking, 2002, p. 8). Which, to reiterate, refers to how classifications interact with the people classified in ways that can control, help, or change them, or even lead them being admired (Hacking, 2002).

It was established that Wellington's newspaper media are responsible for predominately representing homelessness as otherness and constructing homeless people as 'other'. Findings confirmed that newspaper reportage overwhelmingly constructs homeless people as 'dirty, diseased, and dangerous' as readers glean familiar messages underpinning the majority of accounts on homelessness. It was further revealed that within their reportage, newspapers also distinguished between homeless individuals and homeless groups in particular ways. Firstly, language and associated images used in much of the reportage on two Wellington homeless men were shown constructing 'Bucket Man' and 'Blanket Man' as 'poster boys' portraying two competing faces of homelessness. These constructions emphasising a whimsical 'Dickensian character' (Haines, 2003a) impression on one hand with an ominous 'manky nomad' (Tratt, 2005) impression on the other, were argued to project a notion of the 'good' homeless person versus the 'bad' homeless person. In other media accounts concentrated on a group of homeless people and their long term habitation in an inner city park, a general consensus within reportage 
projected this group as a 'social problem' that was in urgent need of official intervention. To recall, one article reported the Wellington's City Council's initiative as one that pledged "to cleanse the streets of human detritus [homeless people]". Despite the absence of formal anti-homelessness legislation in New Zealand that was also discussed, a small case study of Wellington's Glover Park was instrumental in exposing the Council in action as it had stepped up its fight against homelessness in response to this group. Through recounting the events that developed surrounding this conflict, Amster's (2003) contention that a negative perception leads to "exclusion, eradication, and erasure" is supported by the case of Glover Park being reclaimed, redesigned, and redefined as a park for housed citizens to enjoy.

Extending examination beyond the way homelessness and homeless people are constructed within the newspaper media, the global world of on-line social media, the international fashion world, public signage, and even local street art, were also found to contribute towards a making, remaking, and unmaking of homeless people. An exploration of how these constructions contributed to the ways in which people are made up extended insight into how categorisation processes further reinforce negative homelessness stereotypes. These constructions operated to stigmatise homeless people on one hand, while glorifying homeless people and romanticising the harsh condition of homelessness on the other. This exposed Hacking's (1995) 'looping effect' in action as having mixed consequences in the lives of homeless individuals. To recall, while British homeless man Gordon was reportedly 'chuffed' with the increased attention, China's Brother Sharp was placed under distress by the notoriety that was bestowed on him.

Fieldwork data were used to explore how homeless people are 'made up' in everyday face-to-face situations at the local scale of the street in Wellington. All three fieldwork vignettes describing groups of homeless people in Cuba Mall and Aro Park portrayed the everyday nature of 'hanging out'. Collectively, these vignettes depicted the presence of homeless people and their everyday activities in public space as fairly innocuous and consistent with similar findings reported on by other homelessness or community studies that argue, for example, the value of 
'hanging out' activity can be understood as consisting of "predictable and desired amounts of companionship, conviviality, and solitude" for participating group members (Duneier, 1992, p. 37). The second vignette highlighted the nuisance factor street people are also capable of producing when congregating in public, particularly when bored, intoxicated, or both. This was revealed through one man's persistent attempts to enrol me to interact with him. The third vignette describing an encounter between homeless men and the police was useful in illustrating the way everyday talk and nuanced humour can classify and denigrate homeless people within face-to-face interaction as having certain stereotypical attributes. This material had further utility in illuminating the way police officers were sometimes observed using obscene language and making jokes at homeless people's expense when conducting routine police inquiries with them. Moreover, this chapter established that increasing surveillance and control over street homelessness was changing the nature of how and where Wellington's homeless people conducted street life. These changes were shown to be aligning the experience of homelessness with the way homelessness is lived in cities overseas, that is, in transit, and traversing the path of least resistance in less visible peripheral public spaces.

Chapter Six critically examined two key elements of Brother's use of space. By closely examining his mundane use of city spaces, it was shown that Brother's spatial style can be understood in similar ways with how housed people use their homes: he has designated living room space, sleeping space, outdoor porch space (when cornering the intersection), and kitchen space (retail food and liquor shops). Mapping his every day (and every night) determined that he does not, however, have any private space. Moreover, while his appropriation of open corner spaces was described as further heightening his visibility, it was countered that these locations also allowed him to more profitably 'corner the market' by way of cash donations and material goods.

Brother's day-in and day-out habitual occupancy in certain spaces combined with the repetition of his everyday activities, some of them illegal, is often dislocated or severed altogether for periods of time. Disruption was shown to occur when court 
orders forbade him from occupying a particular space, or several spaces concurrently, or when he was serving prison time for his transgressions. A trajectory outlining legal interventionist measures responding to his acts of transgression revealed the informal and formal social control processes at work that monitor, regulate, or criminalise his occupancy of city space as home space and his activities within these spaces. Among the various repercussions for Brother were an attempt to ban him from the city centre altogether and an unusual court order that stipulated he must wear underwear in public.

I demonstrated that the way authoritative stances taken in response to his lifestyle were resisted by Brother, who, continuing to engage in out-of-place practices, arguably took the path of most resistance (de Certeau, 1984; Pope, 2008). Fieldwork material illustrated how Brother's activities in public space aligned his actions with Cresswell's (1996, p. 23) assertion: “Transgression is judged by those who react to it, while resistance rests on the intentions of the actor(s)". The most stoic element of his resistance was evidenced by his resolute will that saw him maintain his everyday life in public space despite the conflict arising from that decision to resist. Through this resistance, Brother's actions were said to represent a blatant form of spatial Garfinkeling, because as a transgressor and resister, he challenged what and who are thought to belong where. This chapter further demonstrated how his presence and actions challenged taken-for-granted assumptions about the proper use of public space, appropriate public behaviour, and commonly understood notions of home.

Within this chapter, a parallel exploration of Brother's observable modes of spatial agency and autonomous action was examined. For example, as his mental health increasingly fell under the court's radar, Brother's own talk reflected his sense of control that he was winning the battle against "their mental health bullshit game" (Fieldwork: 04/11/09). However, in chronicling an ongoing and sometimes insidious process, it was revealed that during 2010, the classification of Brother the 'criminal' was eventually replaced with a new classification of Brother as 'mentally ill'. Subsequently, by the end of the chapter, Brother had been committed into Wellington's acute psychiatric ward and a street poster erected at 
one of his primary locations was argued as an act symbolically constituting Sennett's (1990) articulation of 'narrative space'.

Chapter Seven's analytical foci extended these arguments by exploring the body and its material objects - blanket and loincloth - as an integral part of spatial analysis and social control. Fieldwork material closely detailing Brother's movement and interactions as he attended to daily chores emphasised Brother's body, when set against the background of the daily round, as a very visible visceral presence capable of raising disconcertion and alarm in others. In the section, The private body in public space, Brother's social and spatial organisational methods were shown to allow a demarcation of personal territory in urban space. Drawing on Wardhaugh's (1999) notions of the 'contracted' and 'expanded' body and Goffman's spatial and bodily metaphor of 'bodily preserves' in relation to fieldwork, demonstrated the various roles Brother's blanket provided in allowing him to not only claim space, but also create and manage boundaries. It was further established that the blanket, beyond providing cushioning and warmth and a means for materially mapping out personal space, could be understood as holding symbolic political value for Brother in signifying the land in Aotearoa. This material artefact, as one of only two consistent objects in Brother's life, was demonstrated to hold multi-faceted utility and meaning.

Chapter Seven included images that highlighted the contrasted the 'contracted body' and the 'extended body' of Brother, and discussed what these bodily presentations represented for others when seeing this body on the street. I argued the huddled body readily fitted with ordinary people's understandings of the homeless existence, as one that is subjugated and marginalised. The spatial imagery of the overtly 'extended body' on the other hand, was argued to prompt public interpretations of the homeless body as one that is socially disorganised and lacking in any self-control. A close analysis of the 'horizontal, dirty, and seminaked body', found these three bodily breaches were read by other people through opposing binaries of horizontal/vertical, dirty/clean, and clothed/unclothed. It was further argued that opposition arising around Brother's bodily actions was premised on taken-for-granted understood codes of acceptable conduct and 
behaviour based on opposing binaries of public/private, illegal/legal, and normal/deviant. In contrast to the 'good' homeless body that was found to minimise its surface, the overt 'extended body' sent a powerful signal emphasising social (dis)order through signifying a symbolic dis(ordering) of the individual body in public. However, despite the contracted and expanded body evoking different readings in people, it was shown that both presentations were understood to constitute a threat of contagion to others. This point was elaborated on by noting how even the sleeping body of Brother was susceptible to scrutiny and interventionist social control measures.

Duneier's (1999) theory of the 'Fuck it! mentality' was transferred to the local scene to assess its utility for understanding Brother's cavalier attitude when presenting his body in the most blatant ways. While his presentation of the self in a filthy and pungent state lying in the full view and close proximity of pedestrians was found to fit with this form of retreatism, I also argued that Brother's case signified a noteworthy departure. I contended that what could appear as an established 'Fuck it! mentality' was on closer inspection explainable as a preferred state of being that had emerged through an embodied acclimatisation process with the physical environment. Through this acclimatisation, I argued a preference for all things 'outside' had developed. Conversely, I also suggested that such acclimatisation be seen as fluid when detailing a partial reversal of this that was observed within the psychiatric unit. Yet, I conceded that regardless of whether a form of the 'Fuck it! mentality' was reached through situational factors as Duneier found, or reached through environmental factors as I suggest, the net result could appear similar to onlookers. That is, others understood Brother's dirt and associated stench as resulting from the apathetic attitude of an individual who had hit rock bottom. Extending Duneier's model further, I claimed that because Brother exhibited no outward discernible shame, that rather, an 'I don't give a shit' attitude had developed. On the other hand, I countered he did 'give a shit' in another sense. That is, I argued that although he did not care about his visible manifestation of homelessness per se, he cared very much that others registered his staunch ability for toughing it out on the street. This was poignantly illustrated through his swift reaction to restore the status quo impression of blanket, outside, 244 
and ground, when I discovered him succumbing to the comfort of a mattress when in the psychiatric ward. Arguably, it is his tenacity to endure a most gruelling form of street life that gives him his own sense of identity or mana in the presence of others.

Throughout this chapter, Hacking's (2002) articulation of 'making up people' provided a conceptual platform when making scholarly sense and analytical links between the shifting classification procedures being observed. For example, when examining the collision between agency and structure, I was able to detect and explain Brother's response to the 'community of expert knowledge' as it imposed its reality from above and Brother pressed back in resistance from below. Here, Hacking's 'looping effect of human kinds' was rendered visible in action in the case of a homeless individual who under the targeted aim of the institutions of social control, then became increasingly also subjected to the medical gaze.

In Chapter Eight, I positioned the thinking, acting, talking, laughing individual at the centre of analysis to examine how social meanings are locally produced and can be understood in the situatedness of everyday talk and routine action. My indepth analysis of the nature and form of Brother's interactive relationships with others and how these were interpreted, realised a departure from the way the experience of homelessness has been predominately presented within the homelessness literature (for example, Lee et al., 2004; Snow \& Anderson, 1993); that is, as one strongly linked to hopelessness. Within such accounts, homeless people themselves are often described as suffering 'non-person' treatment through others practicing 'civil inattention' (Goffman, 1972) that treats them as if they are not there at all, as rather, they are 'objects' not worthy of even a glance. Contrasting with that dominant portrayal, my fieldwork material emphasised Brother's marked presence on the street while also drawing out problems that were observed to arise through this that were experienced by him.

Analysing the varied and complex forms of social interaction observed occurring between Brother and the public exposed a prevalence of humour in Brother's talk and actions. This raised questions about how the fundamental processes of humour 
could be observed working-in-action in the interactive street life of Brother and the role humour could be understood to play. Goffmanian micro-sociology, and in particular its insightful metaphor of the front and back stage was central to my analytical identification of interactional techniques and methods that allowed Brother to invite, sustain, or shut down public interaction with him. I elucidated the ways these methods functioned to enable Brother to manage pedestrian contact, brush off public sympathy, challenge homelessness stereotypes, subvert understood membership categorisations, and enjoy moments of solidarity in the street life experience.

I also exposed the ways Brother's methods of disengagement did not always provide a 'fool' proof system when examining what Brother sometimes tolerated when others failed to read his interactional cues. In light of those arguments, Duneier and Molotch's (1999) concept of interactional vandalism, which refers to vandalism against propriety as opposed to vandalism against property, was imported to the local setting and argued to occur in a reversed form in the Wellington context in Brother's case.

To further demonstrate how in a particular context, Goffman's (1959) front and back stage dynamic could be conceptualised as a physical temporal dynamic, two empirical examples were critically assessed. The first explored the role of humour within an interactional stance frequently adopted by Brother. The second explored humourous interaction 'at play' between Brother and a man who occasionally visited him on the street. As an interactional resource, the Māori side-step tactically employed and spatially managed by Brother, was argued to provide a social conduit through which he was able to infer a fluid sense of his felt place-inthe-world. The 'fun and folly' described importantly illuminated the nuanced ways in which one is able to maintain role distance even as one is engrossed in the moment. 


\section{Lessons learned from the street corner}

My discussion in Chapter Four, explaining the research process used for 'doing street corner sociology' in this thesis, aimed to provide more than a rational methodological statement of methods used. I wanted to explain how gaining access to insight beyond that which the ordinary observer or passerby was able to see for themselves was made possible. I also wanted to reveal how the doing of this research was a learning process for me as a novice ethnographer. This involved exposing messier aspects of the research process as well as aspects of the self when critically examining the ways my fieldwork venture required me to be intuitive, open, flexible, and negotiable so that participant observation worked for both Brother and me. I also reflected on using my own body as a research tool when probing what it meant to be a feeling and acting body within the research setting. Using and reading my own 'tuned up body', an embodied approach advocated by Goffman (1989), enabled me to make pragmatic sense of mundane moments as they were subjectively lived in Brother's way of 'doing ordinary'. With my research orientation embedded within an everyday life sociology approach, my own experiences of doing fieldwork in close body-to-body proximity for hours at a time, as elaborated upon in my methodological discussion, contributed a fresh perspective by also making the 'invisible visible' in the 'doing' of everyday life sociology research itself. Considering too, that the nature of the research locations where my observational work was conducted could more aptly be described as having done 'gutter-sociology', I hope to have also added new insight in a way that 'throws a little of real-life mess' into the mix of the more formulaic 'talking-heads' accounts that tend to dominate social science research discussions on methods.

Reflecting on the research process, had I approached things differently, or insisted on things being done differently once I was ‘in', Brother's mostly good-humoured acceptance shown towards me when regularly sharing his space would not have endured. As with any relationship, we negotiated (and sometimes muddled along) when working out an arrangement that was mutually satisfactory to us both. Throughout the years I have now known Brother, I have not lost sight of the gift he afforded me by enabling me to learn and document the day-in and day-out 
workings of the social world surrounding his (extra)ordinary life lived on the corner.

This thesis has demonstrated that Brother's unusual domestic arrangement prompted the strategic management of his particular "accommodation hazard", that is, the $24 / 7$ presence of other people. This thesis has also articulated that for Brother, being among others can also significantly enhance the day in and day out experience of "doing life on the street" (Fieldwork: 08/02/09). However, this was made possible through his development of strategic spatial, bodily, and interactional methods premised on lines of conduct and modes of being that are firmly founded on his autonomous actions. These 'tricks of the trade' enable him to maintain balance between his "impulse to embrace that which is public, and the drive to escape the discomfort of group demands" (Schwartz, 1968, p. 752). By extension, Brother's command at turning an extreme existence into one that he clearly embraces has been demonstrated to subvert the ascribed membership categorisation of homelessness by troubling normative understandings and challenging common preconceptions about how a life lived on the street can be experienced.

A key theoretical argument throughout this thesis has stressed the way space is made meaningful through embodied experiences. Yet, in order for space to become place, no exceptional happening need have occurred. Rather, I have shown, as many theorists have established, how space becomes invested with emotional and symbolic meaning through the ordinary everyday practices that contextualise it (de Certeau, 1984; Pope, 2008; Sennett, 1990). But achieving and maintaining these ends is only part of the story. I have also revealed the darker side of street life experienced when naming, classifying and re-classifying processes intersect to dampen or fracture the otherwise enjoyed city-as-whare experience. How, then, can the ongoing and sometimes insidious practices exercised by others to construct, classify and re-classify Brother as demonstrated in this thesis, now be concluded? 
It is fair to surmise that 'Wellington' does not quite know what to do with a person who has taken the street corner as a fixed place of residence for the past ten years. Despite the jovial street persona Brother is often observed to project, this visible manifestation of homelessness and its association with poverty, is certainly not a sight that Wellington City Council would wish to have "on the front door step of the city" (Allen, 2004). However, having extended scholarly understanding in this thesis about what can happen when difference is contested, and bearing in mind Brother's desire for autonomy, I wonder whether 'indifference' shown towards his (perceived) difference most clearly read by others through his choice to live on the corner, might be a more cost effective way of dealing with 'the problem of Brother', particularly by those working within the institutions of expert knowledge. That is, as Brother himself liked to sometimes remind me, the financial cost of legal proceedings ${ }^{67}$ taken in reaction to his often petty offending was significant. In a similar vein, the exploratory ${ }^{68}$ CAT scans he underwent do not come cheaply. I argue that an attitude of indifference to his difference would also have come at a far less personal cost to Brother himself, who at the mercy of those 'who knew better' eventually had his expressions of free will and 'doing being ordinary' (Sacks, 1992) problematised into a psychiatric trouble. I further contend that his homelessness status need not have become a diagnosis.

Brother's story has further exposed that 'no space' is available in which his voice could be heard. This thesis has exposed that while for Brother his street life is an active choice that propels his actions, those working within the institutions of expert power and knowledge have not been open to hearing his reality from his viewpoint. People like Brother, who are impelled to do things differently, are placed in the 'too hard basket' at which high-level reactive intervention must then aim. This is a problem not only for some Wellington pedestrians, but for particular

\footnotetext{
${ }^{67}$ Although the majority of criminal charges related to petty offences and while many were later discharged in court, they still accrued massive costs in this process. See Wright and King-Jones (2003) to view Brother giving an itemised account of what he estimates his arrests, legal representation, court appearances, prison sentences had already cost 'the system' to date.

${ }^{68}$ While it could be argued all CAT scans are exploratory by nature, ordinarily, clinical symptoms or a suspected or known medical condition determines the decision for a CAT scan procedure to be carried out.
} 
sections of society - retailers operating in the central business district, the police, the Wellington City Council, and even organisations working with homeless people. I have demonstrated that at a state or institutional level, as well as at a local street level, people were ill equipped in their preparedness to listen to or their openness to see (Brother's) doing 'ordinary' in a new way. Rather, it was shown that people remain steadfast sharing a common view that no order can be found in the apparent (dis)order that his life represents. Resultantly, Brother, then 'the patient' (and described by one nurse as 'the most patient of patients'), was rendered impotent under what he identified as their thinking and their rules. In recalling his own sense making around this development, "This is what happens when other people think for you...this is not my life I'm living...we'll just have to wait and see what their politically correct ways say next”. Here, Hacking's (2002) contention that naming needs authority and usage within institutions is illuminated.

Throughout my fieldwork, I observed and came to understand a person I considered to be of sound mind and strong disposition whom simply elected to do stuff his way. He was nonetheless institutionalised and as a consequence, he was in due course inevitably labelled with a psychiatric condition. Ultimately, my view is that Brother's way of 'being ordinary' can co-exist harmoniously within the everyday hum of conventional society, even as he prompts others to reflect on his way of doing everyday life. This is not to suggest that he exist outside of the laws the rest of us have to abide by, but rather as Brother himself has put it to me, he can deal with going to prison over the effects of pills any day. Hacking's (1995) 'looping effect' articulating how people once classified can change in conjunction with the way they have been classified, with what they believe about themselves, or because of the way they have been treated as so classified, can be heard resonating in Brother's words. My home visits to Brother that I have continued from time-to-time beyond the data collection phase of this research, now encounter a very changed mood. My observation is that Brother, now living under the shadow of a psychiatric classification, simply exists today. His zest for life has all but evaporated, his body trembles and his appetite is poor. His daily nap now dominates his day. He blames the pills that keep him medicated and are administered to him on a daily basis by a mental health worker dispensing them 
out on the street corner. Brother's current situation accords with C. Wright Mills claim that, "man can be turned into a robot, by chemical and psychiatric means, by steady coercion and by controlled environment; but also by random pressures and unplanned sequences of circumstances" (1959, p. 189).

The nature of his daily spatial mapping has also altered. While no law can permanently prevent his occupation of footpath space outside the bank, it would seem his blanket has been prohibited from resting against the building's façade. This development has impacted significantly on Brother. To recall, his blanket holds personal symbolic value in representing the land in Aotearoa, but it has also been demonstrated as having an important role in demarcating street space as home space in the micro-setting studied. Brother, no longer able to use primary location $1 \mathrm{~b}$ during business hours must now reside during inclement weather in new space around the corner and across the intersection.

Yet, the stance taken by the bank reveals that the blanket - a bodily extension of Brother - has become the targeted means through which social control intervention next aimed - fracturing Brother's routine daily spatial mapping of the city-aswhare and displacing his sense of place and belonging in the process. Required to find a new primary space, he has taken up footpath space outside Fix, a 24-hour convenience store (pictured below in Figure 9:1), explaining to me that his need for a new location as arising through another 'occupational hazard': "Their politically correct 'tactics' are still trying to fix me" (Fieldwork: 21/12/11). 


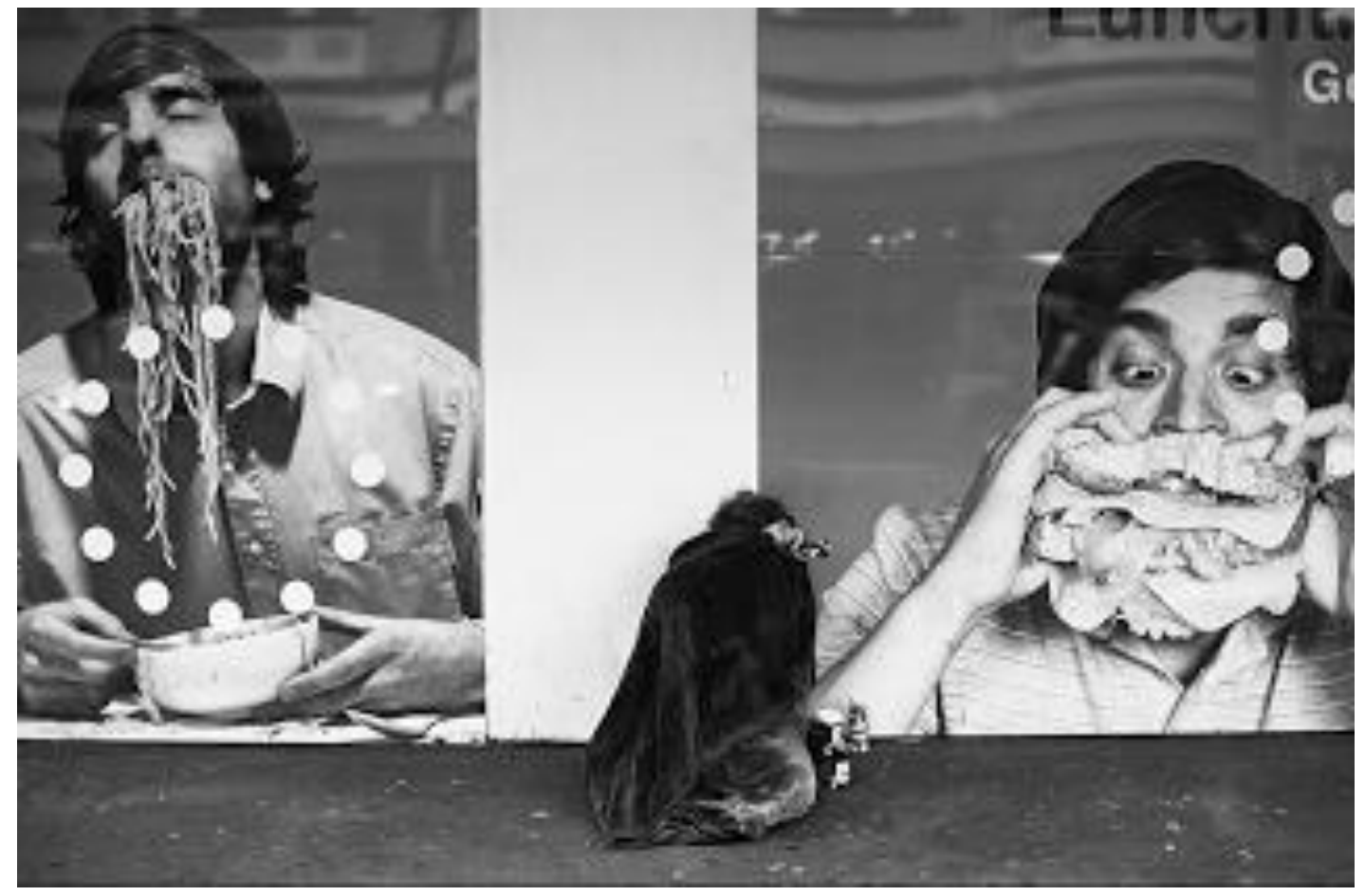

Figure 9:1 Brother dozing outside Fix - the new location he was forced to take up when prevented from occupying Primary location 1a during banking business hours

Source: Google image search, keyword 'Blanket Man', photographer unknown

His comment reveals his experience of living in public space continues to be an experience fraught by contestation over who is thought to belong to the public and who should have access to public space (Kawash, 1998). His understanding of that experience has some resonance with $\mathrm{C}$. Wright Mills observation:

From the individual's standpoint, much that happens seems the result of manipulation, of management, of blind drift; authority is often not explicit; those with power often feel no need. That is one reason why ordinary men, when they are in trouble or even when they sense they are up against issues, cannot get clear targets for thought and for action; they cannot determine what it is that imperils the values they vaguely discern as theirs...given these effects the individual does the best he can...he adapts" (1959, p. 188).

Off the main pedestrian grid, he is now an outsider looking out and across at his old locale. This is powerfully representative of Hacking's looping effect articulating the way naming can dynamically interact with the named, directly changing people and closing off or modifying options they once held. In this vein, Hacking's existentialist view that invites reflection about the degree of personal freedom we each have when choosing "the space of possibilities for personhood" 
(1986, p. 229) has been examinable in my study of a real life as it is lived on a street corner. Hacking's interrelated claim that as a society we also "medicalise kinds of deviant people relentlessly, but not always with success" (2007, p. 309) has been demonstrated to involve an unmaking of the person occurred in Brother's case as the making up interacted with successive classifications of homeless person, criminal, and mentally ill.

I have endeavoured to capture and include in this thesis what C. Wright Mills (1959, p. 148) described as "the human variety of individual human beings" which he argued the sociological imagination must also grasp and understand to consider how "order as well as disorder is relative to viewpoint". In this light, I have revealed that Brother's presence and elected lifestyle means different things to different people bringing him a variety of responses reflecting what he symbolises to people. These responses have been shown to range from admiration of his defiance (evident in the talk of people visiting his whare), to his being perceived as a pesky nuisance (by his 'neighbours'), to his representing a friendly face for fellow 'whare dwellers' (from street cleaners to other people also 'of' the street), to his constituting a rule-breaker (for the authorities). Such multiple readings are significant in relation to his trajectory and tell us a lot about the 'kinds of people' that make up society.

This thesis has brought the everyday experience and expression of doing street life to the foreground contributing an Aotearoa New Zealand perspective to the international sociological street corner landscape. It has also contributed a reflexive and intimate examination of a Wellington individual's street life to the emerging domestic literature on homelessness and homeless people. I hope to have further stimulated some debate for those people working with the homeless. This research has not only produced insider knowledge from the perspective of a longterm street dweller, but my empirical material has also highlighted some avoidable difficulties. The needs (and wishes) of clients should regularly be revised and placed at the forefront of any decisions, which should also be made in concert with the individual concerned. Revised methods need to be instigated from a bottom up approach. For example, a 'blanket approach' regarding what homeless people are 
required to wear when accessing services that are there to assist them, should not be so rigid that a barrier is erected hindering those needing to utilise them.

Finally, I hope to have somehow urged the reader alongside me to rethink our being, and being together in the world. Given Brother's elected way of living banal everyday life emphasises the way notions of difference are often connected to understandings of 'home', I hope to have triggered insight into closely related concepts of homeliness and belonging when examining an alternative way of life. Significantly, Brother does not consider himself to be a homeless person. Rather, his view is that he has a home; he 'knows his place'. It is this subjective view, of course, and the visible social action it produces that has been argued throughout this thesis to be at the crux of the problem that Brother symbolises for 'the other'. Ultimately, my exploration investigating the workings of the social world of the street to which Brother is an integral part, that has incorporated an examination of the ways wider social structures and institutions can bear upon the local microsetting, has aimed to contribute awareness of how 'doing ordinary' by a city street dweller can be understood in a different (and better) light. 


\section{Epilogue}

Less than a year has lapsed between Brother's passing and the completion of this thesis. During this time, the grass has had a chance to grow over his grave and new arrivals to Wellington may never know of the man who wore blankets while living everyday life on a city street corner. Even for the average Wellington native, the memory of Brother is shifting in the passage of time. Eventually it will settle to reside within local lore that remembers those who have made up the city's more 'lively' folk at one time or the other. Meanwhile, for others, Brother's death continues to have a more profound effect. A handful of street people speak of actively missing the man they called 'Bro'. One of them can still be observed from time to time cutting a lonely presence in Brother's old space, a physical domain rich with the history of past habitation. A key theoretical argument articulated throughout this thesis is that space is made meaningful through embodied experiences. Yet, as was also stressed, for space to become place, no exceptional happening need occur, rather, space becomes invested with emotional and symbolic meaning through ordinary everyday practices that contextualise it. Speaking from personal experience, my lived sense of 'being in the city', especially as I have remained at the same time immersed in writing Brother's story, lingers at a level where it is Brother's city-as-whare that penetrates my own perception and emotion. But time will eventually alter this feeling too, restoring my normative experience of city space.

As summer turned to autumn and then winter, the keen observer may have noticed other, more subtle changes. Brother's primary home location outside the bank, where the shrine sprang up and where the chap mentioned above still holds intermittent vigil, is today shrouded in darkness once night falls. When Brother dwelled there, his territory and the surrounding area were highly visible at night, as harsh artificial lighting illuminated the area. To me, at least, this change speaks volumes. There is no longer any need for ongoing surveillance of human presence or traffic on this particular patch of asphalt. There is no longer anyone (home) 'making trouble' by breaching socio-spatial bodily order in urban space. On a more symbolic note, the darkened space speaks of a place now bereft of a life once 
lived there in all its mundane glory. A life that touched the lives of others in (extra)ordinary ways. The simple message shown in the figure below (containing a likely unintentional, but appropriate, misspelling of 'dearly') poignantly expresses one person's sentiment regarding Brother's discontinued presence.

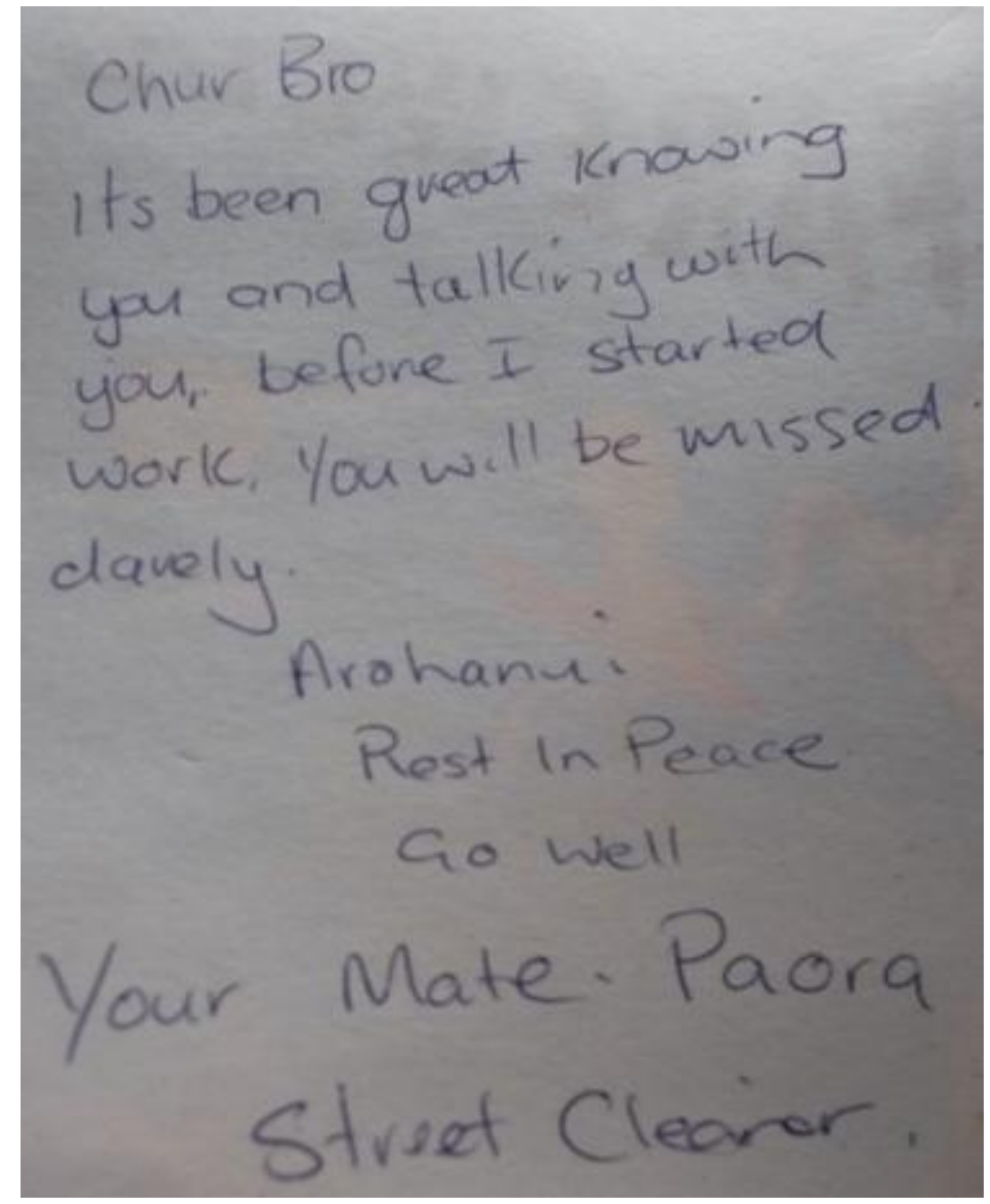

Epilogue:1 One of many public condolences expressed at the makeshift memorial Source: Author

In death, as in life, Brother's chosen street lifestyle continued to evoke strong public debate. The prologue to this thesis described the hordes of people who visited Brother's street shrine to pay their last respects. At the same time, various 
media commentators argued that "near-glorification of him by some as a symbol of liberty and non-conformity" ("A tormented life far from romantic," 2012) contributed to his early death. This view held that Brother had come to believe his 'Blanket Man' persona gave him a public identity that was more important to him than his health (see, for example, du Fresne, 2012; McLeod, 2012). Underpinning this position was a collective struggling, failing, or refusing to grasp that a rational person could ever freely choose to live on a street corner, wearing little more than a loincloth, with no interest in material goods. As I argued in Chapters Six and Seven, it was an easier option to view Brother and his chosen lifestyle from a 'social problem' perspective, dismissing in this process any notion of individual agency as simply 'abnormal'. In this vein, he was considered 'bad, mad, and sad': first he was categorised as criminal, then as mentally unwell. This thesis demonstrates how these classifications become emblematic of how society 'makes up people', and how, in Brother's case, the assigned classifications led to the 'unmaking' of a person. 


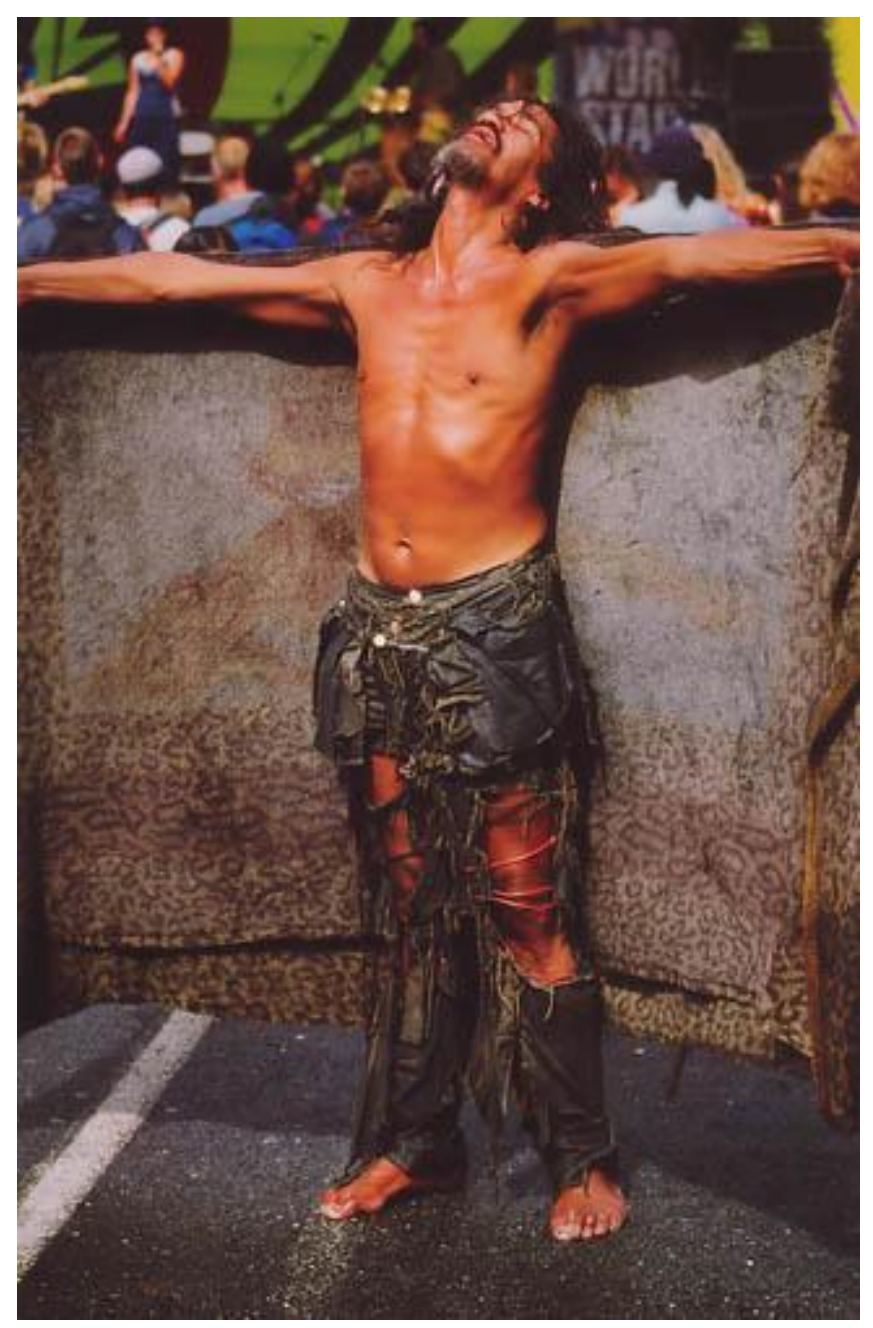

Epilogue:2 Brother in 2001, at Wellington's 'One Love' concert, which commemorates Bob Marley's birthday

Source: Google image search, keyword 'Blanket Man', photographer unknown

Ultimately, my view is that Brother's different mode of being could co-exist harmoniously within the everyday hum of conventional society, even though he forced others to confront difference head-on as he dwelled in the midst of a bustling pedestrian flow. A disciple of Bob Marley, Brother stood for liberty and freedom. He advocated peace, love, and harmony. His street lifestyle could be understood as the longest solitary land protest ever staged in this country. Brother's street campaigning encapsulated his vision of an Aotearoa wherein the land would belong to all people. His prophecy envisaged unhindered access to the land, that simultaneous utilisation of the land would achieve collective wellbeing and equal opportunity. To this end, it is fitting to conclude with a few of Brother's own words, taken from one of his campaign street posters (of which a fuller script 
was presented in Chapter Six). These words are symbolic of the philosophical vision that propelled his choices and actions throughout the final chapter of his life's work.

\section{R.E.S.P.E.C.T}

E Toa! Hine Toa! Te Hei Mauriora

We Shall Carve A Vista More Than A Sense Of Being "More" Than A Feeling Belonging - Participation - Involvement -

The Freedom Of Choice Is Ours

(Brother, 2009) 


\section{References}

Abelson, E. S. (1999). Homeless in America. Journal of Urban History, 25(2), 258-270. doi: 10.1177/009614429902500204

Agar, M. (1999). How to Ask for a Study in Qualitatisch. Qualitative Health Research, 9(5), 684-697. doi: 10.1177/104973299129122162

Al-Nasrallah, B., Amory, K., Blackett, J., Chan, D., Moore, J., Oldfield, K., . . . van Rij, K. (2005). Slipping through the Cracks: A Study of Homelessness in Wellington. Retrieved from He Kainga Oranga's webite http://www.healthyhousing.org.nz

Allen, S. (2004, April 20). Eviction 'forcing' homeless into city. The Dominion Post, p. 3.

Amin, A. (2006). The Good City. Urban Studies, 43(5-6), 1009-1023. doi: $10.1080 / 00420980600676717$

Amster, R. (2003). Patterns of exclusion: Sanitizing space, criminalizing homelessness. Social Justice, 30(1), 195-217. Retrieved from http://www.jstor.org/stable/29768172

Anderson, E. (1978). A Place on the Corner. Chicago, IL: University of Chicago Press.

Anderson, I., \& Christian, J. (2003). Causes of homelessness in the UK: a dynamic analysis. Journal of Community \& Applied Social Psychology, 13(2), 105-118. doi: 10.1002/casp.714

Anderson, L., \& Calhoun, T. C. (1992). Facilitative Aspects of Field Research with Deviant Street Populations. Sociological Inquiry, 62(4), 490-498. doi: 10.1111/j.1475-682X.1992.tb00297.x

Anderson, N. (1923). The Hobo: The Sociology of the Homeless Man. Chicago: University of Chicago Press.

Aron, L. Y., \& Fitchen, J. M. (1996). Rural homelessness: A synopsis. In J. Baumohl (Ed.), Homelessness in America (pp. 81-85). Pheonix, AZ: Oryx Press.

Australian Bureau of Statistics. (2012). Information Paper - A Statistical Definition of Homelessness, Cat. No. 4922.0. Retrieved from http://www.abs.gov.au 
Ayres, V. E. (1974). Research Report on the Residents in the Christchurch City Mission Night Shelter. Christchurch, NZ: Christchurch City Mission.

Barcan, R. (2004). Nudity: A Cultural Anatomy. Oxford, England: Berg.

Baumohl, J., \& Huebner, R. B. (1991). Alcohol and other drug problems among the homeless: Research, practice, and future directions. Housing Policy Debate, 2(3), 837-866. doi: 10.1080/10511482.1991.9521074

Becker, H. S. (1953). Becoming a Marihuana User. American Journal of Sociology, 59(3), 235-242. doi: 10.2307/2771989

Becker, H. S. (1998). Tricks of the Trade: How to Think About Research While Doing It. Chicago: University of Chicago Press.

Becker, H. S. (2002). Visual evidence: A Seventh Man, the specified generalization, and the work of the reader. Visual Studies, 17(1), 3-11. doi: $10.1080 / 14725860220137327$

Becker, H. S. (2009. Interaction: Some Ideas. Paper presented at the Université Pierre Mendes-France, Grenoble. Retrieved from http://home.earthlink.net/ hsbecker/articles/interaction.html

Bennett, T., \& Watson, D. (Eds.). (2002). Understanding Everyday Life. Oxford: Blackwell Publishing.

Berman, S. S., \& Pulcini, R. (Directors). (2003). American Splendor [Motion picture]. U.S.A.: Fine Line Films

Betensky, C. (2004). Princes as Paupers: Pleasure and the Imagination of Powerlessness. Cultural Critique, 56(WInter), 129-157. doi: 10.1353/cul.2003.0055

Black, A., \& Crann, M. (2002). In the public eye: A mass observation of the public library. Journal of Librarianship and Information Science, 34(3), 145-157. doi: 10.1177/096100060203400303

Blanket Man. (2006). Retrieved March 4, 2008 from http://www.wikipedia.com

Blanket man. (2009). Retrieved March 21, 2013 from

http://www.facebook.com/pages/Blanket-man/206049819427

Blanket Man. (n.d.). Retrieved March 21, 2013 from

http://www.myspace.com/blanketmanwgtn 
Borchard, K. (2005). Word on the Street: Homeless Men in Las Vegas. Reno, NV: University of Nevada Press.

Bradley-Engen, M. S., \& Ulmer, J. T. (2009). Social Worlds of Stripping: The Processual Orders of Exotic Dance. Sociological Quarterly, 50(1), 29-60. doi: 10.1111/j.1533-8525.2008.01132.x

Bridgman, R. (1999). "Oh, so you have a home to go to?": Empowerment and resistance in work with chronically homeless women. In R. Bridgman, S. Cole \& H. Howard - Bobiwash (Eds.), Feminist Fields: Ethnographic Insights (pp. 103116).

Bullock, H. E., Fraser Wyche, K., \& Williams, W. R. (2001). Media Images of the Poor. Journal of Social Issues, 57(2), 229-246. doi: 10.1111/0022-4537.00210

Burt, M. (1992). Over the edge: The growth of homelessness in the 1980s. New York: Russell Sage Foundation.

Bylaw tweaking is a risky business. (2004, April 26). The Dominion Post.

Calman, R., \& Sinclair, M. (2001). The Reed Essential Māori Dictionary. Auckland, NZ: Reed Publishing (NZ).

Calsyn, R. J., \& Morse, G. (1990). Homeless men and women: Commonalities and a service gender gap. American Journal of Community Psychology, 18(4), $597-$ 608. doi: 10.1007/BF00938062

Carlin, A. (2003). Observation and membership categorization: Recognizing 'normal appearances' in public space. Journal of Mundane Behavior, 4(1), 77-91.

Carr, S., Francis, M., Rivlin, L. G., \& Stone, A. (1992). Public Space. New York: Cambridge University Press.

Casey, R., Goudie, R., \& Reeve, K. (2008). Homeless Women in Public Spaces: Strategies of Resistance. Housing Studies, 23(6), 899-916. doi: $10.1080 / 02673030802416627$

Clapham, D. (2008). Homelessness and Social Exclusion. In D. Abrams, J. Christian \& D. Gordon (Eds.), Multidisciplinary Handbook of Social Exclusion Research (pp. 79-94). Chichester, England: John Wiley \& Sons.

Claridge, A. (2005, January 26). Homeless could be unfairly blamed. The Press, p. 3. 
Clifford, J. (1986). Partial Truths. In J. Clifford \& G. E. Marcus (Eds.), Writing Culture: The Poetics and Politics of Ethnography. Berkeley: University of California Press.

Cloke, P., Cooke, P., Cursons, J., Milbourne, P., \& Widdowfield, R. (2000). Ethics, Reflexivity and Research: Encounters with Homeless People. Ethics, Place \& Environment, 3(2), 133-154. doi: 10.1080/13668790050031731

Coffey, A. (1999). The Ethnographic Self: Fieldwork and the Representation of Identity. London: Sage.

Colton, K. W. (2003). Housing in the twenty-first century: Achieving common ground. Cambridge, MA: Harvard University Press.

Connelly, F. M., \& Clandinin, D. J. (1990). Stories of Experience and Narrative Inquiry. Educational Researcher, 19(5), 2-14. doi: 10.3102/0013189x019005002

Cooper, R. (2001). The Intersection of Space and Homelessness in Central Auckland (Unpublished master's thesis). University of Auckland, Auckland, NZ.

Coser, R. L. (1959). Some Social Functions of Laughter: A Study of Humor in a Hospital Setting. Human Relations, 12(2), 171-182. doi: 10.1177/001872675901200205

Cowlishaw, G. (2004). Blackfellas, Whitefellas and the Hidden Injuries of Race. Carlton, Victoria, Australia: Blackwell.

Crang, M. (2003). Qualitative Methods: Touchy, Feely, Look-see? Progress in Human Geography, 27(4), 494-504. doi:

http://dx.doi.org/10.1191/0309132503ph445pr

Crang, M., \& Thrift, N. (Eds.). (2000). Thinking Space. New York: Routledge.

Cresswell, T. (1996). In Place/Out of Place: Geography, Ideology and Transgression. Minneapolis: University of Minnesota Press.

Cresswell, T. (1997). Weeds, Plagues, and Bodily Secretions: A Geographical Interpretation of Metaphors of Displacement. Annals of the Association of American Geographers, 87(2), 330-345. doi: 10.1111/0004-5608.872056

Croteau, D., \& Hoynes, W. (2003). Media/Society: Industries, Images, and Audiences. Thousand Oaks, CA: Sage.

Crotty, M. (1998). The Foundations of Social Research: Meaning and Perspective in the Research Process. St. Leonards, NSW, Australia: Allen \& Unwin. 
Daly, G. (1996). Homeless: Policies, strategies, and lives on the street. London: Routledge.

de Certeau, M. (1984). The Practice of Everyday Life. Berkeley and Los Angeles, CA: University of California Press.

Denzin, N. K. (2003). Performance ethnography: Critical pedagogy and the politics of culture. Thousand Oaks, CA: Sage.

DeWalt, K. M., \& DeWalt, B. R. (2011). Participant Observation: A Guide for Fieldworkers (2nd ed.). Lanham, MD: AltaMira Press.

Doogue, J. (2008). Oral Judgment of Judge Doogue, CRI-2008-485-4. Wellington Registry: High Court of New Zealand.

Dordick, G. A. (1997). Something left to lose: Personal relations and survival among New York's homeless. Philadelphia: Temple University Press.

Douglas, M. (1966). Purity and Danger: An Analysis of Concepts of Pollution and Taboo. New York: Routledge.

du Fresne, K. (2012, January 17). Two versions of Blanket Man [blog post]. Retrieved from http://www.karldufresne.blogspot.co.nz

dubryferkin. (2011). Top Tramps. Retrieved March 18, 2012 from

http://www.funnyordie.com/lists/4aebb83a80/top-tramps

Duneier, M. (1992). Slim's Table: Race, responsibility, and masculinity. Chicago: University of Chicago Press.

Duneier, M. (1999). Sidewalk. New York: Farrar, Straus \& Giroux.

Duneier, M., \& Back, L. (2006). Voices from the sidewalk: Ethnography and writing race. Ethnic and Racial Studies, 29(3), 543-565. doi: 10.1080/01419870600598113

Duneier, M., \& Molotch, H. (1999). Talking City Trouble: Interactional Vandalism, Social Inequality, and the "Urban Interaction Problem". American Journal of Sociology, 104(5), 1263-1295. doi: 10.1086/210175

Erikson, K. (2008). On Sociological Writing. Sociological Inquiry, 78(3), 399-411. doi: 10.1111/j.1475-682X.2008.00246.x

Etherington, K. (2007). Ethical Research in Reflexive Relationships. Qualitative Inquiry, 13(5), 599-616. doi: 10.1177/1077800407301175 
Ezawa, A. (2002). Japan's "New Homeless". Journal of Social Distress and the Homeless, 11(4), 279-291. doi: 10.1023/A\%3A1016885115047

Fawkes, B. (2009, January 1). Free - if he wears pants. The Dominion Post, p. 1.

Felski, R. (2000). Doing Time: Feminist Theory and Postmodern Culture. New York \& London: New York University Press.

Fergusson, L. (2006, November 4). Safe conduct. The Dominion Post, p. E7.

Ferrell, J. (2001). Remapping the City: Public identity, cultural space, and social injustice. Contemporary Justice Review, 4(2), 161-180.

Fischer, P. J., \& Breakey, W. R. (1991). The Epidemiology of Alcohol, Drug, and Mental Disorders Among Homeless Persons. American Psychologist, 46(11), 1115-1128. doi: 10.1037/0003-066X.46.11.1115

Flats found for Wellington homeless. (2003, September 17). The New Zealand Herald.

Forster, E. M. (1927). Aspects of the novel (1949 ed.). London: Arnold.

Francis, D., \& Hester, S. (2004). An Invitation to Ethnomethodology: Language, Society and Interaction. London: Sage.

Fujimura, C. (2003). Urban Myths and Street Children in Russia: Coping with Cultural and Environmental Hazards. In B. A. Ruble, J. S. Tulchin, D. H. Varat \& L. M. Hanley (Eds.), Youth Explosion in Developing World Cities: Approaches to reducing poverty and conflict in an urban age (pp. 127-139). Washington, D.C.: Woodrow Wilson International Center for Scholars. Retrieved from USAID's website http://www.usaid.gov.

Garfinkel, H. (1967). Studies in Ethnomethodology. Cambridge, England: Polity Press.

Gee, M. (2005). Blindsight : a novel. Auckland, NZ: Penguin Books.

Gelb, D. (Director). (2011). Jiro Dreams of Sushi [Documentary film]. U.S.A.: Magnolia Pictures

Giddens, A. (1984). The constitution of society: Outline of the theory of structuration. California: University of California Press.

Gieryn, T. F. (2000). A Space for Place in Sociology. Annual Review of Sociology, 26, 463-496. doi: 10.2307/223453 
Glasser, I. (1988). More than bread: Ethnography of a soup kitchen. Tuscaloosa, AL: University of Alabama Press.

Goffman, E. (1959). The Presentation of Self in Everyday Life. Garden City, NY: Doubleday.

Goffman, E. (1961a). Asylums: Essays on the social situation of mental patients. Garden City, New York: Anchor.

Goffman, E. (1961b). Encounters: Two Studies in the Sociology of Interaction. Indianapolis, IN: Bobbs-Merrill Company.

Goffman, E. (1963a). Behavior in Public Places: Notes on the Social Organization of Gatherings New York: Free Press of Glencoe.

Goffman, E. (1963b). Stigma: Notes on the Management of Spoiled Identity. Englewood Cliffs, NJ: Prentice-Hall.

Goffman, E. (1965). Attitudes and Rationalization Regarding Body Exposure. In M. E. Roach \& J. B. Eichler (Eds.), Dress, Adornment, and the Social Order. New York: John Wiley.

Goffman, E. (1971). Relations in Public: Microstudies of the Public Order. New York: Allen Lane The Penguin Press.

Goffman, E. (1972). Interaction Ritual: Essays on face-to-face behaviour. Harmondworth, England: Penguin Books.

Goffman, E. (1983). The Interaction Order: American Sociological Association, 1982 Presidential Address. American Sociological Review, 48(1), 1-17. doi: $10.2307 / 2095141$

Goffman, E. (1989). On fieldwork [transcript of talk given in 1974 during the Pacific Sociological Association Meetings]. Journal of Contemporary Ethnography, 18(2), 123-132.

Goonewardena, K. (2008). Marxism and everyday life: on Henri Lefebvre, Guy Debord, and some others. In K. Goonewardena, S. Kipfer, R. Milgrom \& C. Schmid (Eds.), Space, Difference, Everyday Life: Reading Henri Lefebvre. New York: Routledge.

Gordon Roberts (Gordon the Tramp) for Bournemouth's Olympic Torch Bearer. (2011). Retrieved March 21, 2013 from http://www.facebook.com/NominateGordy 
Gotham, K. F. (2003). Toward an understanding of the spatiality of urban poverty: the urban poor as spatial actors. International Journal of Urban and Regional Research, 27(3), 723-737. doi: 10.1111/1468-2427.00478

Gotham, K. F., \& Brumley, K. (2002). Using Space: Agency and Identity in a Public-Housing Development. City \& Community, 1(3), 267-289. doi: 10.1111/1540-6040.00023

Grace, P. (2000). No Place to Go (Except the Public Library). American Libraries, $31(5), 53$.

Grosz, E. (2004). Volatile Bodies: Towards a Corporate Feminism. St. Leonards, NSW, Australia: Allen \& Unwin.

Gunzenhauser, M. G. (2006). A Moral Epistemology of Knowing Subjects: Theorizing a Relational Turn for Qualitative Research. Qualitative Inquiry, 12(3), 621-647. doi: 10.1177/1077800405282800

Guzewicz, T. D. (1998). Tokyo's homeless: A city in denial. New York: Kroshka.

Hacking, I. (1986). Making up people. In T. C. Heller, M. Sosna \& D. E. Wellberry (Eds.), Reconstructing individualism (pp. 222-236). Stanford: University Press.

Hacking, I. (1995). The looping effects of human kinds. In D. Sperber, D. Premack \& A. Premack (Eds.), Causal Cognition: A Multidisciplinary Debate (pp. 351383). New York: Oxford Universtiy Press.

Hacking, I. (2002). Inaugural lecture: Chair of Philosophy and History of Scientific Concepts at the Collège de France, 16 January 2001. Economy and Society, 31(1), 1-14. doi: 10.1080/03085140120109222

Hacking, I. (2004). Between Michel Foucault and Erving Goffman: between discourse in the abstract and face-to-face interaction. Economy and Society, 33(3), 277-302. doi: 10.1080/0308514042000225671

Hacking, I. (2007). Kinds of people: Moving targets. Proceedings of the British Academy, 151, 285-318. doi: 10.5871/bacad/9780197264249.003.0010

Haines, L. (2003a, July 2). Bush-dwelling 'bucket man' dies in gutter. The Dominion Post, p. 1.

Haines, L. (2003b, July 9). The funeral of Wellington's 'Bucket Man'. The Dominion Post, p. 1. 
Haines, L. (2003c, July 5). Plan to sweep vagrants off street. The Dominion Post, p. 1.

Hallett, A. (2012, January 29). Mediawatch. Radio New Zealand. Retrieved from http://www.radionz.co.nz

Hand, J. (1983). Shopping-Bag Women: Aging Deviants in the City. In E. Markson (Ed.), Older Women: Issues and Prospects. Toronto: Lexington Books.

Harding, E. (2011, January 12). Community garden 'thwarted' by WINZ. The Southland Times, p. 3.

Haydon, D. (2004, July 30). Police step up fight over vagrants. The Dominion Post, p. 8.

Heritage, J. (1987). Ethnomethodology. In A. Giddens \& J. Turner (Eds.), Social Theory Today (Vol. 224-272). Stanford, CA: Stanford University Press.

Hersberger, J. (2005). The homeless and information need and services. Reference and User Services Quarterly, 44(3), 199-202.

Hester, S. (2009). Ethnomethodolgy. In M. H. Jacobsen (Ed.), Encountering the Everyday: An Introduction to the Sociologies of the Unnoticed (pp. 234-256). London: Palgrave Macmillan.

Highmore, B. (Ed.). (2002). The Everyday Life Reader. London: Routledge.

Hirschoff, E. C., \& Hart, J. (2002). Down \& out: The life and death of Minneapolis's skid row. Minneapolis, MN: University of Minneapolis Press.

Hoch, C., \& Slayton, R. (1989). New homeless and old: Community and the skid row hotel. Philadelphia, PA: Temple University Press.

Hodgetts, D., Cullen, A., \& Radley, A. (2005). Television Characterizations of Homeless People in the United Kingdom. Analyses of Social Issues and Public Policy, 5(1), 29-48. doi: 10.1111/j.1530-2415.2005.00054.x

Hodgetts, D., Stolte, O., Chamberlain, K., Radley, A., Nikora, L., Nabalarua, E., \& Groot, S. (2008). A trip to the library: homelessness and social inclusion. Social \& Cultural Geography, 9(8), 933-953. doi: 10.1080/14649360802441432

Hodgetts, D., Stolte, O., Radley, A., Leggatt-Cook, C., Groot, S., \& Chamberlain, K. (2011). 'Near and Far'Social Distancing in Domiciled Characterisations of Homeless People. Urban Studies, 48(8), 1739-1753. 
Hodgetts, D., Stolte, O., Waimarie Nikora, L., \& Groot, S. (2012). Drifting Along or Dropping into Homelessness: A Class Analysis of Responses to Homelessness. Antipode, 44(4), 1209-1226. doi: 10.1111/j.1467-8330.2011.00977.x

Homeless chic on Milan catwalk. (2010, January 19). The Dominion Post, p. B5.

Homeless win park trespass case. (2004, August 4). The New Zealand Herald.

Hughes, J. (1990). The Philosophy of Social Research (2nd ed.). London: Longman.

Hull, G. A., \& Zacher, J. (2007). Enacting Identities: An Ethnography of a Job Training Program. Identity, 7(1), 71-102. doi: 10.1080/15283480701319708

Hunt, T. (2010, June 19). The man behind the blanket: Courtenay Place won't be the same without him. The Dominion Post, p. 4.

Hurley, M. E. (2007). Who's on whose margins? In M. K. Pitts \& A. M. A. Smith (Eds.), Researching the Margins : Strategies for Ethical and Rigorous Research with Marginalised Communities (pp. 160-189). London: Palgrave Macmillan.

Iveson, K. (1998). Putting the public back into public space. Urban Policy and Research, 16(1), 21-33. doi: 10.1080/08111149808727745

Jacobs, J. (1961). The Death and Life of Great American Cities. New York: Random House.

Jacobsen, M. H. (Ed.). (2009). Encountering the Everyday: An Introduction to the Sociologies of the Unnoticed. London: Palgrave Macmillan.

Jacobson, C. D. (Director). (2006). Kenny [Motion picture]. Australia: Madman Cinema

Jenkins, R. (2008). Social Identity (3rd ed.). Milton Park, Oxfordshire, England: Routledge.

Jimerson, J. B., \& Oware, M. K. (2006). Telling the Code of the Street: An Ethnomethodological Ethnography. Journal of Contemporary Ethnography, 35(1), 24-50. doi: $10.1177 / 0891241605280417$

Johnson, A. (2003, July 9). Unreformed, unrepentant - the city's hardline homeless. The Dominion Post, p. 3.

Karn, V. (1990). Homelessness in the USA and Britain. Detroit, MI: Wayne State University. 
Katz, J. (2010). Time for new urban ethnographies. Ethnography, 11(1), 25-44. doi: $10.1177 / 1466138109346999$

Kawash, S. (1998). The Homeless Body. Public Culture, 10(2), 319-339. doi: $10.1215 / 08992363-10-2-319$

Kearns, R. A., Smith, C. J., \& Abbott, M. W. (1991). Another day in paradise? Life on the margins in urban New Zealand. Social Science \& Medicine, 33(4), 369-379. doi: 10.1016/0277-9536(91)90318-7

Kemp, P., Lynch, E., \& MacKay, D. (2001). Structural trends and homelessness: A quantitative analysis. Retrieved from the Scottish Executive's website http://www.scotland.gov

Kevan, P. (2007, July 2). Tramp becomes facebook hero. Retrieved from http://www.metro.co.uk

Kitchin, P. (2006, September 16). Capital of non-conformists. The Dominion Post, p. E10.

Klapp, O. E. (1954). Heroes, Villains and Fools, as Agents of Social Control. American Sociological Review, 19(1), 56-62. doi: 10.2307/2088173

Koegel, P., Burnam, M. A., \& Baumohl, J. (1996). The Causes of Homelessness. In J. Baumohl (Ed.), Homelessness in America (pp. 24-33). Phoenix, AZ: Oryx Press.

Kuiper, K. (1990). New Zealand sporting formulae: Two models of male socialisation. In J. Cheshire (Ed.), English around the World: Sociolinguistic Perspectives (pp. 200-209). Cambridge, England: Cambridge University Press.

Kuipers, G. (2008). The Sociology of Humour. In V. Raskin (Ed.), Humour Research (pp. 361-398). Berlin \& New York: Mouton de Gruyter.

Kusenbach, M. (2003). Street Phenomenology: The Go-Along as Ethnographic Research Tool. Ethnography, 4(3), 455-485. doi: 10.1177/146613810343007

Lankenau, S. E. (1999). Stronger Than Dirt: Public Humiliation and Status Enhancement among Panhandlers. Journal of Contemporary Ethnography, 28(3), 288-318. doi: 10.1177/089124199129023451

Latour, B. (2005). Reassembling the Social: An Introduction to Actor-NetworkTheory Oxford: Oxford University Press. 
Laurenson, P., \& Collins, D. (2006). Towards inclusion: Local government, public space and homelessness in New Zealand. New Zealand Geographer, 62(3), 185195. doi: 10.1111/j.1745-7939.2006.00069.x

Laurenson, P., \& Collins, D. (2007). Beyond Punitive Regulation? New Zealand Local Governments' Responses to Homelessness. Antipode, 39(4), 649-667. doi: 10.1111/j.1467-8330.2007.00545.x

Lea, P., \& Cole, J. (1983). Homelessness in Christchurch. Christchurch, NZ: Christchurch Housing Research Unit.

Leave Brother Sharp alone. (2010, March 8). China Daily. Retrieved from http://www.chinadaily.com.cn

Lee, B. A., \& Farrell, C. R. (2003). Buddy, Can You Spare A Dime?: Homelessness, Panhandling, and the Public. Urban Affairs Review, 38(3), 299324. doi: $10.1177 / 1078087402238804$

Lee, B. A., Farrell, C. R., \& Link, B. G. (2004). Revisiting the Contact Hypothesis: The Case of Public Exposure to Homelessness. American Sociological Review, 69(1), 40-63. doi: 10.1177/000312240406900104

Lee, B. A., Link, B. G., \& Toro, P. A. (1991). Images of the homeless: Public views and media messages. Housing Policy Debate, 2(3), 649-682. doi: 10.1080/10511482.1991.9521068

Lee, J. (2009). Battlin' on the Corner: Techniques for Sustaining Play. Social Problems, 56(3), 578-598. doi: 10.1525/sp.2009.56.3.578

Lefebvre, H. (1971). Everyday life in the modern world (S. Rabinovitch, Trans.). Harmondsworth, England: Penguin.

Liebow, E. (1967). Tally's Corner: A Study of Negro Streetcorner Men. Boston, MA: Little, Brown and Company.

Lloyd, M. (2006). Focus. Sites, 3(1), 34-47. doi: 10.11157/sites-vol3iss1id39

Lloyd, M., \& McGovern, B. (2007). World Famous in Wellington: 'Blanket Man' and contemporary celebrity. Sites, 4(2), 137-154. doi: 10.11157/sites-vol4iss2id77

Lloyd, M., \& McGovern, B. (2008). Legendary life on the street: 'Blanket Man' and contemporary celebrity. Continuum, 22(5), 701-714. doi: $10.1080 / 10304310802192372$ 
Lofland, J., \& Lofland, L. H. (1984). Analyzing social settings: a guide to qualitative observation and analysis (2nd ed.). Belmont, CA: Wadsworth Publishing Company, Inc.

Lofland, L. H. (1973). A World of Strangers: Order and Action in Urban Public Space. Illinois: Waveland Printing Incorporation.

Longhurst, R., Ho, E., \& Johnston, L. (2008). Using 'the body' as an 'instrument of research': kimch'i and pavlova. Area, 40(2), 208-217. doi: 10.1111/j.14754762.2008.00805.x

Love, E. (1957). Subways are for sleeping. New York: Harcourt, Brace.

Lupton, D. (2002). Road rage: drivers' understandings and experiences. Journal of Sociology, 38(3), 275-290. doi: 10.1177/144078302128756660

Mallon, J. (2006). Judgment of Mallon J. CRI-2006-485-78. Wellington: High Court of New Zealand Wellington Registry.

maori side-step. (2011, October 31). Retrieved from http://www.urbandictionary.com

Marsh, K. (2006). People Out of Place: Representations and experiences of female homelessness in Christchurch (Unpublished master's thesis). University of Canterbury, Christchurch, NZ.

Marston, G. (2004). Social policy and discourse analysis: Policy change in public housing. Aldershot, Hants, England; Burlington, VT: Ashgate.

Masters, A. (2005). Stuart: a life backwards. London: Fourth Estate.

Mauss, M. (1973). Techniques of the body. Economy and Society, 2(1), 70-88. doi: $10.1080 / 03085147300000003$

Mauthner, N. S., \& Doucet, A. (2003). Reflexive Accounts and Accounts of Reflexivity in Qualitative Data Analysis. Sociology, 37(3), 413-431. doi: 10.1177/00380385030373002

Maxwell, J. A. (2012). A realist approach for qualitative research. Thousand Oaks, CA: Sage.

May, J. (2000). Of nomads and vagrants: single homelessness and narratives of home as place. Environment and Planning D: Society and Space, 18(6), 737-759. 
May, J., Cloke, P., \& Johnsen, S. (2007). Alternative Cartographies of Homelessness: Rendering visible British women's experiences of 'visible' homelessness. Gender, Place \& Culture, 14(2), 121-140. doi: $10.1080 / 09663690701213677$

McClintock, W. (1982). Night Shelter: An Appraisal of the Changing Demand for Emergency Accommodation at the Christchurch City Mission Night Shelter. Chritchurch: Christchurch City Mission.

McDonald, N. (2003, August 20). Homeless given their own toilet. The Dominion Post, p. 3.

McGovern, B. (2005). Bringing Home the Homeless: Media Representations of Homelessness (Unpublished honours thesis). Victoria University of Wellington, Wellington, NZ.

McLeod, R. (2011, January 16). Blanket Man a living monument to our failure and shame. Sunday Star-Times.

McLeod, R. (2012, January 19). Blanket Man committed slow suicide on street. The Dominion Post, p. 4.

McNaughton Nicholls, C. (2009). Agency, Transgression and the Causation of Homelessness: A Contextualised Rational Action Analysis. International Journal of Housing Policy, 9(1), 69-84. doi: 10.1080/14616710802693607

McNulty, B. R. (1992). Homeless and hopeless: Resignation in news media constructions of homelessness as a social problem (Doctoral dissertation). Available from Proquest Dissertations and Theses Fulltext database. (UMI No. AAI9235176)

Merleau-Ponty, M. (1962). Phenomenology of perception (Colin Smith, trans.). New York: Humanities Press.

Merrifield, A. (2000). Henri Lefebvre: A socialist in space. In M. Crang \& N. Thrift (Eds.), Thinking Space (pp. 167-182). New York: Routledge.

Miller, D. E. (1998). Experiencing Homelessness. Journal of Contemporary Ethnography, 27(3), 422-427. doi: 10.1177/089124198027003008

Miller, H. (1991). On the Fringe: The Dispossessed in America. Toronto: Lexington.

Mills, C. W. (1959). The sociological imagination. New York: Oxford University Press. 
Min, E. (Ed.). (1999). Reading the homeless: The media's image of homeless culture. Westport, CA: Praegar.

Ministry of Justice. (2006). Crime and Safety Survey. Retrieved from http://www.justice.govt.nz/

Ministry of Justice. (2007). Crime in public places. Retrieved from http://www.justice.govt.nz

Mitchell, D. (1995). The End of Public Space? People's Park, Definitions of the Public, and Democracy. Annals of the Association of American Geographers, 85(1), 108-133. doi: 10.1111/j.1467-8306.1995.tb01797.xa

Molotch, H. (2012). Howard S. Becker [Interview]. Public Culture, 24(2 67), 421443. doi: 10.1215/08992363-1535561

Monaghan, L. (2007). Speaking of Ethnography. In L. Monaghan \& J. E. Goodman (Eds.), A Cultural Approach to Interpersonal Communication: Essential Readings (pp. 31-34). Malden, MA: Blackwell.

Morton, M. (1995). The Tunnel: The Underground Homeless of New York City. New Haven, CT: Yale Universtiy Press.

Netdoctor (CTscan). (2013). Retrieved March 15, 2013 from http://www.netdoctor.co.uk/health_advice/examinations/ctgeeneral.htm

New Zealand's Urban Design Protocol. (2005). Retrieved from Ministry for the Environment's website http://www.mfe.govt.nz

Neyland, D. (2008). Handbook of Ethnography. London: Sage.

Nicholls, D. (2010, September 28). Homeless chic: how Brother Sharp conquered the fashion world. The Telegraph. Retrieved from http://www.telegraph.co.uk

No quick fix. (2005, 23 November). Capital Times, p. 4.

Nonn, T. (1995). Hitting Bottom: Homelessness, Poverty and Masculinities. Theology and Sexuality, 2(3), 11-26. doi: 10.1177/135583589500200302

O'Brien, M., \& de Haan, I. (2000). Their Place: Homelessness in Auckland. Auckland: Auckland City Mission.

O'Brien, M., \& de Haan, I. (2002). Empowerment research with a vulnerable group - homelessness and the social services: The story of a research project. Social Work Review, 14(1), 29-35. 
Olufemi, O. (1998). Street homelessness in Johannesburg inner-city: a preliminary survey. Environment and Urbanization, 10(2), 223-234. doi: $10.1177 / 095624789801000210$

Olufemi, O. (2002). Barriers that disconnect homeless people and make homelessness difficult to interpret. Development Southern Africa, 19(4), 455-466. doi: 10.1080/0376835022000019455

Orwell, G. (1933). Down and Out in Paris and London. London: Victor Gollancz.

Parsell, C. (2011). Homeless identities: enacted and ascribed. The British Journal of Sociology, 62(3), 442-461. doi: 10.1111/j.1468-4446.2011.01373.x

Pascale, C. (2005). There's No Place Like Home: The Discursive Creation of Homelessness. Cultural Studies $\leftrightarrow$ Critical Methodologies, 5(2), 250-268. doi: $10.1177 / 1532708605274558$

Patel, S., \& Masselos, J. (2003). Bombay and Mumbai: The city in transition. New Delhi, India: Oxford University Press.

Pellow, D. (1996). Setting boundaries: The anthropology of spatial and social organization. Westport, CT: Bergin \& Garvey.

Percy, K. (1982). Homelessness in the Auckland Region. Wellington: National Housing Commission.

Phelan, J., Link, B. G., Moore, R. E., \& Stueve, A. (1997). The Stigma of Homelessness: The Impact of the Label "Homeless" on Attitudes Toward Poor Persons. Social Psychology Quarterly, 60(4), 323-337. doi: 10.2307/2787093

Phillips, R. (2000). Politics of Reading: Cultural Politics of Homelessness. Antipode, 32(4), 429-462. doi: 10.1111/1467-8330.00145

Pink, S. (2007). Walking with video. Visual Studies, 22(3), 240-252. doi: $10.1080 / 14725860701657142$

Platt, S. (1999). Home truths: Media representations of homelessness. In B. Franklin (Ed.), Social policy, media, and misrepresentation (pp. 104-117). New York: Routledge.

Pogrebin, M. R., \& Poole, E. D. (1988). Humor in the Briefing Room: A Study of the Strategic Uses of Humor Among Police. Journal of Contemporary Ethnography, 17(2), 183-210. doi: 10.1177/089124188017002003 
Pope, W. L. (2008). Crawling in Public. In M. Nelligan \& N. Mauro (Eds.), Intersection: Sidewalks and Public Space (pp. 73-88). Oakland, Philedeplphia: ChainLinks.

Pyatt, J. (2011, July 28). Olympic trampion. The Sun, p. 2G. Retrieved from http://www.thesun.co.uk

Radley, A. (1996). Displays and Fragments Embodiment and the Configuration of Social Worlds. Theory \& Psychology, 6(4), 559-576.

Radley, A., Hodgetts, D., \& Cullen, A. (2005). Visualizing homelessness: a study in photography and estrangement. Journal of Community \& Applied Social Psychology, 15(4), 273-295. doi: 10.1002/casp.825

Ritchie, L. D. (2011). "You're lying to Jesus!": Humor and play in a discussion about homelessness. Humor - International Journal of Humor Research, 24(4), 481. doi: 10.1515/humr.2011.027

Roberts, B. (2006). Micro Social Theory. New York \& London: Palgrave MacMillan.

Rodman, M., \& Cooper, M. (1996). Boundaries of home in Toronto housing cooperatives. In D. Pellow (Ed.), Setting boundaries: The anthropology of spatial and social organization (pp. 91-110). Westport, CT: Bergin \& Garvey.

Rose, G. (2007). Visual Methodologies: An Introduction to the Interpretation of Visual Materials (2nd ed.). London: Sage.

Rosenhan, D. (1974). On Being Sane In Insane Places. Retrieved from http://web.cocc.edu/minorevans/on_being_sane_in_insane_places.htm

Rowe, M. (1999). Crossing the border: Encounters between homeless people and outreach workers. Berkeley, CA: University of California Press.

Rowe, S., \& Wolch, J. (1990). Social Networks in Time and Space: Homeless Women in Skid Row, Los Angeles. Annals of the Association of American Geographers, 80(2), 184-204. doi: 10.1111/j.1467-8306.1990.tb00287.x

Russell, B. (1991). Silent Sisters: A Study of Homeless Women. London: Hemisphere Publishing.

Ryan, P. M. (2008). The Raupō dictionary of modern Māori (2nd rev. ed.). North Shore, N.Z.: Penguin. 
Sacks, H. (1989). Lecture Four: An Impromptu Survey of the Literature. Human Studies, 12(3/4), 253-259. doi: 10.2307/20009061

Sacks, H. (1992). Lectures on Conversation (Vol. 1). Oxford: Blackwell Publishing.

Sahlins, M. (1972). Stone Age Economics. Hawthorne, NY: Aldine de Gruyter.

Sanders, T. (2004). Controllable Laughter: Managing Sex Work through Humour. Sociology, 38(2), 273-291. doi: 10.1177/0038038504040864

Schneider, B., Chamberlain, K., \& Hodgetts, D. (2010). Representations of Homelessness in Four Canadian Newspapers: Regulation, Control, and Social Order. Journal of Sociology \& Social Welfare, 37(4), 147-172.

Schrader, B. (2005). We Call It Home - A History of State Housing in New Zealand. Auckland, NZ: Reed Publishing NZ.

Schwartz, B. (1968). The Social Psychology of Privacy. American Journal of Sociology, 73(6), 741-752. doi: 10.2307/2775779

Schwartz, M. (1997). Morrie: In HIs Own Words. New York: Dell Publishing Group.

Scott, M. (2004, July 4). What the capital needs. The Dominion Post, p. 4.

Scott, S. (2009). Making sense of everyday life. Cambridge: Polity Press.

Sennett, R. (1990). The conscience of the eye: The design and social life of cities. New York: Norton.

Shilling, C. (2003). The Body and Social Theory (2nd ed.). London: Sage.

Shuman, B. A. (1996). Down and out in the reading room. In B. a. J. McNeil, D. J. (Ed.), Patron Behavior in Libraries: A Handbook of Positive Approaches to Negative Situations, (pp. 3-17). Chicago, IL: American Library Association.

Sibley, D. (1988). Survey 13: Purification of space. Environment and Planning Design: Society and Space, 6(4), 409-421. doi: 10.1068/d060409

Sibley, D. (1995). Geographies of Exclusion: Society and Difference in the West. London: Routledge.

Silverman, D. (1993). Interpreting Qualitative Data. London: Sage. 
Silverman, D. (1998). Harvey Sacks: Social science and conversation analysis. USA: Oxford University Press.

Silverman, D. (2007). A Very Short, Fairly Interesting and Reasonably Cheap Book about Qualitative Research. London: Sage.

Silverstone, R. (2007). Media and Morality: On the Rise of the Mediapolis. Cambridge: Polity.

Sim, M., Morgan, E., \& Batchelor, J. (2005). The impact of enforcement on intoxication and alcohol-related harm. Wellington, New Zealand: Accident Compensation Corporation.

Smith, L. (2005, June 2). City park nightmare. The Wellingtonian.

Snow, D. A., \& Anderson, L. (1987). Identity Work Among the Homeless: The Verbal Construction and Avowal of Personal Identities. American Journal of Sociology, 92(6), 1336-1371. doi: 10.2307/2779840

Snow, D. A., \& Anderson, L. (1993). Down on their luck: A study of homeless street people. Berkeley, CA: University of California Press.

Snow, D. A., Morrill, C., \& Anderson, L. (2003). Elaborating Analytic Ethnography: Linking Fieldwork and Theory. Ethnography, 4(2), 181-200. doi: $10.1177 / 14661381030042002$

Sosin, M. R. (1992). Homeless and Vulnerable Meal Program Users: A Comparison Study. Social Problems, 39(2), 170-188. doi: 10.2307/3097036

Spradley, J. (1970). You owe yourself a drunk: An ethnography of urban nomads. Boston, MA: Little, Brown and Company.

Statistics New Zealand. (2009). New Zealand Definition of Homelessness. Retrieved from http://www.stats.govt.nz

Stein, J. A., \& Gelberg, L. (1997). Comparability and representativeness of clinical homeless, community homeless, and domiciled clinic samples: physical and mental health, substance use, and health services utilization. Health Psychology, $16(2), 155-162$.

Stephenson, S. (2006). Crossing the Line: Vagrancy, Homelessness and Social Displacement in Russia. Aldershot, England: Ashgate.

Stiller, B. (Director). (2001). Zoolander [Motion picture]. U.S.A.: Paramount Pictures 
Suchar, C. S. (1997). Grounding Visual Sociology Research in Shooting Scripts. Qualitative Sociology, 20(1), 33-55. doi: 10.1023/a:1024712230783

Sundstrom, R. R. (2003). Race and place: Social space in the production of human kinds. Philosophy \& Geography, 6(1), 83-95. doi: 10.1080/1090377032000063333

Terry, C. M. (1997). The Function of Humor for Prison Inmates. Journal of Contemporary Criminal Justice, 13(1), 23-40. doi: $10.1177 / 1043986297013001003$

Thorns, D. C. (1989). The production of homelessness: From individual failure to system inadequacies. Housing Studies, 4(4), 253-266. doi: $10.1080 / 02673038908720665$

Thrift, N. (1996). Spatial Formations. London: Sage.

Thrift, N. (2008). Non-representational theory: Space, politics, affect. Abingdon, England: Routledge.

Tiffen, R. (2003, July 8). Wellington plan appalling, says Wells. The Press, p. 4.

Tonkiss, F. (2003). The Ethics of Indifference: Community and Solitude in the City. International Journal of Cultural Studies, 6(3), 297-311. doi: $10.1177 / 13678779030063004$

A tormented life far from romantic. (2012, January 17). The Dominion Post.

Toro, P. A., \& McDonell, D. M. (1992). Beliefs, attitudes, and knowledge about homelessness: A survey of the general public. American Journal of Community Psychology, 20(1), 53-80. doi: 10.1007/bf00942181

Tratt, D. (2005, December 1). Blanket Politics. Capital Times. Retrieved from http://www.capitaltimes.co.nz/article/465/Blanketpolitics.html

Underwood, J. (1993). The bridge people: Daily life in a camp of the homeless. Lanham, MD: University Press of America.

Ungar, S. (1984). Self-Mockery: An Alternative Form of Slef-Presentation. Symbolic Interaction, 7(1), 121-133. doi: 10.1525/si.1984.7.1.121

Urban Tarzan. (2007, October 12). The Eastern Press, pp. 2-8.

Valentine, G. (2001). Social Geography: Space and Society. Harlow England: Pearson Education Ltd. 
van Doorn, L. (2010). Perceptions of Time and Space of (Formerly) Homeless People. Journal of Human Behavior in the Social Environment, 20(2), 218-238. doi: 10.1080/10911350903269864

van Loon, J. (2002). Social Spatialization and Everyday Life. Space and Culture, 5(2), 88-95. doi: 10.1177/1206331202005002002

Vanquishing the vagrants. (2004, August 6). The Dominion Post.

Wacquant, L. (2009). Chicago fade: putting the researcher's body back into play. City, 13(4), 510-516. doi: 10.1080/13604810903298797

Wagner, D. (1993). Checkerboard Square: Culture and resistance in a homeless community. Boulder, CO Westview Press.

Wagner, D., \& Cohen, M. B. (1991). The Power of the People: Homeless Protesters in the Aftermath of Social Movement Participation. Social Problems, 38(4), 543-561. doi: 10.2307/800570

Walby, K., \& Lippert, R. (2012). Spatial Regulation, Dispersal, and the Aesthetics of the City: Conservation Officer Policing of Homeless People in Ottawa, Canada. Antipode, 44(3), 1015-1033. doi: 10.1111/j.1467-8330.2011.00923.x

Wardhaugh, J. (1999). The Unaccommodated Woman: Home, Homelessness and Identity. The Sociological Review, 47(1), 91-109. doi: 10.1111/1467-954x.00164

Watson, S. (2000). Homelessness revisited: New reflections on old paradigms. Urban Policy and Research, 18(2), 159-170. doi: 10.1080/08111140008727830

Watson, S., \& Austerberry, H. (1986). Housing and Homelessness: A Feminist Perspective. London: Routledge \& Kegan Paul.

Wellington City Council. (2004). Homelessness Strategy. Retrieved from http://www.wellington.govt.nz

Wellington City Council. (2013). Te Mahana Homelessness Strategy. Retrieved from http://wellington.govt.nz/your-council/news/2013/02/te-mahanahomelessness-strategy

Whyte, W. F. (1943). Street Corner Society: The social structure of an Italian slum. Chicago, IL: University of Chicago Press.

Wilkinson, A. (1983). On the Skids: The management of respectability on skid row. In M. S. Hill, R. Bowman \& C. Carr-Gregg (Eds.), Shades of Deviance (pp. 14-25). Palmerston North, NZ: Dunmore Press. 
Williams, S., \& Bendelow, G. (1998). The Lived Body: Sociological Themes, Embodied Issues. London: Routledge.

Wong, S. (2010, June 4). Blanket Man mystery solved. Marlborough Express.

Wong, Y.-L. I., \& Piliavin, I. (1997). A Dynamic Analysis of Homeless-Domicile Transitions. Social Problems, 44(3), 408-423. doi: 10.2307/3097185

Wright, E. (2010, June 20). Retrieved from http://www.facebook.com/permalink.php?story_fbid=137966962880743\&id=2060 49819427

Wright, E., \& King-Jones, A. (Directors). (2003). Te Whanau O Aotearoa Caretakers of the Land [Film documentary]. Available at http://www.nzonscreen.com

Wright, K. (2007, January 30). New beat on the street. The Dominion Post, p. 6.

Wright, T. (1997). Out of Place: Homeless mobilisations subcities, and contested landscapes. Albany, NY: State of University of New York Press.

Young, R. (2008). Oral Judgment of Ronald Young J. CRI-2008-485-4. Wellington: High Court of New Zealand Wellington Registry. 